TABLE OF CONTENTS

1. Introduction .................. . . . 3

IL. Approach for Improving Toughness-

Strength Propertles ................. 5

d. Design Guidelines.............. . . . . . . .

B. Choice of Ouaternary Alloying.......... 11

II. Fxpetimental procedure . . . . . . . . . . . 12

A. Materials Preparation............. . 12

B. Hoat-Treatment ................. 12

C. Y-ray Analysis ................. 13

D. Dilatumetry................... !'s

E. Mechanical Testing .............. 14

F. Metallography................ 15

IV. Results...................... 17

A. Transformation Temperatures and Heat-Treatment. . 17

B. Microstructural Characterization ....... 18

C. Behavior of Retained Austenite........ 25

D. Mechanical Properties........... 30

E. Fractugraphy and Particle Characterization . . 33

v. Discussion ................. 36

A. Influence of Composition and Heat-Treatment on Microstructure 
B. Thetmal stability of Retained Austentite..... 48

C. Tempered Martensite Enbrittlement......... SI

D. Correlation of Microstructure and Mechanical Properties............ 59

PART 2: MORPHOLOGY, CRYSTALLOGRAPHY AND FORMATION OF DISLOCATED (LATH) MARTENSITFS IN STEELS ....... . . . . 67

I. Introduction .............. 67

I [. Experimental .............. 68

III. Results.................... 69

A. Morphology and Cell Structure of Martensite . . . 69

B. Crystallography of the Transformation....... 69

c. HIgh Resolution Latice Inaging . . . . . . 73

IV. Discussion ................. 74

SUMMARY AND CONCLUSIONS . . . . . . . . . . . . . . 78

ACKNOWLEDGMENTS .................... 84

Appendix 1............................. 85

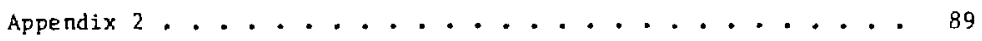

REFERENCES . . . . . . . . . . . . . . . . . . . . 92

TABLES . . . . . . . . . . . . . . . . . . . . 99

FIGURE CAPTIONS . . . . . . . . . . . . . . . . 106

FIGURES ........................ 111 


\author{
$-\mathrm{v}-$ \\ ROLE OF QUATERNARY ADIITIONS ON DISLOCATFB MARTENSITE, \\ RETAIN ALSTENITE. AND MFCHANICAL PROPERTIES OF \\ Fe/Cr/C STRUCTURAL STEELS \\ Bangaru Venkata Narasimha Rao \\ Materials and Molecular Research Division \\ Lawrence Berkeley Laboratory \\ and \\ Materials Science and Mineral Engineering \\ University of California \\ Berkeley, California 94720
}

\title{
ABSTRACT
}

The influence of quaternary alloy additions of $\mathrm{Mn}$ and $\mathrm{Ni}: 0$ Fe/Cr/C steels which have been designed to provide superior mechanical propertles has been investigated. Transmission electron microscopy and $x$-ray analysis revealed increasing amounts of retained austenite with Mn up to $2 \mathrm{w} / 0$ and with $5 \mathrm{w} / \mathrm{O} l: i$ additions after quenching frorn $1100^{\circ} \mathrm{C}$. This is accompanied by a corresponding improvement in toughness properties of the quaternary alloys. In addition, the generally attractive combinations of strength and toughness in these quaternary alloys is attrihuted to the production of dislocated lath martensite from a homogeneous austenite phase free from undissolved alloy carbides. Grain-refining resulted in a further increase in the amount of retained austenite.

The phenomeron of Tempered Martensite Embrittlement (TME) has been scudied in detall in the quaternary alloys using a combination of TIM, fractography and mechanical property testing involving both slow as well 


\section{$-v i-$}

as high strain rate toughness parameters and it is shown that TMF. 1s a fairly general phenomenon in steels containing appreciable amounts of retained austenfte. TME is coincident with the decomposition of retained austenite into incerlath coarse carbldes and the fracture path is transgranular with respect to prior austenfte grains but intergrarular with respect to Individual martensite crystals. Addition of Mn did not show any shift in the TME terperature of the base alloy $\left(300^{\circ} \mathrm{C}\right)$ although $5 \mathrm{N1}$ addition postponed the onset of TMF to $400^{\circ} \mathrm{C}$. It is roncluded that graphitizing elements such as $N i, A l$, Si are beneficial in postponing TME.

Fundamertal studies of lath martensite formation revealed that the so called "laths" are indeed "small platelets" and that the orientation of adjacent laths in a pazket is the result of minimization of the overall shape deformation. This is not normally achieved by a single-step twin mechanism but most commonly chrough a multistep orientation process involving rotation of adjacent laths along a common axis such that the shear vector completes a $2 \pi$ rotation in a group of adjacent laths. The austenite retention in these alloys is studied in detail and is is shown that carbon is essential in the stabilization of austente and that both KurdjumovSachs (K-S) and Nishiyama-Wasserman (N-W) orientation relations between retained austenite and martensite can occur within a single martensite packet . 
GENERAL TNTFODUCTION

The martensitic transformation in ferrous materials is perhaps the most widely exploited transformation for producing a variety of strengtl.toughness combinations in structural alloys. Yet, it is the most complex transformation defying the attempts by varlous investigators to synthesize a clear understanding of the structure-property relations in alloys transformed to produce martensite. Metallurgically, this transformation Is of considerable significance as it is the simplest and yet nost economical known means of producing a homogeneous distribution of a high density of dislocations in the product phase simply via the solid scate shear transformation in the parent phase of sultable conposition. In spite of numerous investigations of this important class of transformation, several questions regarding the mechanism of transformation, crystallography, norphology and substructure in interstitial free ferrous alloys, plain carbon as well as alloy steels, remain incompletely answered. (1-6) The mechanisn of hardenability and the reasons for the observed variations in marcensite formation temperatures as well as substructure as a function of alloying are not wel1 understood. $(2,4,7-11)$ So also, questions regarding martensite nucleation remain quite elusive $(2,3,12,13)$. The shear transformation is characterized by innumerable slip barriers such as boundaries and interfaces, for e.g., lath, packet, grain boundaries and several incerfaces: carbide/matrix, twin, austenite/martensite. These varfous interfaces and boundaries either by themselves (14) or due to secondary processes such as segregation ${ }^{(15)}$ and/or precipitation of second phase particles at these interfaces $(16,17)$ can control in a signifcant 
way the deforation and fracture behavior of steel and it is only recently that a systematic correlation of structure-property relations in these alloys has been carried out. $(18-20)$

It is clear from the brief summary above that both a fundamental understanding of the martensitic transformation as well as the influence of microstructure developed on the subsequent mechanical preoperties are vital for further exploftation of this transformation in ferrous materials. The present investigation is concerned with these two important aspects and is divided into two parts. The first part deals with the structureproperty relations and the control of microstructure by means of alloying and heat-treatment to achieve desirable combinations of mechanical properties. The second part is concerned with a fundamental understanding of the formation of dislocated (lath) martensite as 1 th is by far the least understcod but most widely utilized transformation in metallurgical applicaticns. 
PART 1 ,

DESIGN OF Fe-4Cr-0.3C-X QUATERNARY ALLO'S

FOR IMPROVED TOUGHNESS-STRENGTH PROPERTIES

\section{INTRODUCTION}

As part of a continuing program $(18,21,22)$ on the systematic investigation of the influence of alloying on the microstructure and mechanical properties of experimental steels, the pleseuh work is concerned with the influence of quaternary alloy additions to the experfmental FelCrlC ternary system. From the previous work on the influence of ternary substitutional solute additions to simple Fe-C steels, important conclusions regarding the effects of $\mathrm{Cr}^{(18)}, \mathrm{Mo}^{(21)}$, $M^{(22)}, C_{0}(10)$ etc. on the substructure and morphology of Fe-C martensites have emerged which eventually led to the control and Jesign of alloys to obtain desirable microstructures for nptimum combination of properties $(18,21,23)$. However, the commercial steels existing today have normally a very complex chemistry based on one or several of the following reasons: (i) elements added in combination give better hardenability than if added individually $(8,24)$, (ii) several elements are added in combination to exploit the benefits of secondary hardening ${ }^{(8,25)}$ and/or strengthening from intermetallics such as in very low carbon maraging sceels $(26,27)$, (iii) some elements are added to produce grain refinement $(8,28)$ and (iv) a few elements are added in nrder to eliminate/defer the onset of various kinds of embrittlement durting tempering of steel $(29,30)$ while others are added to suppress 
$\mathrm{H}_{2}$ susceptibility, (31) often, however, the influence of the individual alloying elements in a complex commercial steel on its microstructure and properties is unknown and thus, in designing commercial steels, empiricism has taken the place of a systematic approach. The need for an understanding of the individual influence of various alloying elements on the structure and properties of much simpler, impurity free experimental alloys clearly exists. It is not alwiys easy to isolate the individual effects of two alloying elements present in a steel due mainly to the uncertainty of their mutual interaction behavior. Nevertheless, an attempt is made here to study the effects of quaternary additions on the structure and properties of the experimental $\mathrm{Fe}: \mathrm{Cr}$ C steel. The ternary $\mathrm{Fe}|\mathrm{Cr}| \mathrm{C}$ steel was choser mainly because a large volume of insoration about this steel is already available and because it can possess superior combinations of properifes to existing complex commercial alloys $([0,18,32,33)$. A significant wiservation made recently $(18,34)$ using the sophisticated merhods of high resolution transmissicn electron microscopy is toe Identification of thin interlath films of retained austenite in allovs apparently having their $M_{s}$ and $M_{f}$ temperatures much above room tenperature. Since its discovery several investigators attributed 1mproved fracture toughness properties to the presence of retained austenite $(18,23,30,35-38)$. Although in several instances the improvement in toughness properties could not be singly attributed to the retalned austonite, $(30,35,37)$ best properties were often associated with microstructures containing large quantities of stable retained austenite. $(23,35,37)$ Kohn observed ${ }^{(36)}$ that excessive enrichment of austenite during isothermal holding above $M_{s}$ temperature may make the retained $\gamma$ an undesirable 
constituent for plane strain fracture toughness. Almost all the previous work on the influence of austenite on toughness was carried out on commercial steels wherein the complex chemistry and anpurlties complicate the interpretation. The chemlcal and mechanical stabilizations of austerit. as well as its morphology (whether contin is interlath films or discrece islands) could have important repercussions on its influence on the toughness of steel. It is thus, one of the important objectives of the current investlgation to try to assess unambiguously the role of retained austenite on the mechanical behavior by varying its amount and stabtlity by either heat-treatment or alloying (or both) of the simple experimenta? Fe-Cr-C alloys. Secondly, in order to improve the toughness to strergth ratio (which in turn 1ncreases the iritical flaw size) steels are usually tempered following quenching and the thermal instability of austenite ensuing Lempering could significantly affect the coughness properties. It is thus annther objective of the research to study the thermal stability of austenite as a function of type and anount of qua-ternary alloying. In addition, design of quaternary alloys of optimum conposition to further develop the stength and toughness of the base steel from the above understanding constitutes an ininerent part of the research. For this purpose some selection guidelines discussed in the following section are used to select the quaternary alloy additions.

\section{APPROACH FOR IMPROVING TOUGHNESS-STRENGTH PROPERT LES}

The approach adopted to obtaining good combinations of strength and toughness is primarily microstructural control by alloylng, heat-treatment or combinations of both. In what follows, the design guidelines for 
improved mechanical propertles are out lined and in the subsequent section, the choice of quaternary alloying based on these principlea is discusser.

\section{A. Design Guidnilnes}

1) Carbon Content:

Increasing the carbon content of the steel is by far the most effective and economiral way of raising the strength of steel. However, depending, on the total alloy content of the steel, it has been shinwn $(32)$, above $0.4 \% C$, the steel is susceptible to intergrisular cracking. Besittes, while significant gains in strength rouid he obtained through $c$ addition, the toughness deteriorates monotonically. From a fracture mechanies viewpoint, inrreasing strengrh without a corresponding fncrease in toughness would only result in poor utillzation of the available strength of strel in engineering applications where resistance to the propagation of existing cracks is important (See Appendix 1). At 200,0no psi yield strength level, m minimum of $80 \mathrm{KSI}-i \mathrm{n}^{1 / 2}$ plane strain fracture toughness ic needed for a critical flaw size of 0.1 " if $60-80 \%$ of available strength is to be utilized (Appendix 1). Above about $0.35 \% \mathrm{C}$, martensitic si el attains significant contribution to strengthening from substructural twinning. However, as will be discussed shortly, this kind of strengthening is undesirable from a coughness viewpoint. Thus, with a view to designing cough structural steels at an yield strengti level of 200,000 psi, the carbon content of all the alloys investigated is 
maintalned at a maximum of $0.3 \%$.

\section{1) Martensite Substructure:}

The invariant plane strain condition for the martensitic transformation requires an inhomogenous shear in the product phase on a fine scale which will not alter the crystal structure of the product $(1)$. This requirement contributes to the substructures observed in martensitic steels and there are only two known types of shear which would not alter the original crystal structure, viz., slip and twinning. The former produces dislocated substructures while the latter twinned. Several investigations in the past $(18,39)$ (recently summarized in ref. 4) revealed thi $L$ winned martensites possessed much inferior colighness properties to dislocated martensites when compared at the same strength level. Upon tempering the twinned martensite, extensive twin houndary carbide precipitation occurs and this twin boundary carbide may be even more detrimental than twinning itself. Twinning reduces the available number of active slip systems $(40)$ and is detrimental to the toughness of carbon containing steels( 41$)$ both in as-quenched and tempered conditons and therefore, should be avoided.

\section{iii) Retained Austenite:}

Although the exact mechanisms by which interlath films of retained austerite promote tcughness of a steel are not clearly understood, several recent investigations $(18,23,35)$ suggest that small quantities of interlath austenite are beneficial to toughness properties. By Increasing the stability 
of retained austente to transformation under mochanical strisst scrain or under tharmal energy, its potrotial for improved properties can be vastly increased. One of the simplest ways of increasing the stability of austenite woud be to add an austenite (for) stabiliget. The most ecrnomical way of dolng this is to increase carbon content. However, the detrimental effects of retalned $y$ in high carion strelit wherein it transforms to twinnted mintuside have been rerognized for a long time. Therefore, fer siatilltzors which de not irerease the propensity for twimiro should be solected for stabilizing

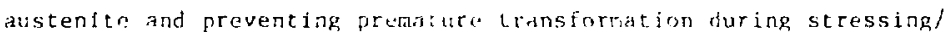

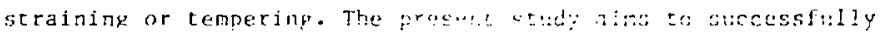
exploit the austenite for improwed properties by

(1) avoiding, excessive carbon ent ctment

(2) inproving scablity with fir tiabilizers which to not markedy further increase its tedeny for twinning

(3) maintaining continums interlath : 1 m morphology wherein ibr juividual martensite crystais are entrapped by austenite

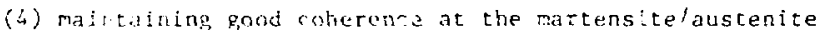
interfaces

(5) increasing the amount of austerite if found beneficlal iv) Coarse Undissolved Carbides:

Coarse undissulved alloy carbides can act as slip barriers resulting ir a stress concentration at the carbide/matrix interface (42). This could result in either (i) carbide cracking (43) or (ii) interface cracking or (iii) crack nucleation in the 
matrix due to plied up dislocations. In addtion, the carbide/matrix interfaces can provide an easy crack path if the treteractal cohesion is poor. Cox and Low ${ }^{(44)}$ denonstraled that during plastic fracture, the resistance to fracture decreat. wh thereasing 1nclusion size which is attributed to the ease of vold nucleation and growth at coarser particles. Therefore, coarse undissolved carbldes can promote brittle fracture and also reduce fracture resistance during plastic fracture and should be elfminated by proper heat treatment. The problem of undissolved coarse carbides becomes particularly acute in al loy steels containing alloying elements which have a stronger carbjde forming tendency than iron.

v) Lowering of Ductile to Brittle Transition Iemp (DBTT): Pbenomenologically DBTT represents a change in mode of fracture-from low energy brittle (often cleavage) Eracture below UBTT to high energy ductile iracture (dimpled rupture) abo:e DBTT. While the $\mathrm{Fe} / 4 \mathrm{Cr} / 0.35 \mathrm{C}$ base steals exhibited srcellent plane strain fracture toughness properties $(18)$, their impact properties remained tachet low $(10,33)$. Relatively high DBTT in these steels was thought to be the reason and in fact, it was shown ${ }^{(33)}$ that in Fe/4Cr|0.4C bainitic steel, the DBTI lies above room temperature. In order to further develop these steels for technological applications, it is necessary to lower the DBTT through suitable alloying. Again, the underlying principle in the selection of suitable alloying elements for this purpose is the achlevement of lower DBTT 


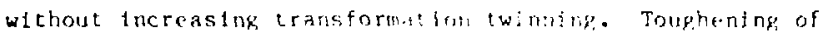
alloys by second phases has bern known for a long time. The Impact toughness at $-196^{\circ} \mathrm{C}$ of cryogenlc 9 PCt $1 \mathrm{l}$. oteel was shown to be enhanced by austerlte of vline I rartion (f) $=0.1$ and size $(r) 0.1$ en b. Is wir diarered in ferr:te, formed

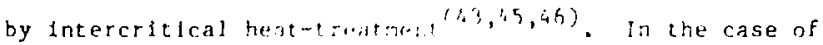
brittle matriers insertior i, durlle metalli? phase renders a startling lmptovenort in strenseth-toughness combinations ${ }^{(4)}$. A sultable dispersion ol a iat ti. mritallas prase of sultable

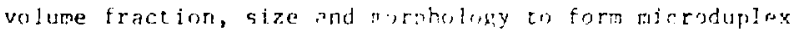

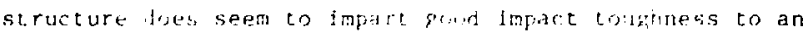
othcrase hrittle matrix.

vi) Crain Refining:

Fur a given alloy compositinn, ite dit? can be altered

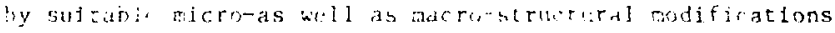

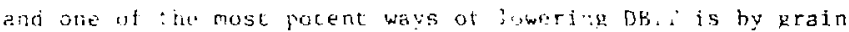

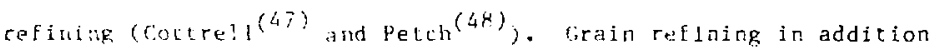
iuparis the added berfits to the struture in jecreasing the severity of sepregation of embrittling constitutents ${ }^{(49)}$, increasing the yicid strength ${ }^{(50)}$ and jmproving fatigue properties ${ }^{(51)}$.

Thus, in order to improve the mechanical properties microstructural cortrol is the basic appros h adopted to achieve the following features:

(i) Hintain dislocated lath martensite.

(ii) Promote a fine dispersion of carbides in mattensite elther through auto-tempering or tempering following quenching. (1i1) Fromote stability and occurcence of retalned austentte 
as thin interlath filfis. This is also necessiog to avoid incerlath hrittle li]ns of cathide.

(iv) Eliminate codrse undissolved allny carbides.

(v) Lower DBr? and increase uper ahelf eneryy.

The above design criteria are arhieded through a rombination of non-conventional heat-tratments and quaternary alleying, she choice of non-conventiunal heat-treatments will he discussed in a later section but for the present the next sertion deals with the choice of quatermary alloying.

\section{B. Choice of Quatronary Alloyirg}

Although no systematic structure-proper'y cotrelation exists, it is generally derepted $(52)$ i hat of all th. common alloying elements that are often added to medium and low carbon steels, only Mn and :i improve both toughness and stremgth as measurea hy impact and room temperature tension tests. Additions of up to $2 \%$ Mn to a sterl is known $(9)$ to increase its hardenability substantially. Nevertheless, excessive additions of $M n$ are to he avoided for it was shown (2?) that in medium carbon steels, Mn in excess of 3 w/o leads to large iractions of twinned substructures and secondly, since $M_{n}$ lowers $M_{S}$ significantly ${ }^{(4)}$, higher Mn contents result in the suppression of auto-tempering. There are also reports that Mn addition lowers DBTT $(52,53)$. The intluence of $\mathrm{Ni}$ is in several respects identical to that of Mn although higher percentages of $\mathrm{Ni}$ can be added to a steel without promoting substructural twinning ${ }^{(54)}$ especially in the presence of carbon (39). Importantly, both $M n$ and Ni are Ecc austenite stabilizers 


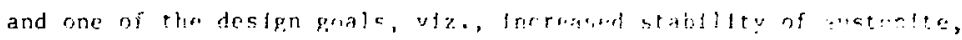

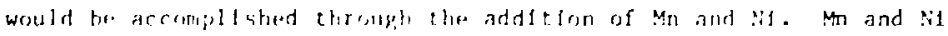
are in fart reporeded (8) to promeste retentelon of $y$ in the asequenched

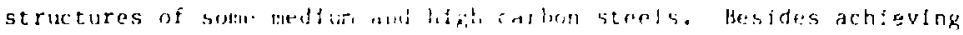
the design irfterla whth Ma and N1 there are further acadente interests In studying the effacts of Mn ard $i$ : ace these twe eloments itre Invariably present in most cromerial al\}rys. Mn ls adried in commerctal alloys primarily to combtne with residurl sillphur in prefertnce to Fe to produce less damaging Mn $:$.

Quaternary alloys rontalning Mn up to 2 wio and Hij raf 5 w/o are thus designed to meet the sperific microstrurtural iriteria.

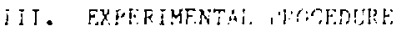

\section{A. Materials preparation}

The quaterary al Joys and Lernary hat ll lov were supplied by baido Steel Coripany in Japan in the Enrm of 2.5" wide "y 1" thirts baxs and $1 / 2 "$ dia. rods. Round tensile sperimens were obtit ned from the $1 / 2 "$ dia. rods and the $K_{i C}$ planes strain fracture toughness specimens and the Charpy-v-notch imfact toughness specimens wer cotained from the l" thick hars. The chemical compositions of the vacuum melted alloys after homogenization at $1200^{\circ} \mathrm{C}$ for $24 \mathrm{hrs}$ furnace cooled) aze given in Table I.

\section{B. Heat-Treatment}

All austentizing treatments were carried out in vertical tube furnazes under argon atmosphere. Oversized tensile, Charpy and $\mathrm{K}_{\mathrm{IC}}$ epecimens were cut from their respective stock and final machining 


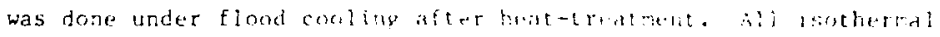
transformatings wete carriat mat by quenching ant , walt pot located directy underiedth the firnace containing aglated salt maintained

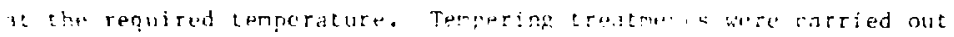
by inmersing the specimens for one hub in salt pots maintained at the requited temperature. At. the ent uf imperim troatments all

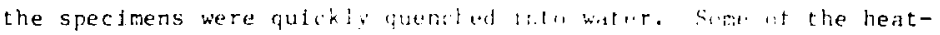

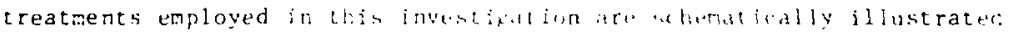
in fig. 1.

\section{r.. Y-Ray Analysis}

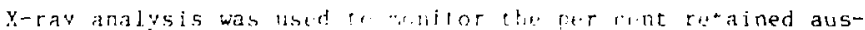

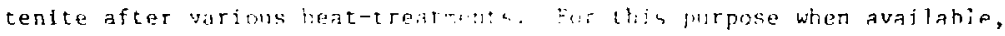

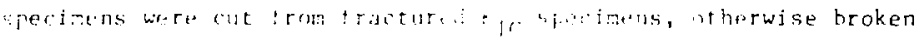

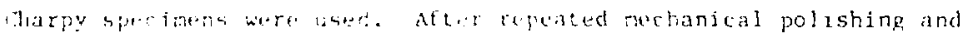

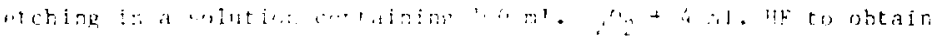

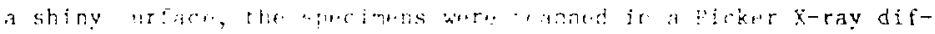

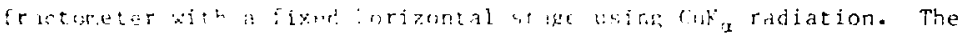

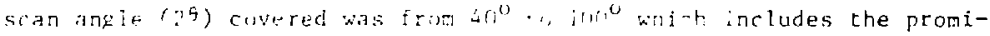
nent $\left.(1-1)_{Y},(311)_{Y},(220)\right)_{Y}$, and $(222)_{y}$ rerlertions. Careful analysis of the diffraction data obtained failed tis reveal any retained austenite in any of the samples. There was considcable background noise in the diffractngram which might have obscured any peaks fron retained austenite. A modified method consisting of a more sophisticated instruinent and tecinique to suppress the background roise to accertuate the retained austenite peaks was used by Dr. R. L. M11ler $(55,56)$ at U.S. Steel 
Corporalion to detect the austenite levels in these specimens.

\section{Dilacometry}

A comercial dilatometer (Theta Bilatrondc III R dilatometer) was used to establish the phase transformation temperatures, $\because z, M_{S}, M_{f}$, austenite start temperature $A_{S}$ and alstenite finish temperature $A_{f}$ of the alloy steels.

\section{E. Mechanical Testing}

\section{l. Tensile Testing}

The dimenstons of the $1.25^{\prime \prime}$ gange round tensile specimen are show in $F 1 g$. 2(A). Tensile testing was dione at room temperature in a 300 Kip capacity MTS testing wrhine at a cross head speed of $0.04^{\prime \prime}: \mathrm{min}$.

\section{Fracture Tughness Testing}

Plane strain fracture toughness values were obtained by cesting standard compact censton crack-lint loaded toughness specimens shown in $i g .2(B)$. Following heat-treatment at least 0.01 ia. was removed from efther flat-surface of the $K_{I C}$ blanks. The thickness for most of the specimens conformed to the ASTM specification ${ }^{(57)}$ for plane strain condition, viz., thickness $2.5\left(\frac{K_{I C}}{a_{y}}\right)^{2}$. However, for some heat treatments of the Mn modified specimens the thickness was less than that required to sacisfy plane strain condition. In this case, a method based on Chells criteria and dealt with in tetall in Appendix 2 was used to convert the $K_{Q}$ values into calculated $K_{I C}$. The 300 Kip MTS machine was again used for fatigue pre-cracking the specimens 
co a minimum cract length of $0.05 \mathrm{in}$. which were subsequently tested In the same machine to obtain the fracture toughness data. The orientation of crack propagation with respect to the long dimension of the bar stock is L-T. (57)

\section{Charpy Impact Testing}

Standard Charpy-V-Notch specimens shown in F1g. 2(C) were obtalned from oversized heat-treated blanks. A minimum of 2 , and In most cases, 3 Tharpy-V-Notch specimens were tested for each treatment and the tabulated results correspond to the average of these tests. In some plots the scatterband is also shown. Some below and above roum temperature impact tests were also conducted in order to detemine the duclile-dorittle transition tumperature. For this purpose, a mixture of methanol and dry ice were used to obtain suhzero temperatures. Ch.rpy specimens were immersed in these nixtu or for sufficiently long times to atrain the temperature of the bath before breaking them. Fo- above roon temperature tests a water bath with thermostat was used.

\section{F. Hetallography}

\section{Optical Metallography}

Specimers for optical thetallography were cut from broken Charpy bars, mounted in boldmount, abraded on silfcon carbide papers down to 600 grit, and polished on $1 \mu$ diamond abrastve wheel. For revealing the tartensite microstructure the specimens were etched in $2 \%$ and $5 \%$ nital solutions. For revealing 
prior austente grain boundis ries in fine grafned specimens, etching was carried out in an etchant of $5 \mathrm{gm}$. of picric acid in $100 \mathrm{cc}$ of water saturated with dodecylbenzene sulfonate.

2. Electron Metallography

Wh a avalable, thin foljs fot transmission electron microsc ny were obtalned from bulk, heat-treated fractured $K_{I C}$ test specimens and in other situations broken Charpy specimens were used. About 25 m11. tilick slices were cut from these specimens and following. clealling to remove any oxide scale, these were chemically ihinned to less than 5 mils, at room temperature In a solution if $4-5 \%$ if in $\mathrm{H}_{2} \mathrm{O}_{2}$. Both $2.3 \mathrm{~nm}$ and $3.00 \mathrm{~mm}$ dises were spark tut ren the rinemically thinned slices which were then sanded thin to about: mils thick. These thin folls were finally edectromished in a twin jet electro-polishing apparatus at rorre temprature lsins a

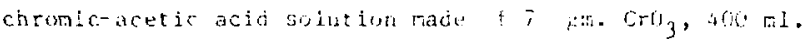
Cil 3 CooH anc $21 \mathrm{~mL}$. distilifd water. Ihe ellisilig voltage varied from 25 to 35 volts for $2.3 \mathrm{mn}$ j. -5 and : rnm $35-45$ volts for 3 mer discs. Thin folls so ohlained were stored in alcohol and were subseguently examined in Siemens Elmiskop IA (2.3 $\mathrm{mm}$ discs) and Philips EM $30 \mathrm{~L}$ ( $3 \mathrm{~mm}$ discs) microscopes at an operating voltage of $10 \mathrm{i} \mathrm{kV}$.

3. Scanning Electron Microscopy and

Energy Dispersive Analysis of $X$-rays

Eractography was conducted on both tensile as well as Charpy spectmens, using an AMR-1000 scanntug electron microscope 
at $20 \mathrm{KV}$. The fracture surfaces were preserved by nasking with a tape during cutting and specimen preparation. This tape was later dissolved in acetone. An energy dispersive analysis of $x$-rays (EDAX) unit, attached to the microscope permitted semiquantitative analysts of inclusions and precipitates.

\section{RESULTS}

\section{A. Transformation Temperatures and Heat-Treatment}

The martensite transformation temperatures $M_{s}$ and $M_{f}$ and the austenite formation temperatures obtained by dilatometry are tabulated in Table . The somewhat lower $M_{S}$ and $M_{f}$ temperatures in the hase FelCrlC steel are attributed to the somewhat higher carbon content of the base alloy over the quaternary alloys. In general, both the $M_{S}$ and $M_{f}$ cemperacures decreased with the quaternary alloy additions although their difference remained approximately constant around $100^{\circ} \mathrm{C}$. Mn and Ni both being strong fcc stabilizers, from Table I one could notice a general trend of lowered $A_{s}$ and $A_{f}$ temperatures as well as narrower austenite fomation region with additions of $M$ and $X 1$. It will be clear from the discussion presented in subsequent sections that while $\mathrm{M}_{\mathrm{s}}$ temperatures measured by dilatometry are fatrly precise, the Mf temperatures represent only approximate martensite finish temperatures and they are not true indication of $100 \%$ martensite formation.

It was proposed to characterize initially the influence of various alloy additions on the morphology and substructure of singly treated Fe/4Cr $0.3 \mathrm{C}$ base steel. For this an austenitizing temperature of $1100^{\circ} \mathrm{C}$ and lce water quench were chosen ( $F 1$. 1). This temperature is in the 
single phase austentte region ${ }^{(58)}$, Fig 3 anc 1 high enough to dissolve all the alloy carbides. $(18,58)$ For the alloy modified with 5 Ni (alloy E), a conventional high temperature austenization foilowed by rapid quench resulted in quench cracking ${ }^{(32)}$. Thus, tt was necessary to modify the heat-treatment for this alloy and based on earlier research on the phenomenon of intergranular quench cracking(32), the morification consisted of isothermal holding below $M_{s}$ at $200^{\circ} \mathrm{C}$ for $1-5$ min before finally quenching into water at room temperature (Fig. 1).

Grain refining double treatments designed with a view to conbine the benefits of high temperature austenitization and fine grain size consfeted of Intemediate low temperature $\left(200^{\circ} \mathrm{C}-1 \mathrm{hr}\right)$ rempering between the intial high temperature austentclation and final low temperature grain refining austenitizing treatment (Fig. L) at $870^{\circ} \mathrm{C}$. In the case of bas: and $M n$ modified alloys, the intermediate tempering treatrent was ust to promoce a fine dispersian of tempered carbides. This dicpersinn was toped to augment the preferontial nucleation of austenite at carbide/matrix interfaces $(59,60)$ and thus, serve to bring about a no:e uniform, fine discribution of austenite crystals during subsequent austenitization. In the sase of Ni modifled alloys, the need for an incermediate tempering cycle is obviated by the interrupted quench during the inftial high temperature austentization.

\section{B. Microstructural Characterization}

\section{(i) Optical Metallography:}

Optical metallography was carried out with the intention of recording any variations in the gross features of micro- 
structure, for e.g., prior austentce grain slze, coarse undissolved carbldes etc. with composition and heat-treatment. Fig. 4 shows representative optical micrographs for steels $D$ and $E$. There were no observable differences in the optical microstrurtur. between the base and nodified alloys. The structure represents typical lath martensite orcurring in packets (Fig. 4a) although

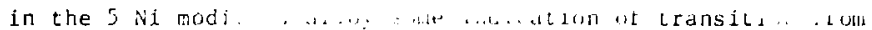
lath to plate moŕphology is discernible (Fig. $4 \mathrm{c}$ ). However, as wll be shown in a later section, transmission electron microscopy revealed predominately lath matcensitic structure even in the 5 Ni modified aliuy. There were no undissolved coarse alloy carbides frensent in duv ur the single high temperature treated alloys [see for eg. Fig. $4(\mathrm{a})$ and (c)] not could optical metalineriphy resolve: any undissolved second phase particles in any of the ganin refined steels ffigs. $4(b)$ and (d)!. These stwitures also did not eveal any proeutectoid or jsothemal decomposition products.

Fig. 5 shows the plot of mezsured average prior auscente grain sizes (61) as a function of alloying for the single and grain refining double treatments. The grain sizes of $5 \mathrm{Vi}$ modified alloy closely resembled chose of base alloy, viz., 170 : am for the single high temperature treated specimens and $20 \mathrm{im}$ for the grain refined specimens. In every case, double treatments caused an approximate ton fold refinement in the grain size compared to single treatments. För the same length of holding at $2100^{\circ} \mathrm{C}$, there appears to be a significant austenite 
grain coarsening with increasing Mn content particularly above. about $0.5 \mathrm{w} / \mathrm{Mn}$. The $2 \mathrm{wt}$. Mn alloy had about $60-70 \%$ larger prlor austenite grain size compared to the hase ternary Fe/Cr|C alloy. In contrast, the Ni modifled alloy did not show any such grain coarsening. Both Mn and Ni act simflarly in stabliling austenite and since both of them lower $\Lambda_{3}$ temperature, from Fig. 3, $1100^{n} \mathrm{C}$ is certainly expected to fall within the single austenite phase fleld. However, Mn can form Mns with the restdual sulptur in the alloy steels $\left(<0.01 \mathrm{w} / 0\right.$ in all steels) in preference to CrS ${ }^{(62)}$ : 3 tle stabilities of sulphides on the hats is of free energies of formation can be represented in decreasing urger as MinS>CrS>FeS>NiS. (63) However, this can not explain the observed austenite grain growth as the solution temperature for MnS is higher than that for $\left(\right.$ rs. $(63,64)$ Allen et a! ${ }^{(65)}$ and Jo2ioy $(52)$ eported that Mn refined erain toundary carbides whereas Ni djd not have any such refining, ability. However, it was pointed out earlier that no undissolved carbides could be resolved in any of the quaternary alioys after $1100^{\circ} \mathrm{C}$ austenitization. Thus, the exact reason for the observed grain coarsening with Mi remains unclear.

\section{(ii) Transmission Electron Microscopy:}

Structural characterization by transmission electron microscopy was performed on all the single treated quenched as well as quenched and $200^{\circ} \mathrm{C}$ tempered conditions of all the alloys but a detalled characterization of evolution of the 
microstructure during tempering was 11 mited to the $0.5 \%$ Mn and $2 \%$ an modifled allays in the single treated condicion and for the $5 \% . N i$ modified alloy in the double treated condition as tt was considered that conclusions fron these representative compositions and heat-treatments can be utilized to prediet the behavior of other alluys. In this section nnly the martensite substructure and the carbice precipitation are covered and a detriled treatment of retained austenite is postponed to

a latter section.

a. Structure of as-quenched alioys

The parallel lath morphology of martensite in all the alloys is evident (from fins. 8, 9, 19-21, 55). Two points of significant variation in structure, viz., substructure of martensite and precipitation of carbides due to auto-tempering are worth noting. The substructure of lin modified a] loys (up to 2 w/o $M n$ ) remained essencially dislocated (Figs. h, 7 and 19). However, a small percentage ( $\sim 10 \%$ of the laths examined) of twinning was ohserved in the 5 Ni modified alloy as showr in Fig. 8 (c) through (f). These are the wel 1 known $\{112\}$ a microtwins ${ }^{(66)}$ and the SAD* pattern. Fig. 8 (e) obtained from the BF figure $8(d)$ is analysed in Fig. 8 (f). The amont of auto-tempering decreased with increasing $M_{n}$ content consistent with decreasing $M_{S}$ temperature $^{(4)}$ (Table T). In alloys modified with Mn up to 1 w/o 
both cementite and c-carhide can be found hut in $2 \mathrm{Mn}$ modified alloy little of any auto-tempered carbfdes can be found (F1R. 7). Chararteristit "cross-hatched"(66) appearance of e-carbide was observed in the $0.5 \%$ Mn modified

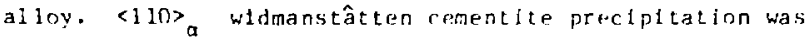
observed in some areas of the $1 \%$ Mn modified alioy. In other areas of the specimen, as Fig. fo shows, extunstue E-carbide precipltation was observed. Comparisor of the micrograph and the diffrartion pattern whirh is a [10]\} zone, Figs. 6 (a) and (c), Indicaces that the needles are growing in $\langle 21 .\rangle_{a}$ directions. The diffraction patteru from the carhjdes is weak due to the small size of the carbide particles but $t t$ is consistent with two $[134]_{\varepsilon}$ zones with the e-catbide zeflections streaked perpendicular to the [010] directions. In spite of the isothermal hold between ${ }^{M} s$ and $M_{f}$ in the case of Ni modified alloy, only f-carbide precipitation was noted in these alloys as shown in Fig. 9. These carbide particles are about $30 n \mathrm{~A}^{\circ}$ wide and about $0.5 \mathrm{w}$ long. The characceristic "wavy" interface $(67)$ of these particles can be clearly seen in Fig. 9 (b) and the "cross-hatched" appearance of e-carbide is also evident in the BF micrograph, Fig. 8 (a).

b. Structure of tempered alloys

$200^{\circ} \mathrm{C}$ Tempering: Tempering at $200^{\circ} \mathrm{C}$ resulted in well established $\langle 110\rangle$ a widmanstatten cementite platelets in all the Mn modifled alloys. Fine, wavy e-carbide preciplcates 
continued to coextse with celent it at aths tenperature. In the rase of $\mathrm{Ni}$ modified a'loys, the doritant cartide is $\varepsilon$ carbide. Fig. 20 shows the widmanstaten carhides in the 2 Mn modifled alloy. These cementite platelets are aboul $200 \Lambda^{\circ}$ wide and 0.5 w long. The influence of Mn in promoting cementite coarsening can he discerned from a comparison of $200^{\circ} \mathrm{C}$ tempered strurtures in the $0.5 \mathrm{Mn}$ and 2 Mn modifled alloys shown in Fig. 48 . $300^{\circ} \mathrm{C}$ Tempering: In this section changes ocrurring within the martensitic laths will be considered. Structural changes occurring at the lath boundaries will be dealt with in the next section in connection with retained austenite. Figs. I1, 12, and 13 illustrate the intralath carbide precipitation in $0.5 \mathrm{Mn}, 2.0 \mathrm{Mn}$ and $5 \mathrm{Ni}$ modified alloys. The heginning of spheroidization of intralath cementite platelets is evident in Figs. 11 and 12 (c) and (d) of the Mn modified alloys. In other areas (110) widmanstatten platelets of cementite still exist as in Fig. 12 (a) and (b). Fig. 12 (d) clearly shows the ongoing process of spheroidization whereln one or mote spheroids form on each cementite platelet. In the case of grain refined $5 \mathrm{Ni}$ modified alloy, the intralath prectpitation consisted of a fine distribution of cementite platelets wherein spheroidization can be considered as in very early stages (Fig. 13). As will be shown in the next section, the large stringers marked by arrows are retained austenite (Fig. 13 (b)) and not carbides. However, a 
very fine distributirn of spheroidal particles,presumably $M_{7} C_{3}$, nucleated a: dislocations seems to be taking place, Fig. 13 (b). It was not possible to 1dentffy this fine carbide due to Insufficlent diffraction information.

One slgniflcant crystallographic observation made with cementite preciptitation in these quaternary alloys Is that the majority of diffraction patterns analyzed (Including Flgs. 11 (c) and 13 (c) did not indicate the well established Ragaryatski orientation relationship hetween ferrite and carhide $(66,68)$.

$500^{\circ} \mathrm{C}$ Tempering: Figs. 14 through 18 illustrate the structural changes accompanying $500^{\circ} \mathrm{C}$ tempering in the quaternary alloys. Coarse spheroidized cemenite in $0.5 \mathrm{Mn}$ modified alloy is showm in Fig. 14 (a) and (b) and Fig. 14 (c) and (d) show the interlath precipitation of cementite. The diffraction patterns for this alloy also showed indication of $\mathrm{M}_{7} \mathrm{C}_{3}$ carbides although precipitation of $\mathrm{M}_{7} \mathrm{C}_{3}$ carbides is more intense in the $2 \mathrm{Mn}$ alloy as shown in 15 (a) and (b). The bright field picture Fig. 15 (a) shows a very fine, uniform distribution of $M_{7} C_{3}$ carbijes. Interestingly enough, some $(110)_{\alpha}$ cementite platelets still exist at this temperature and the DF picture Fig. 15 (b) obtained from a superposed cementite and $M_{7} C_{3}$ reflection shows both these carbides in bright contrast. Fig. 16 also shows the continued presence of fine (110) aidmanstatten cementite platelets in the 2 Mn modified alloy while Fig. 17 reveals the twin boundary cementite precipi- 
tation in the $5 x i$ alloy. The intralath cerentite precipitation in this alloy is showr in fig. 18 revealing a ragged appearance for the carhides inilicating that they nay be dissolving. The occurrence of the carbide $\mathrm{M}_{7} \mathrm{C}_{3}$ $=(\mathrm{Cr}, \mathrm{Fe})_{7} \mathrm{C}_{3}$ in $a^{1}$ lov steels has heert the subject of a nuber of studies $(25,33,69)$. Particular Interest attaches to the gutestlon wlatietr this carbide forms in a fertote matrix al readv cuitaining cerrentite hy ir-situ nucleation or from completuly separate mulei. The present results especially the ewdunce presented in fig. 15 suggest that a separate nucleat ini uf $M_{7} C_{3}$ is the favored reaction in these alloys in agreement with the observations inade by Dyson and Andrews ${ }^{(69)}$. Alst, the SAl) patterus obtained from the at loys showing appreclahle arounts of $M_{7} C_{3}$ frecipitation show considerable streaking (Figs. is (c), l $r(c))$. Precipitate shape can not be held responsthle tor isoducing this diffraction effect is the morphology o: "-eriplate as judged from the BF and DF thicrogrants (Fig. 15) is spherical. Dyson and Andrews ${ }^{(69)}$ alsi obsryed streaky diffraction patcerns associated with $M_{4} C_{3}$ precipitation and they attributed this :o the faulting of crystal structure rather than to the preciptite shape.

\section{Behavior of Retained Austenite}

One of the significant structural observations made recently $(18)$ with the use of transmission electron microscopy is the identification 
of smali amounts of high temperature austenite phase rutajned at rem temperature in alloy steels that were supposed to undergo $100 \%$ transfort..tion to martensite at this temperature. Since this retained austenite is a metastable phase at this temperature its transfomation characteristfcs following the supply of thermal or mechanical energy and a detailed characterizat Ion of structural thangeti rorurring at the austenite/ martensite interfaces become important. This sertion theruiro deals with the identification, morphological characteriantion, tiarisfirming behavior and analysis of volume frartich of this austenite phast. A more fundamental study of the orientation relationships, hitit nlane and Interface coherency etc. are dealt with in the secting on formation of lath martensite.

\section{(i) Electron Meral lographic ghservations:}

Rao et al ${ }^{(3 \dot{4})}$ and Thomas $\left(23,7^{4}\right)$ bave re r.atly dealt in considerable detail with the protilems rncounterid ant the care and sophistication necessary in iho anfquivocal identification of retalned austenite, particulariy when it is present In smal 1 quantities. Furthemore, isterferenc, with the carbide reflections occurs in the selected area diffaction patterns. The discussion here $w 111$ be 11 mited to the presentation of actual results.

Figs. 19 through 21 and Fig. 55 prescinted in connection with the analysis of the crystallography of retained austenite 1llustrate the typical interlath film morphology of the high temperature phase. The advantages of ut1lizing (200) reflection for DF lmaging of retained austenite have been 
emphasized in the past $(34,23)$ and whenever possible the foil Is t1lted such that (200) reflections are strongly excited (Fig. $21(f))$. Of most signiflcance from this study of che amount and morphology of retained austenite is the conclus...n that there is a monotonic increase in the amount of retained austente with $\mathrm{Mn}$ addition (F1gs. 19 and 21) and highest amounts of retained austenite were found in the $5 \mathrm{Ni}$ modified al loy interrupted quenched to rcom temperature following single high temperature austenitization, F1g. 20. Fig. 21 shows this monotonic increase in the volume fraction of retained austenite with quaternary alloying in the DF imaging mode. It is important to emphasize here that the above conclusion is based on examination of not just one or two micrographs but severai nictographs from several thin folls.

The grain refined structures showed a similar behavior in the occurrence of retained austenite with quaternary alloying. Moreover, in every alloy there is an increase in the volume fraction of retained austenite ir the grain refined structures conpared to single treated coarse grained structures. Although the electron metallographic estimation of the volume fraction of retained austenite has its limitations, an attempt was made here and it was estimated that the 2 Mn modified alloy had about 4 to $5 \%$ retained austenite while the 5 Ni modified alloy showed about 6 to $8 \%$ in the single treated condition. Thermal Stab1lify The stability of retained austenite was followed as a function of tempering terperature. At $200^{\circ} \mathrm{C}$ 
tempering, the rothlned austulle wati stahly in all the altoys. Fig. 22 shows this in l.n Mn modifled alloy and evidently there was no decrpass in the ansunt of auscenite following this tempering. Mosr interesting behavior orcurred following $300^{\circ} \mathrm{C}$ tempering. Whale tha ba: al loy and the Yor modified quaternary alloys showed tor firimat for of ary retaired austenite (Figs. 23, 24), the 5 Ni dilu sicewet substantial amounts

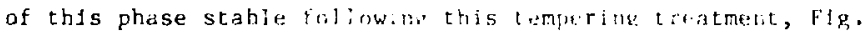
25. As is clear from tire. $\because$ and 24, the secomosition of austente resulted in the provatition ol centse interlath stringers of cementite and che thi:knets ot lfu intertath carbide stringers is a tuntide of initia robibud austente content, vize, the 2 Mn ailoy itsued coarcer jutertacl carbidet; compared to the r.s th alloy.

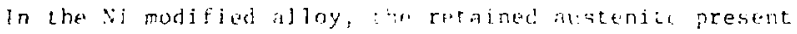

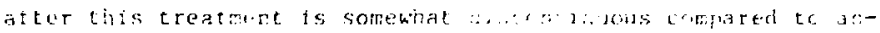
quenchod mornholingy and atendant aith rlits, there is some lateral thirkening, of the austerite filrs, wh revealod in fige. 25 which nay be a rosult of an atcemplo decrease the total aly surface area.

The continued presence of interlath cementite particles following $500^{\circ} \mathrm{C}$ tempering in the $2 \mathrm{Mn}$ and $0.5 \mathrm{Mn}$ modified alloys ic shown in Figs. 26 and 14, respectively, alihough these carbides appear to be somewhat finer than those present following $300^{\circ} \mathrm{C}$ tempering (F1gs. 23 and 24). In contrast, in the 5 si allny most signiffcant structural changes seem to be taking place within the 
martensite laths as already referred to in the earlfer section (Fłgs. 17 and 18 ) and neither coarse boundary carbides nor evidence for significant amounts of retained austenite was obtalned in these alloys following $500^{\circ} \mathrm{C}$ tempering.

\section{(11) $x$-Ray Analysis}

Within the prior austenite grain obviously a single variant of retalned austenite crystal orientation exists and therefore, depending on the prior austenite grain size, a monovariant austenite may be contributing to the x-ray diffraction, a situation slmilar to the cases wherein preferred orlentation exists. This and the fact that only small volume fractions of highly deformed austenite phase are present in these alloy steels complicate the detection and accurate analysis of the volume fraction of this phase $(34,70)$. Conventional $x$-ray analysis failed to resolve the austenite peaks in all the qua-ternary alloys. However, sophisticated methods of $x$-ray analysis wherein special precautions ate taken to suppress the background to accentuate the austenite peaks $(55,56)$ did reveal retained austenite in these alloys. Figs. 27 through 29 show the volume fraction of this phase as a function of composition and heat-treatment. While much confidence can not be laid on the absolute numbers, the trend and relative variations in the volume fraction of austenite are quite important. The following important conclusions can be drawn from these plots: the \% retained austentte 1ncreases with amount of Mn addition (Figs. 27 and 28). Highest amounts of retained austentte were 
found in the 5 N1 modified alloys (Fig. 2B) partirularly wher: held in the $M_{s}-M_{f} r e g 10 n$, durtng the quench from alsitente phase field when a $3.4 \%$ retainred austenite wis found. Craln-refining incrases the dmesut of retainad austenite in the as-quenched structures of all the alloys fonmare Figs. 27 and 28). Fig. 29 shows the therad stathity for this austenite from which it $1 \mathrm{~s}$ cleat that in the "s or modfied alloy, the retalned austerite undergoec inro or less cocolete transformation at $300^{\circ} \mathrm{r}^{\circ}$ Largarine wheras in the 5 al modis sed alloy, a major fraction of the orininal allstintte remains stable even after $400^{\circ} \mathrm{r}$. tumperins. Sigaficanclo, these $x-$ ary analysis results are in total aremert with hose of eleoron netallographic observations and thus, farb tre confirss the other.

D. Techanical Properties

The mechandeal properties of the base and ald wary olloy steels are simmerizai in Tables I I through IV.

\section{(i) Tensile Properties:}

Fig. 30 shows the variation of Rockte: 2 hardaces $R c$, as a function of tempering temperature. The remarkable temper resistance of all the alloys in the tempe:ing range $300-500^{\circ} \mathrm{C}$ is evident which is also reflected in the strength vs. tempering temperature plots of Figs. 3! and 32. The ? Mn alloy in the single treated condition exhibits rapld loss of hardness and strength between as-quenched and $300^{\circ} \mathrm{C}$ tempered conditions. Fig. 33 shows the strength of quaternary alloys as function of Mn content. The 
high strength levels for the base alloy are presumably due to somewhat higher carbon content in this alloy. The variation of tenslle ductilty wh tempering temperature of the single trail: and grain refined structures is shown in Figs. 34 (a) and (b) respectively. The inftial retained rolume " from $x-r a y$ anaiysis 1s also indicated on the plots nt Fig. 34 (a).

\section{(11) Fracture Properties:}

Plane strain fracture toughness tests were conducted only for the as-quenched ard $200^{\circ} \mathrm{C}$ tempered treatments due to material Imitations as well as lack of practical interest for tempering treatments at higher than $200^{\circ} \mathrm{C}$. However, Charpy impact toughness tests were conducted for tempering temperatures up to $600^{\circ} \mathrm{C}$. The data from the plane strain fracture toughness testing as well as impart fusting is tabulated in Tables Ii through IV and plotted in Figs. 35 througt. 42.

Significant improvenent in the plane strain fracture toughness at a given yield strength is chtained with quaternary alloying of either $\mathrm{Xi}$ or Mn, although 2 "n nodified alloy showed better toughness values than the 5 si modified alloy, espectally when compared in the quenched and tempered condition, Fig. 35. The higher Mn alloys are somewhat hrittle in the as-quenched condition (ice water quenching) due to the absence of any auto-terpering but following $200^{\circ} \mathrm{C}$ tempering, these alloys exhibit excellent toughness properties (Tables II \& III and Fig. 35). The substantial improvements in plane strain fracture toughness 
achleved with quaternary alloying fis also reflected la the plot of $\mathrm{K}_{\mathrm{IC}}$ vs $\% \mathrm{Mn}$ or $\mathrm{Ml}$ of the grain reflati structures, Fig. 36. The 1mprovement in this property shown by the quaternacy alloys is particularly significant following, the $200^{\circ} \mathrm{C}$ tempering. Again, the toughness properties of 5.0 .11 modflint alloys are somewhat. Inferior although it should be foted that the 5 N aliogs have higher strengths, (Table iV iad Fia. 32).

The Charpy-U-Notch impoct Loughness Filupertas of the modifled alloys are deplotkd ju igs. 37 through 42. F1g. 37

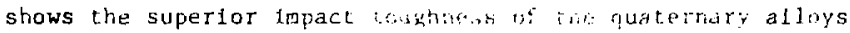

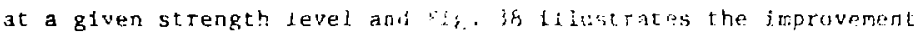

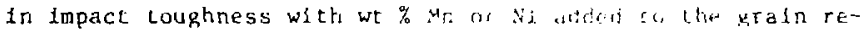

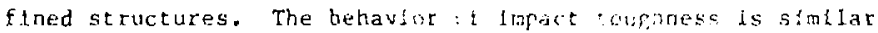

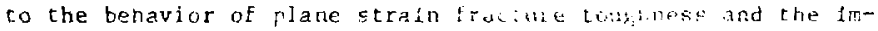

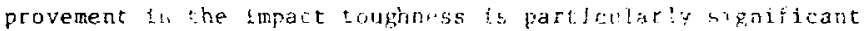

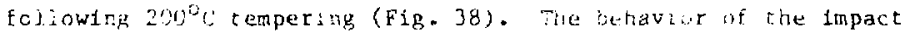

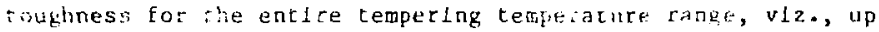
to $600^{\circ} \mathrm{C}$ is illustrated 1 il Figs. 39,40 and 41 as a nction of composition and heat-treatuents. The points oi sigaticant importance that emerg: from these plots are: (1) while the hase ternary alloy, the $\cdot .5 \mathrm{Mn}$ aodifled alloy and the 5 si modifled alloy show anly tempered martensite embrittlement, the $2 \mathrm{Mn}$ modified alloy show: two kinds of embritclement, viz, tempered martensite embrittlement as well as temper embrittlement (Figs. 39, 41). (11) The mbrittlement phenouenon ( $1 n$ impact toughness) occurring in these rodifled alloys can not be avolded by grain 
refining. However, the impact toughness values at all temperatures can be improved by grain refinement (Figs. 40 and 41). (111) The temperature of occurrence of teitpered martensite embrittlement is a function of composition, Fig. 41. In the 2 Mn modifled alloy, it seems to occur around $300^{\circ} \mathrm{C}$ (Fig. 34 (a)) whereas in the 5 N1 alloy, this temperature is around $400^{\circ} \mathrm{C}$.

In order to study the influence of quaternary alloying on the ductile brittle transition temperature (DBTT), the plot of impact energy vs. testing temperature is obtained for various alloys shown in Fig. 42. It is clear that there is no significant variation in the ductile-brittle transition temperature as a result of Mn addition of up to? w/o although the 5 vi addition showed a substantial lowering of the DBTT (50\% Fnergy Criterion) from about $-40^{\circ} \mathrm{C}$ for the ternary alloy to $-70^{\circ} \mathrm{C}$ for the $5 \mathrm{Ni}$ quaternary alloy. More significantly, however, all the ternary alloying resulted in a considerable upward shift in the upper shelf energies. Since there is no sharp drop off in impact energy at a particular temperature for any of these alloys, the DB'T will depend strongly on the criterion used to determine it.

\section{F Fractography and Particle Characterization}

Since the Charpy-V-Notch impact energy values showed the most interesting variations with alloying and heat-treatment particularly followlng various tempering treatments, fractography was concentrated on the broken Charpy bars to study the operative failure modes in these 
alloys and to try and corre?alm the fa"lure modes with the nicroctrueturis changes.

Fig. 43 shows brittle, quasi-clenvagle frarture in as-quenched Mn modifled alloys subjectud to sirgl high lomerature treatment. The 2 Mn alloy does reveal a hiphly brittle fracture with mumpors secondary

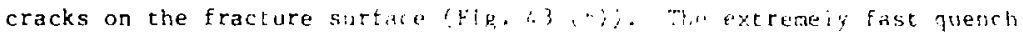

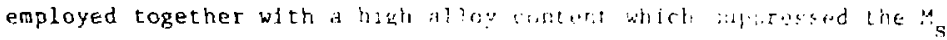

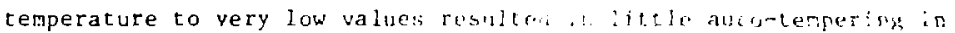

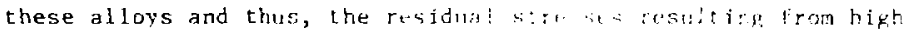

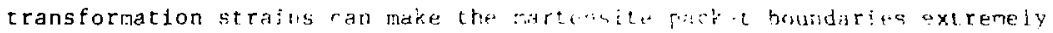

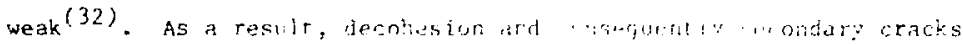

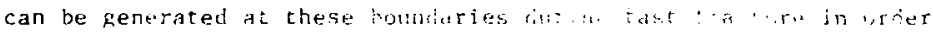

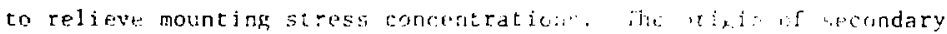

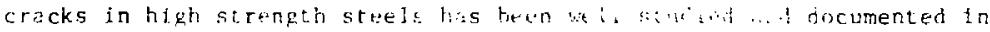

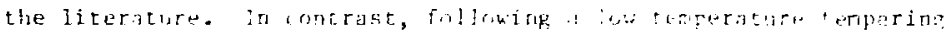

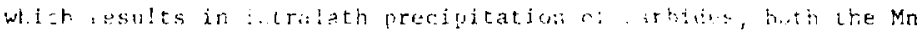

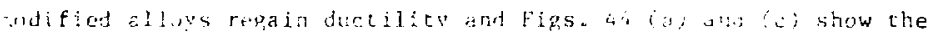

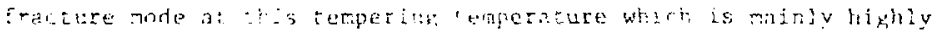
ductile dinuidi rupture. Aso teviden from these tractographs is that the average size of dimples in the $2 \mathrm{Mn}$ alloy is staller than ther of the 0.5 Mn alloy and that most of these dimples in the former are associated with spherical precipitates the identifcation of wich will be presented later. The most interesting changes in fracture mode took place following $300^{\circ} \mathrm{C}$ tempering as shown in Figs. 44 (b) and (d). The ductile dimpled rupture at $200^{\circ} \mathrm{C}$ tempering is replaced by brittle quasicleavage fracture with parallel ridges on the fracture surice. These 
are indicative of severe interlath tearing or fracture which is particularly prominent in the 2 Mn alloy, Fig. 44 (d). The average distance between these parallel ridges measured on the fractograph is of the same order as the average lath width (Table VII).

Following $500^{\circ} \mathrm{C}$ tempering, brittle intergranuiar fracture dominated the fallure mode in $2 \mathrm{Mn}$ alloy (Fig. 45 (b)) whereas transgranular quas1cleavage fracture persisted in the $0.5 \mathrm{Mn}$ alloy (Fig. 45 (a)). The kind of intergranular embrittlement shown in Fig. 45 (b) is commonly associated with segregation of certain species to the prior austenite grain boundaries which lower the intergranular cohesion (15) rather than with any grain boundary precipitation. In contrast, Fig. 46 shows the fractographs of grain refined $5 \mathrm{Ni}$ modifled alloy as a function of tempering temperature and the fallure mode throughout the tempering process remains clearly ductile dimpled rupture. Regions similar in appearance to the intergranular microvoid colaescence ${ }^{(64)}$ on the fractograph of the as-quenched $5 \mathrm{Ni}$ alloy, F1g. 46 (a), are replaced by $100 \%$ ductile dimpled rupture following $200^{\circ} \mathrm{C}$ tempering, Fig. 46 (b) and the gain in impact toughness is apparent from Fig. 41 .

An $x$-ray energy dispersive analysis unit attached to the scanning electron microscope was used to qualitatively characterize any inclusions in the experimental alloys and Fig. 47 presents some of the results in the 2 Mn alloys. The fractographs of this alloy revealed nost inclusions situated at the dimples (Fig. 44 (c) and the analysis of nearly spherical, about $2 \mu$ in dia. inclusions in the $200^{\circ} \mathrm{C}$ tempered alloy (Figs. 47 (a) and (b)) revealed that these are indeed ( $\mathrm{Mn}, \mathrm{Fe}$ ) $S$ particles. These inclusions were also observed near the grain boundaries 


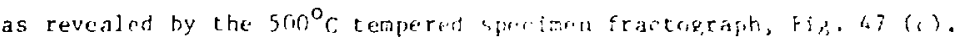
The cortesponding Fiax onalysts again confirmed that the so ar indeed (Mn, Fe) S particles. F1g. 47 (c) als riparly shrws tre decohesion at the partirle/matrix interfase. Himever, at this timporing temperaturn, as discussed earlfer, the prior auctulte intin houndaris are the weakst

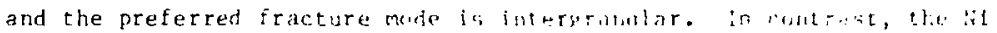

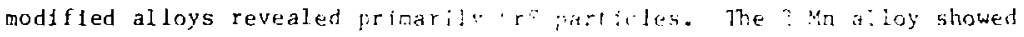
the highest amount of inclusions int this alliy is also rabracteriztd

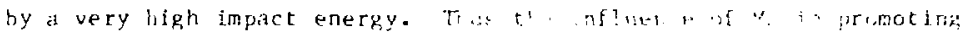

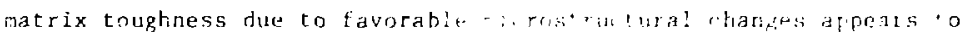

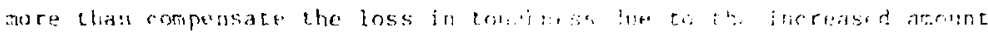

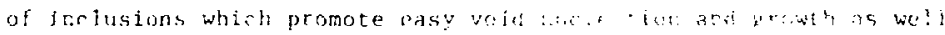
ats docohesinn at the interiart.

v. isisisistis

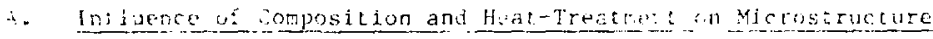

(i) Asthringed stens

Sartancte struciure: The morphology and sthetructure of Ierrous gartensites have been subjects of a muber w investigations $(3-4,10,74, ; 9,21,22,39,40,54)$ anci therefore, a detailed discussion the factors affecting these two important structural parameters will not be attemfted here. In the present investigation all the quaternary alloys revealed predominanty "lath" martensitic structure (Figs. 4, 6-9) 1rrespective of their composition. Thts is to be expected since predominanty 
plate martensitic structure is found only in high-carbon, high nickel and high nitrogen alloys $(54,71,72)$. What is of more signiflcance in these structural steels is their substructure, as tt is now well established $(4,18)$ that substructura plays a paramount role in controlligg the toughness of steel. The substructure of martensice is a consequence of the Invariant plane strain condition for the shear transformation(1) as alluded to before.

The lattfce invariant shear can be either slip (dislocated nartensite) or twinning (twinned martensite) and the factors affecting the transition from slip to twinning are points of considerable debate and controversy $(3,10,54)$. Kelly and Nutting proposed that low stacking faul energy in austenite favors the formation of lath martensite. (40) A problem with this hypothesis is that manganese lowers the stacking fault energy of austente whereas nickel has the opposite effect and yet both of them favor twinned plate martensite formation when present in suffictent quantities. Owen, et. al. (73) advanced a bypothesis according to which dislocated martensite in iron alloys is always associated with a cublc phase whereas twinned martensite is tetragonal. However, this again fails to explain cubtc twinned martensite that forms in $\mathrm{Fe}-\mathrm{Ni}, \mathrm{Fe}-\mathrm{Pt}$ and $\mathrm{Fe}-\mathrm{Mn}$ al loys $(54)$. Other investigators $(3,4,54)$ pointed out the importance of temperature of formation of martensfte in dictating the substructure of martensite, viz., as the $M_{S}$ temperature goes down, at a critical temperature the transition from dislocated 
substructures to twinned structures occurs. A purely temperature explanation 1 s also not satisfactory as Co is shown to ralse $M_{s}$ temperature but wh thout having any significant effect on the amount of substructural cwinning $(10,21)$. Secondly, dislocated mattensite continued to exist in binary Fe-Ni alloys with $\mathrm{M}_{\mathrm{S}}$ cemeratures much lower than the reitical it temperature In alloys containing $c^{(14,74)}$ (for example, compare 5 wi nodified alloy with binary Fe-20Ni alloy sturied in this investigation, Table VI). In order to get around this difficutly, it was first suggested by Joharl and Thomas ${ }^{(75)}$ that not only temperarure but also alloy composition may significantiy influence the ertent of twining in the martenste and the important factor is the relative magnitudes of the critical resolved shear stresses for twinning and sijp at a given temperature for a particuiar alloy composition $(7,4)$.

Das and Thonas ${ }^{(39)}$ reported that idditions of up to 12.5 w/o $\therefore 1$ to it $5.24 \mathrm{C}$ steel did not result in any significant twinning. In the pesent study the base alloy contains $4 \mathrm{w} / \mathrm{o} \mathrm{cr}$ and $=0.3 \mathrm{w} / \mathrm{o}$ $C$ and both $C x$ and $C$ are shown ${ }^{(18)}$ to be potential promocers of twinning. Since $\mathrm{Nf}$ itself is not a strong promoter of twinning. it is concluded that the observed small amount of twinning in 5 N1 modified alloys (Fig. 8) can be considered as a resuit of the Indirect effect of $\mathrm{Ni}$ through lowering of $M_{S}$ (Table I) which, in the presence of potential twin promoters, results in twinning. In contrast to the behavior of N1 steels, Huang and Thomas (22) found that an upper $11 \mathrm{mit}$ to the addition of Mn to a $0.25 \mathrm{w} / \mathrm{o} \mathrm{C}$ 
steel in order to avold excessive amounts of twinning was a mere $3 \mathrm{w} / \mathrm{o}$. This implies that in the presence of $\mathrm{C}$, Mn is just as much a prototer of twinning as $\mathrm{Cr} .(18,22)$ In the present Investigation by limiting the maximum Mn addition to $2 w / 0$, twinning is avoided. This is probably due to the overrlding influence of the somewhat higher $\mathrm{M}_{\mathrm{s}}$ Lemperature (Table I) in these alloys compared to NI modified alloys in malntalning the critical resolved shear stress for slip lower than that for twinning. There were no significant variations in lath widths wh elther composition or heat-treatments designed to change the prior austenice grain size and the martensite parket size (see Table VII and the discussion in a later section). Roberts(76) also found a similar behavior of lath width variation with matcensite packet size and Mn content and an explanation for this is proposed in a latter section.

Retained Austenitr: High temperature fcc austenite phase can be stabilized at room temperature by a variety of mechanisms, some of which are not fully understood. In general, one would expect that elements which are fcc stabilizers should pronote retalned austentce. However, as would be clear from the evidence presented in Part 2 in connection with lath martensite formation, in alloys whose bulk $M_{5}$ and $M_{f}$ temperatures are above room temperature austenite can be stabilized at room temperature only in the presence of Interstitial $C$ (perhaps also N). This is in agreement with the observation made years 
ago by Yeo $(77)$ who reported that carbon is vital for the stabllization of the austenite to martensite transformation. Furthermora, Rao et al. (34) were able to resolve small quantitias of retalned austenite even in very low $C$, uraloyed steels. The fact that presence of $r$ alnne is not a sufficjent condicion for stabilizing austentle in the as-risenched structures is shown by the work of C.lark and Thomas (21) who reported that no resolvable quantities of recained austenite could be found in a medium $C$. steel modified with Mo additinns un to 4 w/o. Clearly, the substittional alluging-interstitial C interactions must also be playing an important role in stabilizing austenite. However, it was sugkested ${ }^{(23)}$ that the atserylloi of retalned austenite in FefCrlo, steels and the absence of this phase in FefMolc steels can he partiy reconcil ad oith the lact rhat Mo is a more potent alloying element(x) vompared to cor in limiting the austenite phase field. Intersteigi 6 an stabilize austenite in several ways: (i) it can physically segregate from the lath martensite to the surcounding austenite and this partitioning can lower the local $y_{s}$ sufficiently below room temperacure whereby austenite is stabilized at room temperature i.e., "chemical stabilization". (74) This kind of stabilization should therefore be particularly effective during slow cooling from austenitizing temperature, for e.g., air cooling. (37)

(ii) The second stabilization, known as thernal stabilization. (78-80) is caused again by diffusion of interstitials $C \& N$ but this time not to achieve partition but to form dislocation atmospheres to 
Inhibit their motion. These pinned dislocations can be in the martensite/austentte interface in which case they would directly Inhibit interface motion or they can be in either phase, thus, Inhiblting stress relaxation in the martensite or austenita; (1i1) The third stablization, known as mechanical stabilization, Is concerned with the plastic deformation in austente accompanying the shear transformation. Edmondson and $\mathrm{Ko}^{(81)}$ and Kelly and Knutting (40) studied this phenomenon. Rao and Thomas (32) have considered in detail the question of accommodation of strain resulting from lath martensite formation and concluded that Increasing $C$ content increases the dilatation in the martensite lattice and the consequent accommodation in austenite.

The direct influence of substitutional alloying elements alone is not sufficient in stabllizing austenite in the drectly quenched structures although strong fcc stabilizers such as $\mathrm{Vi}$ and $M n$ are primarily responsible in reverted austenite formation for e.g. in quenched and reheated specimens of maraging steels. $(82,26)$ This is particularly true in the light of the observations made in Part 2 with binary Fe-Ni alloys where no retained austenite could be resolved.

Thus, it seems that in the structural steels of interest $C$ is necessary for stabllizing austenite and the other substitutional alloying elenents may affect the amount of retained austenfte through their inceraction with $C$. In the present investigation not one but several of the above factors might have been responsible for the observed increase in volume 


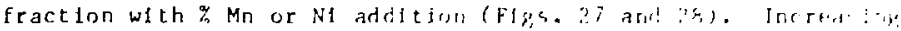
Mn addition results in a drop in $M_{s}$ temperatur. shith therefori discourages large scale migration of 6 durlug and wt ter the: martensitfe transformation. Therefore, wetessive pratitioninp. of $C$ and the consequent chealcal stabilization wity net he.

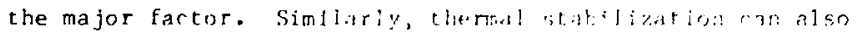

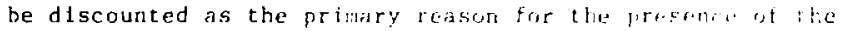
high temperature phase particular?y in the tast quenctied fich

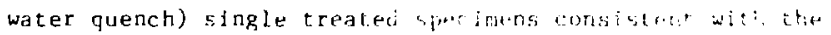

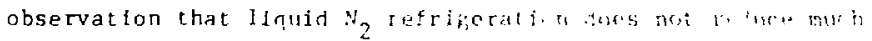

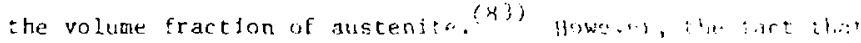

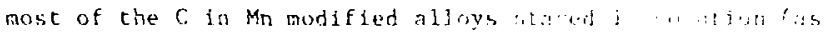

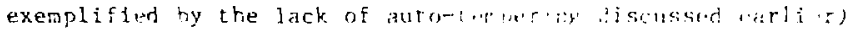

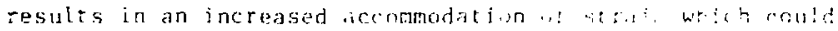

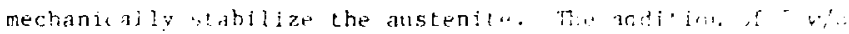

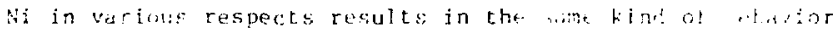

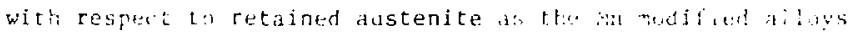

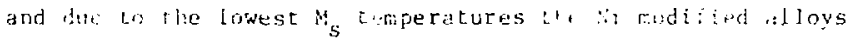
showed the highest amounts of retained aublenit. In the single treated interrupted querched structures of iti modi:ied alioys highest anount of retained austenite was found due to iro promotion of $C$ partitioning and migration to disloratinns during the $M_{S}{ }^{-M_{f}}$ hold (i.e., chemical and thermal stabilization) in addition to the mechanical stabllization. In this connection, an important factor arisling from the alloying element-c interaction which could significantly affect the mobilicy of 
$C$ has to be consldered. Alloying elements such as $S i$, Al and N1 promote graphictzation and have carbide forming tendencies efther less than 1 ron (NI, Al) or negative (Si). (8) In addition N1 and $S i$ also ralse the activity of $C$ in martensite(84) ant similar behavior is expected of $\mathrm{A}^{(30)}$ whereas exactly the reverse behavior is expected with some of the carbide forming elements such as $\mathrm{Mn}, \mathrm{Cr}$, Mo, T1, etc. which due to the attractive Interaction with $C$ (In the increasing order) lower the activity coeffictent for $C$. The result is that $\mathrm{N1}, \mathrm{Si}$ and $\mathrm{Al}$ favor $\mathrm{C}$ partitioning to austenite and thereby increase its volume fractton $(24,36)$ whereas Mn, Cr, Mo, TI etc. disfavor C partitioning and this sort of austenite stabtlization. The situation with the present alloys is complicated due to the quaternary alloying but it appears that in the $5 \mathrm{Ni}$ modifled alloys increased amounts of stabilized austenite can also be expected due to the promotion of c partitioning. It is clear that a technique capable of analysing $C$ concentrations in regions which are typically $300-500 \AA$ wide is invaluable in pinning down the exact $r$ stabilization mechanism. It is being attempted to solve this problem by the use of high resolution lattice 1maging at the $r$ la boundary. In general, the carbide-forming elements, while powerful in deep hardening influence, are not so effective In retaining austenite as are nickel and manganese(8). Apart from composition, one of the important microstructural features that affects the stability of austenite is the prior austenite grain size. In the present investigation the amount of retained 


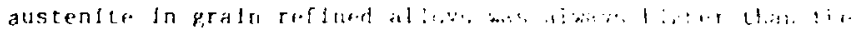

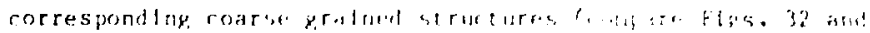

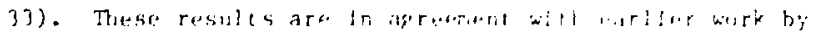

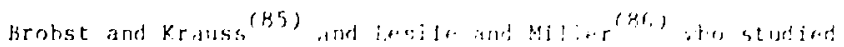

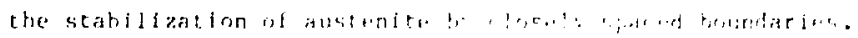

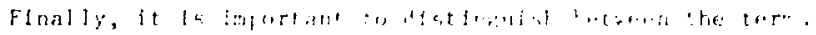

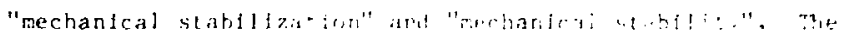

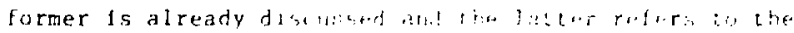

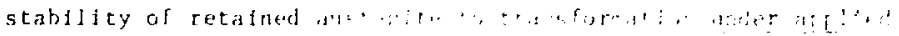

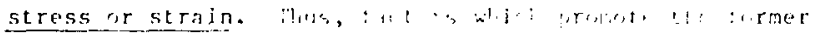

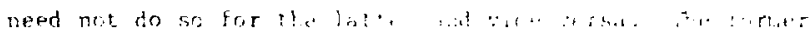

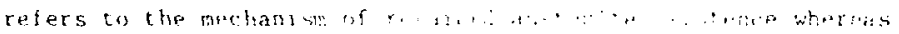

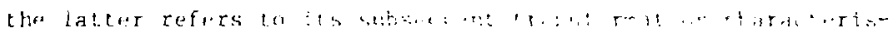

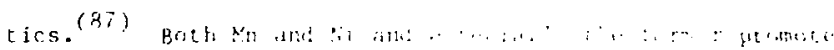

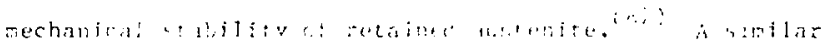

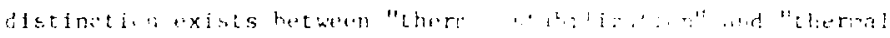
Situitijty".

(ii) Tompterd $5+\theta+1$

Structural Charges and Precipitation ir Martersite: There are three primary variations within the mattensitic phase of the tempered structures that need discussicn, viz., cotrsening of cement1te with increasing Mn additions (Figs. (4-12), stabilization of E-carbide in Ni containing steels (Figs. 8,9) and the observation of $M_{7} C_{3}$ carbides in high $M \pi(2 \mathrm{w} / 0)$ and high $\mathrm{Mi}(5 \mathrm{w} / 0)$ alloys even at low tempering temperatures (Figs. 12, 13, 15). Tempering of alloy steel martensite has been the subject of 
numerous investigators $(44,69,25,2)$. It is now fairly well documenest that $1 \mathrm{t}$ Involves several stikes, viz., clugtering and preprectpitation of interstitial elements, precipitation: of e-carbide (Stage I tempering), decomposition of retained austenite (Stage IT tempering), precipitation of cementite (Stage III tempering) and precipitation of alloy carbides (Stare IV tempering). The complex role of alloying elements in controlling the kinetics of tempering reactions, stability and occurrence of alloy carbides has been the subject of several papers in the literature $(25,30,74,88,89)$ bur unfortunately, most of them are concerned with either plain C steels or $C$ steels modifled primarily with one alloying element. The Introduction of a quaternary alloying eloment in the present study introduces a further degree of complexity which is absent in the several studies made using a ternary system.

The kinetics of coarsening and spleroidization of cementite in the martensite matrix are variously related to the diffusivity of substitutional solute ${ }^{(2,25)}$, alloy content, the disribution coefficient for the alloying elenent between cementite and ferrite $(2)$, the interstitial $C$ activity as influenced by the substitutional solute ${ }^{(84)}$, variations in the interfacial energy between the cementite and ferrite matrix as a result of alloying (25) and in this regard, the degree of lattice coherency ${ }^{(8)}$, etc. Mn and $W i$ have important differences as regards their influence on cementite stability. Both $\mathrm{Cr}$ and $\mathrm{Mn}_{\mathrm{n}}$ stabilize cementite by overcoming the metastability of $\mathrm{Fe}_{3} \mathrm{C}$ existing 


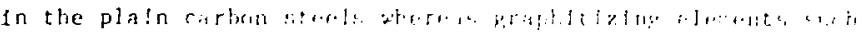
as S1, Al and : I destablithe the alreidly altastable cement ite

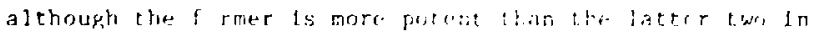

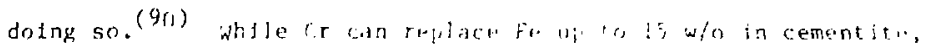

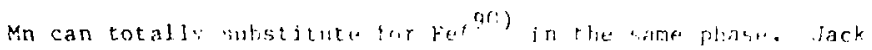

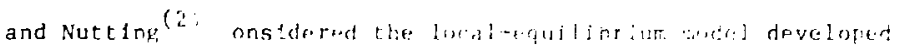

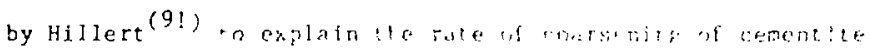

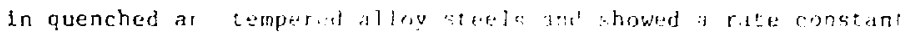

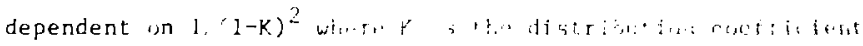

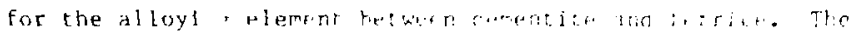

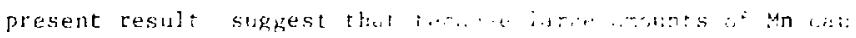

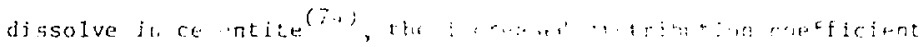

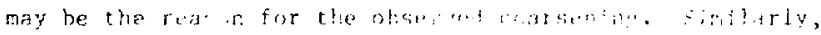

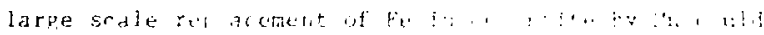

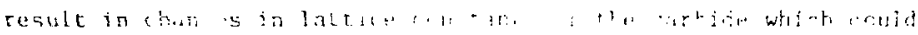

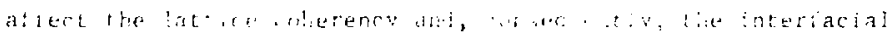

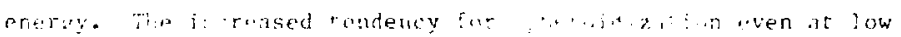

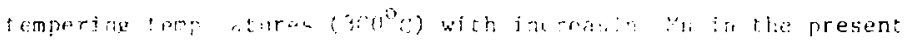

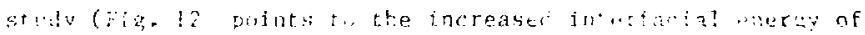
the rarbiden ina in interface.

In the ca of si modified qua-terary alloya, the behavior appears ta be le result of a compromiat he sint the apposing Lendencies of $\mathrm{t}^{2}$ and $\mathrm{Ni}$ in stabilizing celcutite. Ir many tespects, Ni and Si have dentical behavior in the teapering process of the steel (although the degree may be quite different), e.g., as discussed before, both of them raise the $c$ activity and both of 
them destabllize cenentite by promoting graplitization. The expanded occurrence of $\varepsilon$-carbide (Stage I tompering) in si nodffied steels is well documented $(30,36,37,84)$. Several models were porposed $(84,92)$ to explain the c-carblde stabillation and $t:$ : :hibiton of cementite growth in the presence of Si or Ni. Wha :s not clear is whether e-carblde is directly stabilized by Si or indfrectly stabilized due to the postponement of the onset of cementite nucleation. Whlle the proposed models fail to solve this problem, they, nevertheless, present a convincing argument, especially the one by owen ${ }^{(92)}$, In explaintng the inhibition of cementite growth. According to owen ${ }^{(92)}$, as cementite grows, increasing amounts of $S i$ are rejected into the matrix which creates a Si concentration spike discouraglng any C migration to the carbide due to the repellent interaction between $C$ and $s 1^{(84)}$. For further growth of the carbide, this si concentration spike has to be dissipated with is racher slow at low temperatures. A similar explanation may be advanced for carbide growth in the presence of appreciable amounts of Ni in the alloy. King and riover ${ }^{(84)}$ report that the kinetics of $\varepsilon$-carbide precipitation (Stage I tempering) are also slowed down by the presence of graphitizing elements such as $\mathrm{Ni}$ and $\mathrm{S} I$ due to increased activitation energy for this process.

In the present study, E-carblde is the predominant rarbide at $200^{\circ} \mathrm{C}$ tempering in the $5 \mathrm{Ki}$ modffled alloy (Figs. 8, 9) although cementite precipitation occurred as early as $300^{\circ} \mathrm{C}$ tempering (Fig. 13). Since $N 1$ is not a very strong graphitizer, it is suggested 
that the overwhelming influence of Cr 1 n stabilizing cemutite caused it tw zccur at $300^{\circ} \mathrm{C}$ tempering.

Regarding the observation of the alloy carbide $\mathrm{M}_{7} \mathrm{C}_{3}$, unfortunately, there is very little information avaluable in the literature on the Influence of various alloying elenents on the formation and growth of this carbide. Seal and Honeycombe ${ }^{(88)}$ and Rao et al. (33) discussed its formation In the ternary Fe-Cr-C allogs. It has been shown $(88,25)$ that addition of strong carbide f sming elements such as $\mathrm{No}, \mathrm{Nb}$, $\mathrm{Ti}$ to the ternary Fe|Cr|C st els can retard softening and this effect is suggested to be the rasult of these nlenents In restricting the diffusion of cr in fertite and thus the rate at which $\mathrm{Cr}_{7} \mathrm{C}_{3}$ coarser: $(18)$. Therefore, it ts not clear how and why higher $M n$ and N1 additions to the cernary alloy prowote the formation of $M_{7} C_{3}$ (Figs. 12, 13, 15). The absence of any secondary hardening peak ir the hardness vs. tenpering temperature curves (F1g. 30) for all the curves can be explained by the fact that Mn is unly a very mild carbide former and $\mathrm{N} 1$ is not a carbide former a all.

\section{B. Thermal Stability of Retained Austenite}

Whereas Identifcation of retained austenite and studies on its stabilizacton in medium $C$, Low alloy steels are in the very beginning stages, its decomposition following tempering is even much less studied. Most of the earlier studies on retained austenite decomposition were conducted with high $C$ steels $(>0.55 \mathrm{w} / 0 \mathrm{C}$ ) wherein large quantities 
of austenite are retalned. (8) Even here very little careful metallography was carried out. The austenite decomposition reaction was variously characterized as lower bainitic, upper bainftic or even pearlitic. (8) More recently, however, Speich and Leslie ${ }^{(74)}$ characterized the decomposition reaction as bainftic. There is practically no work done in the past on the mechanism of decomposition of the specific type of retalned austenite during tempering, viz., the interlath film aorphology occurring in the structural steels of interest. Thomas (70) has pointed out that some of the factors which promote austenite stabilization in the first place, viz., segregation of $C$ and accommodation of transformation by plastic deformation in austente, will also contribute to its instability during tempering. Th1s is because the increased supersaturation of $C$ in austenite promotes its deconposition to $a+M_{3} C$ due to higher driving force available. So also, the dislocation substructure generated in austenite can pronote heterogeneous nucleation of $M_{3} C$ and thereby the decomposition reaction $r \rightarrow a+M_{3} c$

In the present studies, the retained austenite is stable to $200^{\circ} \mathrm{C}$ tempering in all the alloys (Figs. 20, 22, 29) but in the Mn modified alloys the austentte undergoes decomposition following $300^{\circ} \mathrm{C}$ tempering (Figs $23,24,29)$. This is a temperature which is above the bulk $M_{S}$ Eemperatures for $1 \mathrm{Mn}$ and $2 \mathrm{Mn}$ alloys and about the same as the bulk $M_{s}$ temperature for 0.5 un modiffed alloy (Table I). If we Invoke the possibllity of some segregation and solute enrichment during tempering in austenite, then the decompostion temperature could lie in the upper batnitic transformation region for all the alloys. What is even more 
significant is that the decomposition occurs at a temperature where significant matrix cementite coarsening is also observod (Section A (1i), Figs. 11, 12). The elongated carbide stringers occurring at the lath boundaries following the decomposition, Flgs. 23, 24, are quite typical of upper bainttic transformation. $(4,10,33)$ Also, the analysed selected area diffraction patterns or Figs. 11,23 and $? 4$ reveal an orientation relationship between the interlath cementite and matrix which does not conform to the well established Bagaryatskil orientation relationship, $(67,68)$ between the ferrite and cententice. instead a new orientation relationship, viz.,

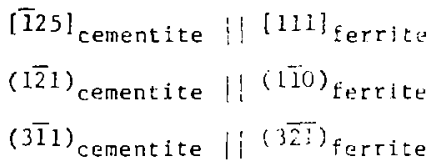

is obtained from figs. 23 (c) and (d). Previous crystalingraphic itudies $(67,68)$ af the orientation relationships between bainitic carbide and ferrita have suggested that these carbides ptucipitate directly fron austenite in upper bainite and therefore, the orientation relationship need not confom to the gagaryatskii relation wich is established for carbide precipitation from ferrite (for e.g., tempered nartensite). Another observation of significance to the present discussion is that cetentite is generally accepted to be the carbide phase in the upper bainitic product. $(93,67)$ In view of these observations, the present results on the differences in the transformation characteristics of retained austenite in $5 \mathrm{Ni}$ modified and 2 Mn modified alloys can be explained as follows. The difficulties involved in the formation and 
growth of cementite in the presence of graphitizing elements such as $\mathrm{S} 1, \mathrm{Ni}$, Al has already been dealt with in the previous section. If the retalned austenite were to transform by upper bainitic transformation, cementile formation and growth are important. The reason why retalned austentte would prefer to transform by an upper balnitle transformation appears to be the much lowered accommodation necessary for this type of transformation due to the fact that carbid. can be preclpitated directly from $r$. Thus, higher temperatures are necessary in the presence of $N 1$ to transform retained austentte to 1sothermal decomposition products. In the present study, untransformed retained austenite was observed in $5 \mathrm{N1}$ alloys at as high temperatures as $400^{\circ} \mathrm{C}$, Fig. 29. With the limited metallography carried out with $500^{\circ} \mathrm{C}$ tempered structures, no retained austenite could be observed in the $5 \mathrm{N1}$ alloy (Fig. 18). Further work to characterize the decomposition products of austenite in specimens tempered between $400^{\circ} \mathrm{C}$ and $500^{\circ} \mathrm{C}$ is necessary in order to understand fully the mechanism of retained austenite decomposition in this alloy.

\section{Tempered Martensite Enbrittlement}

The occurrence of tempered martensite embrittlement in the quaternary alloys has already been referred to in the results section and Figs. 48 and 49 sumarize the microstructural evolution, the micromechanisms of fracture and the correpsonding mechanical properties, of this phenomenon in two Mn modifled alloys. Tempered martensite embrittlement (TME) or, $500^{\circ} \mathrm{F}$ embrittlement has been recognized for a long time $(8,94-96,74)$ but the factors contributing to this phenomenon are not clearly 
resolved. (97-99) a sudden drop in a high strain rate toughness pararfiar, for example Charpy-v-Yotoh impact energy tested at room temperature following tempering in the range $250-450^{\circ} \mathrm{C}$ is generally regarded as the manifestation of the embrittlement; although, depending on the severity of this embrittlement, it is also shown to manifust itself ir othar low strajn rate toughness paranfers sict as censiln ductility $(98,100)$ and plane strain fracture Lmetness. (99) Both the orietin of $\operatorname{TME}^{(98,99)}$ as well as the fracture path(100) and fallure node $(98,99)$ are noints of debate. There is widespread condusion the literature regarding these two aspects primarlly hecause a wite efore trut of allav colpositions

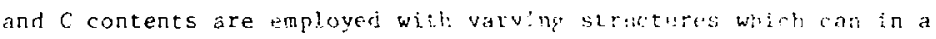

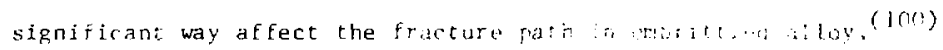
Secondiy, a systematjc unified approact where rareful diterostructural

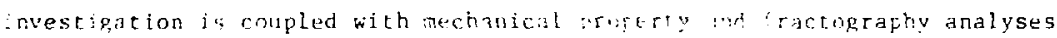

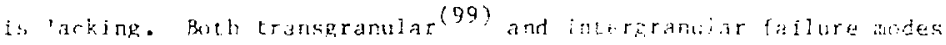

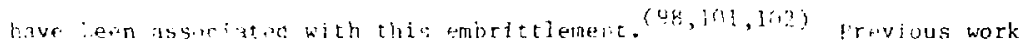

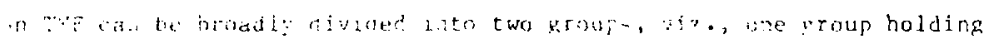

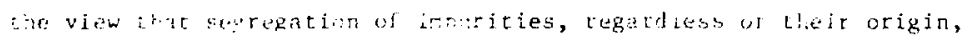

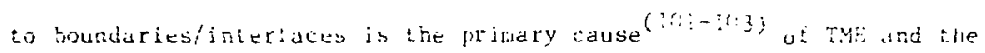
ither group strongly supporting the view that preciptation of brittle carbide phases at boundaries/interfaces/dislocations is the principa! cause $(96,97,99)$ of TME. At this moment it is also jmportant to recogaiza another well established embrittlement $(15,29,74)$ ubserved in certain quenched and tempered alloy steels and in sceels Joped intencionally with impurities such as $\mathrm{Sb}, \mathrm{P}$, As and $\mathrm{S}$, i.e., temper cmbrittiement. This reversible embrittlement occurring becween $370^{\circ} \mathrm{C}$ and $565^{\circ} \mathrm{C}$ is 
generally accepted to result frcm segregation of impurities to the prior austente grain boundaries resulting in a loss of cohesion at these boundaries and the consequent intergranular fracture. In the foregoing discussion, 1 will be slown that depending on alloy composi. it is possible to observe both TME and temper embrittlement in the same alloy and that the latter is more severe than the former. (i00) It appears that some of the confusion and debate over the mechanism of TME in the past investigations also stems from the overlapping influence of temper embrittlement in those steels which were used to investigate TME.

Concerning the association between microstructure and TME, Lement et al (104) attributed the toughness degradations to the precipitation of cementite at the martensite packet boundaries whereas KIInger et al (105) suggested that the formation of cementite at prior austentle grain boundaries and the consequent intergranular fracture caused the embrittlement. Support for the assocation of TME with carbide precipitation can also be derived fron the work of thelisle and Galibois ${ }^{(96)}$ who concluded that the aligred carbides that result following embritting tempering reduce the mobility of dislocations. The general drawback of all the above studies is the absence of high resolution electron metallographic characteriziation of microstructure over a range of tempering temperatures.

It is interesting that the influence of retained austenite in TME has been suggested as early as back in 1924 by Grossman ${ }^{(94)}$ who, from thermal contraction-tempering temperature studies, envisaged the possibility of the preservation of austenite during quenching and 
its subsequent transformation during tempering causing the delcterions effect on toughness. More recently, McMahon and Thomis (1R) observed a loss in toughness which they showed was correlated with the decomposition of austente with the formation of interlath carbide films.

The results obtalned in this investigation show a more defindtive indication of the clear association between the retained ruscente instablity leading to interlath cement te and the TMF. A monotonic increase was found in the volume fraction of retalned austenite in the as-quenched structures as a result of quaternary ailry addicions of Mn up to 2 w/o to the ternary Fe-4Cr-0.3C alloy $(5 i j s, ; 9,21$, 27, 28). Similarly, the $5 \mathrm{NI}$ alloy also showed ithstaltinily increased

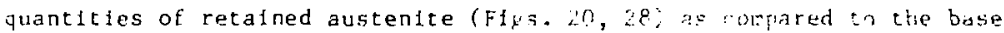
alloy. In the Mn modtfied alloys as well as the hase ternary alloy, this retained austente is unstable to $340^{\circ} \mathrm{C}$ tempoting and all of it is practically decomposed (Figs. 23, 24, 29) leading lu the precipitation of interlath stringers of carbide (cementire), the thicknesis of which increased with initial amount of retained austente (fias. 23,24$)$. The accompany 1 g variations in toughness are prosented in Figs. 39 , 34, 40. It is ciear that the $\%$ reduction in areit, a measure of tensile ductility, shows two minima, viz., one at $300^{\circ} \mathrm{C}$ (transgranular fracture), for the $2 \mathrm{w} / \mathrm{n}$ Mn modified alloy whereas no indication of a minjmum In this property is discernible for the 0.5 Mn nodified alloy, Fig. 34 (a). However, the Charpy Impact toughness, Figs. 39 and 40, clearly reveals toughness minima at $300^{\circ} \mathrm{C}$ tempering for the base and $0.5 \mathrm{Mn}$ alloys whlle for the $2 \mathrm{w} / \mathrm{O} \mathrm{Mn}$ alloy the minimum occurs only at $500^{\circ} \mathrm{C}$ : although severe toughness degradation occurs in this alloy folloring 
$300^{\circ} \mathrm{C}$ tempering. Fractography (F1g. 44) revealed that the predoniantiy dimpled rupture at $200^{\circ} \mathrm{C}$, Figs. 44 (a) and (c), 1 n all the Mn modified alloys is replaced by quasi-cimage at $300^{\circ} \mathrm{C}$ tempering, Figs. 44 ( $\because$ : and (d), which indeed reveal parallel ridges indicative of a fract. path along 1nterlath boundaries which are weakened by the precipitation of coarse carbides. Interestingly, the inter rjige spaciub lucasured from the fractographs is of the same order as the lath width (Table :il measured from transmission electron micrographs, Figs. 23 and 24 . The 2 Mn modified alloy showed increasingly brittle fracture for tempering above $300^{\circ} \mathrm{C}$ and at $500^{\circ} \mathrm{C}$, the fraccure was conpletely intergranular (F1gs. 45 (b) and 49) typical of emper embrittled structures. Transmission electron microscopy did not reveal any grain boundary precipitation that could be Iinked to this embrittlement at $500^{\circ} \mathrm{C}$ tempering although some interlath cementite still persisted at this temperature, Fig. 26. The charpy impact behavior of the $2 \mathrm{Mn}$ alloy appears to be the result of an overlapping influence of both TME (transgranular cleavage fracture) and temper embrittlement (intergranular fracture). In contrast, in the $5 \mathrm{Ni}$ alloy, with only very little retained austenice having undergone decomposition even at tempering temperatures as high as $400^{\circ} \mathrm{C}$ (Figs. 25 and 29 ), the interlath precipitation of cementite is minima1, Fig. 25. Concomitant with this, the impact toughness of the $5 \mathrm{Ni}$ alloy showed only a mild embrittlement and the tensile ductility vs. tempering temperature did not reveal any embrittlement at all, Figs. 41, 34 (b). The degree of embrittlement in the $2 \mathrm{Mn}$ and $5 \mathrm{Ni}$ alloys is compared in Fig. 41. Fractography, Fig. 46, of 5 Ni alloys revealed no signticant changes in fallure mode as a function 
of tempering temperature and the predomianty ductile dimpled rupture fallure mode is evident at all tempering temperatures.

The present results show that the nature of toughness measurements In terms of s rain rate and local stress condftinns ran he importint to be able to detect any enbrittement minlmum in that property. The $2 \mathrm{Mn}$ alloy had a higher percentage of retained austenite and, therefore, would produce a higher volume fraction of interlath carbides (i.e., coarser) following lts decomposition. Thus a m,to scvere entirittement is expectert in the 2 Mn alloy compared to $n .5$ Min alloy whin is qubstantiated by the occurrence of toughness mindma in buth the reduting in area as well as the fmpact toughness for the former. The strin rit. in a tensile or ${ }_{I C}$ test is about a million times sialler ihan that in an impact test

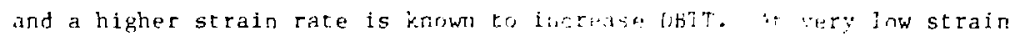
rates (such as in a tensile test), a toughness miminin ma not be

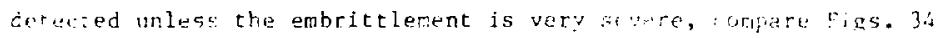
(a) and (b). The mechanisms whereby the britils, coarse paricices an roduce ductificy and coughness are alreaty discussrd in connection wth design gutulitues. The failure stress, $o_{p}$, ran be directly related $(99)$ to the width of carbide assuming carbide cracking occurs and treating. the propagation of this cracked nucleus as that oi a criffith crack,

$$
J_{F}=\left[\frac{2 \mathrm{E} Y_{p}}{\pi\left(1-v^{2}\right) a}\right]^{1 / 2}
$$


where the terms have thelr usual meaning and ' $a$ ' in this case is the' half width of the carbide. It is apparent fiom the above equation that the faflure stress and consequently the toughness $(1.9)$ are inversely related to the square root of the carblde thickness. Furthermore, the ease of cracking in the carbide itself is related lnveraely to the size of the carbide ${ }^{(43)}$. In addition, Cochrane $(106)$ and others ${ }^{(17)}$ hare Found that the Impact transition temperature increases directly with carbide thickness. TME has been observed $(70)$ in several experimental steels but not in FelMolC steels in which no retained austenite was detected ${ }^{(21)}$. This is consistent with earlier observations made by Irvine et al ( 107 ) who reported strikingly few carbide films at martensite lath boundaries in tempered steels containing Mo compared to several other alloy steels. Thus, TME appears to be a more general phenomenon (70) in alloys having appreciable amounts of retained austenite while temper embrittlement is specific to a few alloy compositions. Whatever the henefits of retained austenite to toughenss, following its decomposition, the toughness properties could be worse than not haying it in the first place. A major point of debate concerning TME is the fracture path $(99,100)$ in the embittled steels. The present investigation has shown that the fracture is transgranular with respect to prior austenite but is clearly intergranular with respect to the individual martensite laths (Figs. 44 and 49). The importance of a proper cholce of composition (and hence microtructures) in atriving at the above conclusions can be understood from a critical analysis of the recent work by king et al. (99) on the occurrence of TME in a plain $C$ steel. In the investigation under discussion, the authors chose a $0.6 \mathrm{w} / \mathrm{O} \mathrm{C}$ alloy. Although King et al. 


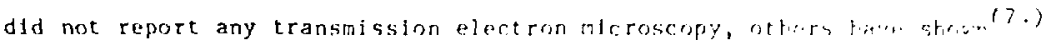
that the martensite morphology is mixed in the abrves str. with about

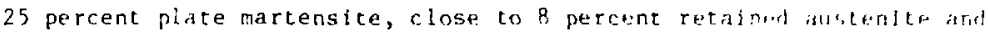
the rest lath martensite. The evidence tot substint ial amounts af plato marcensite in the structure can also he derivet from tha abos anthors" observation of microctacks. The morphology of retajned austenitr orcurring In plate martensite is qujte unlike chat. In the lath nitrtasitir found In the quaternary alloys. The axpected differences are illustriter in

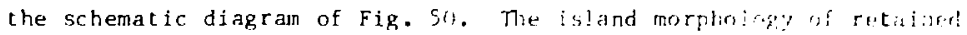
austenite, Fig. S0 (a), in plate martensits is expected to tove tise

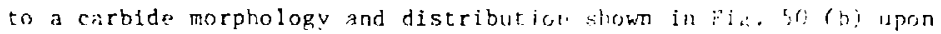
tempering. This is quite different from that ocruriag in lath martensite, Fig. So (d) foliowtng austenite decomposition. In the fromer, the islaris containing coarse carbides should provite eisy crack piathe and that,

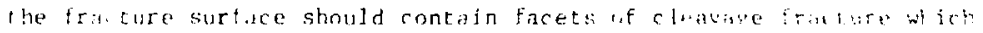

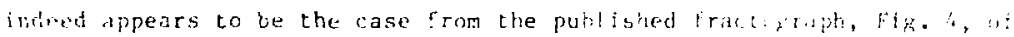
the abous paper. This led the authors co eronewisly aneralize a iracture path that is cransverse to individial martensite rystals in a steel subject to TME. Tt is cloar from the above discussion that is detalled microstructural characterization is vital for pinning dowm the origin of TME.

Crain refining is expected to lower the ductile to iritile transition temperature. $(47,48)$ Grain refining also increased the amounts Fetained austenite in the quaternary alloys (Figs. 27 and 28 ) which is shown in the above diccussion to cause severe embrittlemcot following its decomposition. The results of these two mutually opposing tendencies 


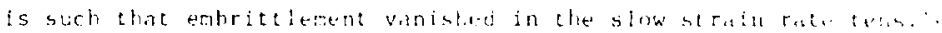

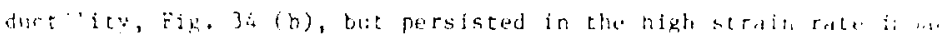

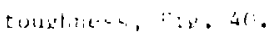

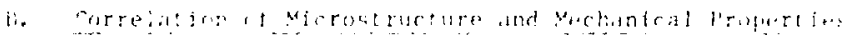

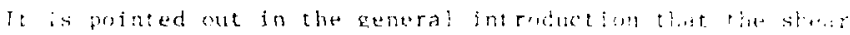

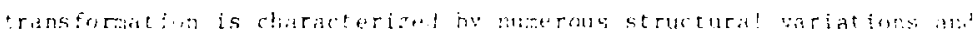

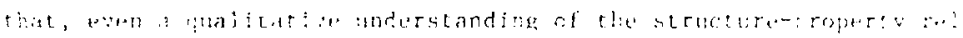

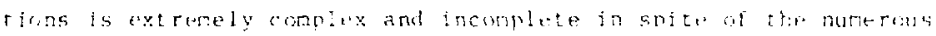

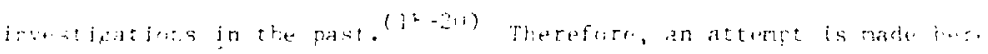

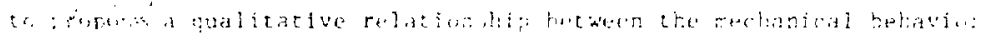

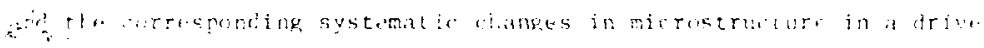

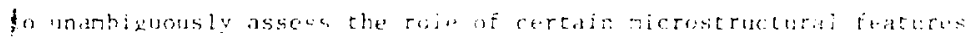

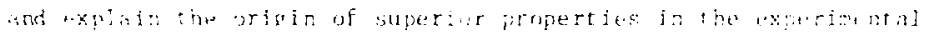

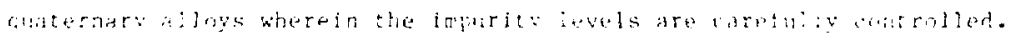

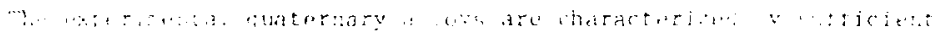

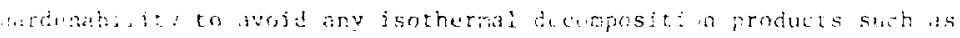

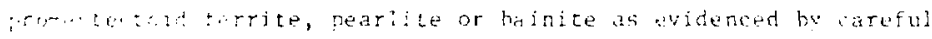

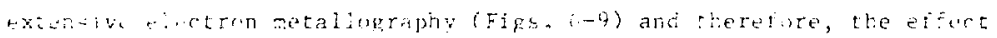
of these in the microstructure need not be considerel here. $\therefore$ the iresert investigation coarse alloy carbides are dissolred

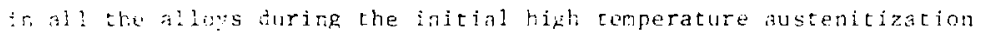
(austenitiziag: temperatur. $11 n^{\circ}(\mathrm{c})$. The size of the carbicies is an important parameter in cuntrolling the flow and fracture behavior $(42-44,1 ;$ as a!reasy discusad in the previous section. Since these coarse carbides are present i: n previous treatments, they will probahly be incoherent 


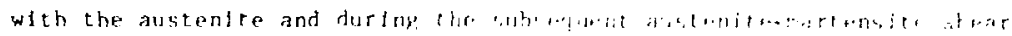

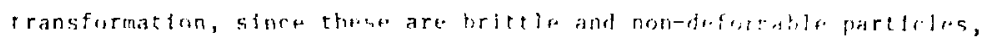

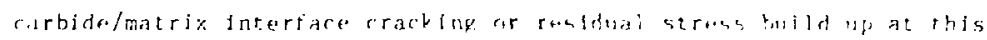

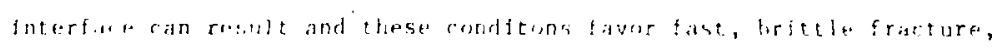

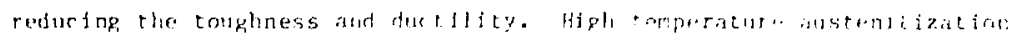

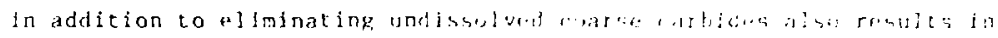

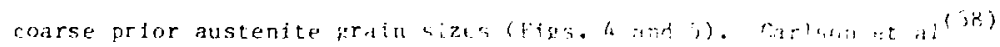

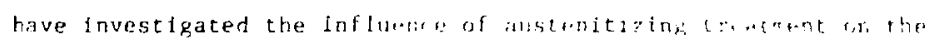

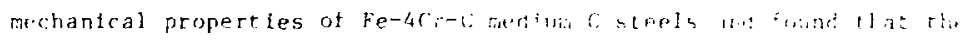

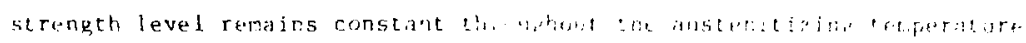

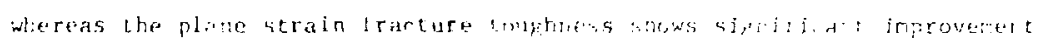

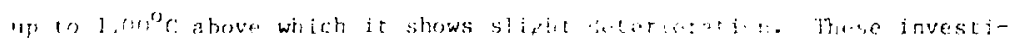

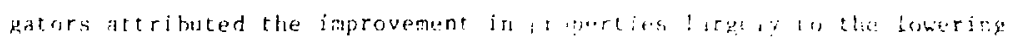

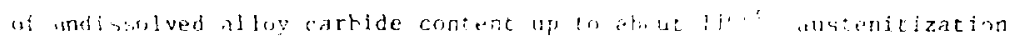

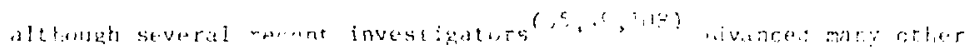

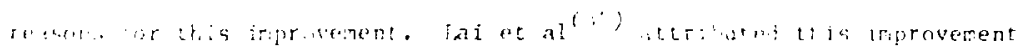

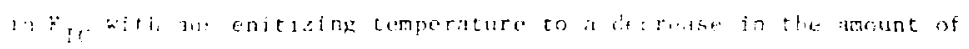

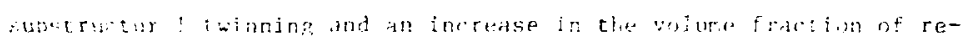

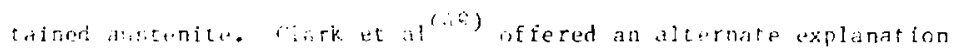
for this improvement based un the proposal that a higher austenitizing : emparature coupled with a fast quefiching rate co suppresa any segregation oi embitting constitutents leads to a decrease or alimination of quench cracks. However, Rao and Thomas ${ }^{(32)}$ showed that quench cracking in these alloys has a different origin and in any case the above explanation fails to account for the absence of continued inprovement in toughness properties $(33,58)$ in these alloys ahove a 
cercaln temperature which roinctiles witl a shirb decrease in the volume fractions of undisolved alloy carbides. More recentiy, Ritrbie et al. (Ing) advanced a model according to whtch the roter root radius has an inportant hearing on the toughness parameter evaluated. There

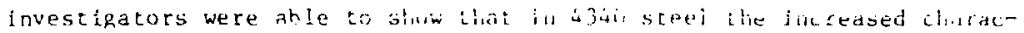
teristic distance availahle with codscer frior austenite grain sizes with higher austenitizine temperatures would result in superior $K_{I C}$ values (sharp crack) but poor impact energy values (blunt crack). However, the generality of this motel can he questinriod particularly in the case of the quaternary alloy steels under investigation since these al loys contain a large anrunt ( $4 \mathrm{w} / 0$ ) of the carbide forming element Cr. Furthemore, several recent investications $(109,110)$ shriwed that eracture toughness $\left(k_{I C}\right)$ increases with a decrease in prior austenite grain size. An important observacion made hy lais] and kretzschnann(110) is that at small plastic zone sizes at the crack tip as are common with the ultathigh strength structural steels, the fracture coughos is in deperifent of grain size. In contrast it is well established $(47,48)$ that the Charpy impact toughness is very sensicive to the prior austenite grain size. The lowering of ductile to brittle transition temperature with grain refinement and the consequent improvement in impact toughness is quite well known( $(11)$ for scme time. Thus, from the above discussion, it appears that the generally attractive combinations of properties achjeved with the non-conventional austenitizing in the experimental alloys (Figs. 75 and 37 ) could be the results of an overwhelming beneficial influence of the elimination of undissolved alloy carbides on fracture coughness and in the case of impact energy (Fig. 37), the behavior 
appears to be a compromise ietwen the heneficial effert of lower!ng. of undissolved carbide content and the unfavorable influencr of coarse r grain size.

Since the quaternary and the hase alloys art heat-trated so as to dissolve all the alloy carbides (i.e., homogenenus austeilte phase before quenching) it will be easter to correlate the nechanical propert: variations to the microstructural cianges. The Mn modifitu! allyys wil! be discussed first and later on the effect of 5 sidadition to tipe cernary alloy wlll be considered. is shown in Figs, n and 7 there are no differences in either the martensite morphlryy or substructure (whic: is essentially dislncated) as a resul: of Mr addition up to $2 \mathrm{w} / \mathrm{o}$. The most significant structural change as a rueut w hatensig arioutts of. Mn addition is the increase in the retained alstenite volums fration

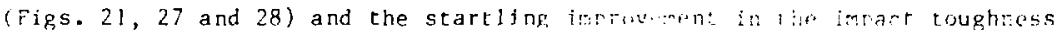

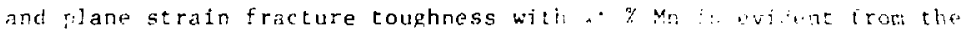

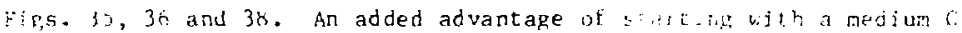

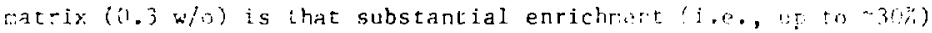
in auscente of $C$ is possible before significan: amounts of lwinned martensite car form. Previous work showed ${ }^{(4)}$ that thinning is very pronounced if $\mathrm{C}$ is $>0.4 \mathrm{w} / \mathrm{o}$. In a previous section, it was also shown ihat in the Mn modified alloys substantial $C$ segregation to austenite is not probable and that the stabilization of anstenite is related to the increased chenical stabilization due to the presence of fcc stabilizer, Mn, and to the increased accomodation in austenite. As pointed out earlier, several investigators $(18,23,30,35-38)$ associated Improved mechanical properties to the presence of recained austenite 
although in most instances, $(30,35,37)$ the improvernent can not be sing:? attributed to the presence of retained austente. The continuous interlath film morphology of retalned austente in the alloys unceinvestigation would prevent propagation of a crack nucleated in the relatively brittle martensite to the adjacent martensite lath, i.e., the networks of retained austenlte would help to break the continuity of the brittle phase martensite. Since fracture properties are of $\therefore$. incern in the present investigation, attention wil' he focussed on the mechantsms whereby retairud austenite could provide resistance to the initiation and propagation of cracks. Suggested mechanisms of increased crack propagation resistance in the presence of retained austenite include: (i) crack branching, (112) resulting in a more tortuous crack fropagation and the consequent increased energy expended, ( $i i)$ crack blunting, (113) as a result of plastic flow in austenite resulting in a decrease in stress concentration requiring higher applied stresses for unstable fracture and (iii) transformation induced plasticity $(\text { TRIP })^{(114)}$ in which case, as the name suggests, the transformation of retained austenite to martnesite under stress/strain in the plastic zone ahead of a crack relieves the stress concentration. In all the three cases, the effectiveness of retained austenite in providing for improved toughness properties increases with its stability to transformation under mechanical stress/strain.

Besides the above direct effects of austenite on toughness, there are indirect benefits. Fetention of austenite at lath boundaries prevents brittle lath boundary carbide fomation $(88,4)$ in the as-quenched as well as quenched and tempered structures if the tempering cemperature 
is below instablity temperature for austente. Another significant benefit aristng from retention of austentie is that, as wll be shown in the next part, the y/a boundary is highly coherent. In contrast, in the absence of $Y$, two adjacent laths impinge laterally to form rotation boundary thus creating high eturr: inlerfaces for crack propagation and/or segregation and precipitation.

Gerberich (113) proposed a fracture runcept hased on iritical displacement for treating two phase structures wherein a cough inidirectional phase is dispersed in a relatively britte natrix, Fir. 51. The situation is very similar to the one under discussion biree within a martansite packet, the retained autrute fijas can he ansidered unidirectional (Figs. 19, 22 and 55). In the afreve treatment, the Hahn and Rosenfield fracture criterion swing tio equivalence of the

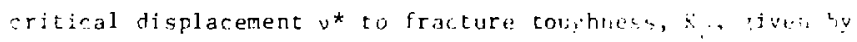

$$
k_{C}=\left(2 v *_{0}(z) ! \cdots\right.
$$

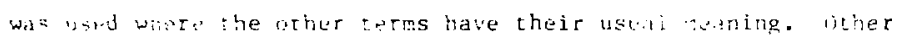

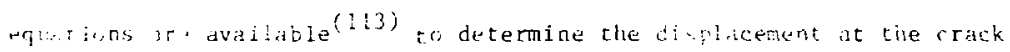
tif, $v_{0}$ and at any tistarce, $v_{x}$, in front of the ratk tip as shown in yig. 5i. As the material is Ioaded, when $v_{c}>v_{M l}^{\star}$ the crak muves from posirios 1 to position 2 where it ent, nters the tough second phase. If $v_{62}=v_{\mathrm{H} 2}^{\star}$ (Fig 51) then the rrack will he arrested Frovider the width of the $M_{2}$ phase (tough phase) is suffictent)y i.r.ge. This is so because, if $M_{2}$ is very thin, then the displacement at the distance $x$, (representing the dimenston of the second phase) in front of the crack may be larger than the critical displacement for failura 
in the brittle material. If $v_{x}>v_{M I}^{\star}$, then failure will procesd in the brittle materlal. This model brings out two very important pointa: (i) the thicker the austentte films (hence higher the volume fractirin), higher wll be its crack blunting ability and (ii) some degree of ductildty in martensite is needed in order to prevent britcle failur: In mattensite even in the presence of austenite.

This model very nicely explains the observed improvement in frar: toughness and impact toughness values with 1ncreasing Mn (Figs. 35, 37) particularly after $200^{\circ} \mathrm{C}$ tempering (Figs. 36, 38 and Tables II and III). This is so, because in the higher Mn alloys, auto-tempering did not take place (Figs. 7 and 55) due to low $4_{s}$ temperature and a low temperature tempering is necessary in order to induce some plasticity. It has been also reported $(30,37)$ that such low tenperature tempering augments the mechanical stability of austenite.

The advantages of grain refining are discussed in the heginning. In order to combine the rinefits of high temperature austenitization, i.e., reduce coarse undissolved alloy carbide volume eraction and maintain a fine y grain size, double treatments (fig. 1) are necessary. The increased volume Eraction of $y$ as a result of grain refining is evident from a comparison of Figs. 27 and 28 and the corresponding improvement in fracture and impact properties can be seen from a comparison of Figs. 36 and 38 and Tables II through IV. However, the strength properties are somewhat lower probably due to the increased anount of retained austenite. (115)

In the $5 \mathrm{Ni}$ modified alloy, there are two variations in the microstructure compared to the base allov, viz., some substructural 
twinning (Fig. 8) and increased amount of retained austenite, (Figs. 28 and 21). The detrimental effects of twinning on toughness have already been discussed and the somewhat pooret toughness properthes in this alloy conpared to some of the Mn modified alloys (Figs 35 - 38) is attributed to the presence of substructural twinning. Although the toughness of $5 \mathrm{Ni}$ alloys are somewhat lowet than that of the Mn steels, their toughness and strength combinations are guite attractive as shown in Figs. 35 and 37 .

The desirable microstructural features for good stronsth and toughness combinations as concluded from this investigation art scheratically iliustrated in Fig. 52. Bv adhering to the dosian guirellnes, microstructures are developed l" quateriary diloys which hale towhress to strength combinations much superiot to the enuivalent romercial alloys, shown in Figs. 53 (a) and (b). 
PART 2.

\author{
MORPHOLOGY, CHYSTALLOGRAPHY AND FORMATION OF \\ DISLOCATED (LATH) MARTENSITES IN STEELS
}

\title{
I. INTRODUCTION
}

It is now known that there are two basic morphologles of bulk martensite in ferrous alloys: $(4,6)$ dislocated lath martensite and twinned plate marcensite. Although the morphology and crystallograpty of plate martensites are well understood, the same is not true for the dislocated lath martensites occurring in the technologically more important medius and low carbon steels. $(3,4,6,116)$ This part of the investigation is concerned with a detailed electron diffraction and microscopy examination of dislocated lath martensites in an effort to characterize the morphology and crystallogrpahy in greater detail than has been done previously and to hetier understanding of the austenitemartensite transfomation merhanisn. This work has been parcly stimulated hy the fact that small amounts of retained austenite have heen detected (Part 1) in many lath martensites during an excensive al loy design program on dislocated martensitic steels. $(4,34)$ consequently, the unfque orientation relationships can be obtained directly by utilizing selected area diffraction ar lyses of the lath hundles and their surrounding austenite. Such analysis is more precise at high voltages due to the reduction of spherical aberration. This method serves to eliminate controversies that must arise if indirect methods of habit plane analysis were to be used. $(116-124)$ These 
usually involve the determination of the habit plane in martensite and converting it back to austentte usfing either the known traces of austenite or the presupposed orientation relationships. There 1s a wide scatter in the existing data as can be seen from Table $v$. Another important aspect of the debate surrounding the lath martensite is the mechanism of its fomation. Some of the earlier Invest Igators considered that the packet is a fundamental mucleation and growth unt and the laths and cell boundaries form after transformation as accommodation relaxation in the mattensite. $(76,125)$ others concluded that the laths are fundamental nucleation events and growth units and some cell structure origindtes in the austenite ahead of a growing martensite lath/plate and is inherited by the subsequent]y formed martensite. (126) The present study aims to resolve this conflict.

\section{I. EXPFRIMENTAI}

The steels used for this part of the investigation are given ill Tahle V1. Iron-nickel binary alloys $1 \mathrm{n}$ the form of 5 mil thick sheets encapsulated in evacuated quartz tubed, were austenitized $1 \mathrm{hr}$. at $1100^{\circ} \mathrm{C}$ and quenched into iced water. The carbon steels were austenltized in bulk for $1 \mathrm{hr}$. Followed by quenching into iced water. jifferent austenitizing temperatures were used to change grain sizes. Detalls about the heat-treatment and specimen preparation are described in Part 1. Thin folls were examined in the Phllips EM 301 (100 KV) and Hicach1 HU 650 electron microscopes (500 KV). 


\section{RESULTS}

\section{A. Morphology and Cell Structure of Martensite}

The martensite packet size was found by optical nicroscopy to increase with austenitizng temperature and prior austenite grain side (Table VII) but did not show the same rate of increase as the prior austente grain size when the austenitizing tenperature was increased frow 870 to $1200^{\circ} \mathrm{C}$. There was no noticeable variation in the average lath width as a function of prior austente grain size.

Transmission electron micrographs taken at $100 \mathrm{KV}$ and $500 \mathrm{KV}$ revealed that the laths are parallel with reasonably straight houndaries and a high dislocation density (F1gs. 54 and 55). Although there were no significant differences in lath morphology or substructure as a function of carbon content, retained austenite could only be detected in the carbon containing alloys (cf. Figs. 54 and 55)., in agreement with Yeo. (77) Fig. 55 gives evidence of recained austenite in the ternary Fe-4Cr-0.3C alloy (127) (Figs. 55 (a) through (c)) and quaternary $\mathrm{Fe}-4 \mathrm{Cr}-2 \mathrm{Mn}-() .3 \mathrm{C}$ alloy (Figs. 55 (d) through (f)). Indexed diffraction patterns clearly reveal the austenite zones (110) (Fig. 55 (c)) and (211) (Fig. 55 (f)). A detailed discussion of the occurrences of retained austenite has already been dealt with in part 1.

B. Crystallography of the Transformation

I. Relative Orientations of Ad jacent Laths

Fig. 54 is an example of a detailed analys 15 of parallel laths. The SAD patterns and regions from where the patterns are obtained in the bright-field image are identified by $1,2,3$ 
etc. The $[110]_{a}$ crystal Alrection rematns parallel in all the laths $1 \mathrm{n}$ this packet, Ind lcating that these laths a re separated by $[110]_{\alpha}$ rotation boundaries. Using sterographic analysis, Fig. 56 , it is found that the lath 5 is rotated $180^{\circ} \mathrm{C}$ with respect to lath 1 indicating that the shear components are opposite and accommodative. Thus, within the packet, the relative orlentations of laths is such as to minlmize the overall shape deformation. It is possible that ad jacent laths can be twin related $(124)$ in which case a $180^{\circ}$ rotation of shear vector is nbtained in a single step at adjacent laths. But twin related laths were found to occur infrequently in the carbonless alloys. However, in rarbon containing alloys twin related or near twin related adjacent laths is a common occurrence. In addition, the presence of carbon appears to bring about the $180^{\circ}$ rotation of the sheis vector with less number of laths than without carbon. Mureover, the rotation dxis for producing adjacent lath orientations is not miquely i.10 $\}_{\alpha}$, since $[100]_{a}$ is also occasionally observed.

\section{Austenite/Martensite Orientation Relationships}

The ternary Fe-4Cr-n.3C alloys showed mostly the $\mathrm{K}-\mathrm{S}$ (Kurd jumov-Sachs) relation (Fig. 55(c)) while alloys modified with 2\% $M n$ and $5 \%$ Ni (alloys 5 and 6 ) frequently revenled the $\mathrm{N}-\mathrm{W}$ (Nishiyama-Wasserman) relation (Fig. 55(f)). In Fig. 55(c) there are two martnesite zones, [100] $a$ and [111] $]_{a}$, and yet a single $[110]_{Y}$ zone. Out of the four possible orlentation relationships between fcc austentte and bcc martensite, (72) viz., Bain, Pitsch, $\mathrm{K}-\mathrm{S}$ and $\mathrm{N}-\mathrm{W}$, only $\mathrm{K}-\mathrm{S}$ and $\mathrm{N}-\mathrm{W}$ relations are widely 
recognized $(74,1,83,117)$ to oritu in the ferrous systoms undier Investigation. The $\mathrm{K}-\mathrm{S}$ and $\mathrm{N}-\mathrm{W}$ relations are related simply by a $5.26^{\circ}$ rotation around the normal of a close packed plara. in either crystal structure, $(128,129) \mathrm{Fig}, 57$. In the Iight of these comments, the results presented in the SAD pattern of Fig. 55 (c) need to be re-examined. Considering only one martensite crystal variant at a time, the $[111\}_{a}$ and $\{110\}_{\gamma}$ combination results in K-S relation, but if 1100$]_{\alpha}$ and 1120$]_{\gamma}$ are considered, the result is the $N-W$ relacion, Fig. 58 . It is clear, therefore, that this is an ambiguous patern for orientation relationsh1p analysis although rhis is not apparently well recognized by other workers. $(35,124,129)$ The particular combi-

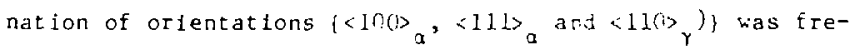
quently observed in the present investigation as bell as sevaral past investigations. $(124,129)$ The inability of the previous investigators to identify retained austitite lud then to nisinterpret the two matrix orientaions as the result of adaptation of two different variants of $k-5$ relation in adjacent laths of a packet. In the absence of retained austenite reflections, the resulting diffraction pattern corresponding to Fig. 55 (c), would be as depicted in $\mathrm{rig}$. 58 consisting of only martensite reflections. Quite obviously, these two matrix orientations do not exactly fit into two variants of the K-S relation and in an effort to find an unique, single orientation telationship, some Russian investigators(129) concluded on the basts of elaborate matrix computations that the orientation relationship is exactly intermediate between 
K-S and N-W. This concluston can not be disproused ats long as only matrix martensite reflections are recorded, Fig. 58. However, the present investigation using direct evidence of retalned austenite reflections, Fig. 55 (c), has shown that what is in fact ha ppening is that both $\mathrm{K}-\mathrm{S}$ and $\mathrm{N}-\mathrm{W}$ orientation relationships are alternating within the same packet and that the orjentation relationsh1p between a partirular martensite crystal (1ath) and parent austente is either $K-S$ or $N-W$ but not intermediate. In the present study, evidence for the $K-S$ relation as the doninant orfentation relationship is obtained from several other unambizuous diffraction patterns. Similerly, the dominant orientation re1a:son in the quaternary alloys (alloys 5 and 5 ia Tarle VI) is the $N-W, F i g .55$ (f). In this figure, although, there are ayain rwo martensite orientations, viz., $[1: 9]_{a}$ as.d $[3: 1\}_{\text {r }}$ ard a single austenfle orientacion, [zl1] $\gamma$, it can he slirwh that neither of the atrix orientations belongs to a $k-5$ varjant. The $(1 \mathrm{In})_{\text {a }}$ and $[311]_{x}$ crystal directions in this figure are rot exactly twin related but rotated $\sim 6^{0}$ about $\{110\}_{y}$ disection. $(141$, th was pointed out $(14,129)$ that the appearance of twin orientations of nartensite crystals is evidence that the orientation relationship during $\gamma^{+a}$ transformation is very close to precise $\mathrm{K}-\mathrm{S}$. Twin orlentations of martensite crystals corresponding to the different variants of an orientation relationship are analytically impossible for $N-W$.

\section{Trace Analysis}

F1g. 59 (c) shows the trace analysis directly in austenite from which it can be seen that the habit plane in austenite is 
very close to the (111) within the limits of the accuracy of the electron metallographic trace analysis $\left(2^{\circ}\right)$. This habit plane in the parent phase agrees with several earlier investigators (Table $V$ ). A determination of the habit direction of the laths in austenite indicates that it falls closely along $[1 \overline{1} 0]_{y}$. Fig. 59 (a) shows the scatter when trace analysis is done only in martensite and emphasizes the advantages of detecting and utilizing the retained austenite. Fig. 59 (b) shows the trace analysis of the long axes of laths; these are always in $\langle 11\rangle_{a}$ within experimental error.

\section{High Resolution Lattice Imaging}

The advantages of employing high resolution lattice imaging to the study of phase transformation $(130)$ is beginning to gain recogniti. An attempt is made here to apply this powerful technique to stur various interfaces such as, lath, packet boundaries in martensite as al o the nost important austenite/martensite interface. The difficulties involved in lattice imaging ferrous martensites are already de $t$ with in

the literature ${ }^{(131)}$ and very presiminary results are shown n Fig. $60(a)$ and (b) which is a $\{110\}_{\alpha}$ lattice image in a martensite recion of fine grained Fe-4Cr-5::-0.3C alloy (alloy 5 ). It is seen tha che martensite packet boundary extends over a region larger than could be measured frum a conventional bright field micrograph, Fig. 60(a). TF . dark contrast observed at the boundary which can be resolved in th conventional bright field image is not a true indication of the actual ocation or extent of the boundary as $\{110\}_{\alpha}$ fringes can be seen beyond this contrast. 
Also, from the visibility of the fringes, it can be seen that the boundary is not straight, but wavy. In Fig. $6 u(b)$ several end-on afslocations can be seen within the martensite tegion and the considerable bending of lattice plane around dislocations is evident. As a next step in this analysis, lattice imaging of the austenter martensite inferface 15 artempted. The main difficulty in simultaneorsis Imaglng lattice fringes in austenite and martensice across the interface (as is required to study the laterface deplcted in Flg. 62) is that the austentte 19 non-magnetic and the marcensire is magnetic. Thus, the objective leas astignatisw correction for optimam resolution is different for lattice lmaging austente and martensite. However, whth approprlate objective lens defocus and astigmatism corrections, : compromise conditon can be obtalned whereby latice fringes in both phases can be formed. Initial success indicates that the lattice fringes nn either side of the boundary undergo consideratle bering and some interfacial dislocations were also detected.

\section{DISGUSSION}

Because packet stze increases at constant lath width (Table VIJ), the aspect ratio of the laths increases with prior austenite grefn size. A constant aspect ratio with increasing packet size would resull in a in Igher volume dependent strain energy.

$$
\text { Regarding relative orlentation of adjacent laths, Kelly(132) }
$$

showed that those variants that are exactly twin related have shears which are equal and opposite. The present observations suggest that the ortentatons of the laths are those which result frod minimization 
of the overall shape deformation and 1 ts accommodation over a group of laths. Aralysis of several adjacent laths in a packet was necessary to reach this conclusion, see for example $\mathrm{Fig} .54$. It is also shown that, in general, a gradual change in orfentation to minimize shafe deformation is preferred to a twin orientation of the adjacent laths. Flg. 61 depicts schematically three possible cases of accommodation within a martensite packet and their correspunding displacement profile. The situation where a stngle shear is operative throughout the width of packet is shown in case I (Fig. 6i) whert the large acconmodation necessary is evident from the displacement profile. This is an energetically very unfavorable situation and the shape deformation can be minimized considerably by breaking the original packet into sub-units, or laths, such that several shear vectors operate within a given packet. In addition, instead of being randon, if these shear vectors are arranged such that over a group of laths, the sheat vector completes a $2 \pi$ rotation case II, then the corresponuing accomnodation is considerably reduced. This is what is happening in Fig. 54. Instead of a multi-step orientation process, this minimizaton of shape deformation can also be obtained in a two step twinning process wherefn, the adjacent laths are twin related, case III. Twinning in this case does not imply physical twinning but describes a situation where the relative orientuton of adjacent laths corresponds to a twin relation. The occurrenc: of twin related adjacent laths is a point of considerable debate ${ }^{(124)}$ and in the oresent investigation twin related adjacent laths were observed occasionally in ail the specimens but their occurrence increased with the presence of interstitital C. As discussed before, the SAD pactern of Fig. 55 (F) 
reveals two diffrartion zones, vize, clins and side corresponding to a near twin related orlentation of adjacent lahs shown in the bright field micrograph, Fig. 55 (d). The presence of carbon alsin appeans to reduce the number of laths requared to achieve a $180^{\circ}$ rotation of the shear vertor, for example, in Flg. 55 (c), the $130^{\circ}$ rotation achieved in a group of three adjacent laths. It thus appears that the increastng dilatation component of the strain enerpy with fromising re requides ( 32$)$ camplete accommodtation over fewer number of laths with a tendency for adjacent twin relation. There are a few examples (f) in the licerature it the $c$ serative accumodation to the fornation of mactensute in sume non-ferrous systems. The presence of multiple shear whing tre <12 shear utrection alternates among the thrae variants in the close packed plane during the fcchcp martensitic eransfonnation in co and ro-Ni alloys is thought to be resposible for the much reduced net shape strain and the consequent straisl caterg.

The habit plane by direct trace analysis is shown tis be 1111$\}_{Y}$. Some of the sratter in the habit plane analysis hu indireat methods mav be due to the presence of ledges in the austenite-martensite interalce as shown in Fig. 62(a). From this figure, the microscopic habi: plane ramains flll\}, hut the macroscoplc habit plane of any (hk2) can be generated by varyiag ledge density, ledge morphology, or both as shown in Figs. 62 (b) and (c). The martensite laths would thicken by propagation of these ledges 1nto the surrounding austenite.

The identffication of retained austente around the lath boundaries supports the view that these laths are indeed individual nucleation events. The proponents of the idea that a packet is a 
fundarental growth unit $(76,125)$ derive their support largely from the observation that surface rellef experiments reveal upheavalsi over distances which are often 5 to 6 lath widths. However, as shown by the present study, adjacent laths may be rotated with respect to a common axis. Therefore, although all the individual laths undergr: shear, they contribute to surface rellef only over distances which are 5 to 6 laths in width. From t: se arguments, it appears that the so-called laths are really small platelets as shown in Fig. 63 with $b>a>c$ where ' $b$ ' 15 the long axis, Fig. 55 (d). In the case of car' in sieels, the laths are separated by thin films of austenite which nay be stabilized to some extent due to the segregation of carbon fron the adjoining laths as indicated in the diagram. For the first time, it is Identifled in this study that austenite/martnesite phases cart obey both $\mathrm{k}-\mathrm{S}$ and $\mathrm{N}-\mathrm{W}$ orientation relations within the same packet. There is no a priori reason why this cannot happen. On the other hand, a hypothesis can br advanced to expla1n this on the basis that the two orientation relations glve better flexibility in terms of increased variants available durirg martensite nucleation. 


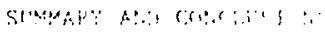

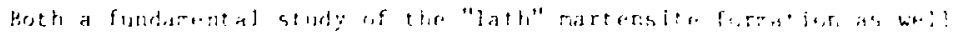

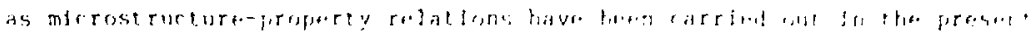

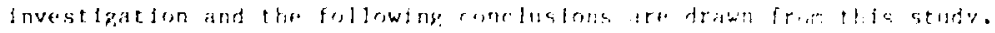

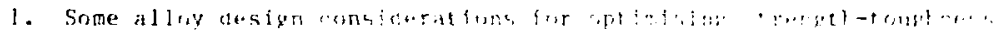
comblations in hizl. strungh strut tural whes were ritiraily

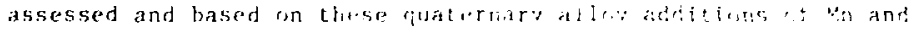

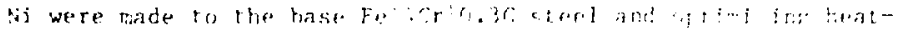

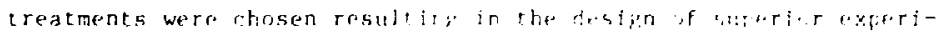
mental steals.

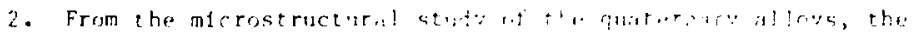
following observations are made:

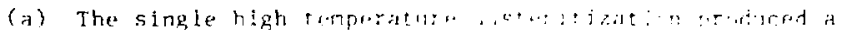

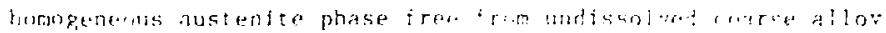
sarbing in al t the ailoys.

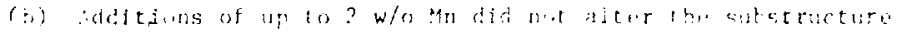

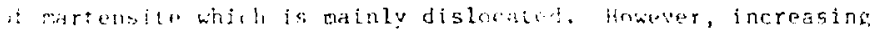

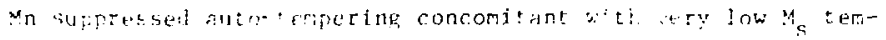
peratures in these alloys.

(c) Interrupted quenching following hlg: temperature austenitizatton was required in order to avoid quench-cracking in 5 ii modified quaternary alloys. Addtion of 5 wio $\mathrm{Ni}$ to the ternary alioy resulted in about $10 \%$ of the martensite laths containing twinned substructures. This is concluded to be due to the indirect fnfluence of $\mathrm{NL}$ in promoting the twinning propensity of $\mathrm{C}$ and $\mathrm{Cr}$. 


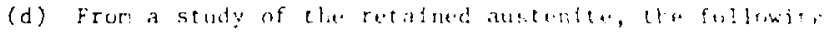
conclustans here made:

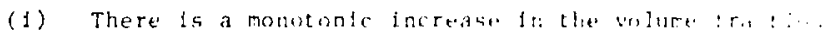
of retafned austentte with Mn als shown by hoth trasis: in electron metallopraphy as well as rareful x-ray diffract ia anaiys1s. The stabillzins mechandsos for auscenteraredincussed and it is concluded that chenical stabilization as a result of excessfver segregation can not he the doniant stabilizing mechanism in Mn modified alloys.

(ii) The 5 wio Ni addition resulted in the highest amont of retalned austenite particularly following $M_{5}-M_{f}$ hold. This is attributed to enhanced roles of thermal and chemisal ic segregation) stabilizations in this treatment. (iii) The morphology of rotained austenite in all th, alloys is of the continuous interlath film type, the thickress of which increased with its volume fraction.

3. Son-conventional double treatments were designed in order to take advantage of high temperature austenitization and fine grain size and the following conclustons on structure are arrived at:

(a) There is roughly a ten-fold refinement in grain size following the double treatments and the substructure of marcensice essentially remained the sane as single treated alloys.

(b) The volune fraction of retained austenite incteased in all the alloys compared to their single treatments. 4. The following conclusions were made from the mechanical property 


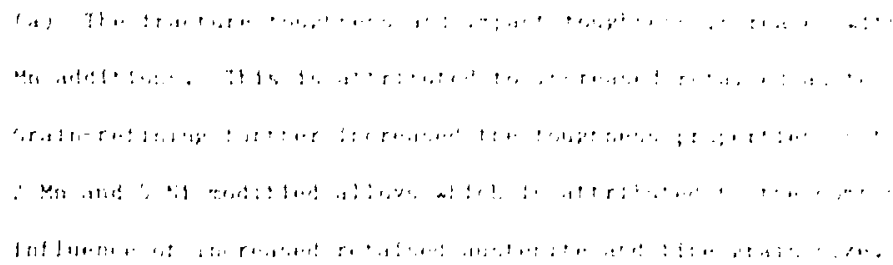

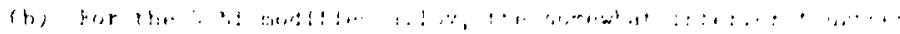

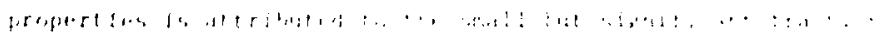

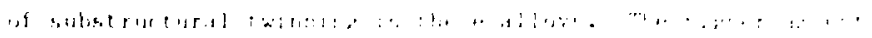

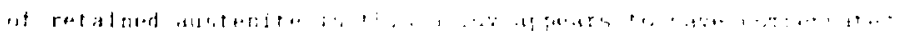

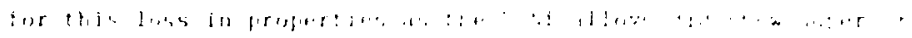

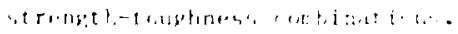

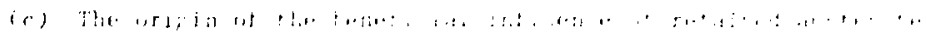

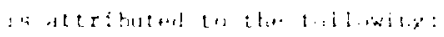

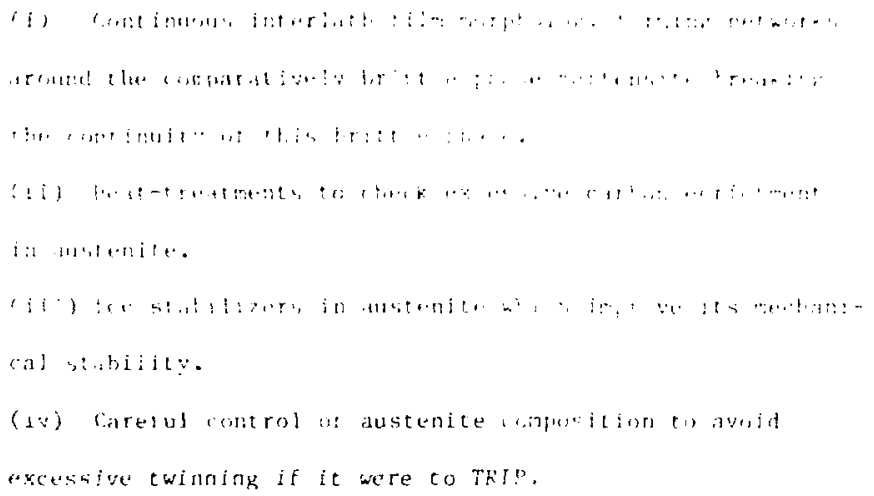

(d) Several possible mecinanisms of the hencricial etfoct of retained austenite on toughness propert es have betn considered but this study could not reveal a single doninant mechaniso. 5. iempering between room temperature and $300^{\circ} \mathrm{C}$ resulted in a rapid drop in strength with Increasing Mn additions. This is 


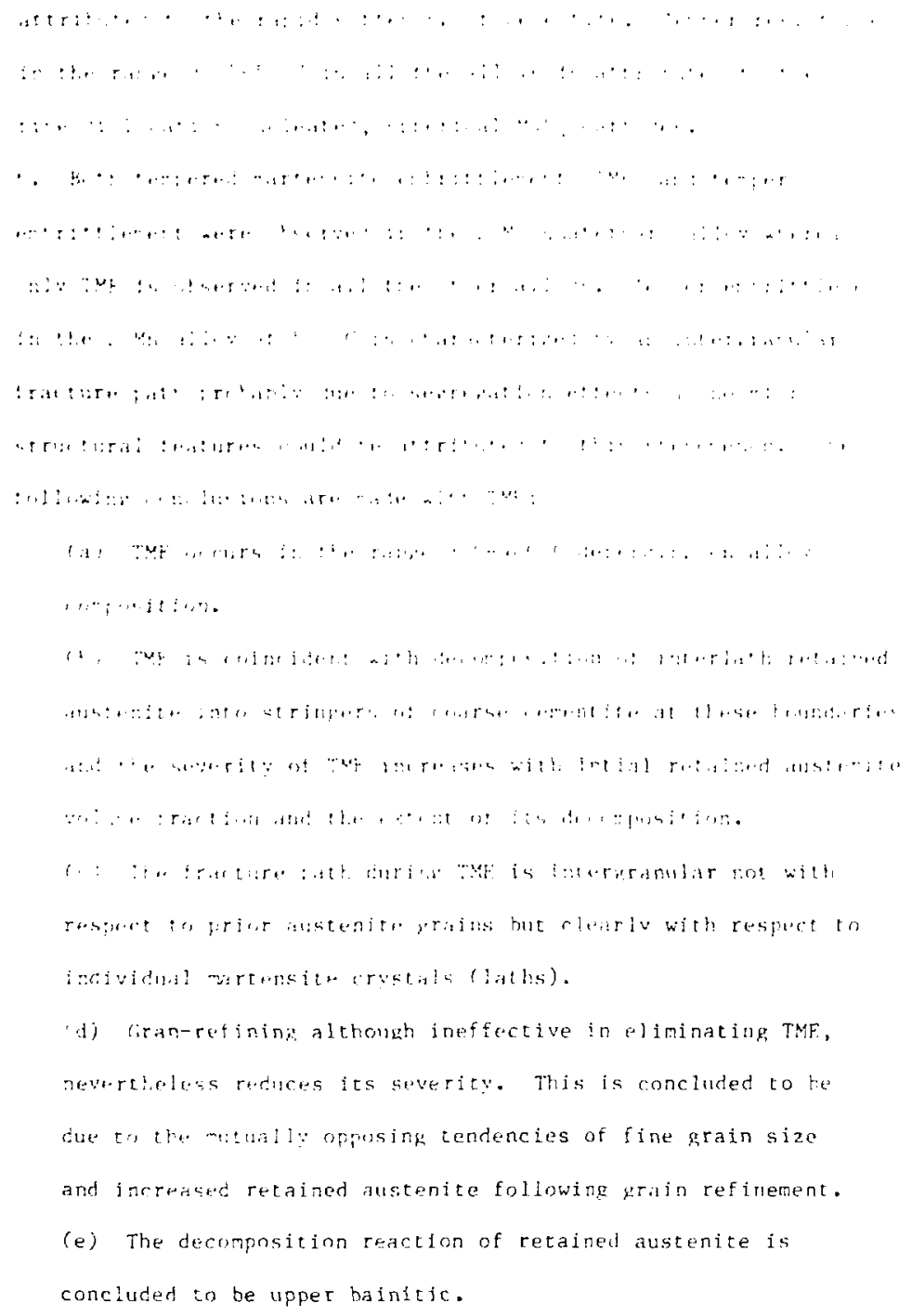

(f) rraphitizing alloving, elements such as $\mathrm{X1}, \mathrm{Al}$ and $\mathrm{Si}$ which 


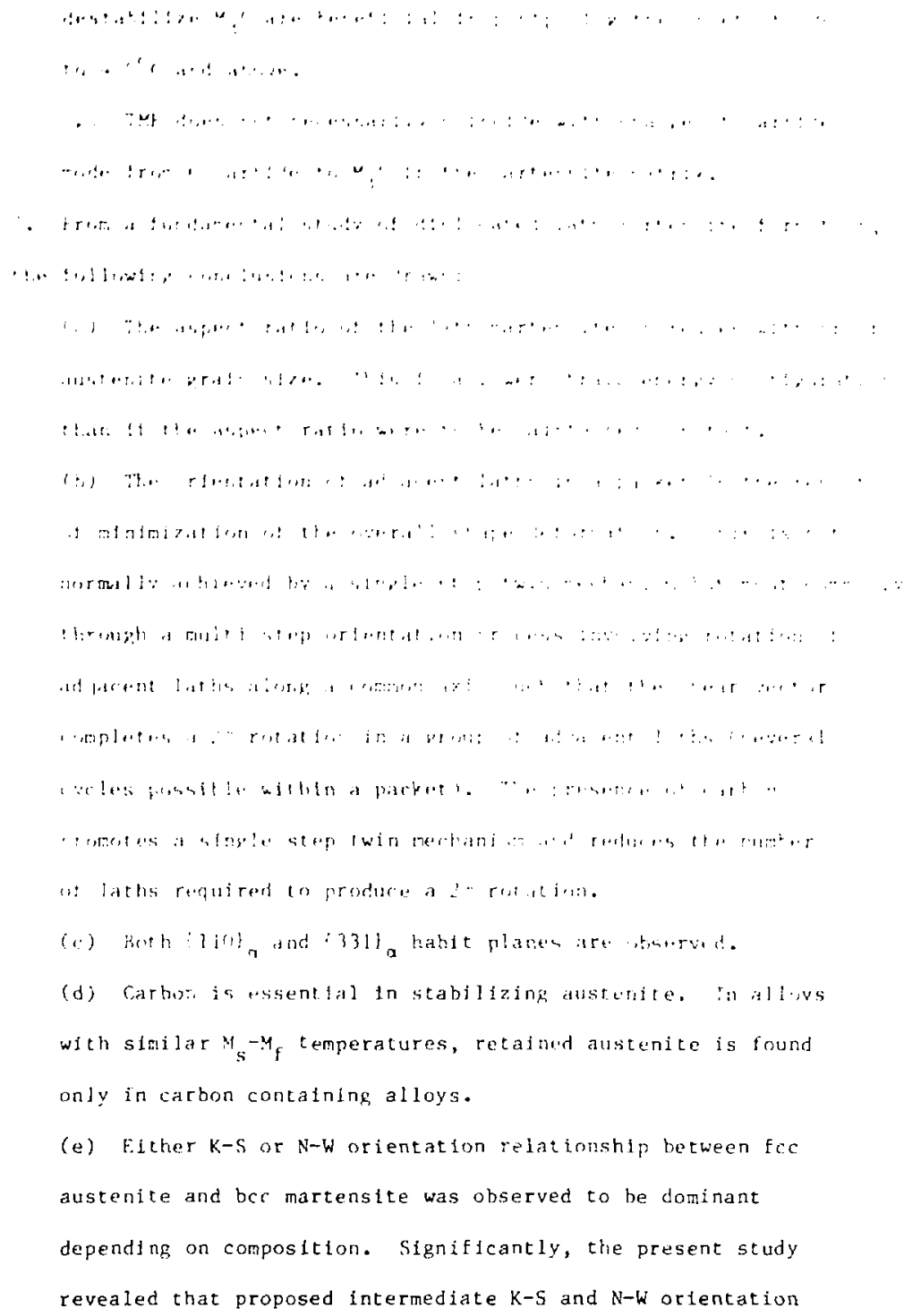




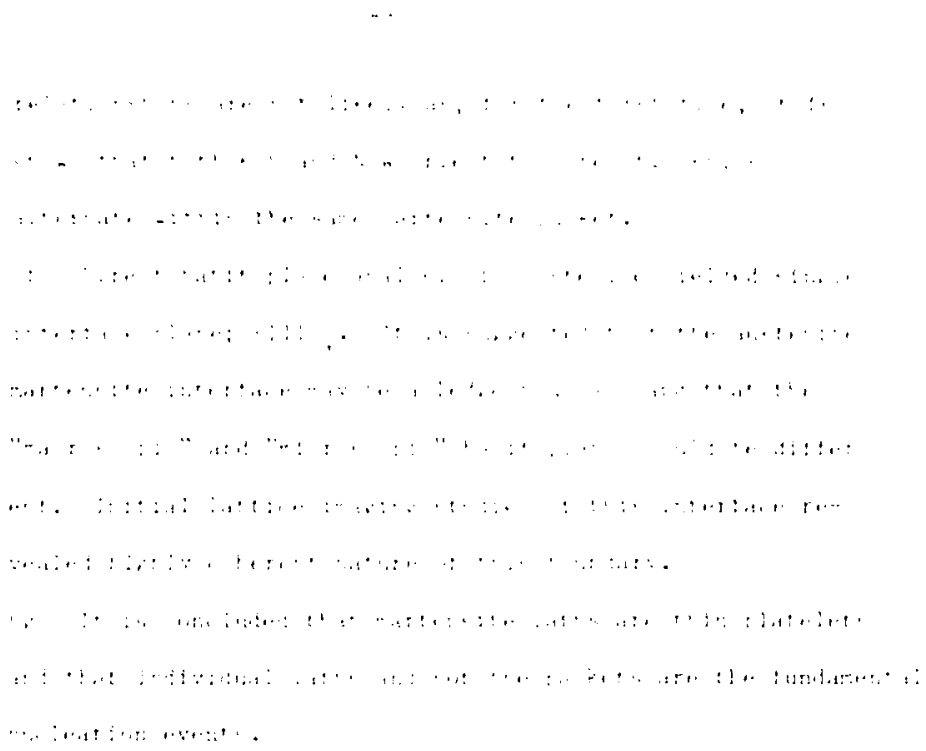




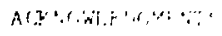

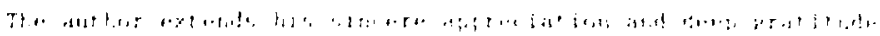

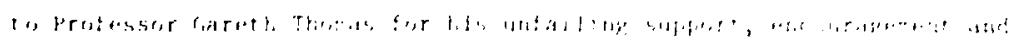

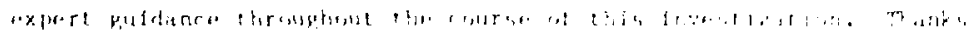

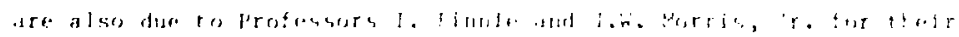

tritiral review of lils manuse i ipt.

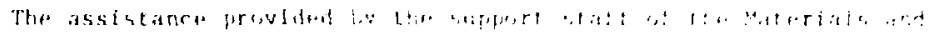

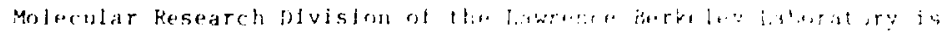

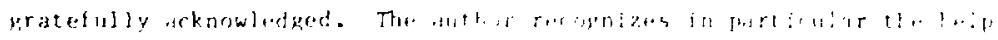

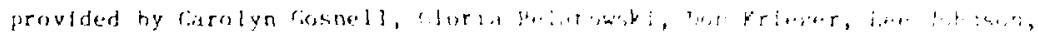

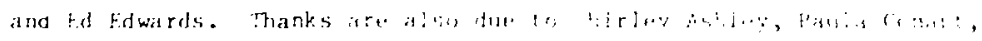

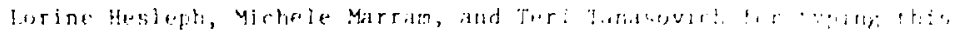

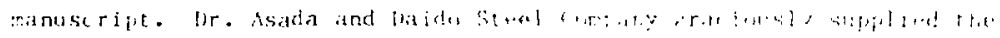

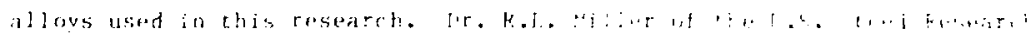

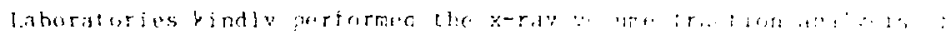
anstedita.

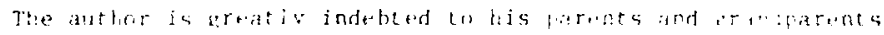
ior their heip in raking this possible.

The autur is islso grateful to Mr. Tom Rabe for his relp with the manuscript preparation and to Mr. Mark Carlson for the use of some of his unpublished data.

Finally, the author remains forever obligated to his wife for her help, cooperation, understandtng and enjoyable companionship. This research was supported by the I.S. Department of Energy. 


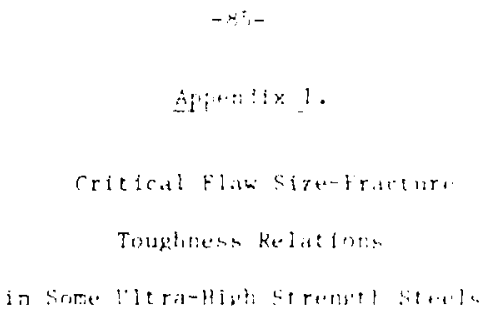

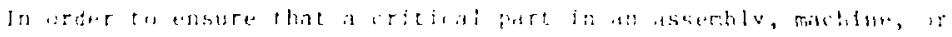

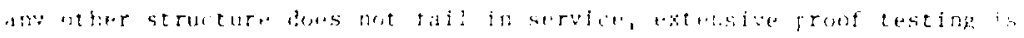

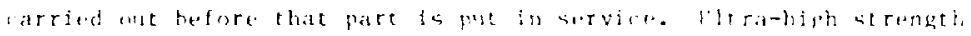

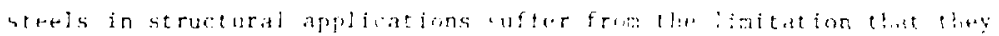

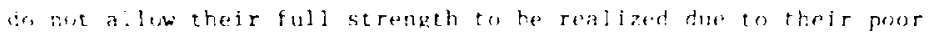

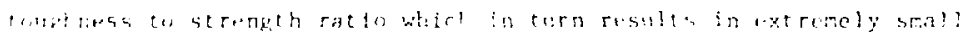
1: ildia: llaw sizes for catastrophir tallure. Pxperimental limitations

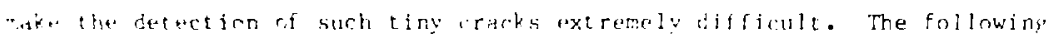
alub (Tabla Al) ni eritical flaw sizes al curtain applied stresses

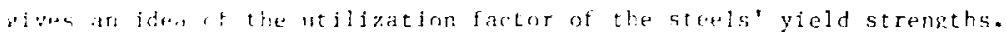

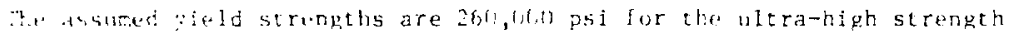

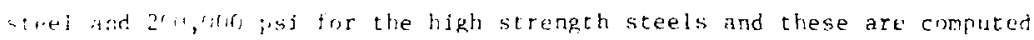
inr a safety factor of 1. Assuming ratastrophic propagation of existing This in the material under service load as the failure criterion, $\therefore$ ad using the relation between critical flaw size $a_{c r}$ and applied stress - fron fractare mechanics (eq. Al), the critical flaw sizes weie conputed and plocted in Fig. Al

$$
K_{I C}=1.1 \sqrt{\pi} \sqrt{\frac{a_{c r}}{O_{c r}}}
$$

where $Q_{\mathrm{Cr}}$ is the flaw-shape parameter. For an elliptical flaw, Q $\mathrm{cr}$, 


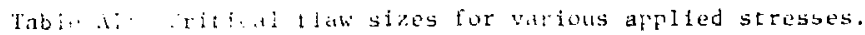

\begin{tabular}{|c|c|c|c|c|c|c|}
\hline \multirow[b]{2}{*}{$\begin{array}{l}\text { APPLIED } \\
\text { STRESS } \\
\sigma(k \text { si) }\end{array}$} & \multicolumn{3}{|c|}{ ULTRAHIGH STRENGTH STEELS } & \multicolumn{3}{|c|}{ HIGH STRENGTH STEELS } \\
\hline & $\sigma / \sigma_{y s}$ & $\begin{array}{l}\text { CRITICAL. FLA } \\
K_{I C}=40 \mathrm{ksi}-\mathrm{in} / 1 / 2\end{array}$ & $\begin{array}{l}W S I Z E, a_{C r}(\mathrm{in}) \\
K_{I C}=80 \mathrm{ksi-in} / \mathrm{L}\end{array}$ & $\sigma / \sigma_{y s}$ & $\begin{array}{l}\text { RITICAL F } \\
\text { IC }=100 \mathrm{ksi-1}\end{array}$ & $\begin{array}{l}\text { WW SIZE, } a_{C \mathrm{C}}(\mathrm{in}) \\
K_{I C}=200 \mathrm{ksi}-\mathrm{n}^{1 / 2}\end{array}$ \\
\hline 100 & 0.385 & 0.042 & 0.168 & 0.5 & 0.263 & 1052 \\
\hline 120 & 0.462 & 0.029 & 0117 & 0.6 & 0.183 & 0.731 \\
\hline 140 & 0.538 & 0.021 & 0086 & 0. & 0134 & 0.537 \\
\hline 160 & 0.615 & 0.016 & 0.066 & 0.8 & 0.103 & 0.411 \\
\hline 180 & 0.692 & 0.013 & 0.052 & 0.9 & 0.081 & 0325 \\
\hline O & 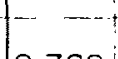 & -1 & 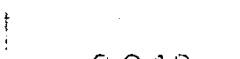 & & & \\
\hline 200 & 0.769 & 0.011 & c: 042 & 1.0 & 0.066 & 0.263 \\
\hline
\end{tabular}




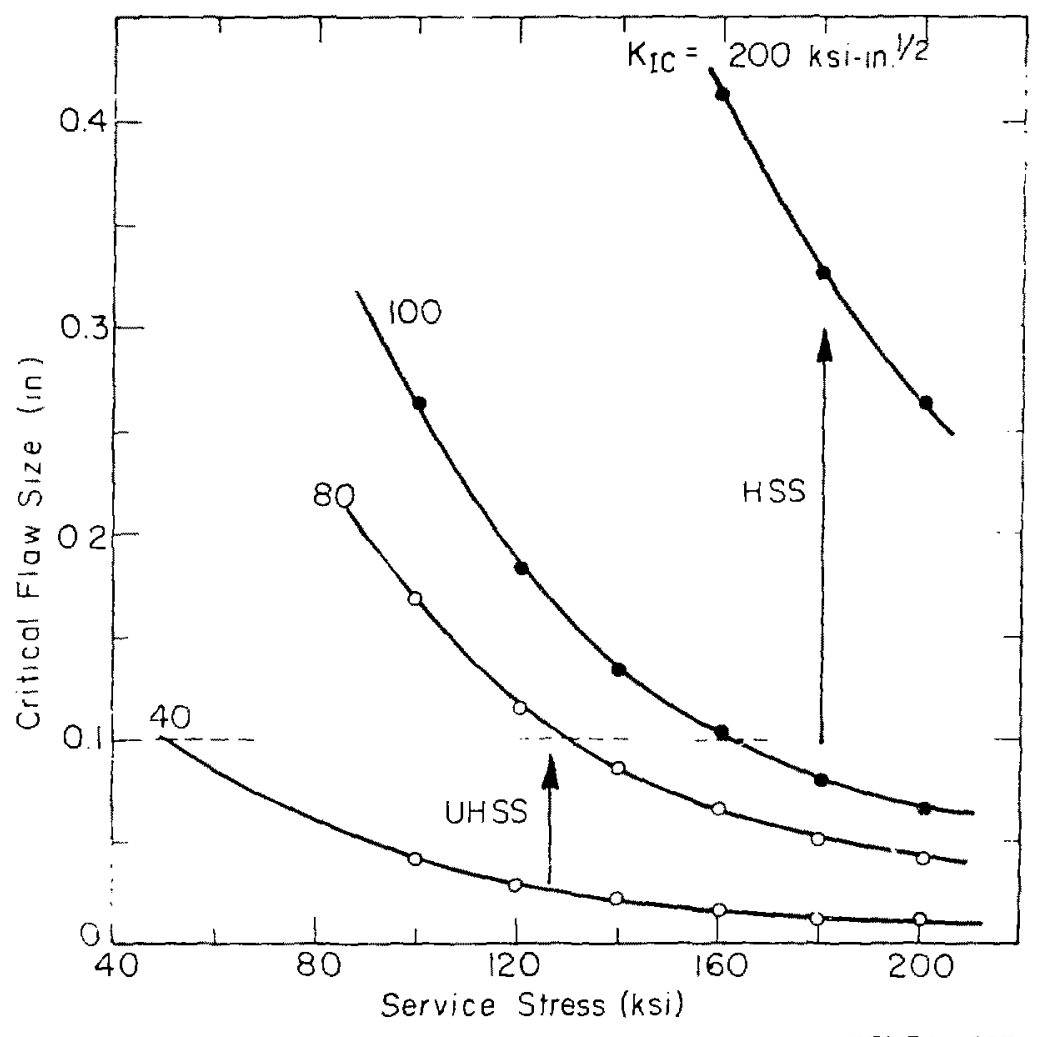

X日L $76|-627|$

Fig. Al. Critical flaw size vs. service stress for two litramigh strength and two high strength steels. 
varies as the ratio of minur axis to major axis. For a circular flaw, $Q_{\mathrm{cr}} \approx 2.5$. Assuming $Q_{\mathrm{cr}} \equiv 1$ (conservat've) and negiectirz plastic zone correction,

$$
a_{C t}=\frac{1}{1.21 \pi}\left(\frac{k_{I C}}{g}\right)^{2}
$$

It is clear from the above equation, at a riven afilied stress, $a, a_{c}$ is dependent only on the $K_{I C}$ value of the steel. The improverent in applied stress that can be tolerated by a stee by an increas. of its $K_{\text {Ir }}$ is apparent from Fig. Al. Aesuing the detection iinjt to be ". i" for a critical crack, the utilization linit of thr yie!d strength for thr ul:ra-high strength steel can be ancreassi from a rere $20 \%$

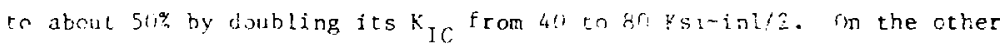
hard, fur the ingh strength steel, as muril is hio: it its yieds strength

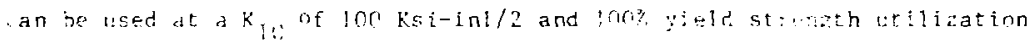
ran be actifued in tis steel by a small inerease dn fic 


\section{Append1x 2. \\ Method for Obtaining Calculated $K_{\text {IC }}$ Values \\ From Apparent Toughness $\left(K_{Q}\right)$}

The ASTM validity criteria(57) for determining fracture toughness relate the specimen geometry to the measured toughness $K_{0}$ and the materia: yield stress oy. When the crack length $C$ and the specimen thickness $B$ both exceed $2.5\left(K_{Q} / a y\right)^{2}, K_{Q}$ is said to be a valid estimate of the plane strain fracture toughness, $K_{I C^{*}} K_{Q}$ is calculated from the equation,

$$
k=\frac{P_{Q}}{B \sqrt{W}} \quad S(C / W)
$$

where $f(C / W)$ is the specimen compliance function for the testing geometry and $W$ the specimen width and the rethod to arrive at $P_{Q}$ from the loaddisplacement curve is dealt in detail in the ASTM standards. (57) In the present investigation, equivalent-energy method described by Chell et al (133) was used to calculate $K_{I C}$ from $K_{Q}$ wherein the invalidity is due to smaller specimen thicknesses. Fig. A2 reproduced from Ref. 133 shows the normalized load-displacement curve wherein the displacement can be considered to be the external crin opening displacement $\delta$ for a compact tension spectuen (see Fig. 2 of nain hody). Large specimens fail on the IInear part of the nomalized load-displacement curve, say at A in Fig. A2, where linear elastic fracture mechanics is applicable. Smaller specimens fail well fr.to the non-li ear part of the curve, at say, B. Considering a fracture test on a specimen that falls at the point 8 , according to the equivalent- 


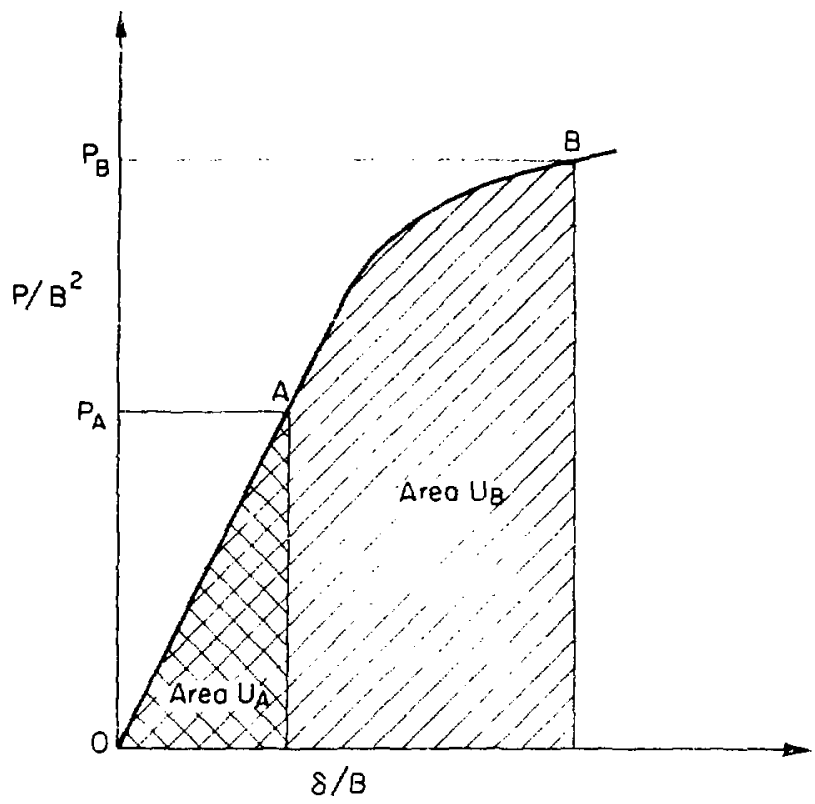

XBL 782-4553

Fig. A2. Normalized load-displacement curve ${ }^{(133)}$. 
energy method the coughness, $K_{I C}$ is obtained from

$$
K_{I C}\left(\text { calculated) }=\frac{P_{A}}{B \sqrt{W}} f(C / W) \sqrt{\frac{U_{B}}{U_{A}}}\right.
$$

where $P_{A}$ is any load which lles on the 11near part of the load-displacement curve, Fig, $A 2, P_{B}$, the maximum load recorded up to fallure and $U_{B}$ and $U_{A}$ are the areas under the load-displacement curve up to the points $B$ and $A$, respectively.

Sample Calculation: 2 Mn modified quaternary alloy, single treated, quenched and $200^{\circ} \mathrm{C}$ tempered condition with $\mathrm{K}_{Q}=126 \mathrm{KSI}-\mathrm{inI} / 2$, Table II

Specimen Th1rkness $\mathrm{B}=0.846^{\prime \prime} ; \mathrm{W}=2.000^{\prime \prime} ; \mathrm{C} / \mathrm{W}=0.500 ; \mathrm{f}(\mathrm{C} / \mathrm{W})=9.6$ from Ref. 57. Maximum load, $P_{B}=17.64 \times 10^{3}$ Ibs. Load chosen in the elastic region, $\mathrm{P}_{\mathrm{A}}=9.6 \times 10^{3} 1 \mathrm{bs}$.

Area under $A, U_{A}=318$ units.

Area under $B, U_{B}=1797$ units.

Lsing eqn. (A3) above, the plane strain fracture toughness is calculated to be $183 \mathrm{KSI}-\mathrm{in} 1 / 2$. 


\section{References}

1. "Phase Transformations", 1970; Metals Park, Ohio (Amer. Soc. Metals)

2. D. H. Jack and J. Nutting: Inti. Met. Reviews, 1974, 19, P. 90

3. C.. Thomas: Met. Trans., 1971, 2, p. 2373

4. G. Thomas: Iron and Steel Int1., 1973. , p. 451

S. S. K. Das and G. Thomas: Met. Trans., 1970,1, p. 325

6. C. M. Wayman: Metallography, 1975, 8, p. 105

7. R. V. Fostint and F. J. Schoen: "Irunsformation and tiardenabililiy In Steels", Symposium, Climax Moly Co., Ann Arbor, :967, p. 195

8. E. C. Bain and H. W. Paxton: "Alloying Elements in Steels", 2nd Edition, ASM, Metals Park, 1966

9. R. A. Grange: Met. Trans., 197\%, 4, p. 223!

10. M. Raghavan and G. Thomas: Met. Trans., 1971, 2, P. 3433

11. S. Jin and D. Huang: Met. Trans. A, 197t, 7A, p. 145

12. K. Shimizu, M. Oka and C. M. Wayman: Acta Met., 1970, 8, p. 1025

13. S. R. Pari and M. Cohen: Acca Met., 1969, 17, p. 189

i4. (;. R. Spelch and P. R. Swann: JISI, 1965, 2013, P. 480

1j. C. J. Ychahon, Jr.: "Temper Emhrittlement in Stee1", p. 127, STP No. 407 ASTM, Phfladelphia, 1968

16. E. Nes and (i. Thomas: Met. Trans. A, 1976, 7A, p. 967

17. M. Holzmann and J. Man: JISI, 1971, 209, p. 836

18. J. McMahon and G. Thomas: Proc. Th1rd Intern. Conf. on Strength of Metals and Alloys, Inst. of Metals, London, 1973, L, p. 180

19. G. E. Pellisster: Engineering Fracture Mechanics, 1968, 1, p. 55

2n. E. R. Parker and V. F. Zackay: Englneering Fracture Mechanics, 1973, 5, P. 147

21. R. Clark and G. Thomas: Met. Trans., 1975, 6A, p. 969

22. D. Huang and G. Thomas: Met. Trans., 1971, 2, p. 1587 


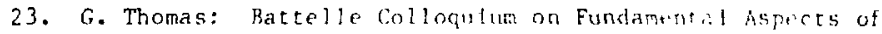
Structural Alloy nesign, R.I. Jaffee and R.A. Wialcox (eds.), Plenum Pub. Co., 1977

24. B. N. P. Babu: D. Eng. Thesis, Univ. of Calif., Berkeley, 1974, LBL Report No. 277 ?

25. R. W. K. Honeycombe: "Struclute and Stenglh of Alloy Steels", Climax Moly. Co., London, 19is

26. G. P. Contractot: J, of Motals, :96t, I8, f.:

27. I-Lin Cheng and 6. Thonas: Transactions of the ASM, 1968, 61,

28. H.J. [rvine, F. B. Yickering and T. Gladran: Z:SI, I967, 205, ?. 161

29. B. C. Woodfine, JISI, :953, 1:3, ก. 229

30. M. S. Bhat: ph.D. Thesis, indy. of Calii., Beriesley, Feb. 1977, LBL Report No. 60ith

31. A. A. Scheinker dnd C. ‥ Kontovich: "Inhibition of Ho Fmbrittlement In 4340 Steel by Ce and ial additions". Reported at AIME Fall 1977 meeting in Chicago

32. B. V. Kirasimha Rau and G. "honas: Yar. Sei. and Fngin, 1975, 20, F 115

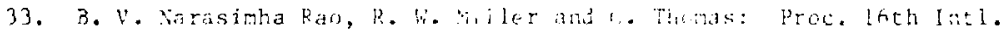
Heat reatment cont, The Meials soctetw, icndon, l974, p. 75

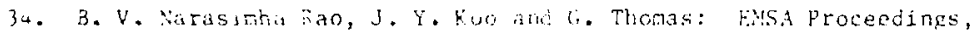
1975, P. 3n, Ciditurs Publishink fiv. Baton Rouge

35. C. Y. Lai, W. E. Wood. A. A. Clath, I. F. Gackay and E. R. Parker: Met. Trans., 1974,5, p. 1663

36. G. Kohn: Ph. D. Thesis, liniv. of Calif, Berkeley, Nov. 1976, LBL Report No. 5466

37. R. M. Horn: Ph. D. Thesis, triv, of Calif., Berkeley, Dec. 1976, LBL Report No. 5787

38. V. F. Zackay, E. R. Parker and W. E. Wood: Proc. 3rd Intl. Conf. on Strength of Metals and Alloys, Inst. of Metals, London, 1973, 1. p. 175

39. S. K. Das and G. Thomas: Trans, of the ASM, 1969, 62, P. 659

40. P. M. Kelly and J. Nutting: JISI, 1961, 197, p. 199 
41. D. Hull, Acta Met., 1950, 8, p. 11

42. R.B. Nicholson: Proc. "Effect of Second Phase Particles on the Mechantcal Properties of Stee], "Iron and Steel Inst., London, 1971 , P. 1

43. R. F. ilecker: Met. Trans., 1973,4, p. 2495

44. T. B. Cox and J. R. Low: Met. Trans., 1974, 5, P. 1457

45. C. R. Brophy and A. J. Miller: Trans. ASM, 1949, 41, F. 1185

46. C. W. Marsha11, R. F. Yehemann and A. R. Troiano: ASM Trans., $1962, \underline{55}, P .135$

47. A. if. Cottrell: Trans: : ATME, 1958, 212, p. 192

4B. N. . . Petch, Ph11. Mag., 1958, ?. R. 1089

49. C. Clark, R. O. Ritchte and J. F. Knott: Sature Phys. Sci. (condon), 1972, 239, p. 144

S?. R. A. Grange: Met. Trans., 1971, $\therefore$ p. 65

31. G. 4. S1nclair and U. J. Craig: Trans ASN, 1952, 44, p. 929

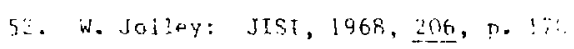

S. '. I. Relton, E. R. Petry and G. B. Allen: Met. Trans., 1971, 2 , F. 201 i

i. :i, Kart:4s and A, P. Marder: Met. Trans, 1911,2, D. 2343

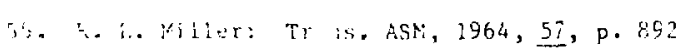

$\therefore$ R. . Ni 2er: Zalk presented at the Metais Show and Materials Eng:- Cering rongress, ort. 1973, Chicago

5). Standard Method of test for "Plane Strain Fracture Toughness of Metaliic Materials", designation E 399-72, Annual ASTM standards, 1973 , p. 960

58. M. Carlson, B.V.N. Rao, R. O. Ritchle and G. Thomas: Proc. Intl. Conf. on Strength of Metals and Alloys, Nancy, France, 1976, p. 509

59. H. W. Paxton: "The Formation of Austenite", Sympostum: Transformation and Hardenability in steels, Cl, max Moly Co., 1967, Ann Ac bor, p. 3

51). G. R. Speich and A. Szirmae: Trans. of AIME, 1969, 245, p. 1063 
61. Standard Methods for "Fistinat tng, the Average Grain Size of Merals," designation Fil2-f3, Annual ASTM Standards, 1973, p.419

62. Y.V. Murty, T. Z. Kattanis, R. Mehrabian, and M. C. Flening: Met. Trans., $1977,8 \mathrm{~A}, \mathrm{p}, 1275$

63. B. J. Schulz and C. J. Mchahor: Met. Trans., 1973, 4, p. 2485

64. R. O. RAtchie and J. F. Knott: Het. Trans., 1974, 5, p. 782

65. N.P. Allen et aI.: JISI, 1953, 174, p. 108

66. S. Murphy and J. A. Whtrenan: Met. Trans., 1970,1, p. 847

67. D. Huang and G. Thomas. Het. Trans., 1977, RA, P. 1661

68. D. N. Sharkleten and ". H. Keliy: ixka Hei., 1967, 15, p. 979

69. D. J. Dyscn and K. W. Andrews: JISI, 1969, 208, p. 208

70. G. Thomas. Met. Trans., 197K, 9A, P. 439

71. D. S. Sama and S. R. keuwn: Yet. Trans., 1975, 6A, p. 934

72. T. Makt and C. M. Waymatl: heta Yet., 1977, 25, p. 681

73. W. S. Owen, E. A. Wilson and T. Bell: High strength Materials, V. F. Zackay ed., P. 1f.7, John Wiley and Sons, New York, 1965

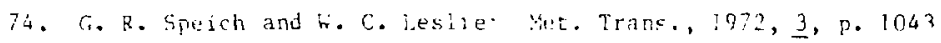

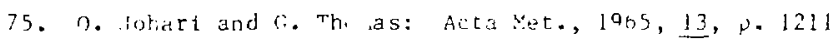

76. 9. J. Roberts: tet. Trans., $: 970,1,5.3287$

7). 9. B. r. Yeo: Trans. ATME, I962, 224, p. 1222

78. "Transformations in Metals," P.G. Shewmon, McGraw-H111 Book Co*, 1969

79. E. P. Klier and A. R. Trriano, Metals Technology, 1945, 12, p. i

80. C. S. Ansell, S. J. Donachle and K. W. Messler, Jr., Met. Trans., 1971,2, p. 2443

81. B. Edmondson and I. Ko: Acta Mer., 1954, 2, p. 235

82. "Cobalt Containing High-Strength steels": Cobalt Monograph serfes, Cobalt Information Center, Columbus, 1974 
83. B. V. Narastmha Rao: M. S. Thesis, Univ. of Calif., Berkeley, June 1975, LBL No. 3794

R4. H. W. King and S. ri, Clover, JISI, 1960, 196., P. 281

85. R. P. Brobst and G. Krauss: Met. Trans., 1974, 5, p. 457

86. W. C. Lesile and R. L. Miller: Trans. ASM, 1964, 57, p. 972

87. W. W. Gerbertch, G. Thomas, E. R. Parker and V. F. Zackay: Proc. 2nd Intl. Conf. on the strength of Metali and Alloys, Asilomar, 1970

88. A. K. Seal and R. W. K. Honeycrmbe: JISI, 1958, 188, 1.9

89. B.J. Relsdorf: Trans. AIME, 1963,227, P. 1334

90. Metals Handbook, Vol. 8, Amerjcal Boc. for Metals, Metals Park 1973

91. S. Rjöklund, L. F. Donaghey, gad M. H11lert: Acta Met, 1972, 20, p. 867

32. H. S. Owen, JISI, 1954, 177, p. 445

93. R. F. Hehemann, K. R. KInsman, and li. i. Aaronecan: Het. Trans., $1972, \underline{3}, \mathrm{P} \cdot \mathrm{i} 077$

44. Mo A. tirossman: "Mriztle Rarge in Liw Alloy steels", Iron Age, Jน! 1924

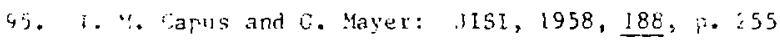

46. C. firijsle and A. Falibols: JISL, 1969, 207, p. 1628

97. R. ‥ Mant?: JTSI, 1965,203, p. 166

G3. C. Bergy and R. Brook, Metal Sc., 1975, 9. ח. 467

59. 1. F. King, R. F. Smith and J. F. Knott: Fracture 1977, llniv. of Katerluo, 1977, 2, p. 279

ion. B. V. Marasimha Rao and G. Thomas: Int J Joirn. of Fracture, 1977,3 , p. 705

101. C. J. McMation, C. L. Braint and S. K. Banerji: Fracture 1977, untv. of Water:00, 1977, 1, p. 363

102. E. B. Kula and A. A. Anct Il: J. Materials, 1969, $\leq$, p. 817 
103. J.R. Rellick and C. J. McMahon: Met. Trans., 1974, 5, P. 2439

104. B. S. Lement, B. L. Averbach and M. Cohen: Trans. ASM, 1954, 4E, P. 851

105. L. J. Klinger, J. W. Barnett, R. P. Frohmberg and A. R. Trolano: Trans. ASM, 1954, 46, P. 1557

106. R. C. Cochrane: Proc. "Effect of Second Phase Particles on the Mechanlcal Properties of Steel", The Irno and Steel Institute, London, 1971, p. 101

107. K. J. Irvine, F. B. Plckering, and J. Garstone: JISI, 1960, 196, p. 66

108. R. 0. Ritchie, B. Francis and W. L. Server, Met. Trans., 1976, 7A, P. 831

109. F. Stonesifer and R. W. Armstrong: Fracture 1977, Univ. of Waterloo, 1977,2, P. I

110. W. Dahl and W. Kretzschmann: Fracture 1977, Lniv. of Waterloo, 1977,2, P. 17

111. R. W. Amstrong: Advances in Malerial Research, H. Herman Ed., $1970,4, p, 101$

112. D. Webster: Met. Trans., 1971, 2, p. 2097

113. W. W. Cerbertch: Trans. AME, 1967, 239, P. 753

114. V. F. Jackay, E. R. Parker, J. W. Morris, 3x., and G. Thomas: Materials Sc. and Engin., 1974, 16, p. 201

1:5. S. k. Hwang: Ph. D. Thesis, Univ of Callf., :erkeley, 1977, IBL no. $66 \cap 3$

116. A. B. Grenninger and A. R. Troiano: Trans. AIYE, 1940, 140, p. 307

117. D. S. Sama, J, A. Whiteman and 3. H. Woodhead: Metal Sci. J., 1976,10, p. 391

118. R. F. Mehl, C. Barret:, and 0. W. Smith, Trans. AIME, 1933, 105, p. 215

119. F. J. Schoen, J. L. Nilles and W. S. Owen: Met. Trans., 1971, 2 , p. 2489

120. A. R. Marder and G. Krauss: Trans. ASM, 1969, 62, p. 957 
121. P. M. Kelly and J. Nutting: Proc. Roy Soc, 1960, A259, p. 45

12.. 7. Bell and W. S. Owen: JISI, 1967, 205, p. 428

123. J. D. Bolton and E. R. Petty: Metal Sc1. J., 1971, 5, P. 166

124. J. M. Chilton, C. J. Barton and G. R. Spelch: JISI, 19\%0, 208, p. 184

125. J. S. Pascover and S. V. Rade11ffe: Acta Met, 1969, 17, p. 321

126. F. I. Schoen and W. S. Gwen: Metallography, 1970, 3, p. 473

127. M. Carison: M. S. Thesls (in progress), Univ. of Calif., Berkeley

128. K. W. Andrews, D. J. Dyson and S. R. Keown: "Interpretation of Electron Diffraction Patterns", Plenum Press, New York, 1967

129. M. P. Nemirovskiy and Yu. R. Nemirovskiy: Fiz. Metal. Metalloved., 1975,39, p. 782

130. G. Thomas: Jourral of Metals, 1977, 29, p. 31

131. I. Y. Koo and G. Thomas: "35th Mnri. Proc. Flectron Microscopy Soc. Amer", Boston 1977, (i. W. Balley (ed)., p. 118

132. P. M. Kelly: Acta Met., 1965, 13, j.695

133. i. G. Chell, $i$. Milne and J. H. Kirby: Metals Techiology, 19i5, ‥ 1.549 
TABLE I.

ALLOY COMPOSITIONS AND TRANSFORMATION TEMPERATURES

\begin{tabular}{|c|c|c|c|c|c|c|c|c|c|}
\hline \multirow{2}{*}{$\begin{array}{c}\text { Alloy } \\
\text { Designation }\end{array}$} & \multicolumn{4}{|c|}{ Conpositjou (wt\%) } & \multicolumn{5}{|c|}{ Measured Temp. $\left({ }^{\circ} \mathrm{C}\right)$} \\
\hline & $s$ & $\mathrm{Cr}$ & $\operatorname{lin}$ & Ni & $\mathrm{Fe}$ & $M_{\mathrm{s}}$ & $M_{f}$ & $A_{s}$ & $A_{f}$ \\
\hline A & 0.29 & 4.0 & $-\cdots$ & $\cdots$ & Ba I. & $27: 1$ & 170 & 726 & 808 \\
\hline$B$ & 0.24 & 4.0 & 19.24 & -- & Ba 1 . & 305 & 190 & 728 & 762 \\
\hline $\mathrm{C}$ & 0.24 & 4.1 & 1.6 & $-\cdots$ & Bat 1 . & 274 & 167 & 700 & 735 \\
\hline D) & 0.25 & 4.8 & 1.93 & --- & Bi1 1. & $\therefore 3$ & 164 & 655 & 685 \\
\hline$E$ & 0.27 & 3.8 & --- & 5.11 & Bal. & 210 & 110 & 641 & 656 \\
\hline
\end{tabular}


TARLE II.

MECHANICAI. PRIPLITIES OF SINGLE TREATED, COARSE. GRAINED STEELS

\begin{tabular}{|c|c|c|c|c|c|c|c|}
\hline Al loy & $\begin{array}{c}\text { Tempering } \\
\text { Temperature } \\
\left({ }^{\circ} \mathrm{C}\right)\end{array}$ & $\begin{array}{c}Y S \\
(K S I)\end{array}$ & $\begin{array}{c}\text { USS } \\
\text { (KSI) }\end{array}$ & $\begin{array}{c}\% \\
\text { Reduction } \\
\text { In Area }\end{array}$ & $\begin{array}{c}\% \\
\text { EIongation } \\
\text { Total (Lniform) }\end{array}$ & $\begin{array}{c}\mathrm{K}_{\mathrm{IC}} \\
\mathrm{KSI}-\mathrm{in} 1 / 2\end{array}$ & $\begin{array}{r}\text { Charpy- } \\
\text { V-Notch } \\
\text { Energy } \\
\text { ft-1 bs }\end{array}$ \\
\hline \multirow[t]{6}{*}{$\mathrm{Fe}^{-4 \mathrm{Cr}-0.3 \mathrm{C}}$} & as-quenched & 195 & 240 & 35.4 & $8.0(3.0)$ & 71 & 18 \\
\hline & 200 & 189 & 230 & 45.5 & $11.0(4.0)$ & 76.5 & 30 \\
\hline & 300 & 173 & 208 & 45.2 & $10.0(3.3)$ & $-\infty$ & 15 \\
\hline & 400 & 169 & 202 & 48.3 & $11.0(3.3)$ & $---\infty$ & 15.5 \\
\hline & 500 & 155 & 175 & 52.4 & $13.5(4.4)$ & $-\infty$ & 19.5 \\
\hline & 600 & 110 & 129 & 78.6 & $17.0 \div 5.2)$ & $-\infty-$ & 36.5 \\
\hline \multirow[t]{6}{*}{$+0.5 \mathrm{Mn}$} & as-quenched & 192 & 233 & 34.1 & $9.0(3.5)$ & 92.5 & 14.0 \\
\hline & 200 & 175 & 214 & 47.0 & $11.0(3.5)$ & $117(150) *$ & 35.0 \\
\hline & 300 & 170 & $20) 4$ & 50.0 & $10.8(3.3)$ & --- & 14.0 \\
\hline & 400 & 163 & 195 & 51.0 & $11.3(3.6)$ & $-\cdots$ & 15.5 \\
\hline & 500 & 150 & 172 & 60.0 & $13.5(4.2)$ & $\cdots$ & 10.5 \\
\hline & 600 & 104 & 125 & 71.0 & $16.2(5.4)$ & $-\infty$ & 36.5 \\
\hline \multirow[t]{2}{*}{$+1.0 \mathrm{Mn}$} & as-quenched & 298 & 240 & 28.5 & $6.4(3.0)$ & 85.5 & 11.5 \\
\hline & 200 & 185 & 224 & 45.7 & $10.0(2.7)$ & $-\cdots$ & 48.0 \\
\hline \multirow[t]{6}{*}{$+2.0 \mathrm{Mn}$} & as-quenched & 207 & 265 & 33.1 & $8.5(3.5)$ & 59 & 3.4 \\
\hline & 200 & 195 & 235 & 36.0 & $6.5(2.5)$ & $126(180) *$ & 40.0 \\
\hline & 300 & 177 & 212 & 19.0 & $-\cdots$ & --- & 18.5 \\
\hline & 400 & 160 & 195 & 45.0 & $11.5(4.0)$ & $-\infty$ & 14.5 \\
\hline & 500 & 150 & 175 & 24,0 & $12.5(4.0)$ & $-\cdots$ & 4.0 \\
\hline & 600 & 105 & 125 & 64.0 & $17.0(6.0)$ & $-\infty$ & 10.2 \\
\hline
\end{tabular}

$*_{Q}$ values onlv, calculated kif in mackets. 
TABLE III.

MF THANICAL PROPERTIES OF GRAIN REFINED (DOUBLE TRFATED) STEELS

\begin{tabular}{|c|c|c|c|c|c|c|c|}
\hline AI lay & $\begin{array}{c}\text { Tempering } \\
\text { Temperature } \\
\left({ }^{\circ} \mathrm{C}\right)\end{array}$ & $\begin{array}{c}\text { YS } \\
(K S I)\end{array}$ & $\begin{array}{c}\text { UTS } \\
(K S I)\end{array}$ & $\begin{array}{c}\% \\
\text { Reduction } \\
\text { in Area }\end{array}$ & $\begin{array}{c}\% \\
\text { F. Iongation } \\
\text { Total }\end{array}$ & $\begin{array}{c}\mathrm{K}_{\mathrm{IC}} \\
\mathrm{KSI}-1 \mathrm{n} 1 / 2\end{array}$ & $\begin{array}{r}\text { Cha rpy- } \\
\text { V-Notch } \\
\text { Energy } \\
\text { ft-Ibs }\end{array}$ \\
\hline \multirow[t]{2}{*}{$\mathrm{Fe}^{-4 \mathrm{Cr}-0.3 \mathrm{C}}$} & as-quenched & 181 & 231 & 24.14 & 9.4 & 66.0 & 20.0 \\
\hline & 200 & 187 & 227 & 32.0 & 9.11 & $m--$ & 20.5 \\
\hline \multirow{2}{*}{$+0.5 \mathrm{Mn}$} & as-quenched & 185 & $23 n$ & 48.2 & 13.3 & 24.5 & 23.5 \\
\hline & 200 & 186 & 222 & 49.1 & 13.7 & 82.5 & 32.5 \\
\hline \multirow[t]{2}{*}{$+1.0 \mathrm{Mn}$} & as-quenched & 177 & $2: H$ & 47.4 & $13 . \bar{i}$ & 85.0 & 29.1 \\
\hline & 200 & 185 & 223 & 50.0 & 13.9 & 110.0 & 40.0 \\
\hline \multirow[t]{6}{*}{$+2.0 \mathrm{Mn}$} & as $-\eta n \in n$ r & 189 & 242 & 38.7 & 11.6 & 84.0 & 30.5 \\
\hline & $2(10)$ & 184 & 230 & 50.8 & $15 .+$ & $126.0 *$ & 44.5 \\
\hline & 300 & $18 \%$ & 215 & 58.5 & 14.5 & ---- & 29.5 \\
\hline & 400 & 177 & 204 & 59.1 & 15.4 & $\cdots$ & 24.5 \\
\hline & 500 & 161 & $1 \delta 0$ & 60.3 & $21.1)$ & --- & 17.0 \\
\hline & 600 & $1118)$ & 127 & 72.6 & 23.3 & --- & 28.0 \\
\hline
\end{tabular}


TABLE IV.

MECHANICAL PROPERTIES OF 5 N1 MODIFIED ALLOYS

\begin{tabular}{|c|c|c|c|c|c|c|c|}
\hline Treatment & $\begin{array}{c}\text { Tempering } \\
\text { Temperature } \\
\left({ }^{\circ} \mathrm{C}\right)\end{array}$ & $\begin{array}{c}\text { YS } \\
(K S I)\end{array}$ & $\begin{array}{l}\text { UTS } \\
(\text { KSI) }\end{array}$ & $\begin{array}{c}\% \\
\text { Reduction } \\
\text { In Area }\end{array}$ & $\begin{array}{c}\% \\
\text { Elongation } \\
\text { Total (Uniform) }\end{array}$ & $\begin{array}{c}\mathrm{K}_{\mathrm{IC}} \\
\text { KSI-1n } 1 / 2\end{array}$ & $\begin{array}{l}\text { CVN } \\
\text { Impact } \\
\text { Energy } \\
\text { ft }-1 \text { bs }\end{array}$ \\
\hline $\begin{array}{l}\text { Single } \\
\text { Treatment }\end{array}$ & as-quenched & 195 & 275 & 25.0 & $9.0(5.5)$ & 89.5 & 19.5 \\
\hline $\begin{array}{l}\mathrm{M}_{\mathrm{S}}-\mathrm{M}_{\mathrm{f}} \text { holding } \\
\text { Coarse grained } \\
\text { Structure }\end{array}$ & 200 & 187 & 234 & - & $12.0(5.0)$ & 123.0 & 43.5 \\
\hline Double & as-quenched & 200 & 280 & 44.5 & 11.1 & 75.0 & 27.0 \\
\hline Treatment & 200 & 193 & $24 ?$ & 57.5 & 15.8 & 102.0 & 41.9 \\
\hline Fine grained & 300 & 183 & 218 & 58.7 & 15.3 & $\ldots$ & 41.0 \\
\hline Structure & 400 & $18 \mathrm{I}$ & 215 & 59.5 & 16.0 & --- & 39.0 \\
\hline & 500 & 172 & 195 & 64.0 & 18.1 & ---- & 48.5 \\
\hline & 600 & 114 & 137 & 75.0 & 24.0 & $\ldots$ & 117.0 \\
\hline
\end{tabular}


TABLE V.

SUMMARY OF CRYSTALIOGRAPHIC STUDIES IN LATH MARTENSITE

Investigator(s)

Habit Plane

Habit Plane

Ref. in Martensite in Austenite

\begin{tabular}{|c|c|c|c|}
\hline Mehl et al. & -- & $\{111\}_{\gamma}$ & 118 \\
\hline Greninger \& Trolano & $\cdots$ & $\{111\}_{\gamma}$ & 116 \\
\hline Schoen et al. & $\cdots-\cdots$ & $\{111\} Y$ & 119 \\
\hline Marder \& Krauss & $-\cdots-$ & $\{557\}_{\curlyvee}$ & 120 \\
\hline Kelly \& Nutting & $\langle 111\rangle_{a}^{*}$ & $\langle 110\rangle_{Y}^{*}$ & 121 \\
\hline Bell \& Dwen & $\{110\}_{\alpha}$ & ----- & 122 \\
\hline Bolton \& Petty & $\{110\}_{\alpha}$ & $\cdots$ & 123 \\
\hline Chilton et al. & {$[213\}_{\alpha}$} & $\cdots$ & 124 \\
\hline Sama et al. & $\{213\}_{\alpha}$ & ------ & 117 \\
\hline
\end{tabular}


TABIF VI.

CHEMISTRY OF THF, ALIOYS ANIJ THEIR MS TEMPERATURFS

\begin{tabular}{lll} 
Alloy \# Alloy Comp. $(w t \%)$, Noninal & Ms $\left({ }^{\circ} \mathrm{C}\right)$ \\
\hline 1) & $\mathrm{Fe}-12 \mathrm{Ni}$ & $300^{*}$ \\
2) & $\mathrm{Fe}-15 \mathrm{Ni}$ & $250^{*}$ \\
3) & $\mathrm{Fe}-20 \mathrm{Ni}$ & $165 *$ \\
4) & $\mathrm{Fe}-4 \mathrm{Cr}-0.3 \mathrm{C}$ & 320 \\
5) & $\mathrm{Fe}-4 \mathrm{Cr}-5 \mathrm{Ni}-0.3 \mathrm{C}$ & 210 \\
6) & $\mathrm{Fe}-4 \mathrm{Cr}-\mathrm{MMn}-0.3 \mathrm{C}$ & 253 \\
\hline
\end{tabular}

*calculated 
TABLE VII.

VARIATION OF MARTENSITE SIZE PARAMETERS WITH AUSTENITIZING TREATMENT

$$
\text { IN } \mathrm{Fe} / 4 \mathrm{Cr} / 0.3 \mathrm{C} \text { Alloy }
$$

\begin{tabular}{cccc} 
Austenitizing & Prior austenite & Martensite & Martensite \\
Temperature $\left({ }^{\circ} \mathrm{C}\right)$ & grain size, um & packet size, um & Lath width, um \\
870 & 29 & 26 & 0.37 \\
1000 & 111 & 31 & 0.35 \\
1100 & 202 & 42 & 0.39 \\
1200 & 254 & 47 & 0.39 \\
\hline
\end{tabular}


Fipure rapt tome

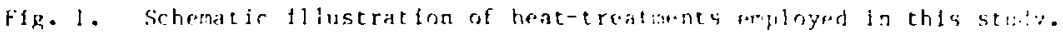

Flg. 2. Sketches of round tenslle (A), frarture touphness (B), and lmpar. toughness ( $C$ ) spectmens.

Fig. 3. Equdlibrium pseudo-binary phase diagran of fe-5cr-c system.

F1g. 4. Optical micrographs of as-quenched steels: (a) and (b) are fir 2 Mn modefled alloy and (c) and (d) are for 5 si modffied alloy. (a) and (c) are from single high temperatur. tratad sptcitiens whereas ( $h$ ) and (d) are from grain-refined sperimers.

Fig. 5. Prior austente grain size as a function of a:loying and heat-treatment.

Fig. 6. Bright fleld (a), dark-fleld (b) revealing alute-tirpered c-carbide in the single treated as-quenched $1 m_{n} \operatorname{modifitd}$ alloy. The $S \wedge \mathrm{D}$ pattern (c) contalning streaked reflectirns from e-carblde is indexnd in $(d)$.

Fip. 7. Pright-ficld micrographs (a) and (b) show the dislucated lath martenstte structure devoid of any auto-tompered carbides in the as-quenched coare grained structure of ? in modffied alloy.

Fig. 8. Bright-field micrographs (a) and (b) roval the dislocated lath: martensite while (c) and (d) show the presence of some substructura 1 twinning in the $5 \mathrm{Mi}$ modlilied alloy single treated and interrupted quenched to room temperature. Twinning reflections from (d) are shown in the SAD of (a) and stitably indexed in ( $f$ ).

Fig. 9. Tempered E-carbide observed in single treated 5 si modified alloy is shown in the BF micrographs (a) aud (b).

Fig. 10. Brfght-fleld (a), dark-field (b), selected area diffraction pattern (c) and the corresponding indexed pattern (d) revealing Widmanstatien cementite in the $200^{\circ} \mathrm{C}$ tempered specimens of 2 Mn modified alloy.

Fig. 11. Bright-field (a), dark-field (b), selected area diffraction (c) and the corresponding indexed pattern (d) revealing cementite precipitation in $0.5 \mathrm{Mn}$ modified alloy tempered at $300^{\circ} \mathrm{C}$.

Fig. 12. Morphology of cementite preclpitation in $300^{\circ} \mathrm{C}$ tempered structures of $2 \mathrm{Mn}$ modiffed alloy: bright-field (a) and dark-field (b) micrographs reveal typical widmanstäten platelets while bright-field (c) and dark-field (d) micrographs reveal on-going process of spheroidization of this carbide. 
Fig. 13. Bright-fleld (a), dark-ficid (b), selected area diffraction pattern (c) and the corresponding indexes pattern (d) showing carbide precipltation in $3 \mathrm{C} J^{\circ} \mathrm{C}$ tempered, fine grained $5 \mathrm{NL}$ nodifled alloy. Retained austenite is identified by arrow's in the DF micrograph (b).

Fig. 14. Bright-field (a), dark-field (b) teveallug spheroldized rumenitt in 0.5 kn modificd il loy tempered at bllo (c) and (d) ale the bright-field and dark-field micrographs showing interlath cementite in the same alloy.

F1g. 15. Bright-field (a), dark-field (b) showing presence of widmanstaten cementite and $\mathrm{M}_{7} \mathrm{C}_{3}$ precipitation in $2 \mathrm{Mn}$ modified alloy tempered at $500^{\circ} \mathrm{C}$. (d) $1 \mathrm{~s}$ the analysis of the selected area diffraction pattern (c), whlch contains streaklng presumably from $M_{7} C_{3}$ carbide.

Fig. 16. (a) BF, (b) DF, (c) SAD and (d) analysis revealing continued presence of fine widmaistäten cementite platelets in the 2 Mn alloy cempered at $500^{\circ} \mathrm{C}$.

F1g. 17. (a) BF showing twinning, (b) DF showing twin boundary carbide precipitation and (c) is revealing twins in bright contrast in $5 \mathrm{Ni}$ alloy tempered at $500^{\circ} \mathrm{C}$.

Fig. 18. (a) $B F$, (b) $D F$ revealing both $M_{7} C_{3}$ and cementite in $5 \mathrm{Ni}$ modifled alloy tempered at $500^{\circ} \mathrm{C}$. The $S A D$ pattern shown in (c) is analysed in (d).

F1g. 19. Retained austenite in the as-quenched $1 \mathrm{Mn}$ single treated alloy. (a) $B F$ and (b) DF micrographs revealing austenite in bright contrast. Fxtensive retained austenite in this alloy is also shown in the BF (c) and DF (d) micrographs from a different area.

F1g. 20. Fotensive retaired zuszanite in the 5 ini ailoy ficoarse grained is revealed in the BF (a) and DF (b) micrographs. (c) is the DF micrograph of retained austenite from a different area of the specimen.

F1g. 2l. DF comparison of the amount of retained atstenite in the quaternary alloys. (a) base alloy, (b) $0.5 \mathrm{Mn}$ alloy, (c) i Mn alloy, (d) 2 Mn alloy, (e) $5 \mathrm{NI}$ alloy, all coarse grained structures. The strong austente reflections observed in the quaternary alloys can be seen from the indexed SAD pattern shown in ( $f$ ).

Flg. 22. DF composite revealing continuous interlath fllms of retained austenite in the $1 \mathrm{Mn}$ alloy (coarse gralned) tempered at $200^{\circ} \mathrm{C}$.

Fig. 23. Decomposition of retafned austenite into interlath stringers of cementite in $300^{\circ} \mathrm{C}$ tempered $0.5 \mathrm{Mn}$ alloy. (a) $\mathrm{BF}$, (b) $\mathrm{DF}$, (c) SAD and (d) analysis of this carbide. 
Fig. 24. Decompostion of retalned austentre into laterlath stringers: cementite in $300^{\circ} \mathrm{C}$. tempered $2 \mathrm{Mn}$ ally. (a) $\mathrm{BF}$, (b) $\mathrm{ll}$, (c) cap) and (d) analysis of this carhide.

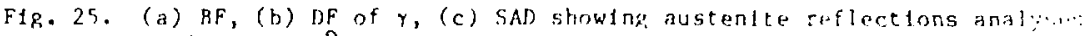
in (d) in $300^{\circ} \mathrm{r}$. teinpered $5 \mathrm{Nl}$ alloy (fine gralned).

Fig. 26. (a) BF and (b) uf reveailug interdath rementlte in crarse grained $2 \mathrm{Mn}$ alloy tempered at $5 m^{\circ} \mathrm{C}$..

F1g. 27. Variation in the zolume fraction isf retalned austente with Mn in single treated alloys.

F1g. 28. Volume fraction of retalned $r$ is. alloying, in gralnoreffned steels. Also shows retalned $Y$ in 5 Ni alliey tniterrupted guenritied $\left(M_{s}{ }^{-x_{f}}\right.$ ) following single high, temperature allstrinitization.

Fig. 29. \% Retalned $\gamma$ us. tempering temperature in 2 Mn and 5 Ni modified alluys.

Fig. 30. $\mathrm{R}_{\mathrm{C}}$ hardness us. tempering temperature.

Fig. 31. Strength vs. tempering temperature of sump triated alloys.

F1g. 32. Strength ys, tampering temperature for prain-refined alloys.

Fig. 33. Strength vs. Mn of the single areatod, asmprimbed alloys.

Fip. 34. \% reduction in area vs. tempering tamerature uf the (a) single treated Mn modffed alloys and ( $b$ ) $x_{n}=t_{n}$ refined Mn and $: i$ modified quaternary alloys.

Fig. 35. Plane strain frarture toughness vi. yie'd strength.

Fig. 36. KIC "s. w/a quaternary alloying for the grain refined structures.

Fig. 37. Inpact energy vs. vield strength of single treated Mu modified alloys and grain refined sit modified alioy.

Fig. 38. Impact energy vs. quaternary alloying for the gratn-refined structures.

F1g. 39. Impact energy vs. tempering temperature for the single treated, coarse grained alloys.

Fig. 40. Comparison of impact energy as a function of tempering temperature for the coarse and fine gralned structures of the 2 Mn alloy.

Fłg. 4l. Impact energy vs. tempering temperature for the grain refined $2 \mathrm{Mn}$ and $5 \mathrm{Ni}$ alloys. 
Fig. 42. Ductile-brittle transition temperature curves foi the base and quaternary steels.

Fig. 43. As-quenched CVN fractographs of coarse grained (a) $0.5 \mathrm{Mn}$ (b) 2 Mn alloys.

Fig. 44. Fractographs of Fe-4Cr-0.3C + Mn alloys. (a) and (b) are from $0.5 \mathrm{Mn}$ alloy at 200 and $300^{\circ} \mathrm{C}$ tempering respectively and (c) and (d) are from $2 \mathrm{Mn}$ alloy at 200 and $300^{\circ} \mathrm{C}$ tempering respectively.

Fig. 45. CVN fractographs of coarse grained, $500^{\circ} \mathrm{C}$ temperei (a) $0.5 \mathrm{Mn}$ and (b) $2 \mathrm{Mn}$ alloys.

Fig. 46. CVN fractographs of grain refined 5 Ni modified alloy: (a) as-quenched, (b) $200^{\circ} \mathrm{C}$ tempered, (c) $400^{\circ} \mathrm{C}$ tempered and (d) $600^{\circ} \mathrm{C}$ tempered.

F1g. 47. Inclusion tdentification in coarse grained 2 Mn alloy: (a) Fractograph and (b) corresponding EDAX analysis of rounded inclusion (arrowed in (a) in $200^{\circ} \mathrm{C}$ tempered structure and (c) fractograph and (d) EDAX analysis of rounded (arrowed in (c) Inclusion in $500^{\circ} \mathrm{C}$ tempered structure.

F1g. 48. Evolution of microsctructure and embrittlement during tempering of modified ultra-high strenght $\mathrm{Fe}-4 \mathrm{Cr}-0.3 \mathrm{C}$ steels.

F1g. 49. Fractography of the evolution of embrittlement during tempering of modified $\mathrm{Fe}-4 \mathrm{Cr}-0.3 \mathrm{C}$ steels.

Fig. 50. Schematic illustration of the morphology of retained austenite and martenstte in high carbon, high alloy steels (a) and low carbon, low alloy steels (c). Morphology of fracture due to decomposition of retained austenite to carbide on tempering [(b) and (d)] depends on the inftial microstructure (see text).

Fig. 51. Schematic of crack, displacements, and plastic zone in a two-phase materfal.

Fig. 52. Schematic showing desired duplex microstructure consisting of major phase martensite contributing to strength and winor phase recalned austent te providing improved toughness.

Fig. 53. Comparison of toughness to strength relations in experimental quaternary alloys and equivalent commerclal alloys. (a) Charpy impact energy vs. tensile strength and (b) plane strain fracture toughness vs. tensile strength.

FIg. 54. (a) Parallel laths in a packet martensite of binary Fe-12 Ni alloy. The $[110]$ remains the same in all the laths of the region. BF micrograph. (b) Corresponding indexed SAD patterns with the electron zone axes shown in the top left circles. 
Fig. 55. (a), (b) and (c): BF, DF and SAD pattern, respertively, trvealjug. retained austenite in alloy 4 (Table VI). DF (b) is obtaines! using (002) reflection $1 n$ (c). (d), (e), (f): BF, DF and SA!' pattern showing retained austenlte in alloy $h$ (Table VI). DF

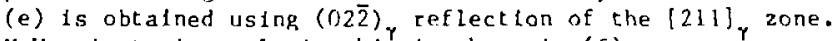
$\mathrm{N}$-W orientation relationship is shown in ( $f$ ).

F1g. 56. Stereographic analysis of relative rotations amongst the laths in a packet corresponding to $F 1 g$. 54. The axis of ratation, $[110]$, is also the standard projection of the stereogram.

Fig. 57. Plotted compostte austenite-martensfte diffraction patterns revealing the relattvely simple correspondence between the $\mathrm{K}-\mathrm{S}$ and $\mathrm{N}-\mathrm{W}$ orfentation relationships between $\mathrm{fcc}$ austenite and bcc martensite.

Fig. 58. Detailed analysis of the diffraction pattern corresponding to FIg. 55 (c).

Fig. 59. Trace analysis of habit plane/directlon for the martensite transfortation, (a) analysis of plane in martensite showing (011) and (133) habits, (b) analysis of direction in martensite showing near [111] a habit, (c) ditect analysis of plane in parent austenite revealing near (111), habit.

Fig. 60. Lattice image micrographs (a) and (b) are obtained from Fe-4Cr-0.3C-5N1 allcy (grain refined): (a) shows (101) lattice fringes near a martensite packet boundary. The location of packet boundary as judged from cont ist variation in conventional bright-field is indicated by arrows, (t) shows (101) atclce fringes within the martensite region. Several end-on dislocations can be seen and one of them is marked on the mierograph.

Fig. 61. Schematic representation of accoumodation within a martensite packet: Case I represents no accommodation, Case II represents accommodation over a group of laths and Case III shows accommodation in adjacent twin related laths.

Fig. 62. (a) Suggested ledge model of the austenite/martensite interface, (b) and (c) show different ledge configurations leading to either different macroscopic and microscopic habit planes (b) or a single habit plane (c).

Fig. 63. Proposed morphology of lath martensite, b $>$ a $\gg$ c. Arrows Indicate carbon segregation into austenite (A) from adjoining martensite $(M)$. 
SINGLE HEAT TREATMENTS

Bose and $\mathrm{Mn}$ Steels

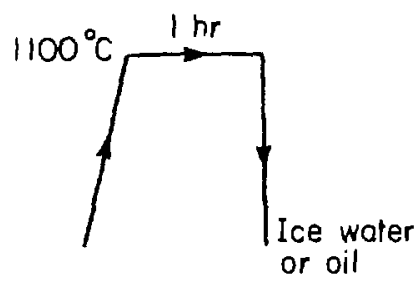

Ni Steels

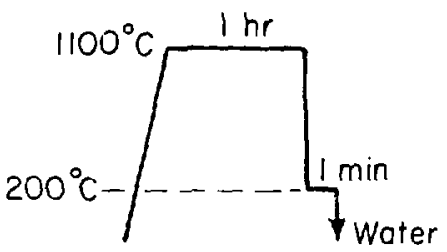

GRAIN REFINING DOUBLE TREATMENTS

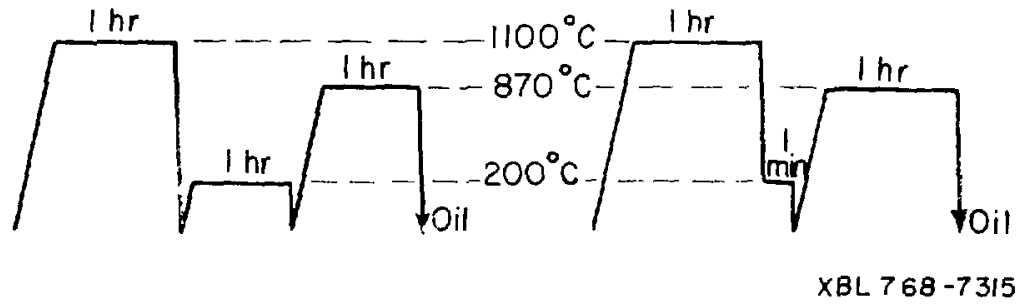

Fig. 1 


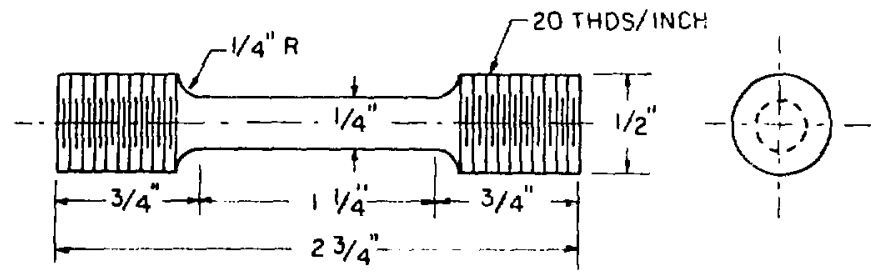

A. ROUNO TENSILE SPECIMEN

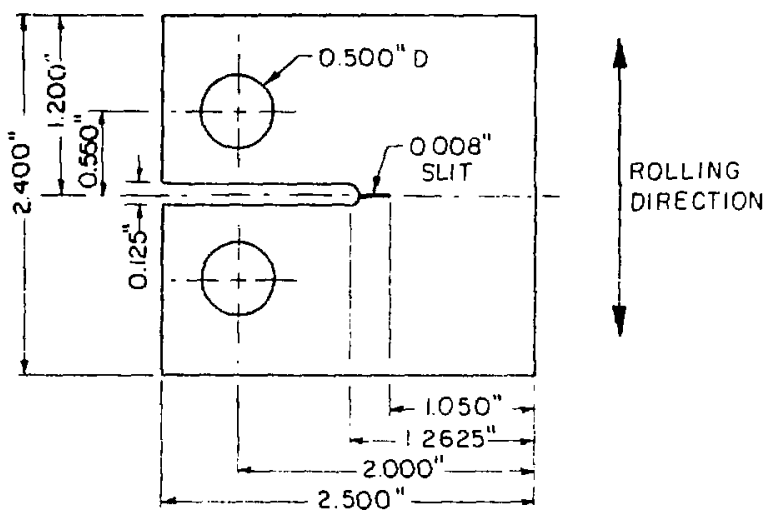

B. FRACTURE TOUGHNESS SPECIMEN

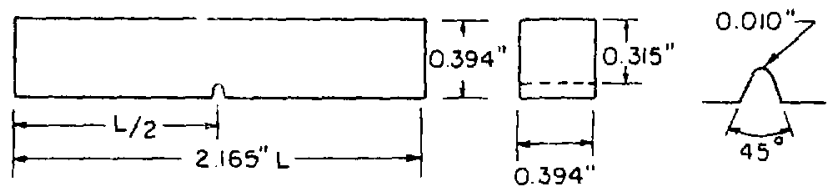

C. CHARPY $V$-NOTCH IMPACT SPECIMEN 


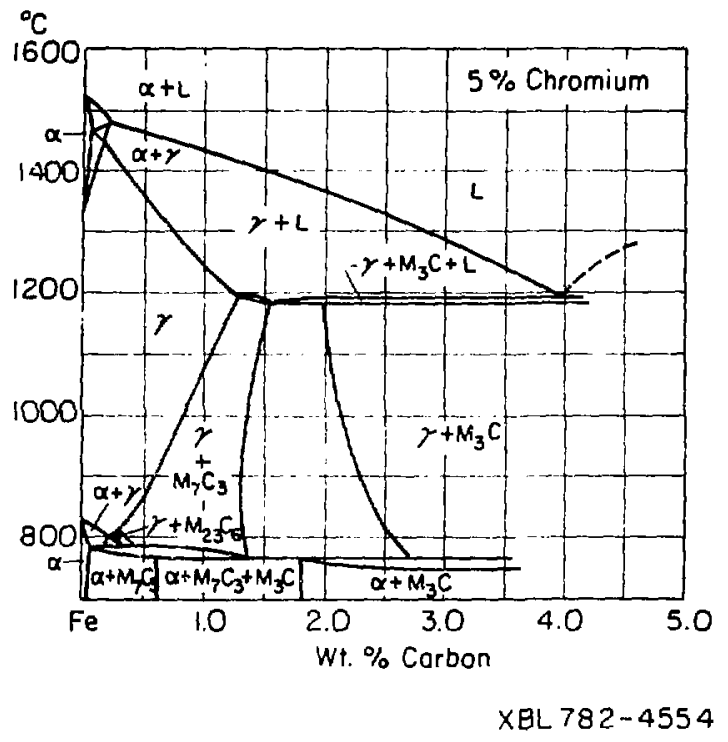

F1g. 3 

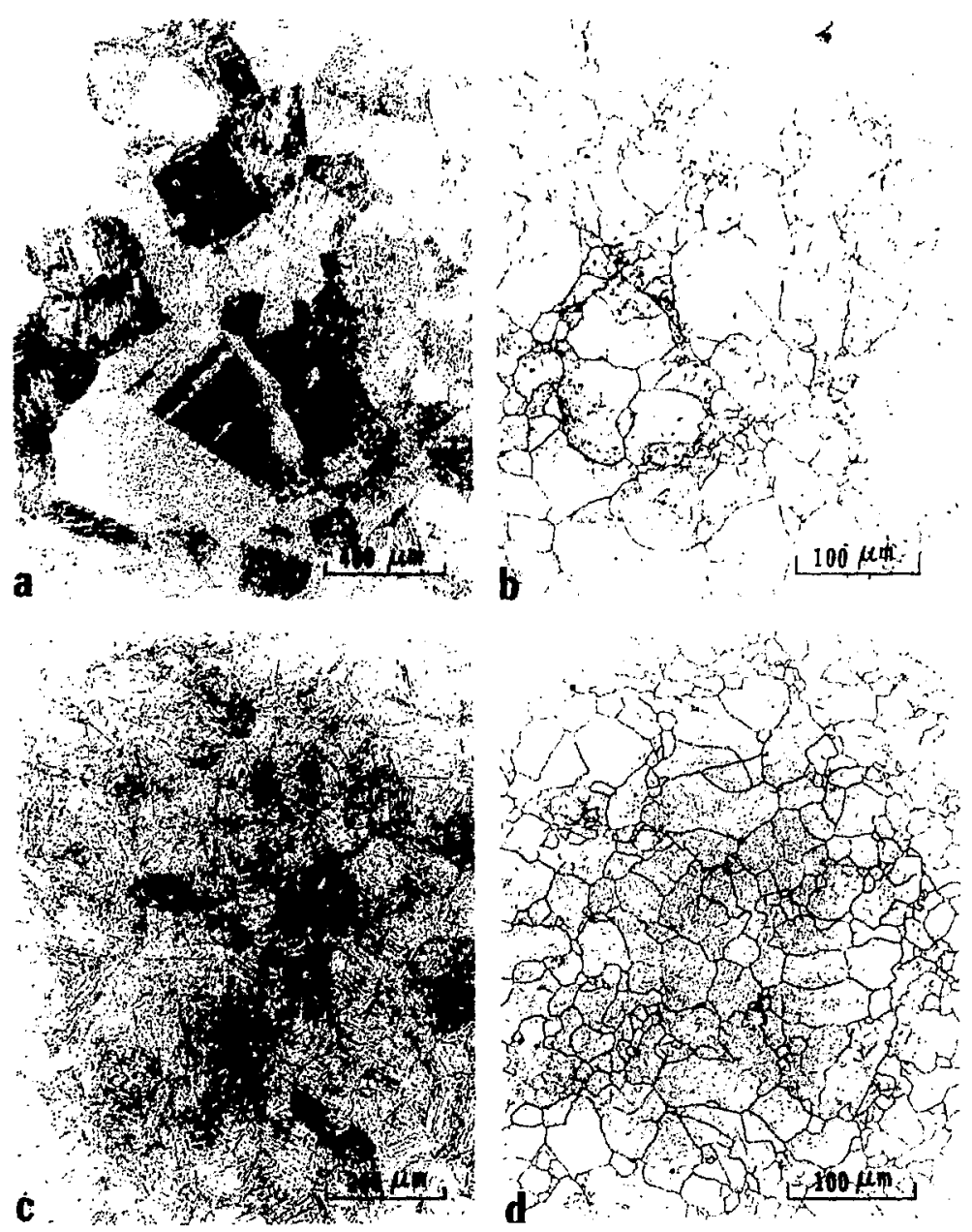

XRE $782-1185$ 


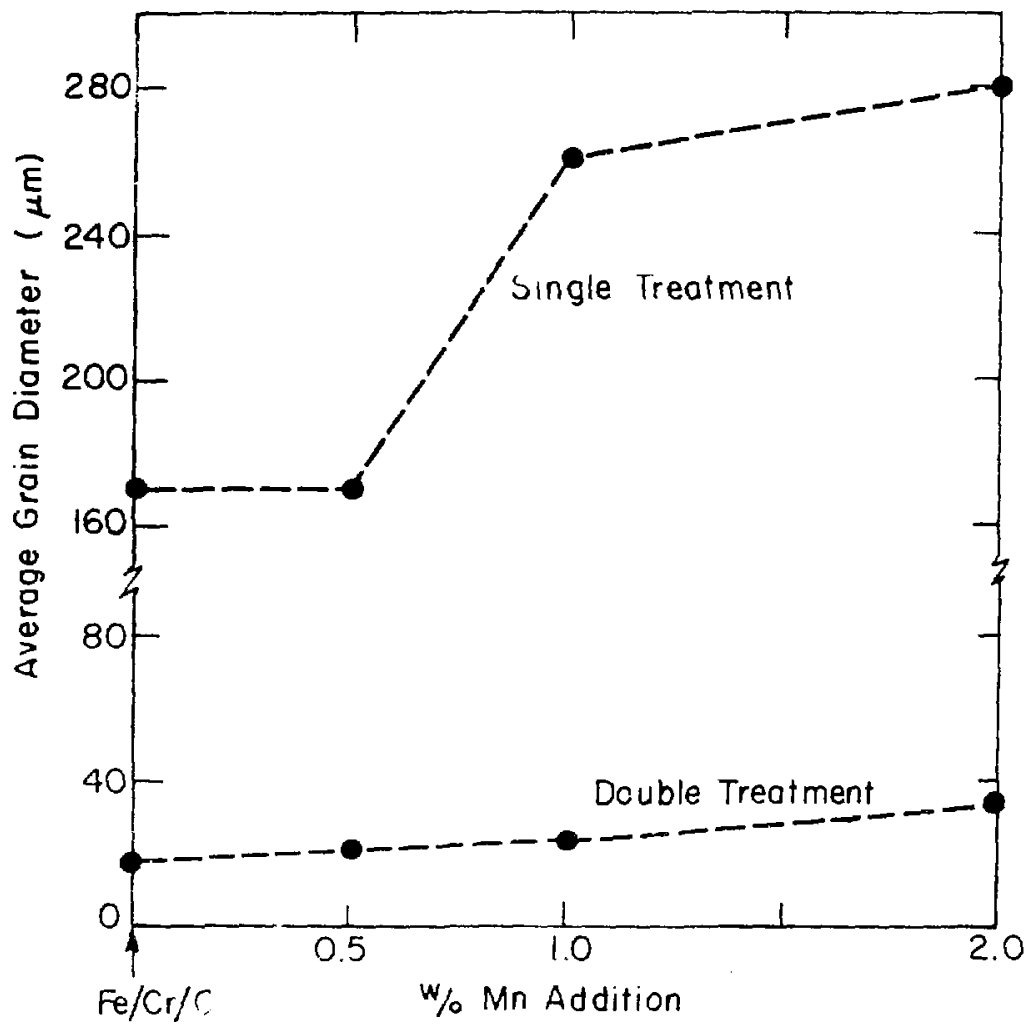

XBL $768-7313$

Fig. 5 

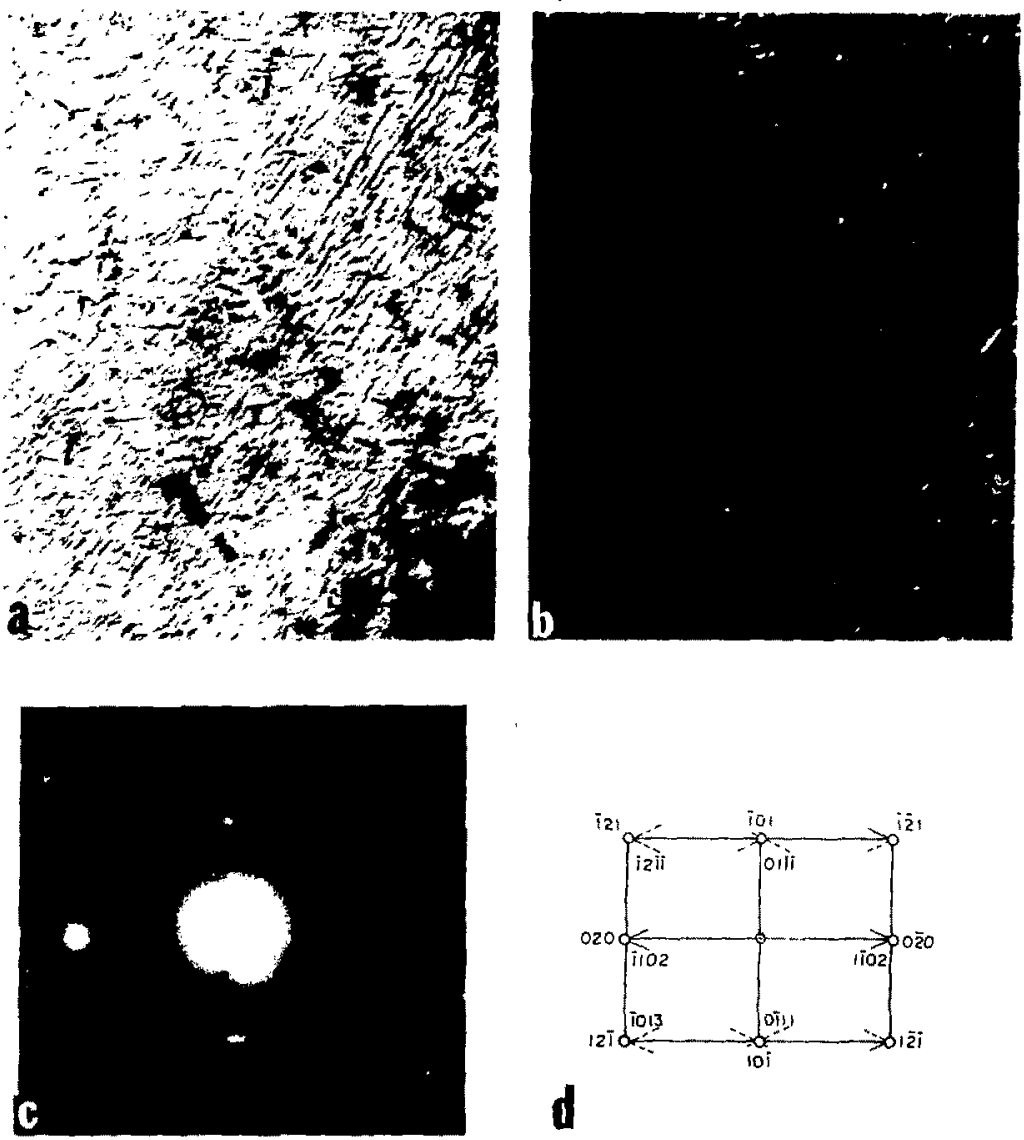

XBB $782-1180$

Fig. 6 

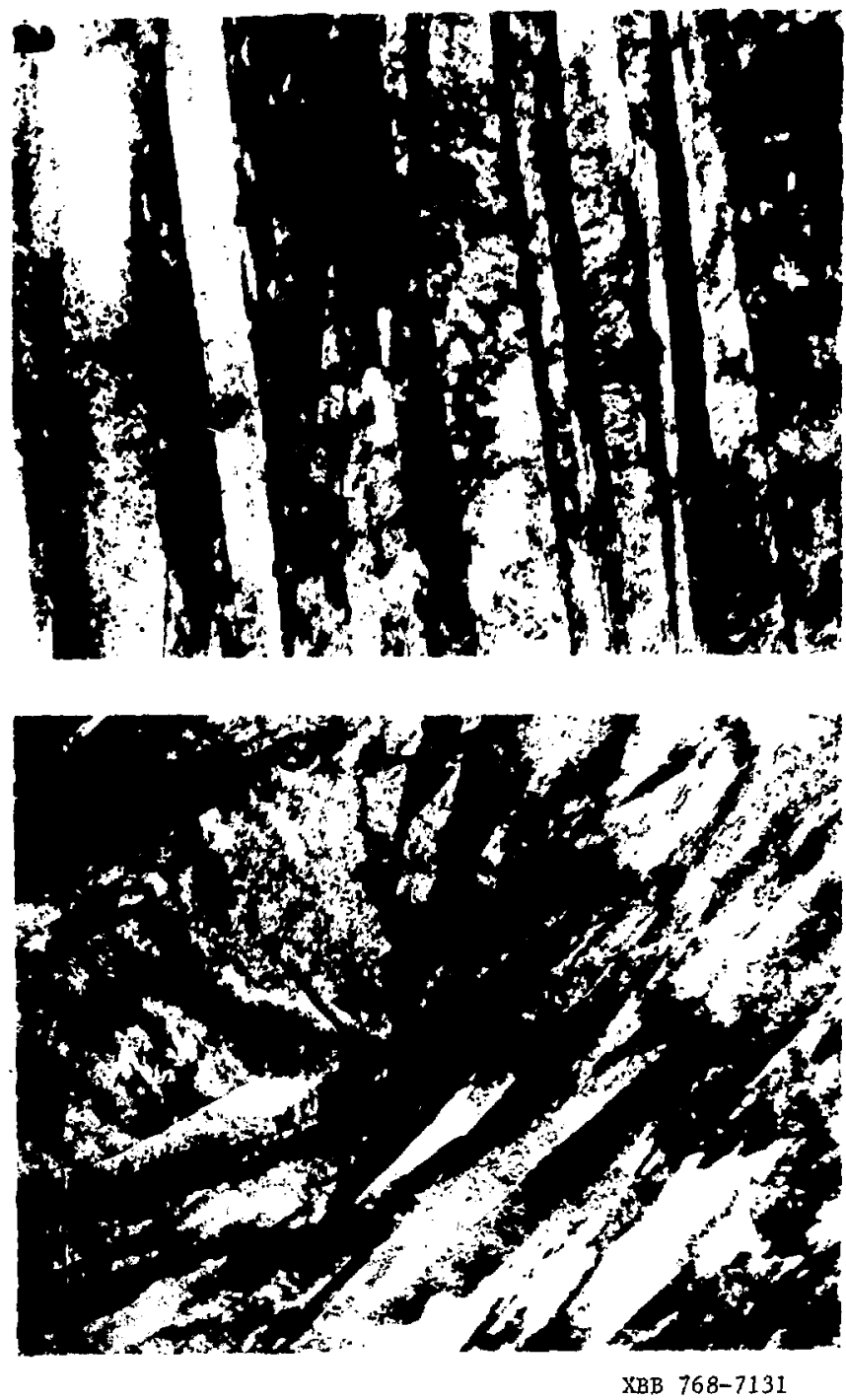

Fig. 7 

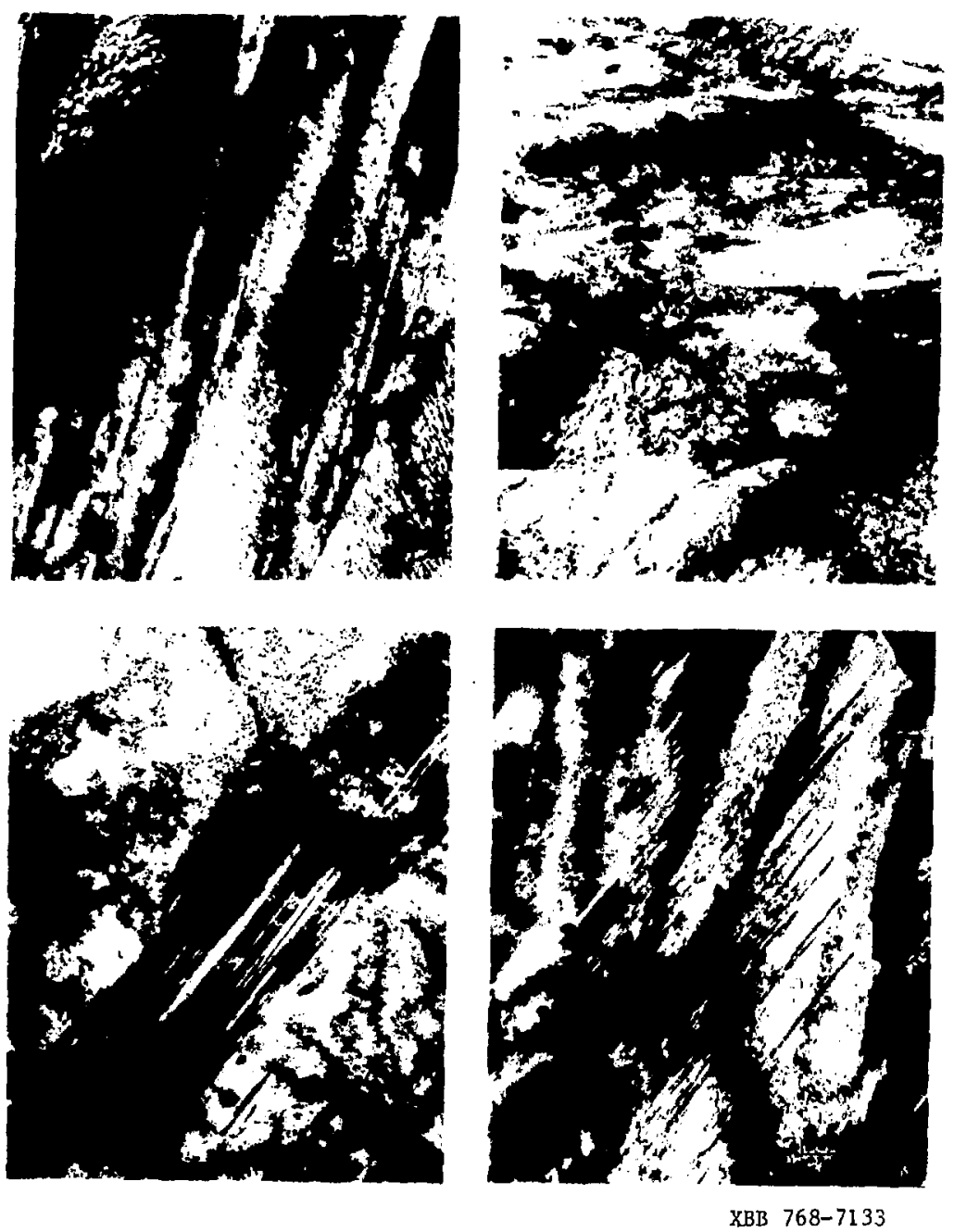

F1g. 8 (a-d) 

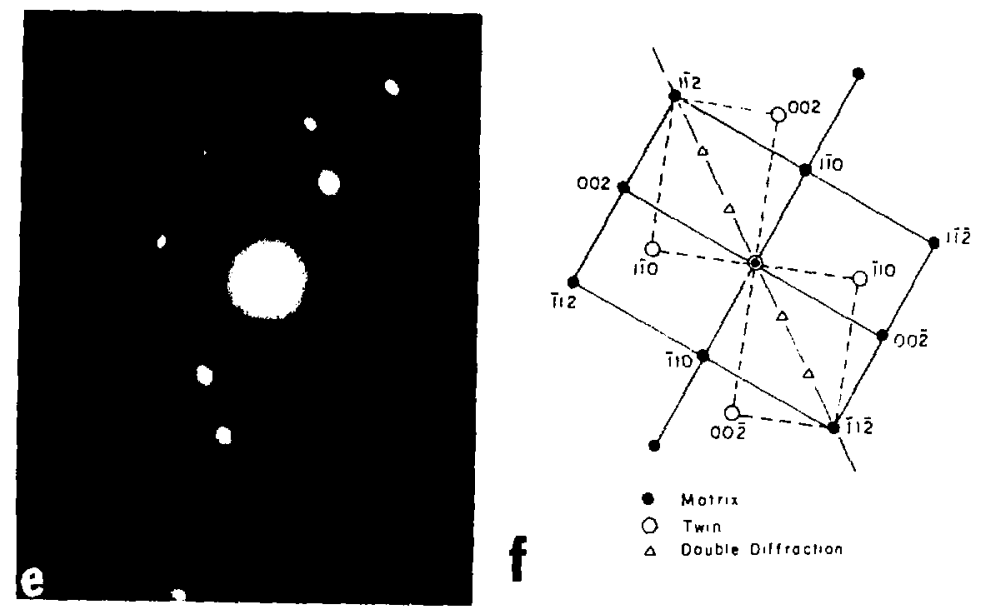

XBB $782-1179$

fig. $8(e-f)$ 

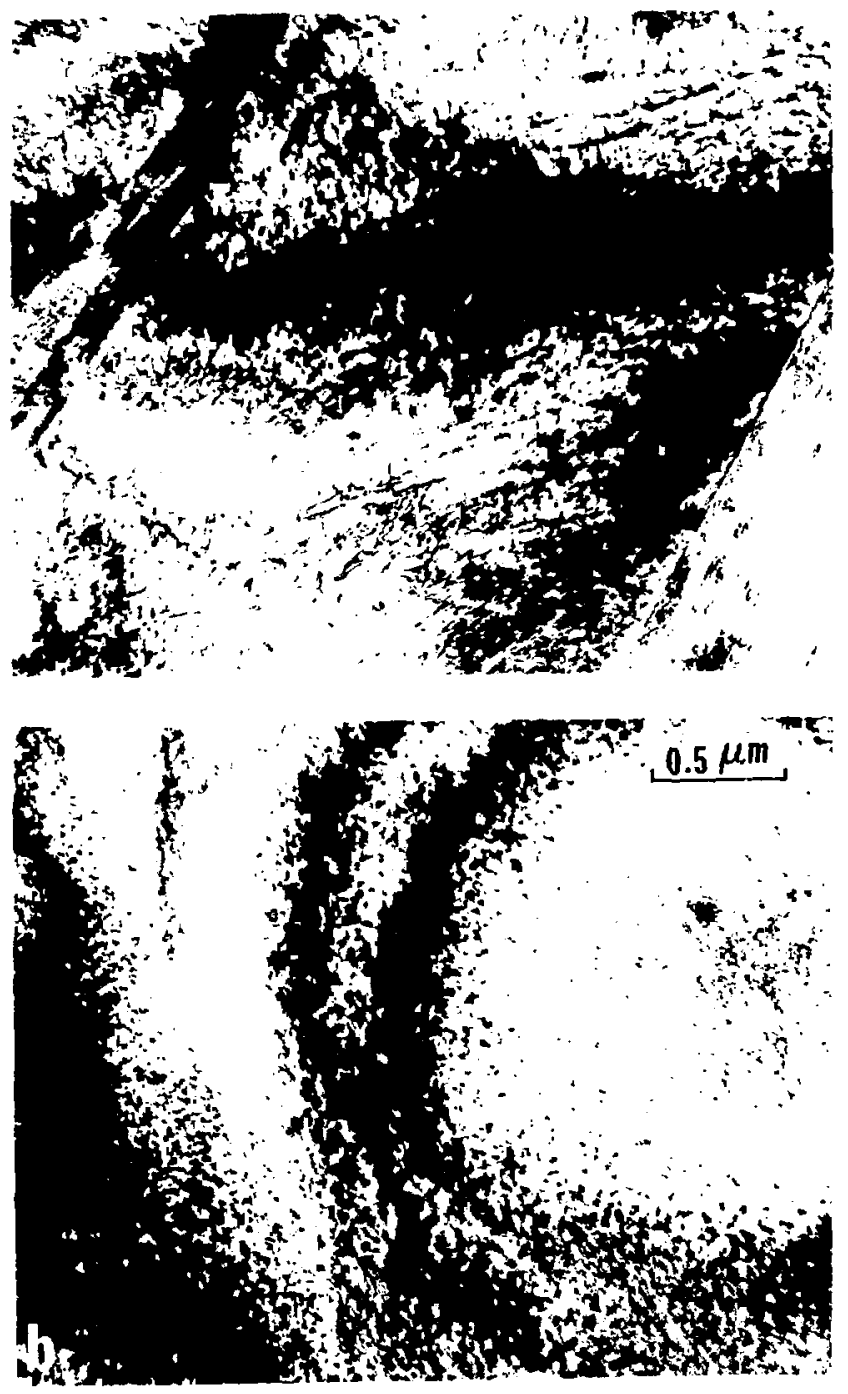

XB13 782-1182 

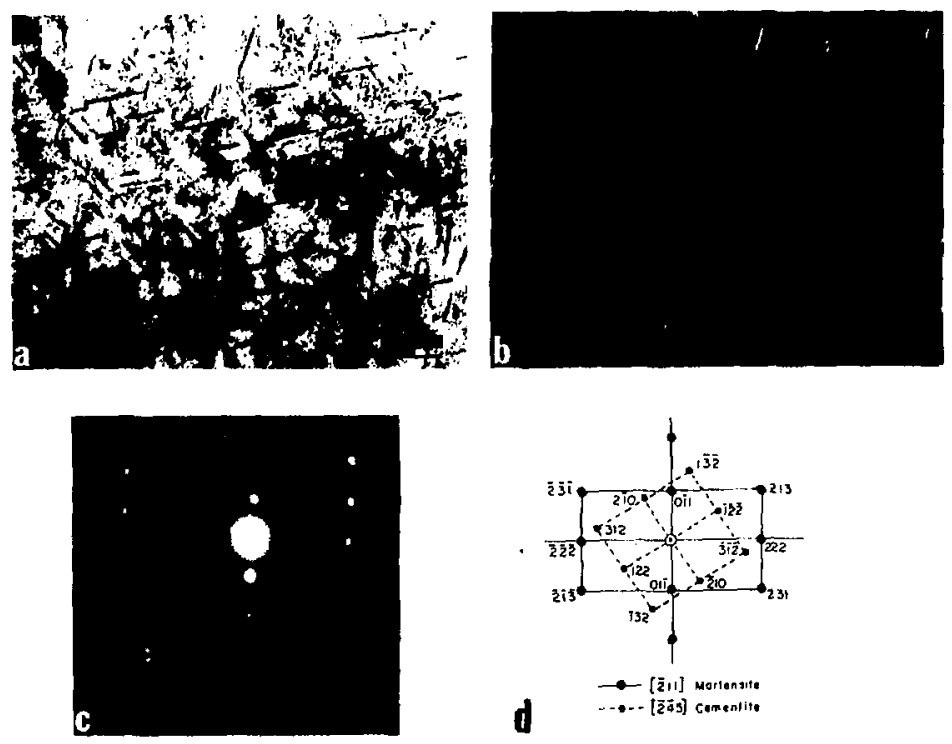

XBB 782-1175

Fig. 10 

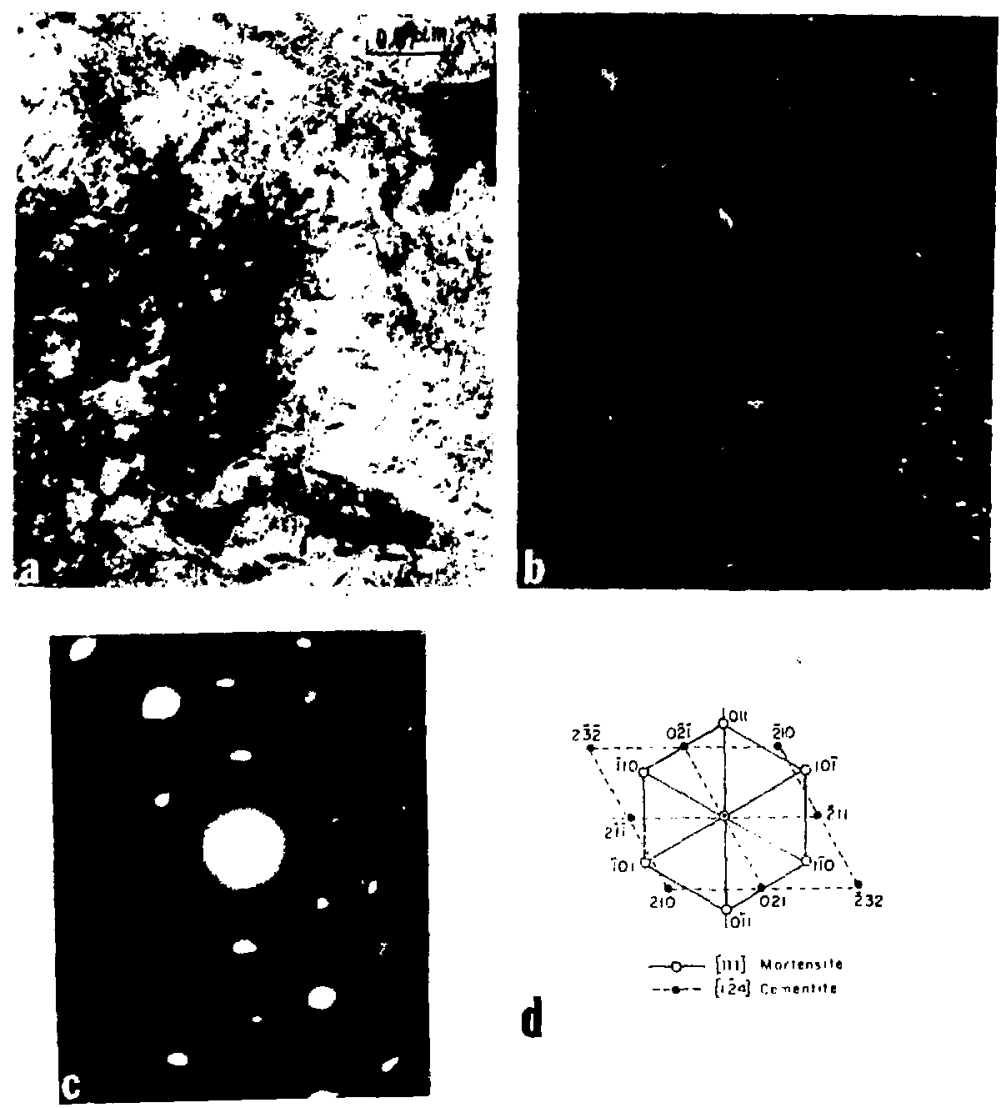

XßB $782-1177$

Fig. 11 

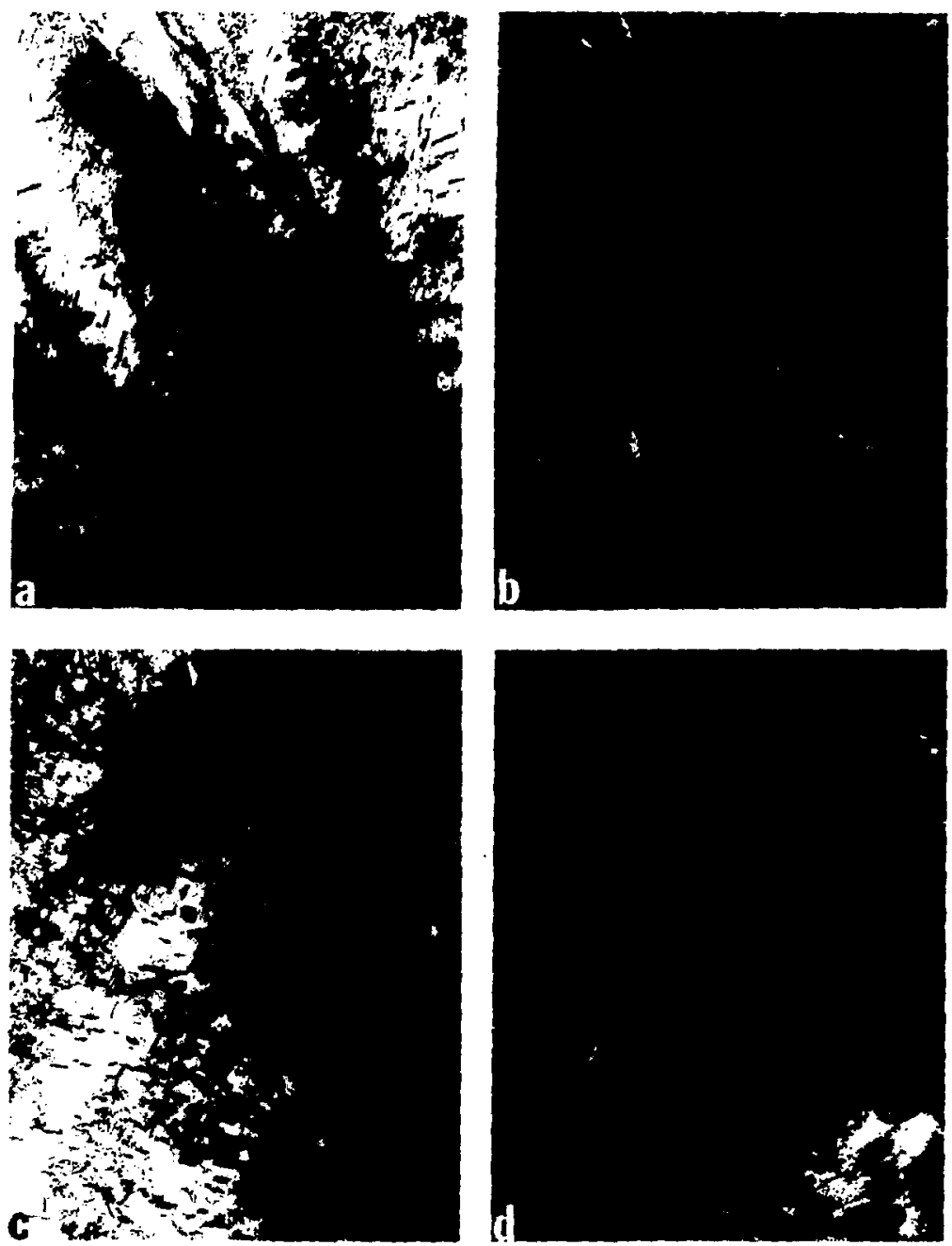

XBB 782-1186

Fig. 12 

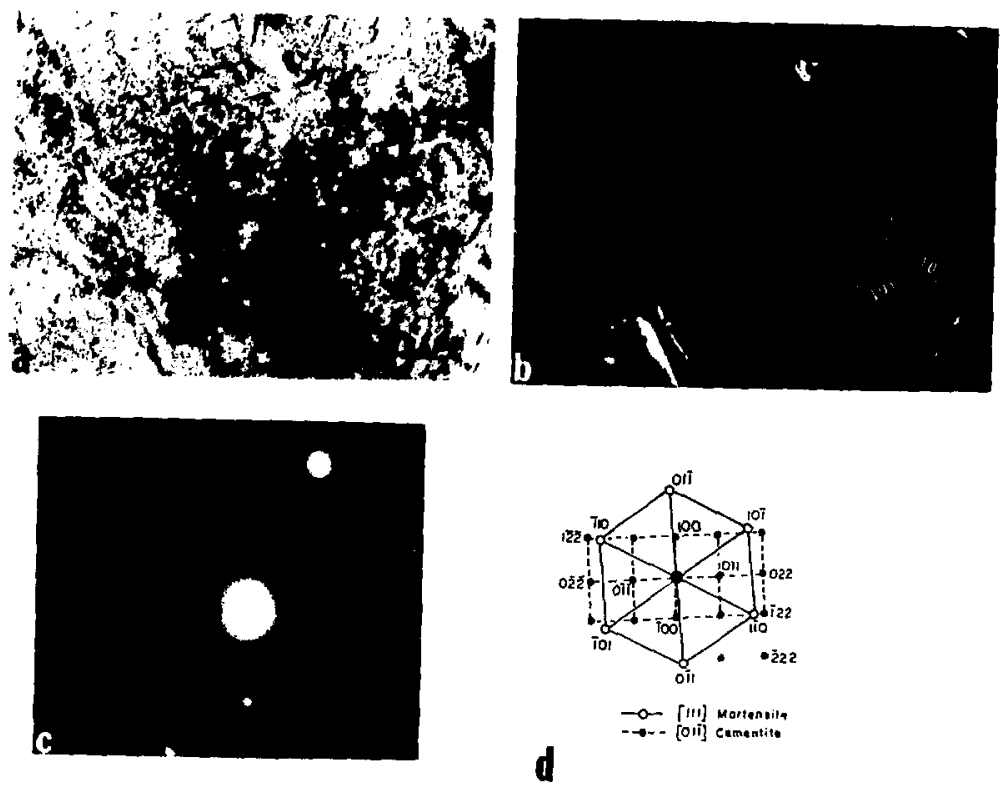

XBB 782-1173

Fig. 13 

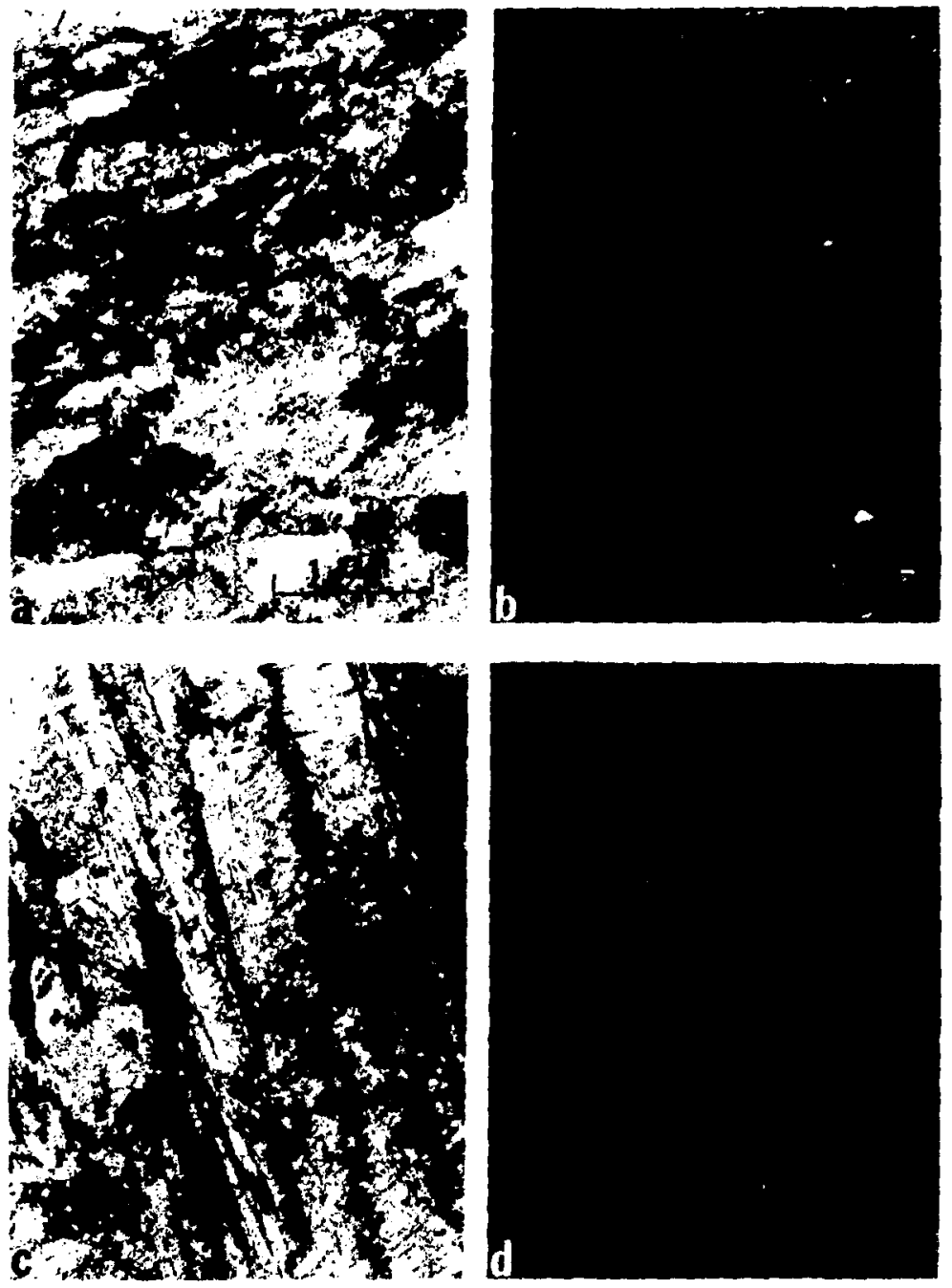

ХBB 782-1056 

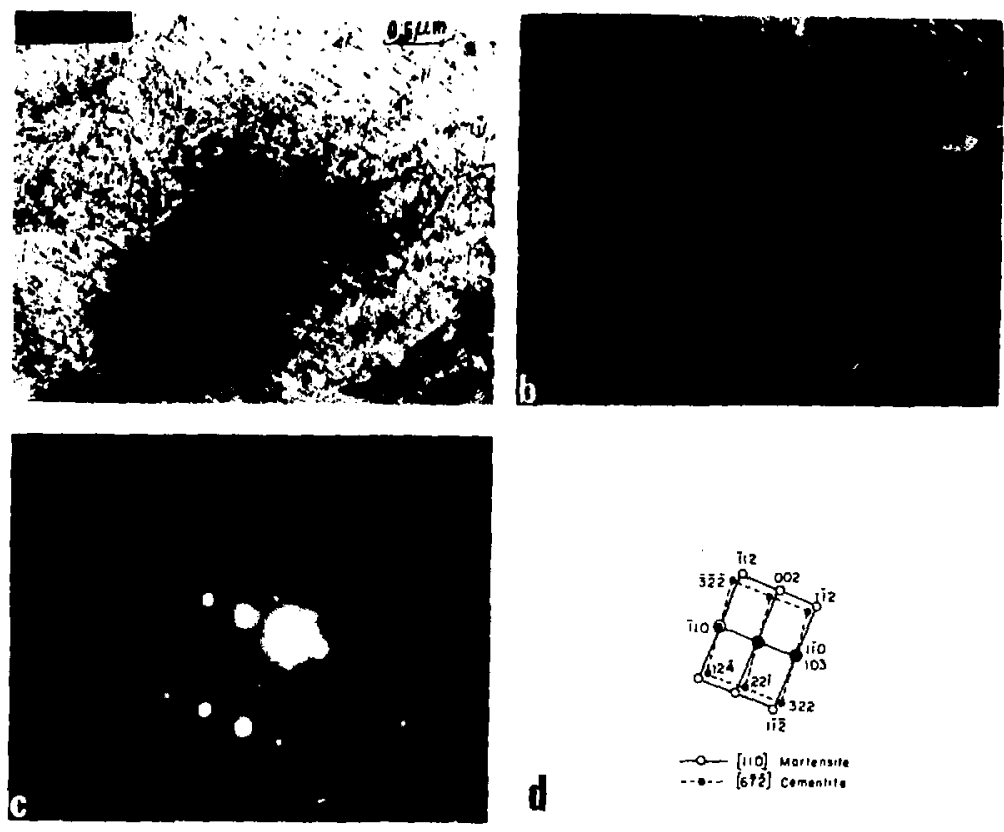

$X B B \quad 782-1171$

F1g, 15 

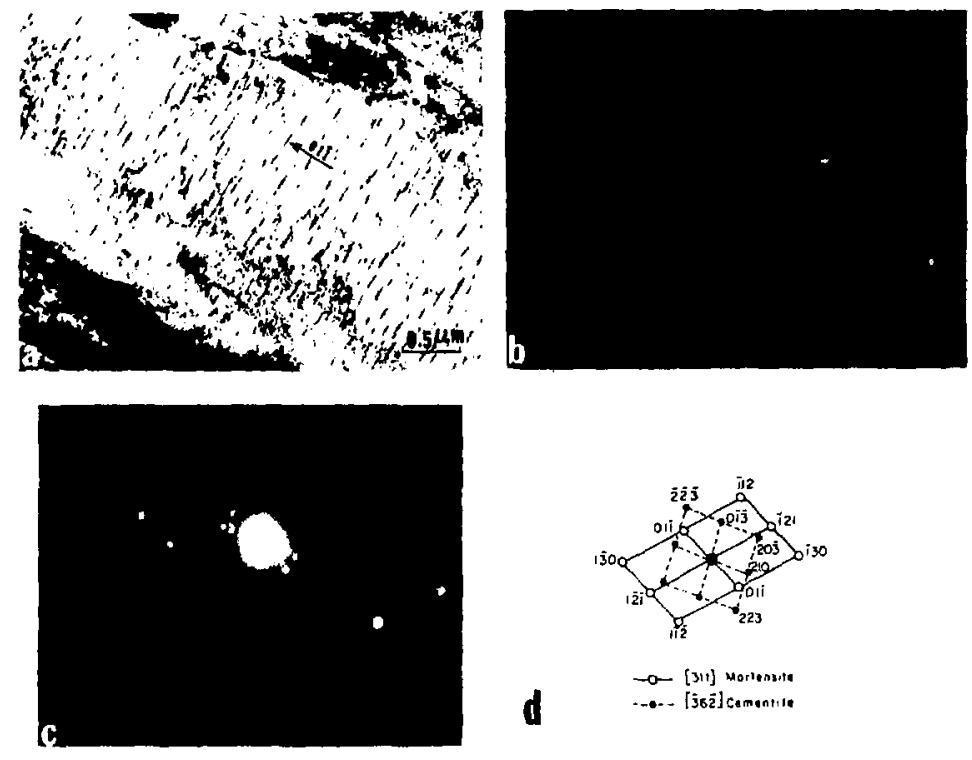

XBB 782-1176

FIg. 16 

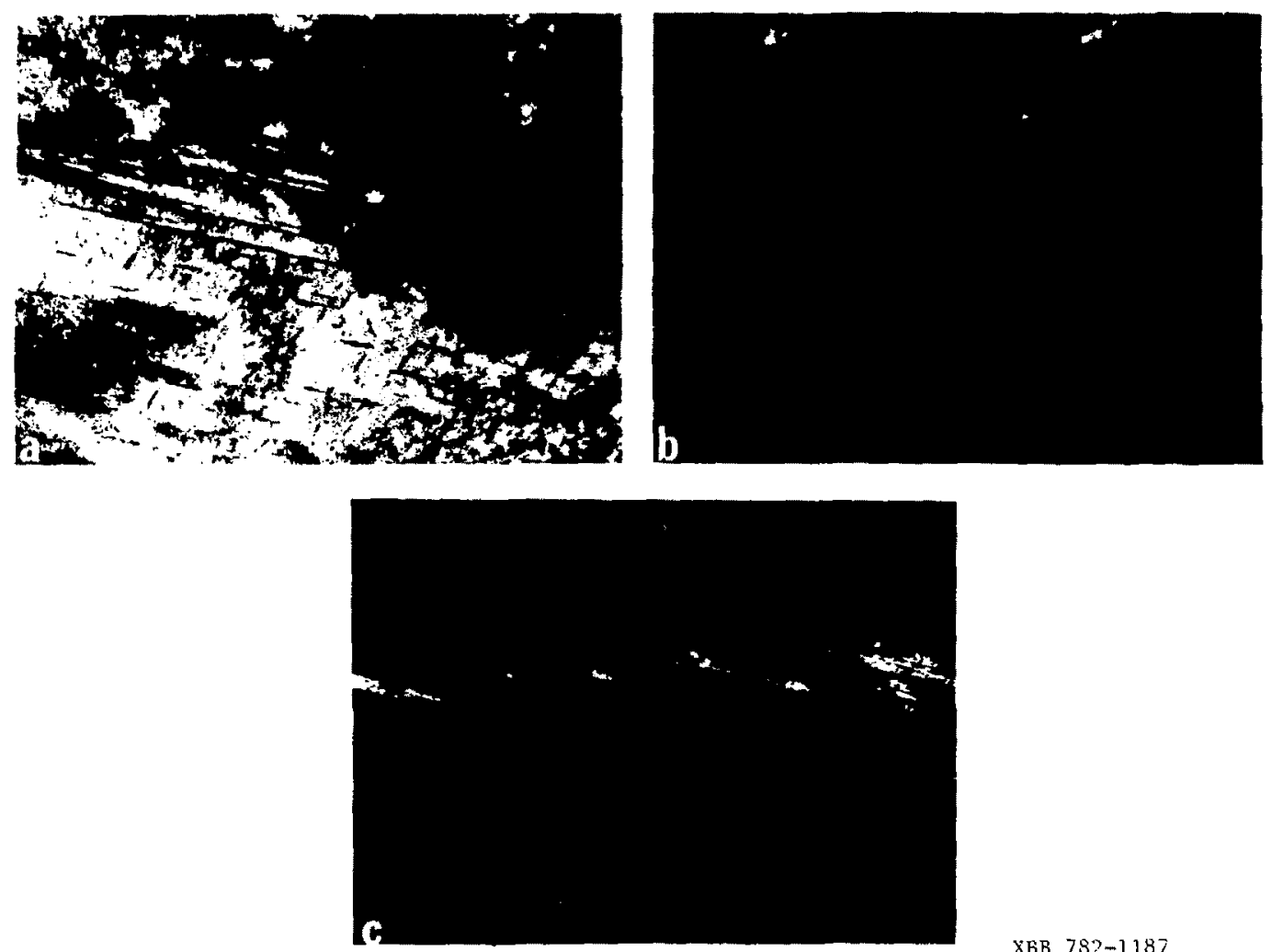

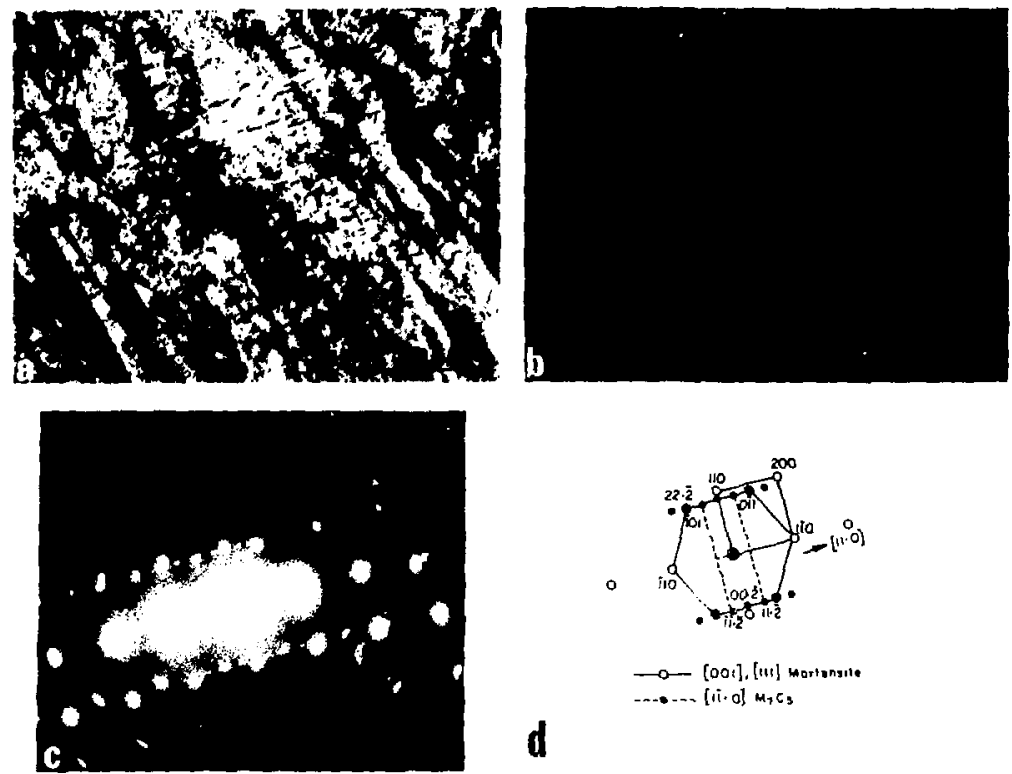

XBB $782-1172$

Fig. 18 


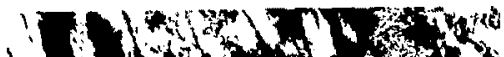

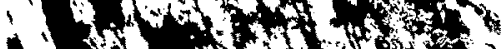

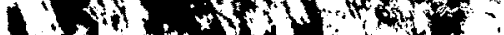

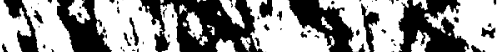

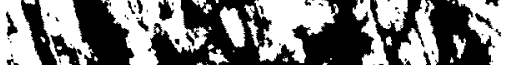
Dfia H

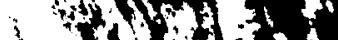

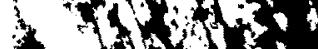

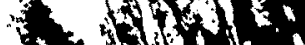

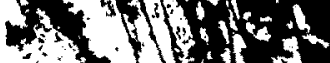

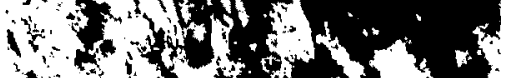

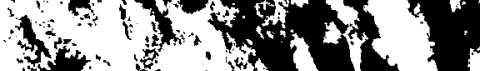

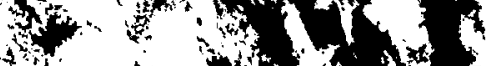

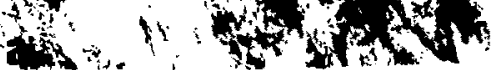
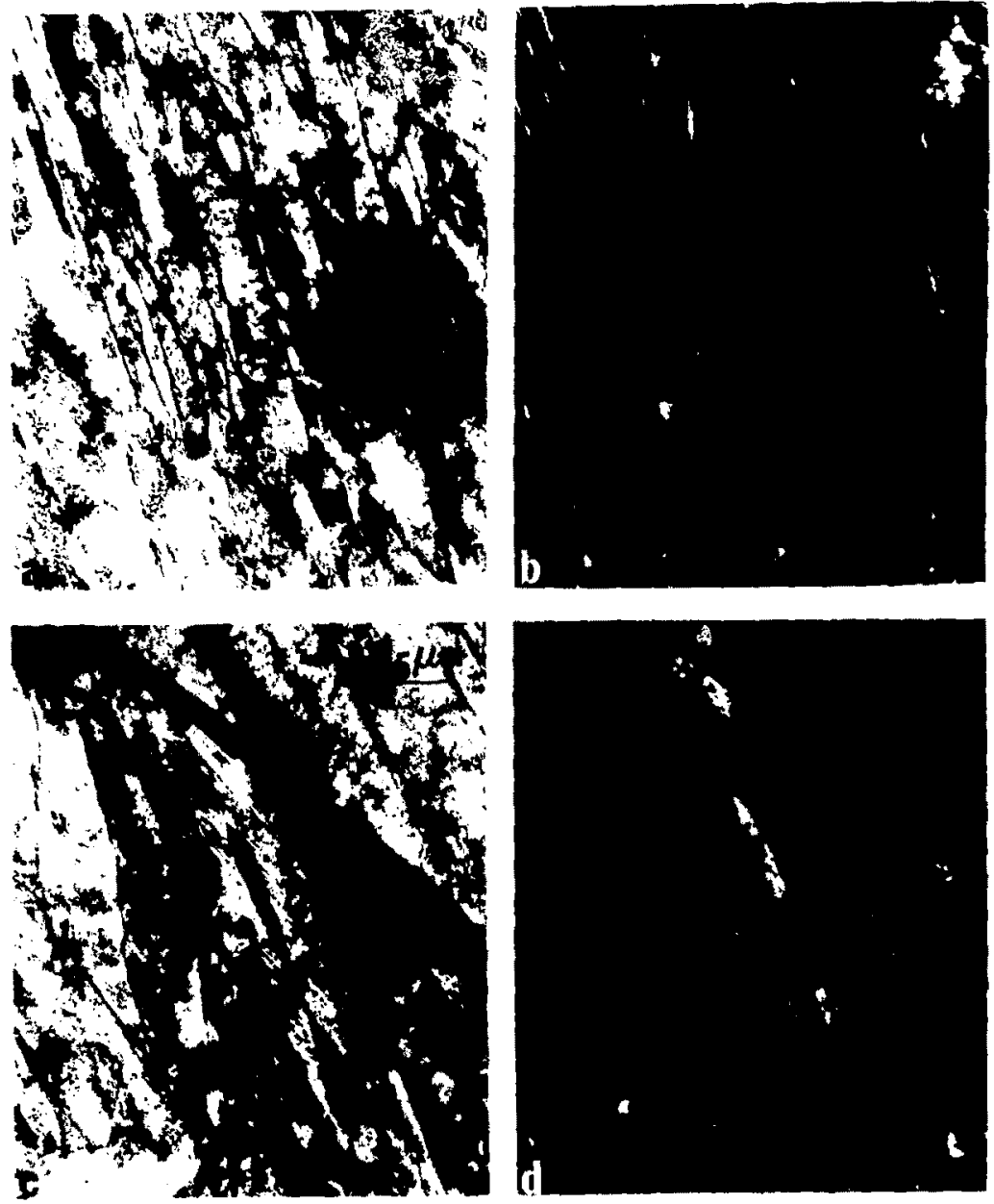

$X B B \quad 782-1055$ 

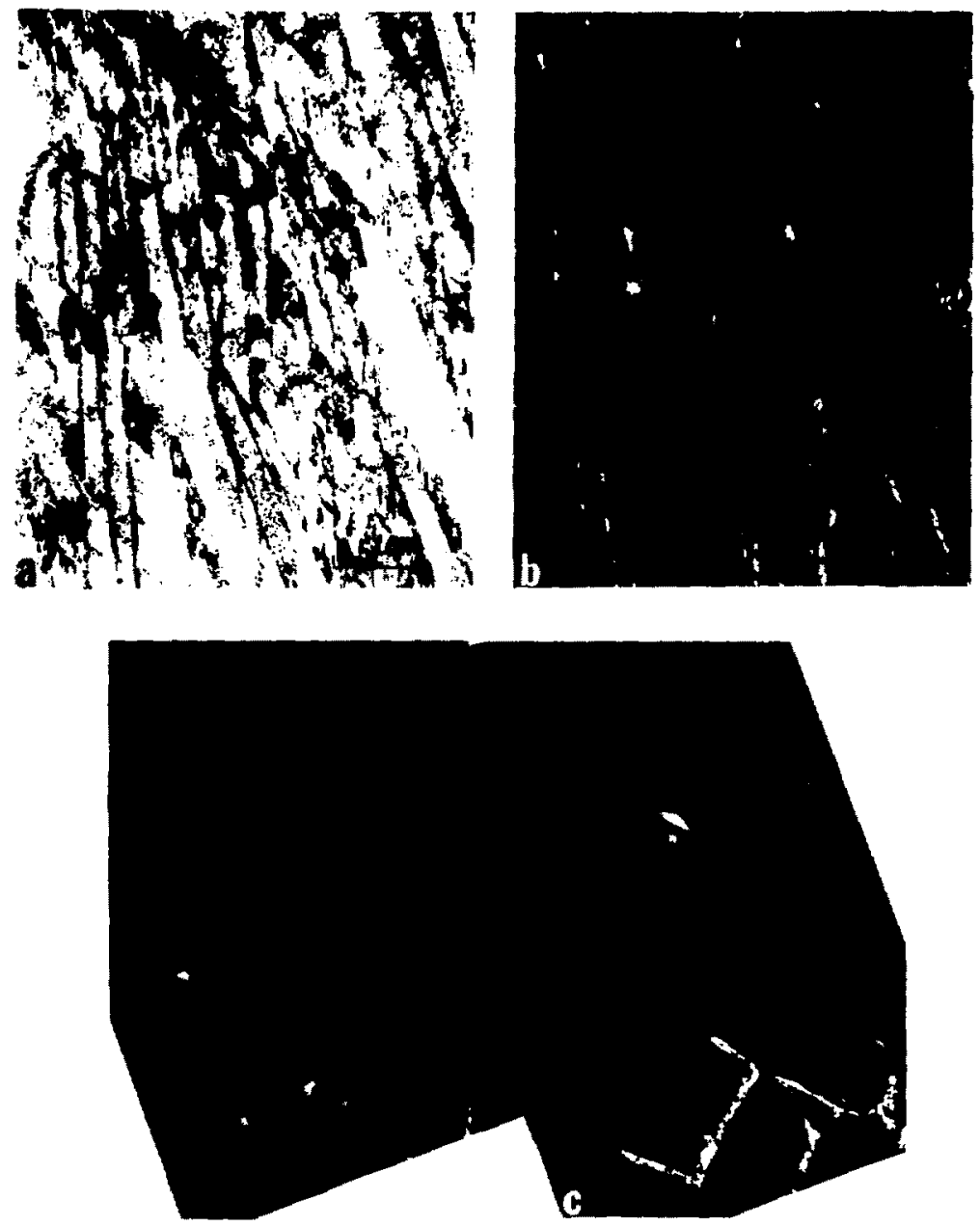

XBB $768-7130$ 

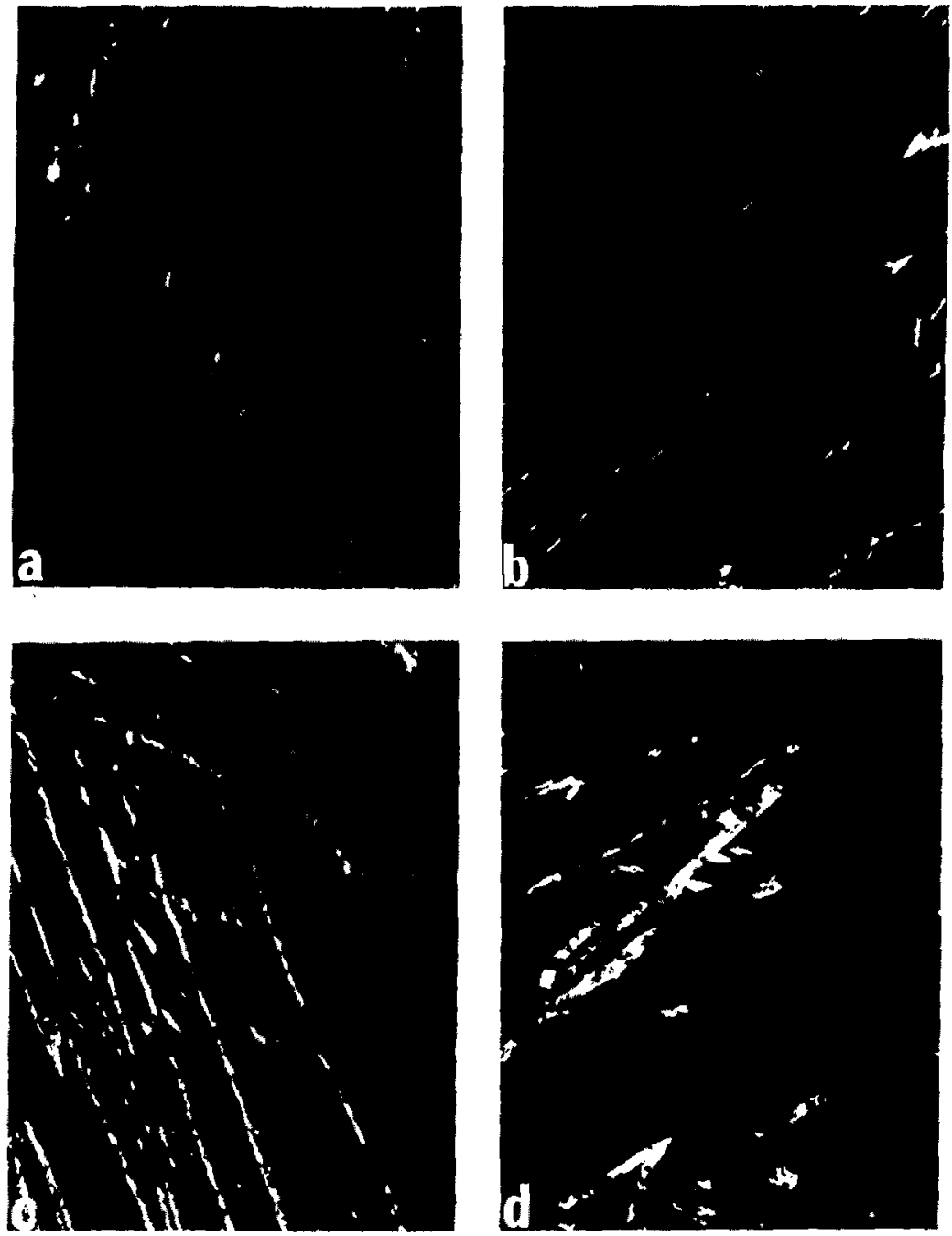

$\mathrm{XBB} \quad 774-3111$

Fig. 21 (amd) 

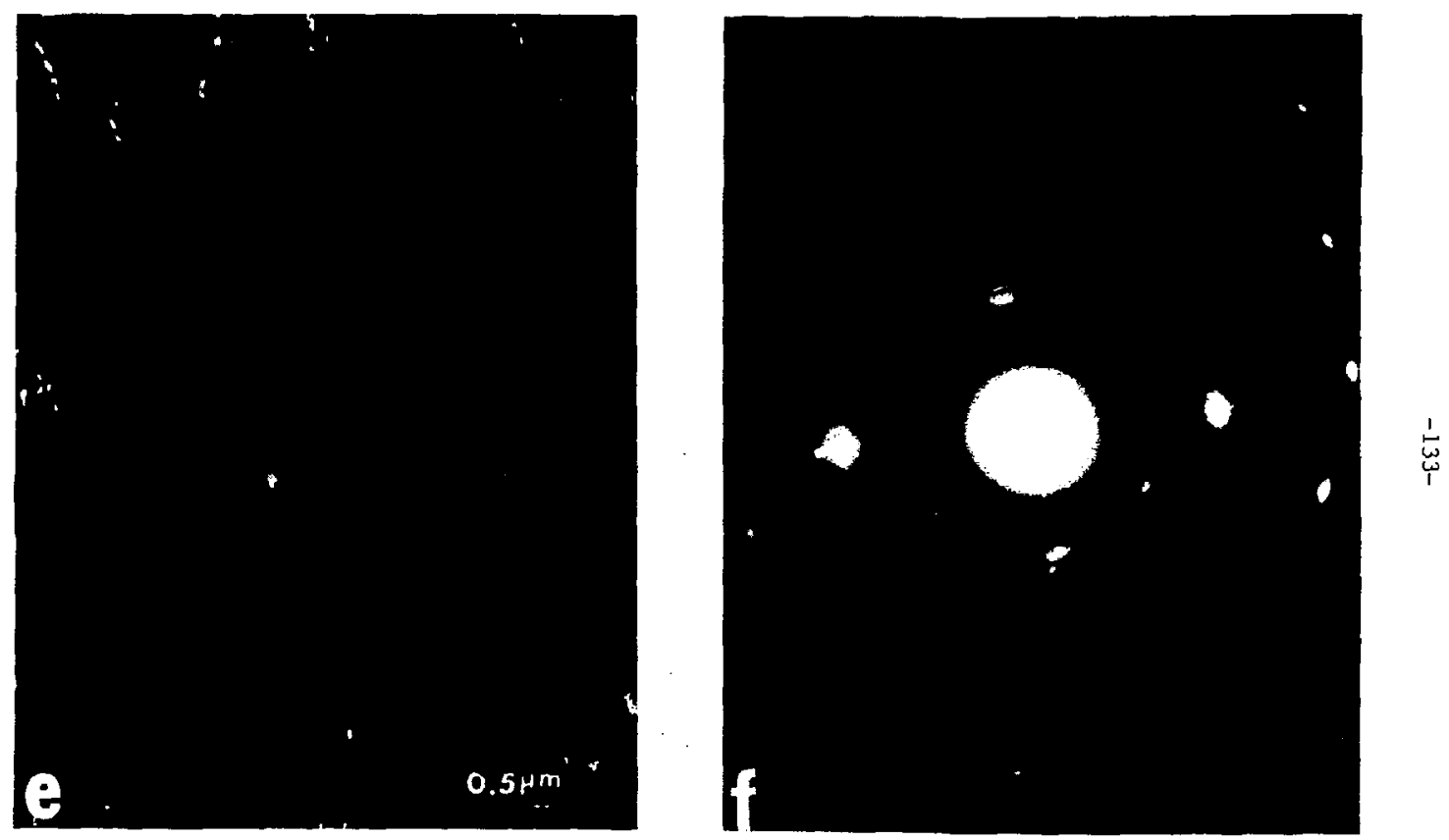

ХВB $774-3112$

Fig. 21 $(e-f)$ 
$-134-$

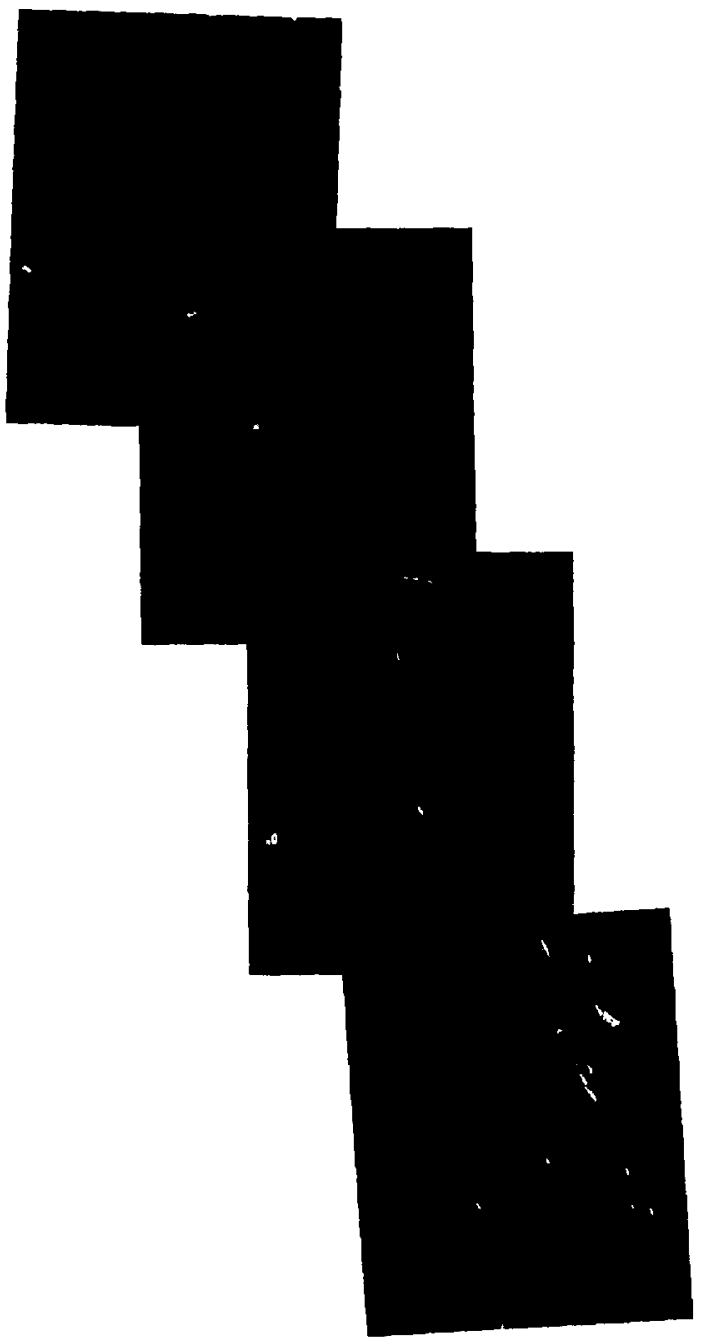

XBB $\quad 782-1054$

Fig. 22 

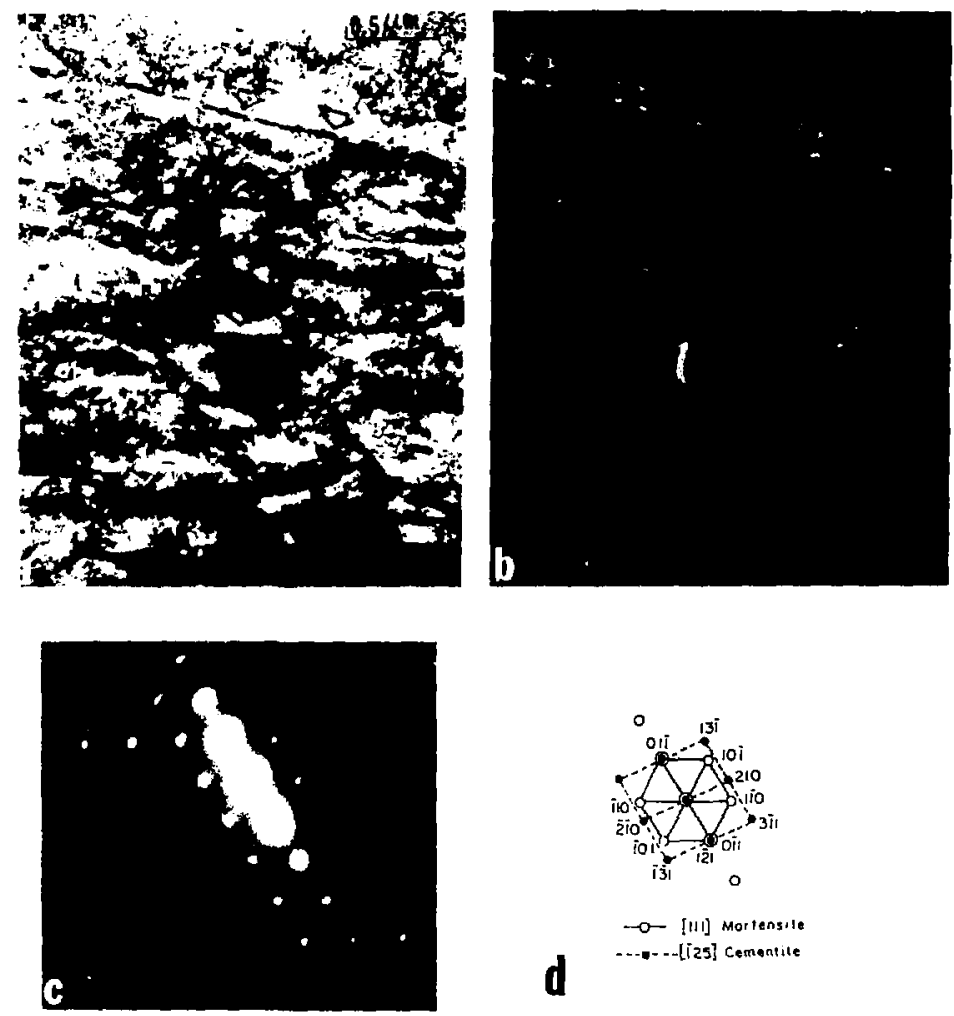

XBB $782-1178$

Fig. 23 

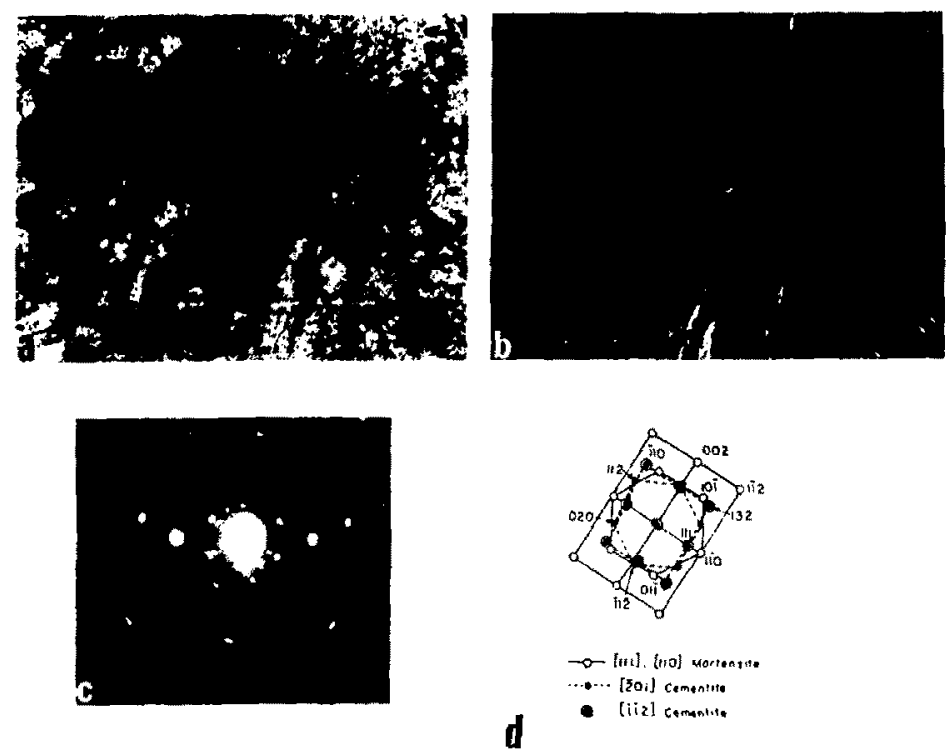

XBB $782-1174$

Fig. 24 

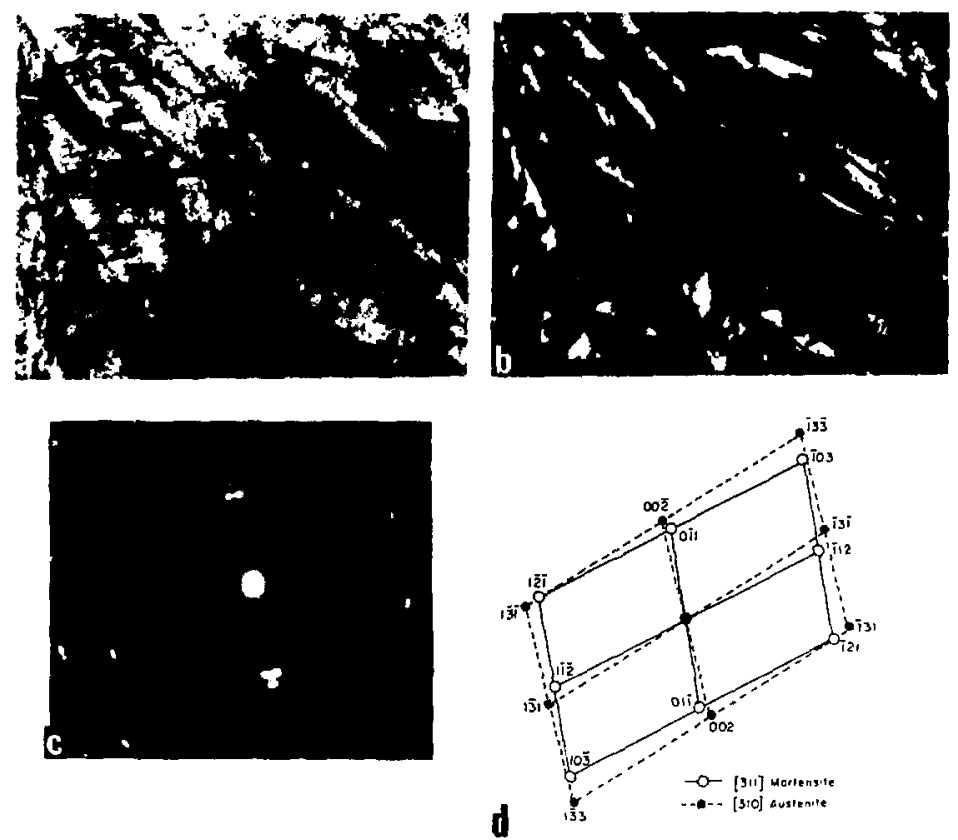

XBE $782-1181$

Fig. 25 

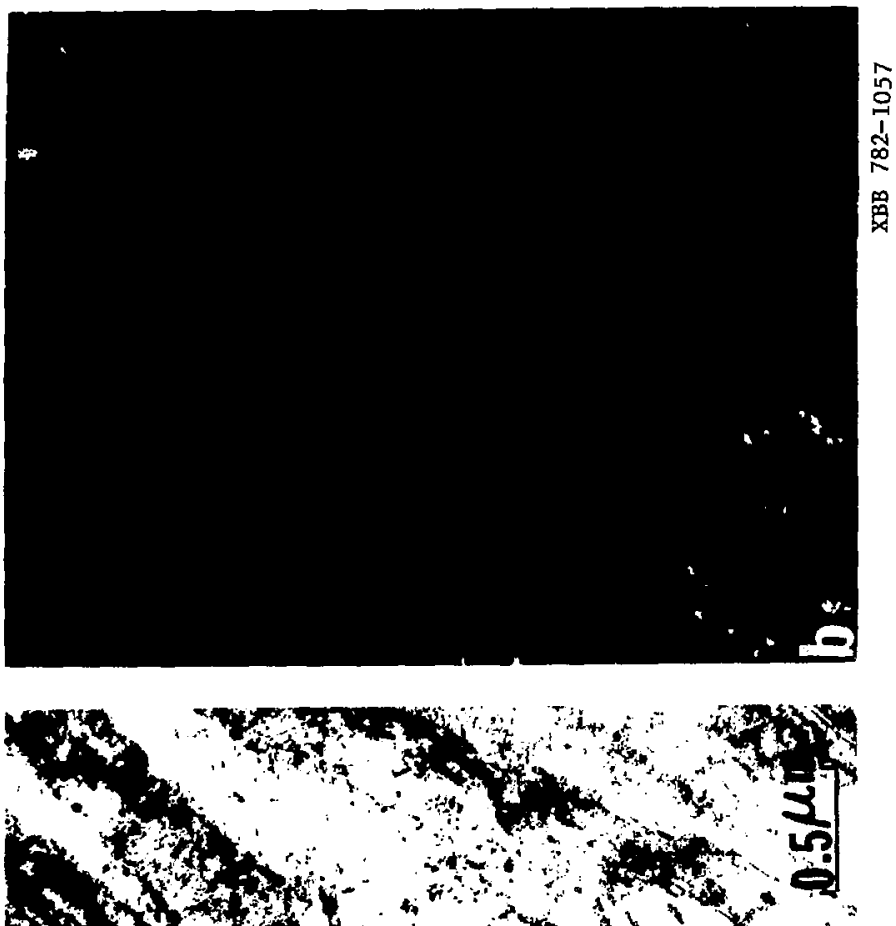

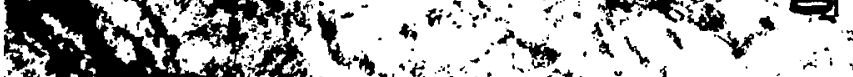

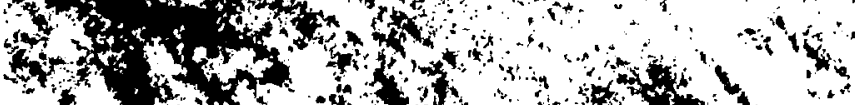

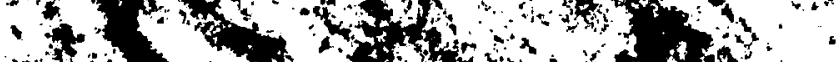

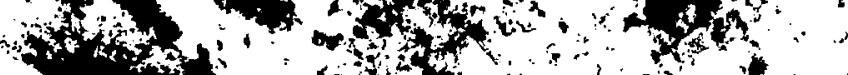
tom

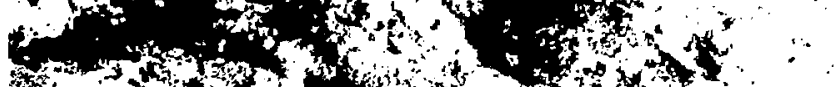

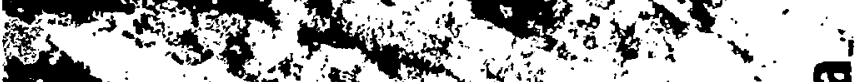

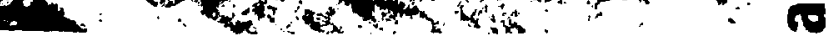




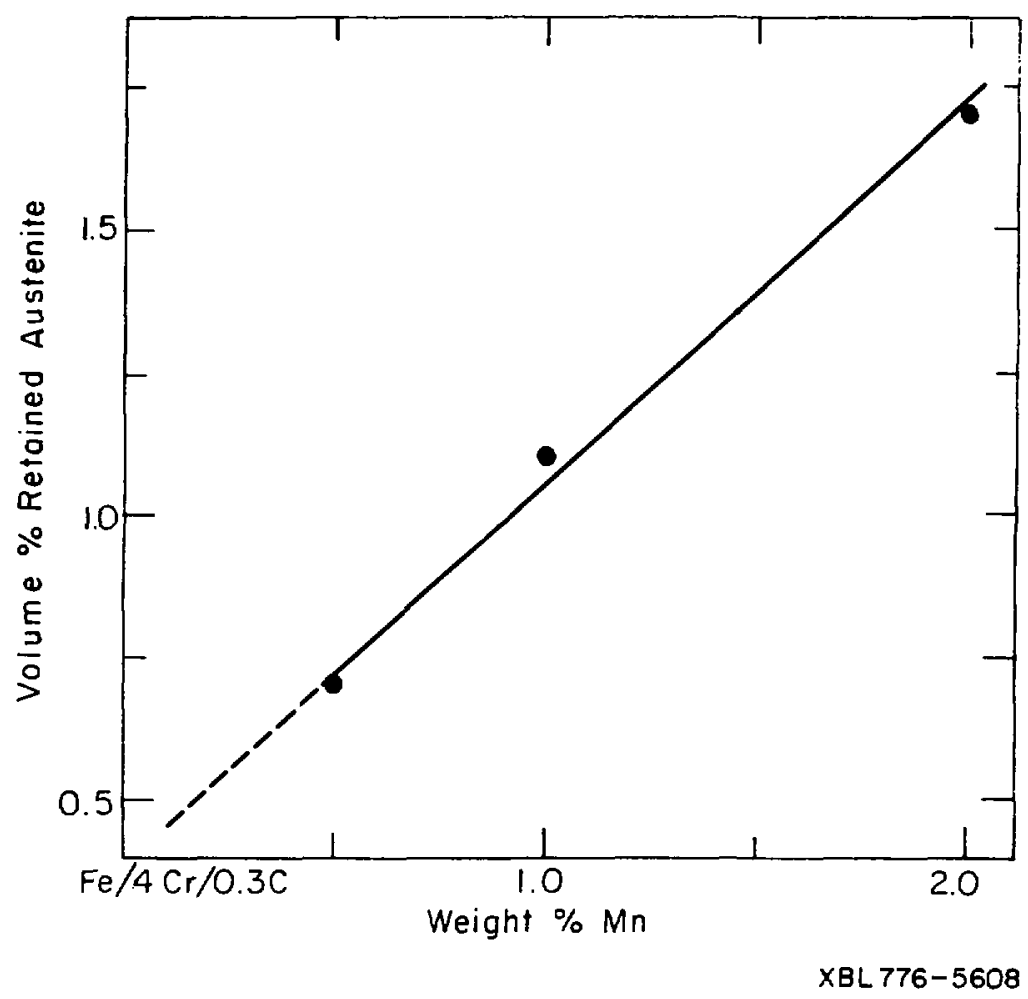

Fig. 27 


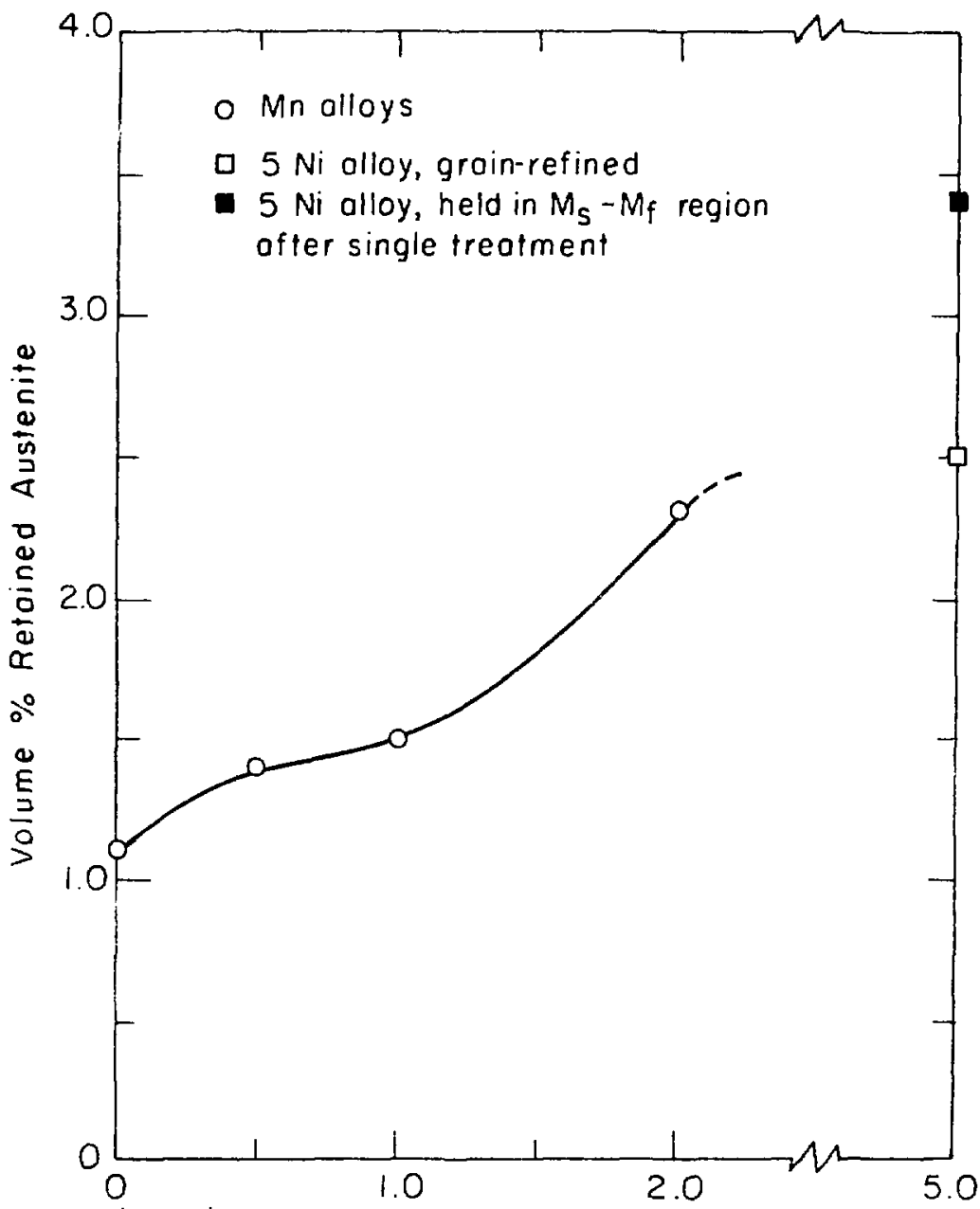

$\mathrm{Fe} / 4 \mathrm{Cr} / \mathrm{O} .3 \mathrm{C}$ Weight $\% \mathrm{Mn}$ or $\mathrm{Ni}$ 


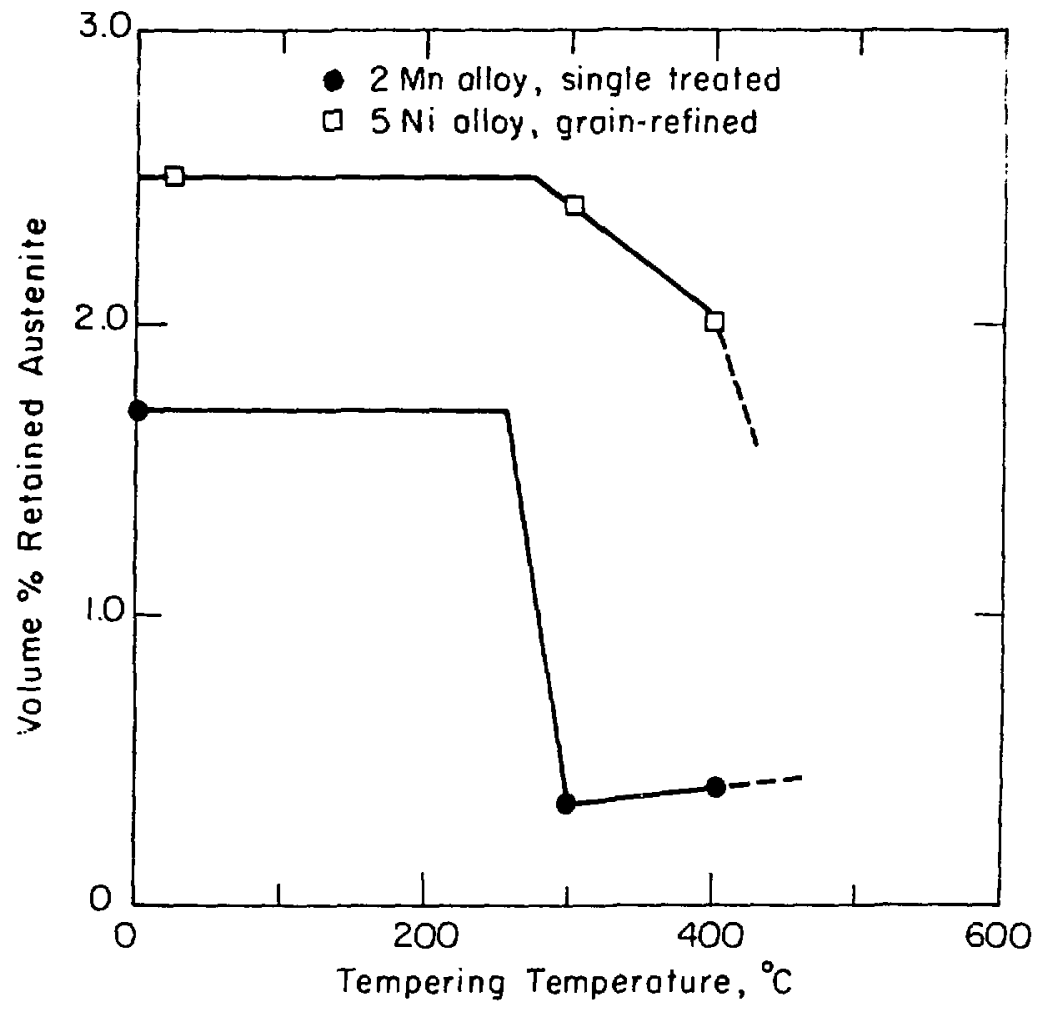

XBL $781-4425$

Fig. 29 


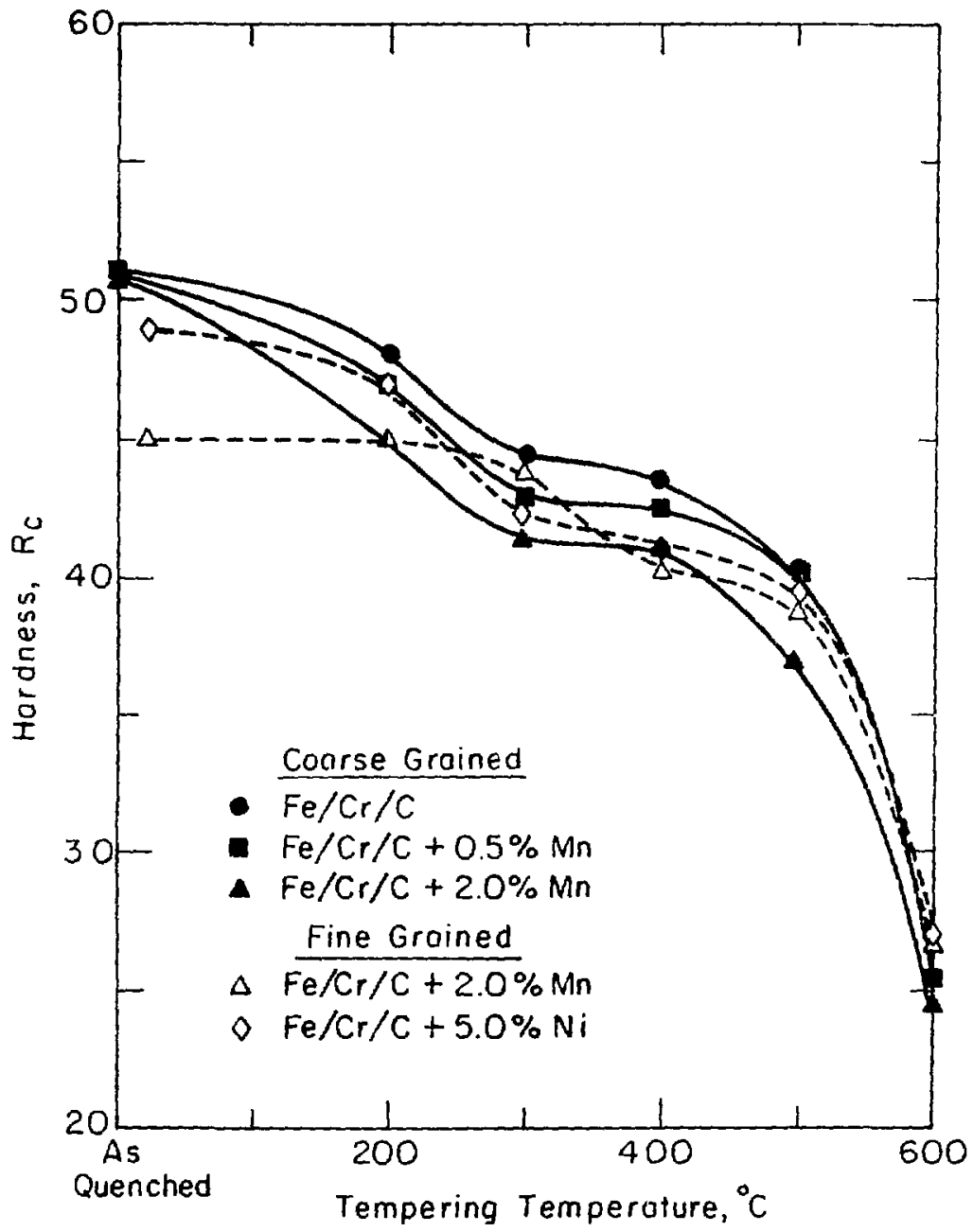

$X B L 781-4428$ 


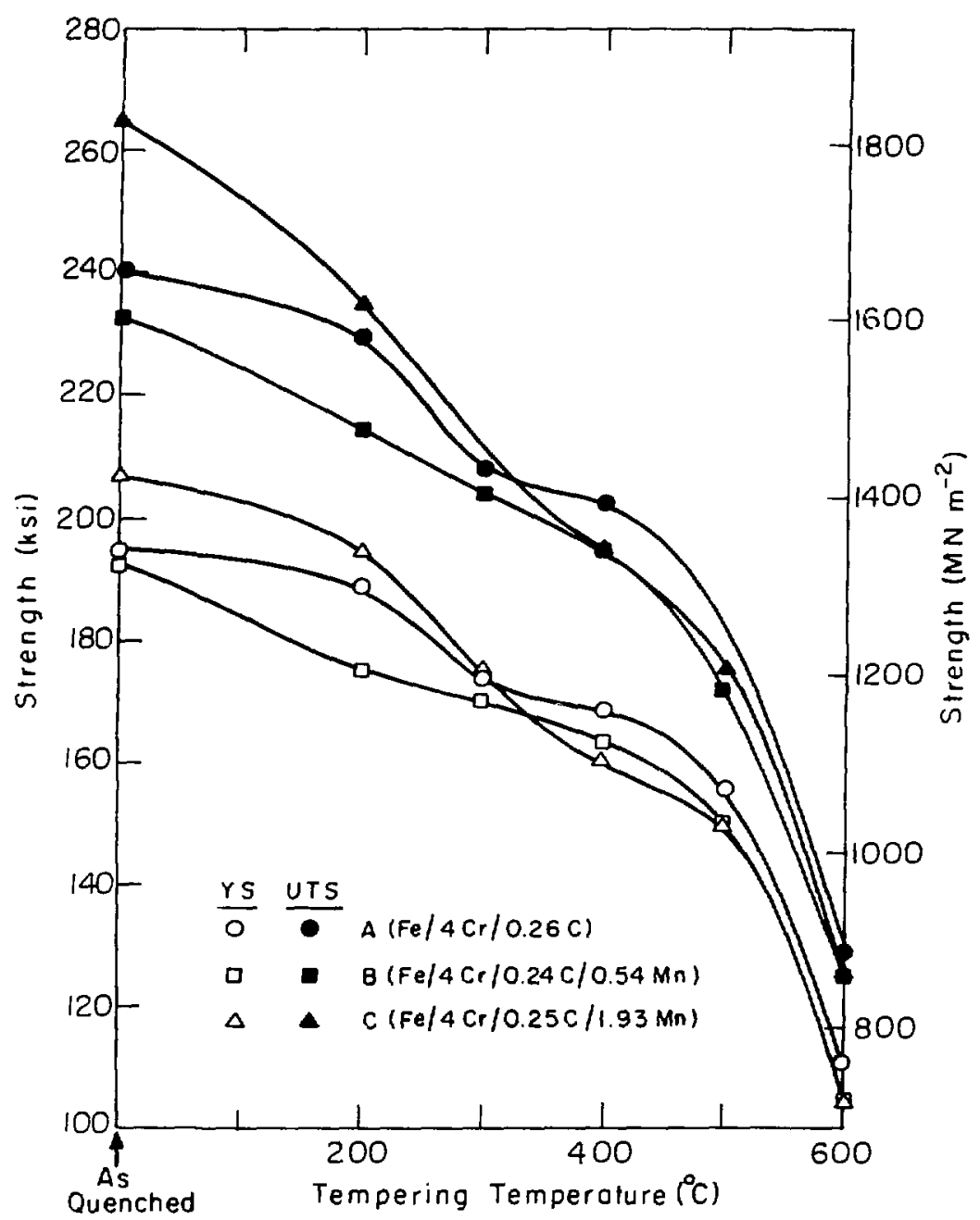

XBL 766-7001

Ffg. 31 


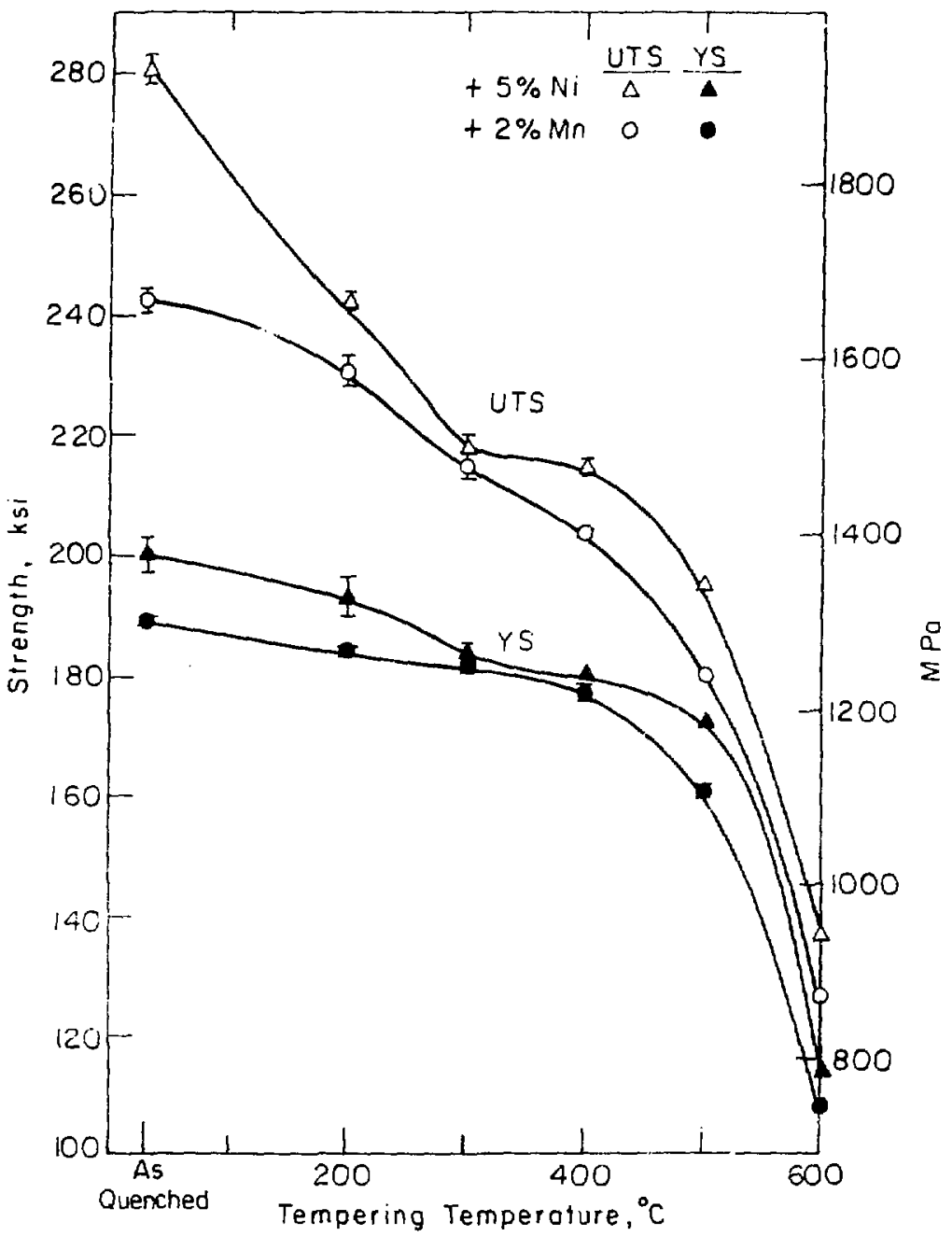

$X B L 78 /-4427$

Fig. 32 


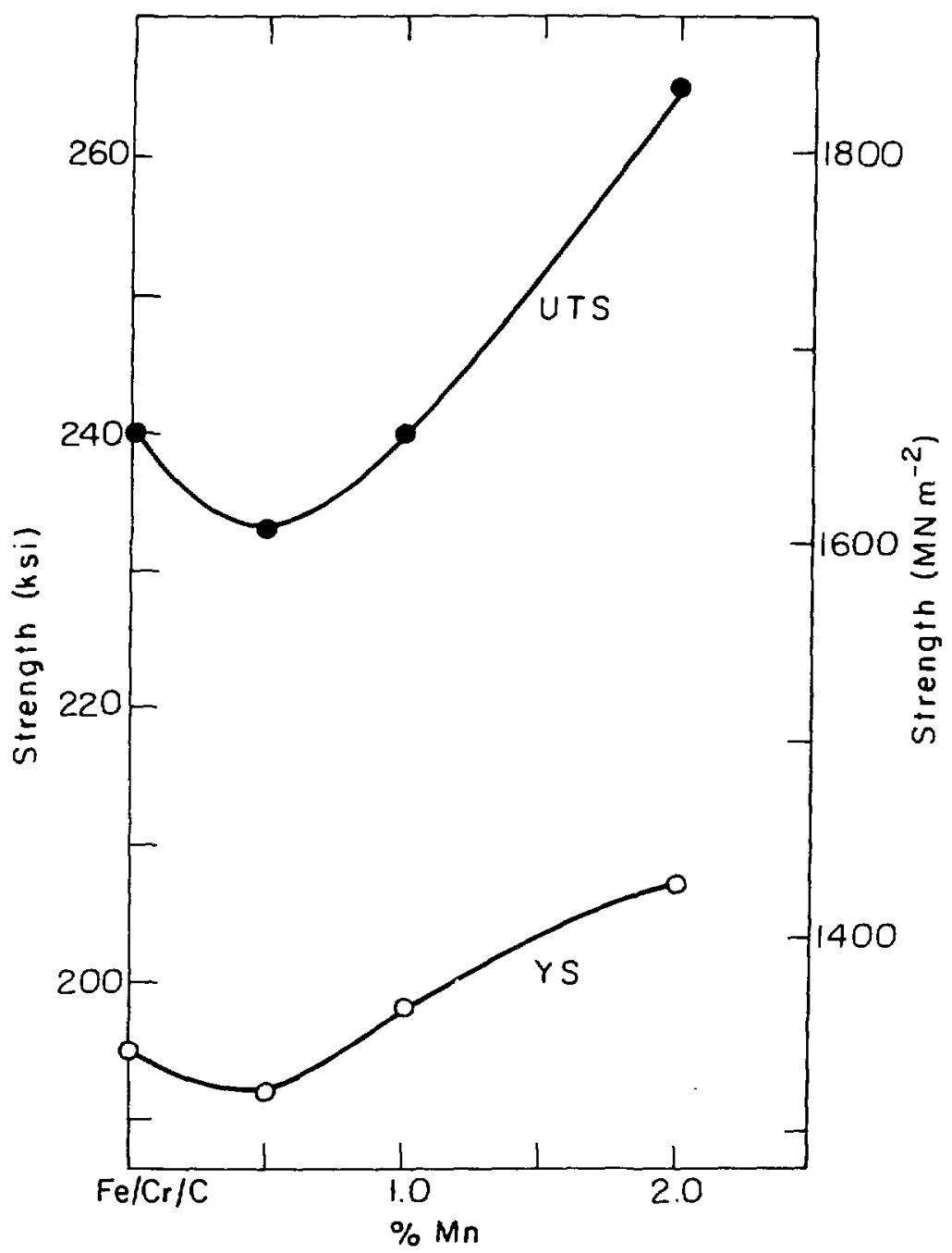

$X B L 76 \epsilon-7000$

E1g. 33 


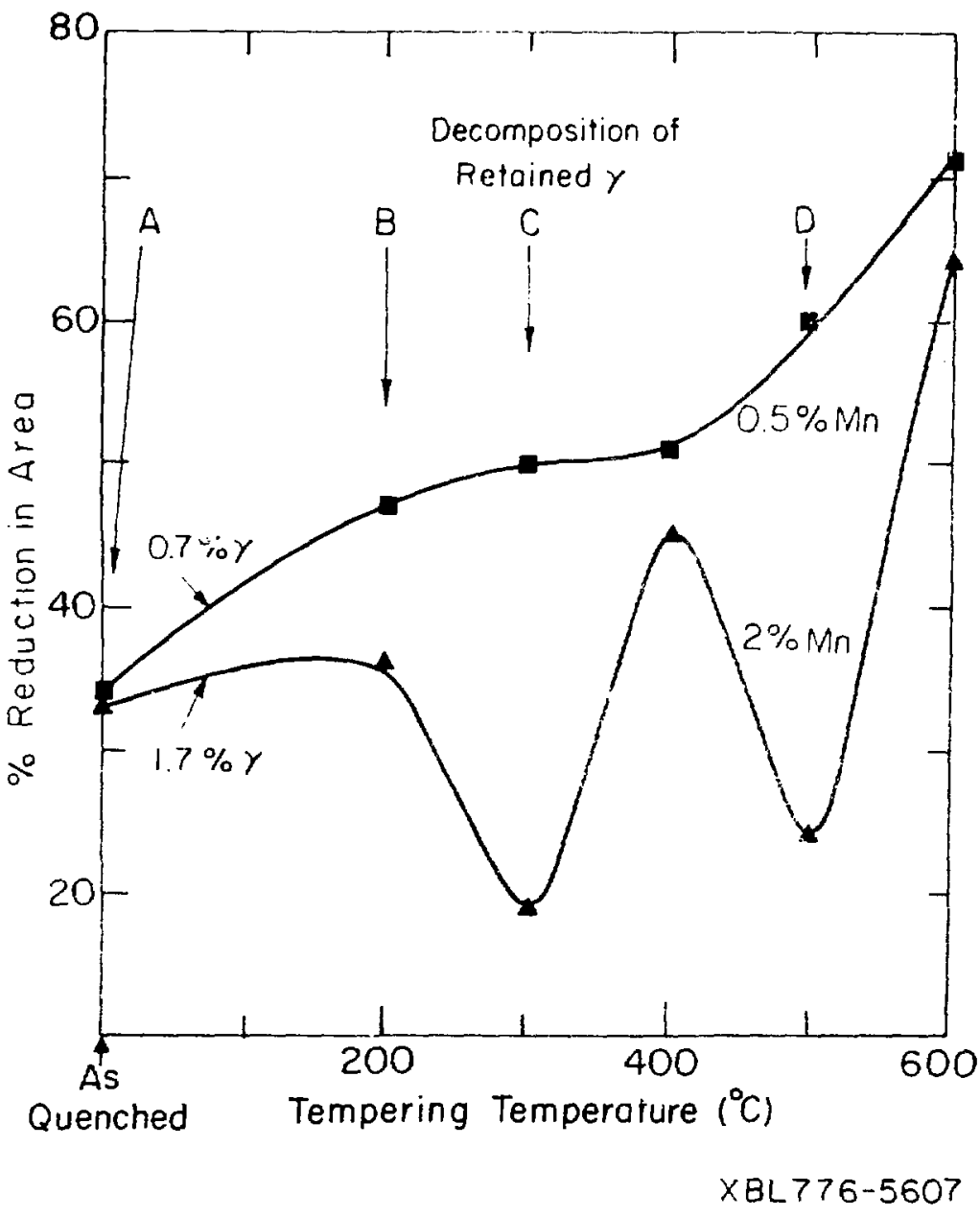

Fig. 34 (a) 


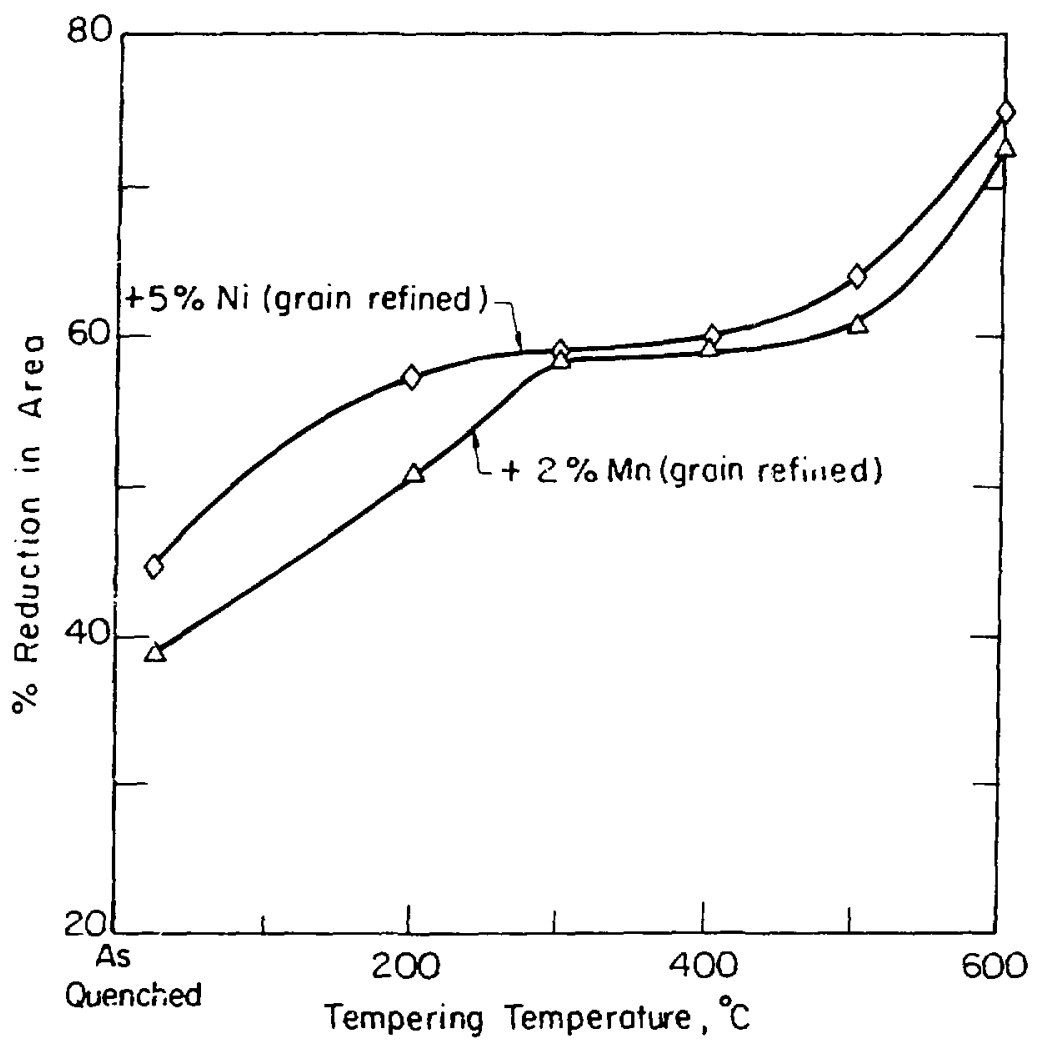

XBL 781.4436

Fig. 34 (b) 


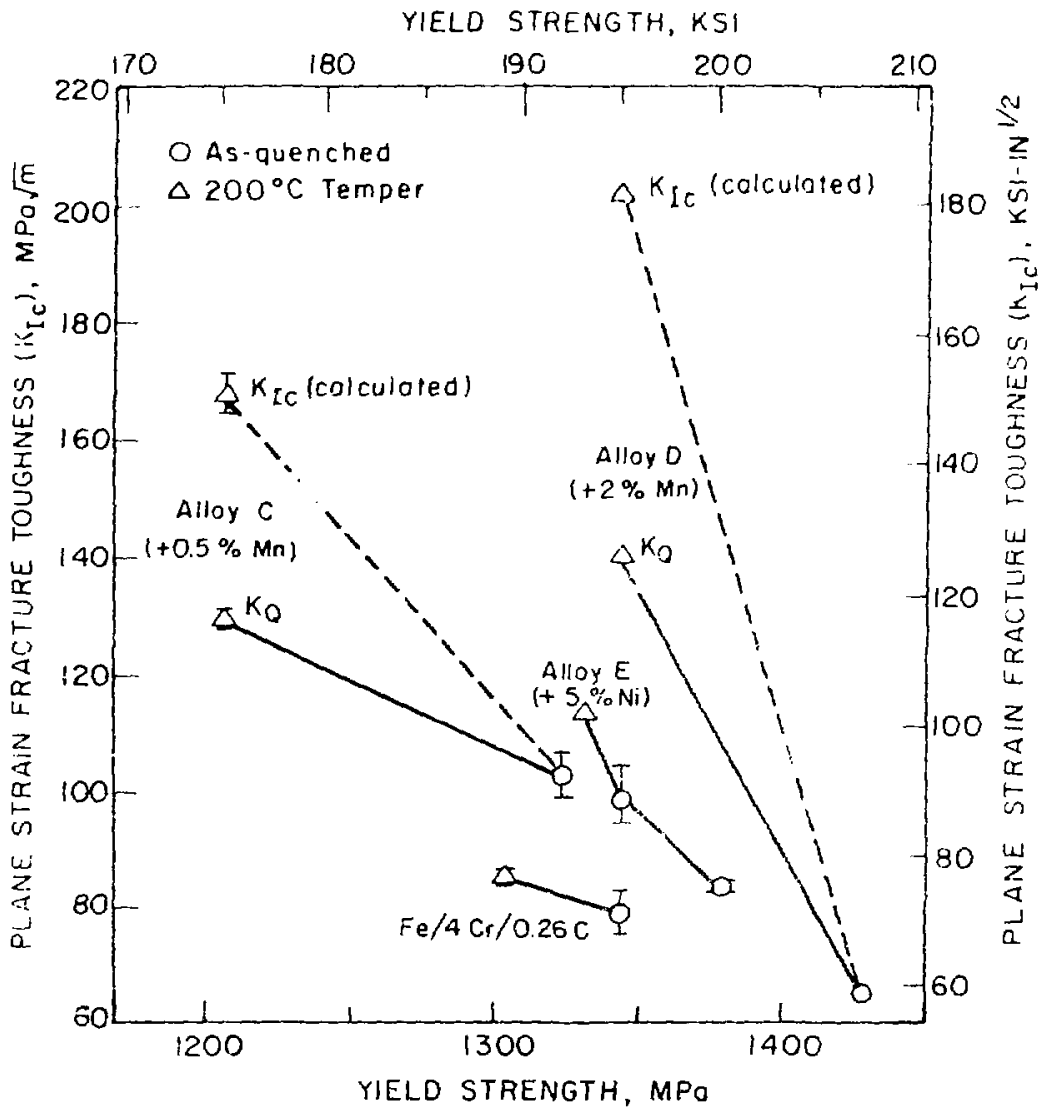

$X B L 7 E 4-6733$

Fig. jj 


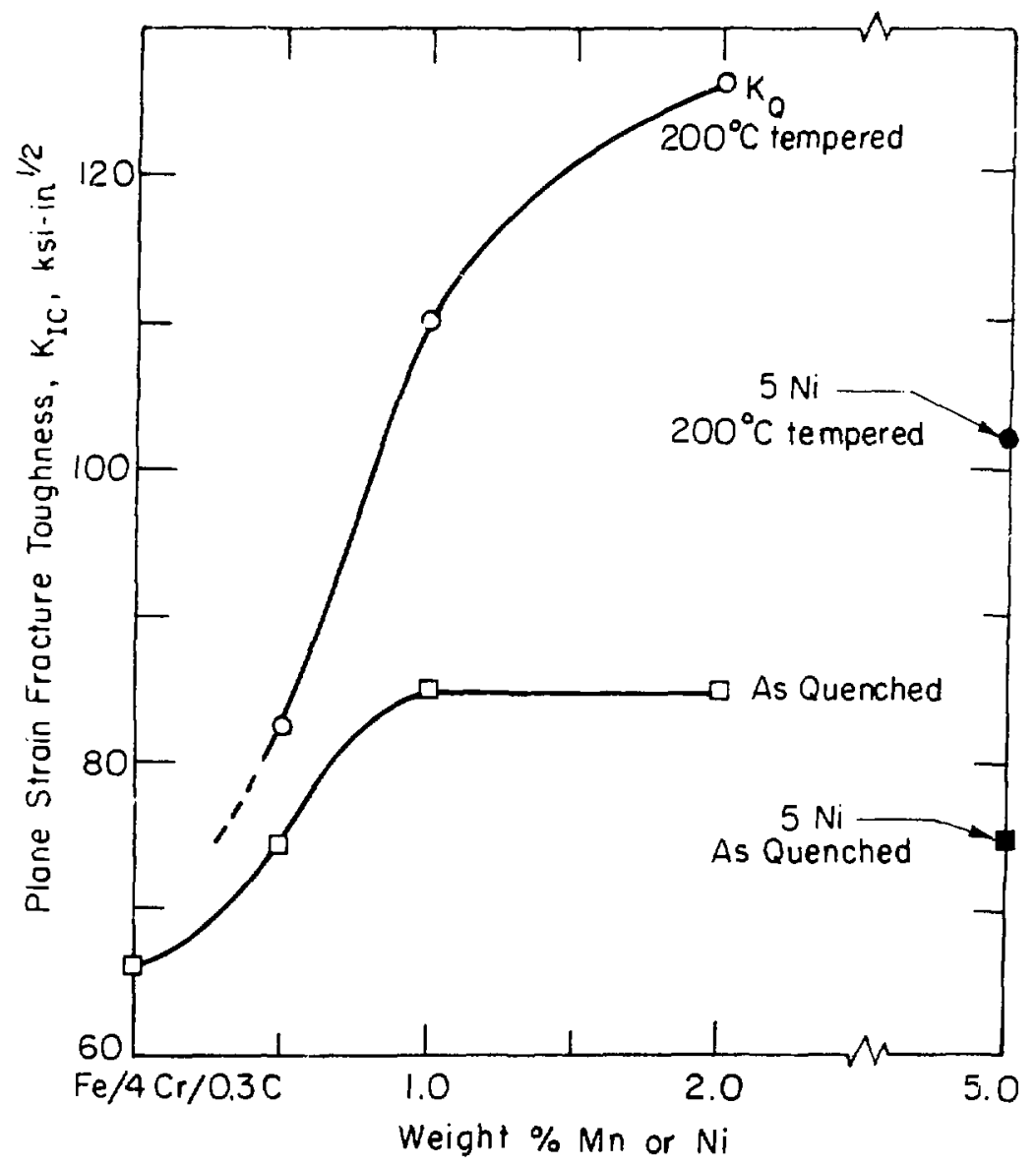

XEL $781-4437$

Fig. 36 


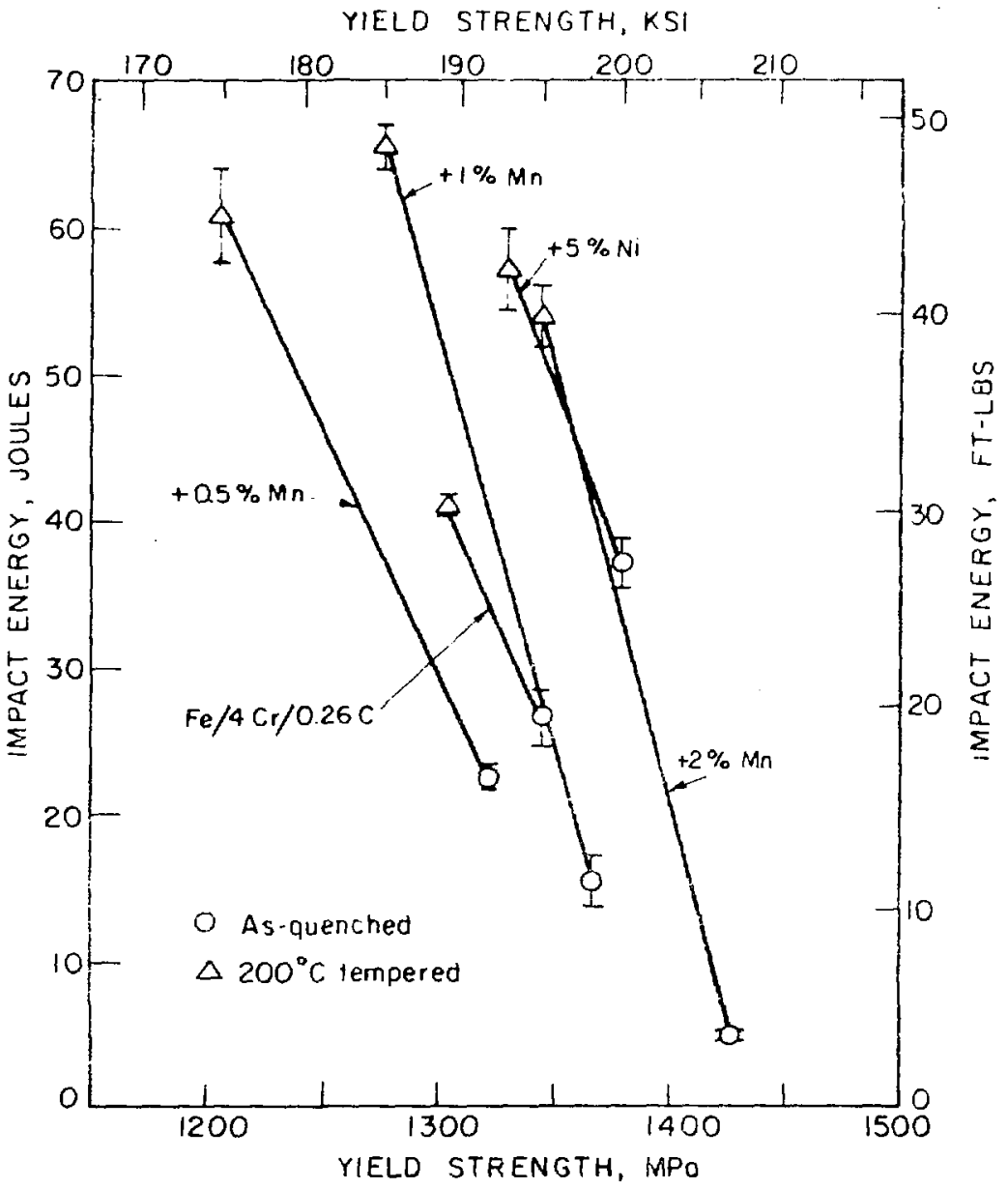

$X B L 764-6732 A$

F1g. 37 


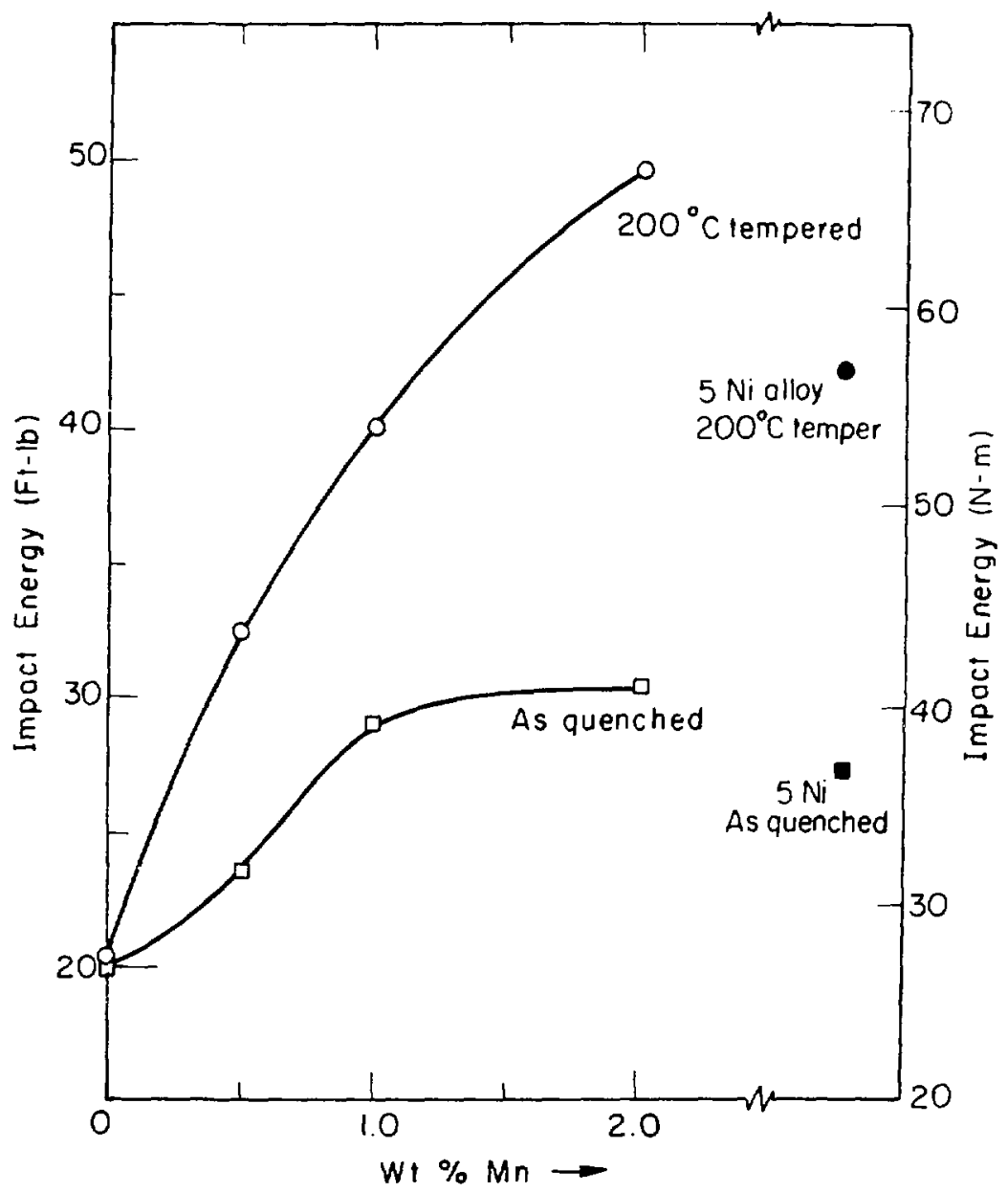

XBL 774-5303

Fig. 38 


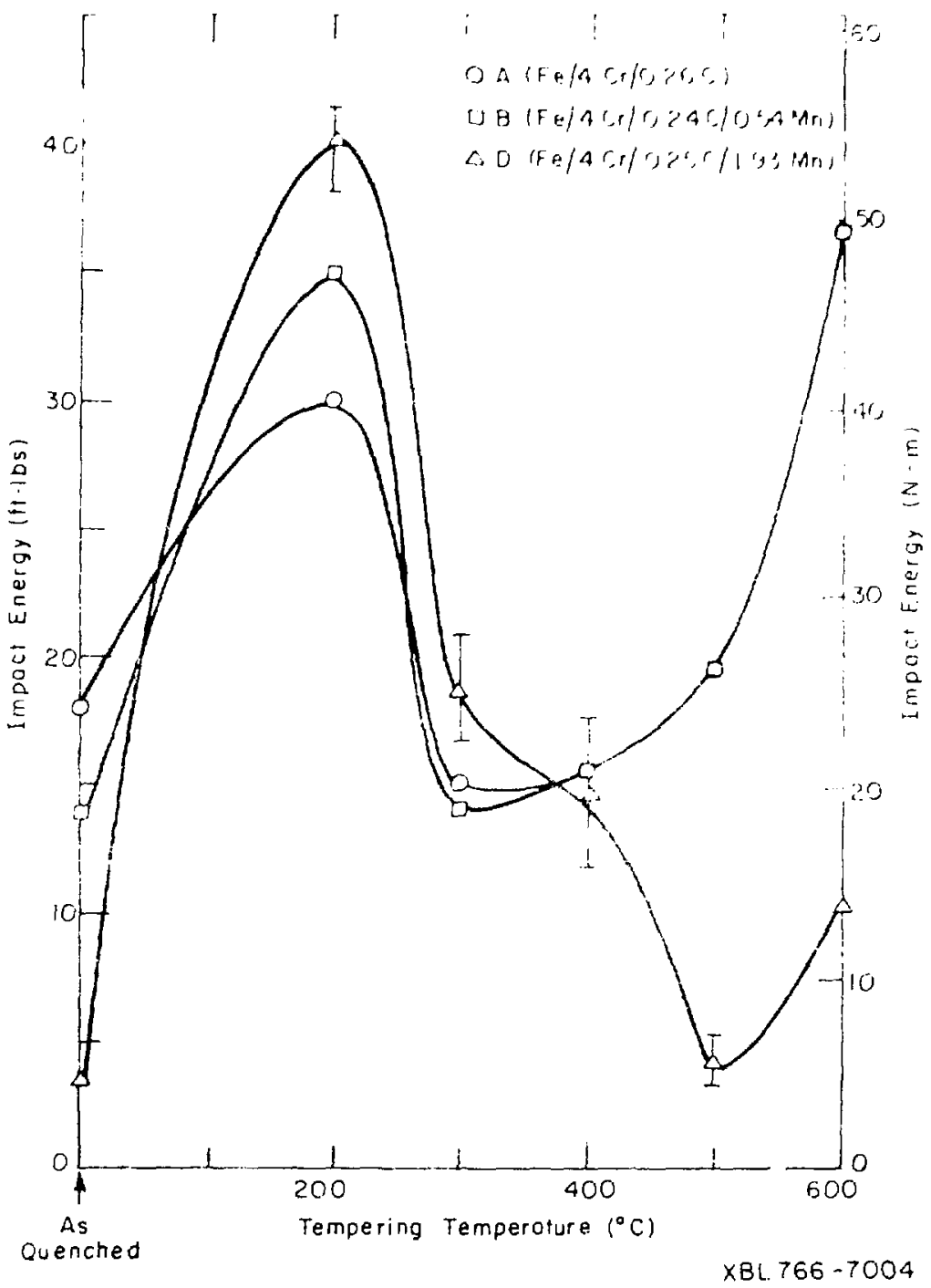

Fig. 39 


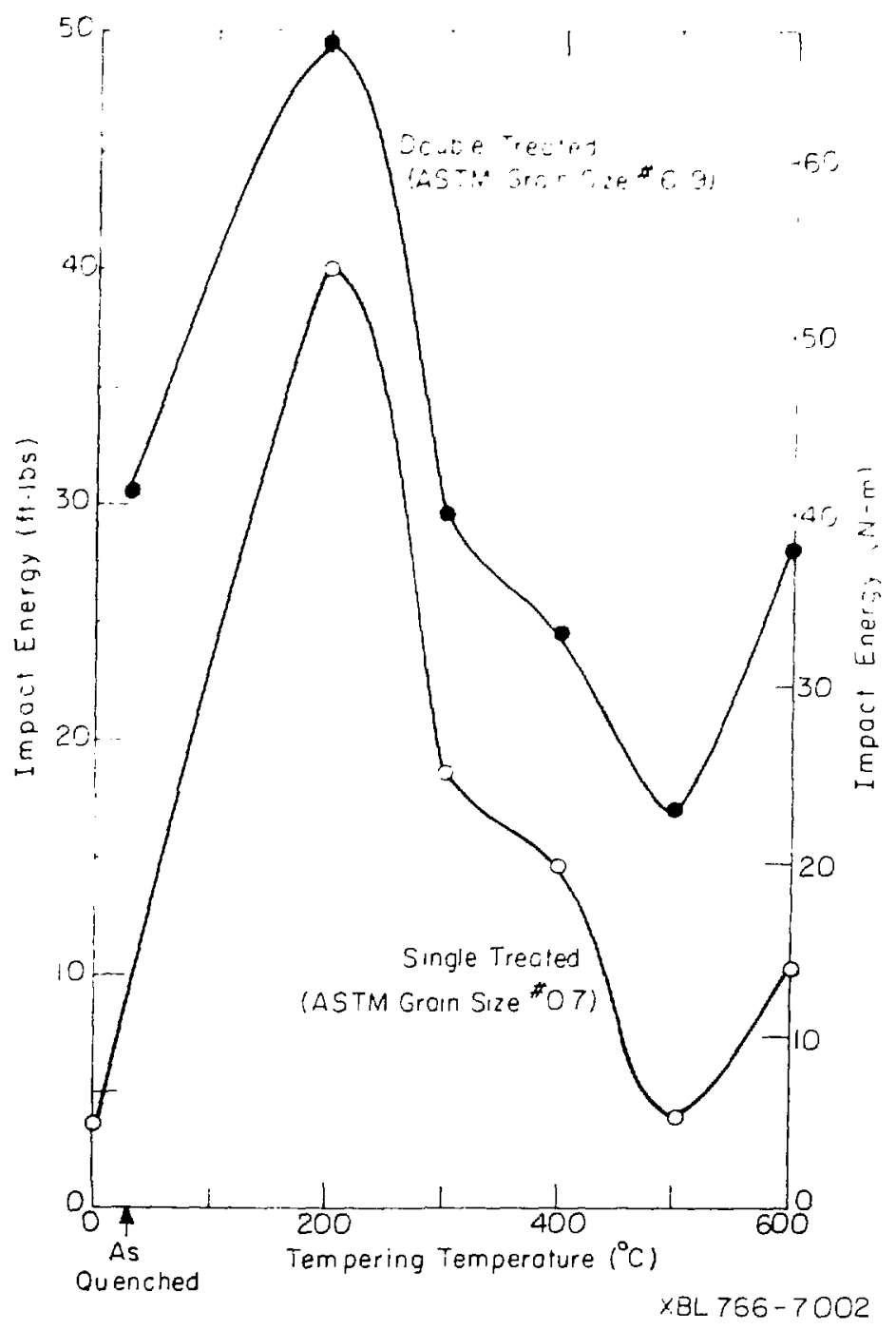

Fig. $4 C$ 


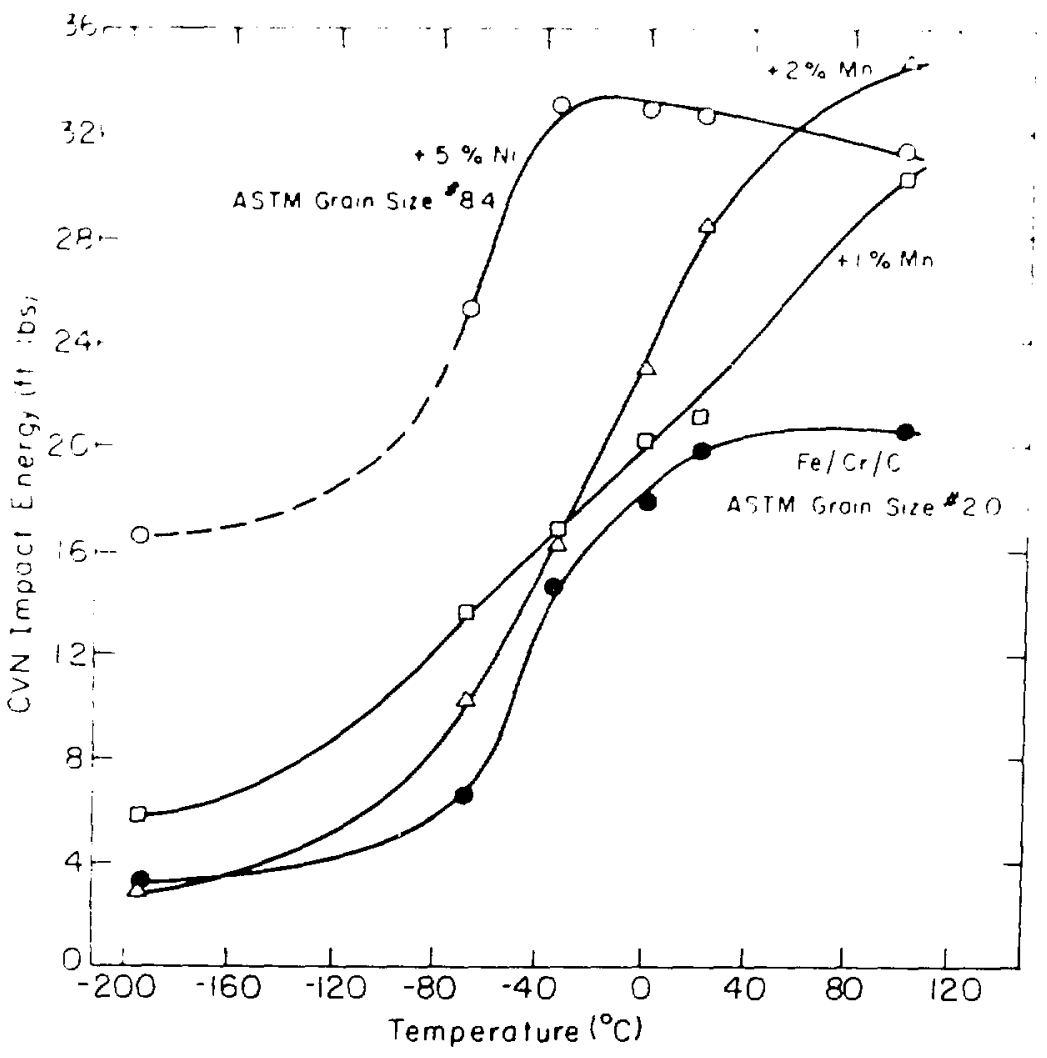

XBL 766-6999

Fig. 42 

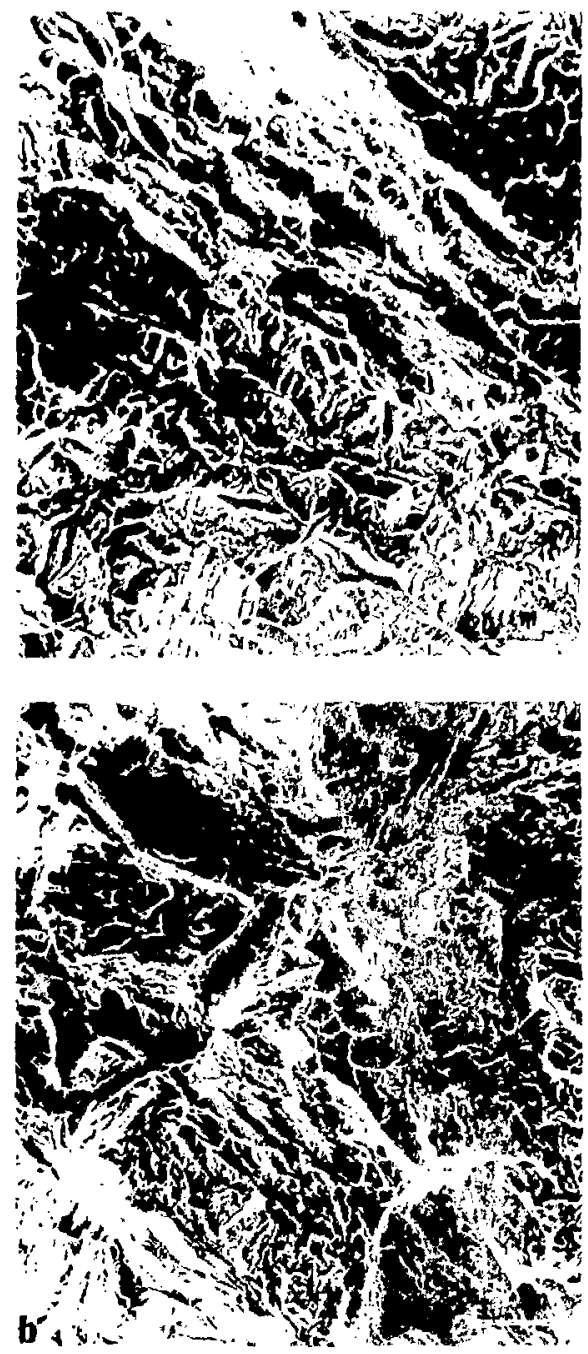

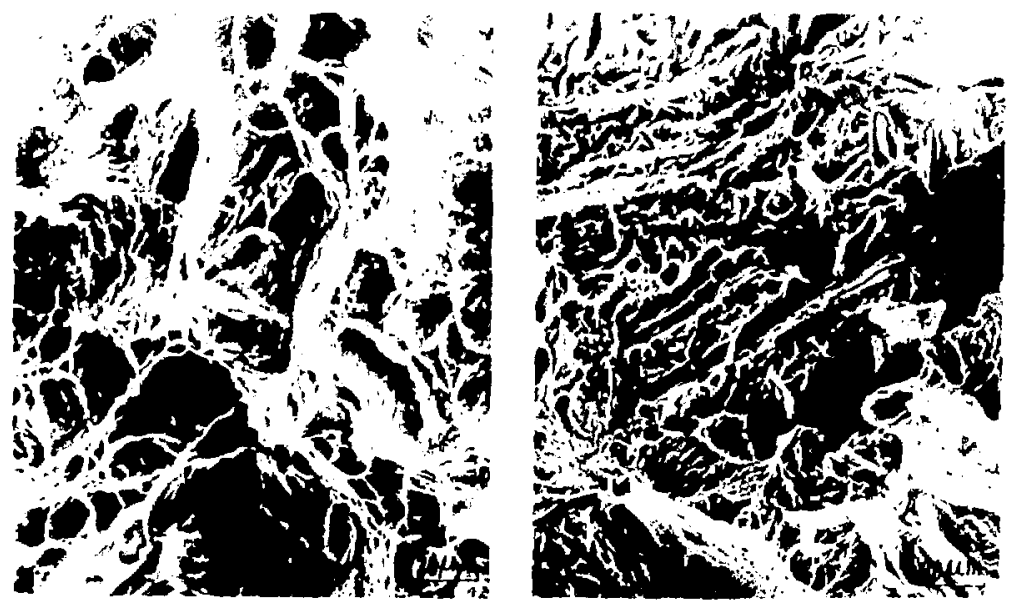

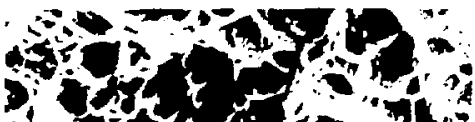

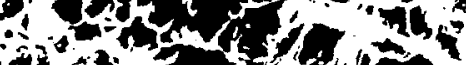

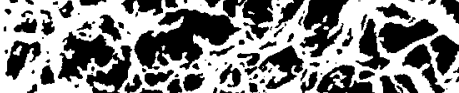

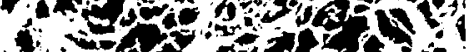

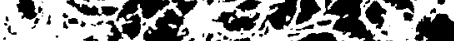

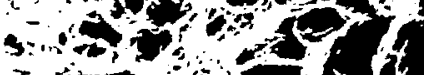
$\because 3,0<1+1)$

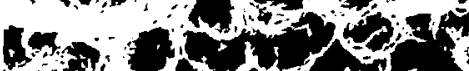

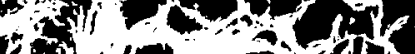

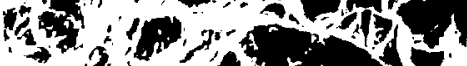

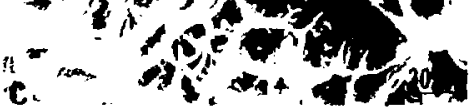

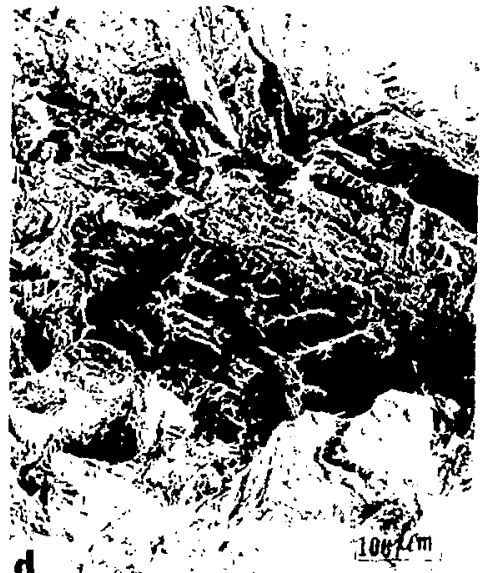



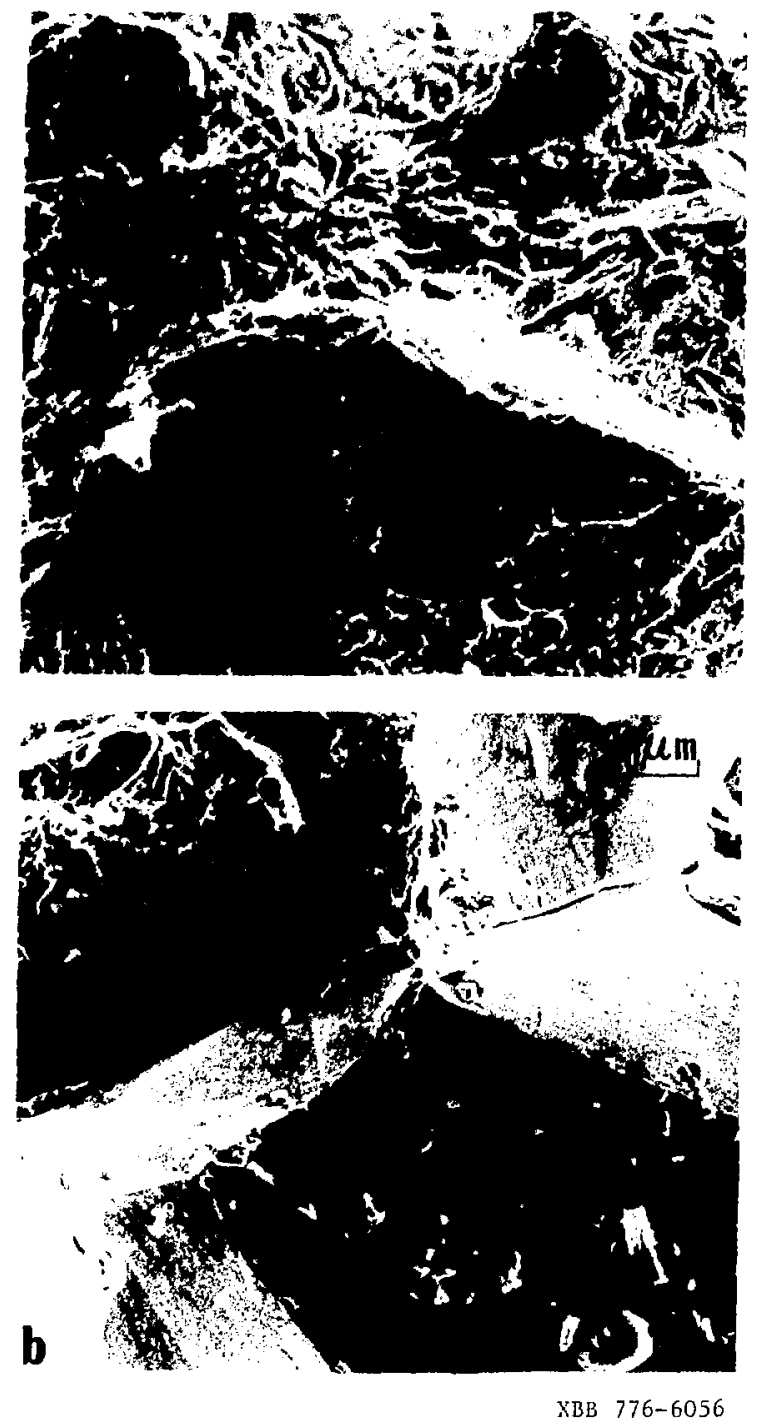

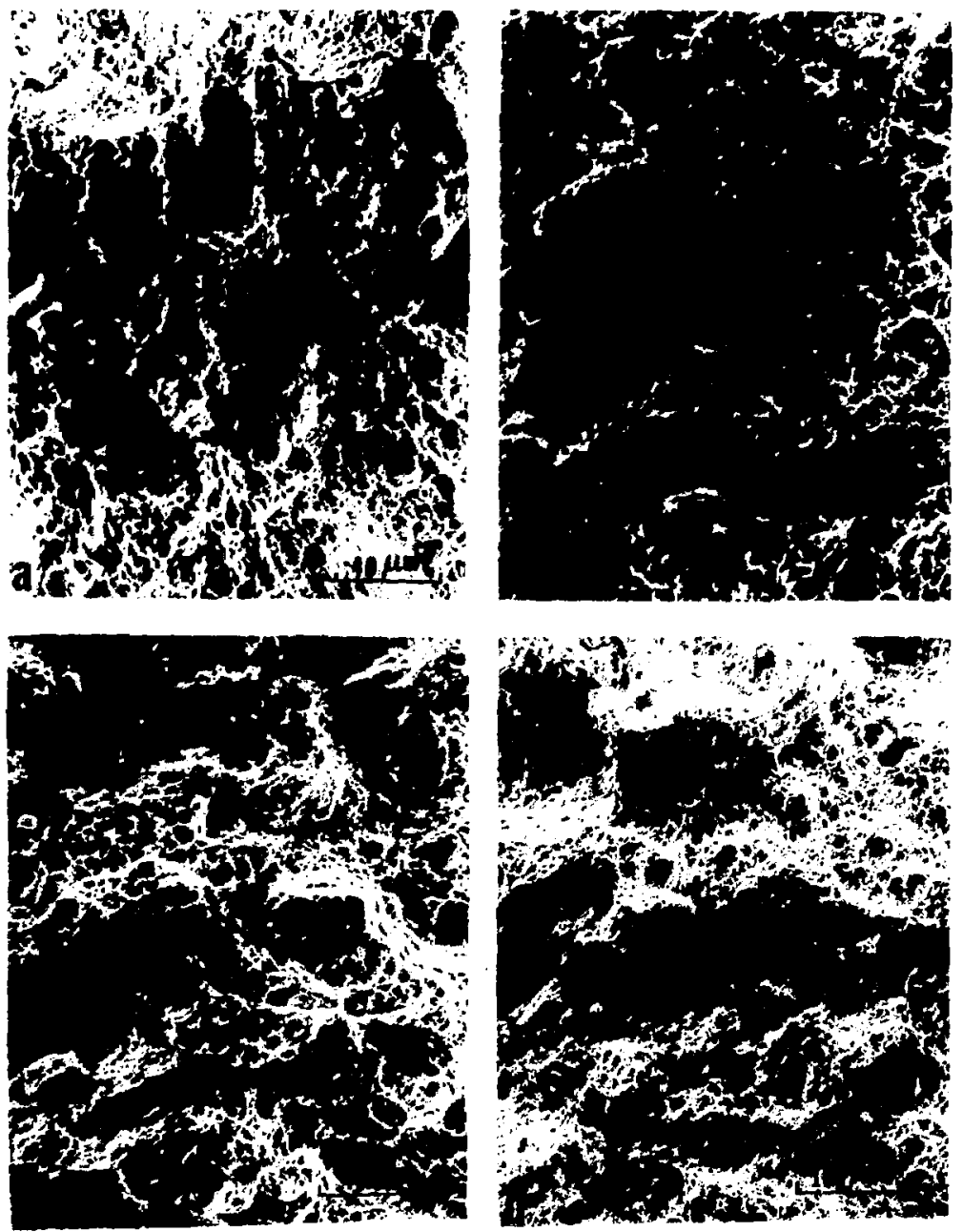

XBB $782-1184$ 

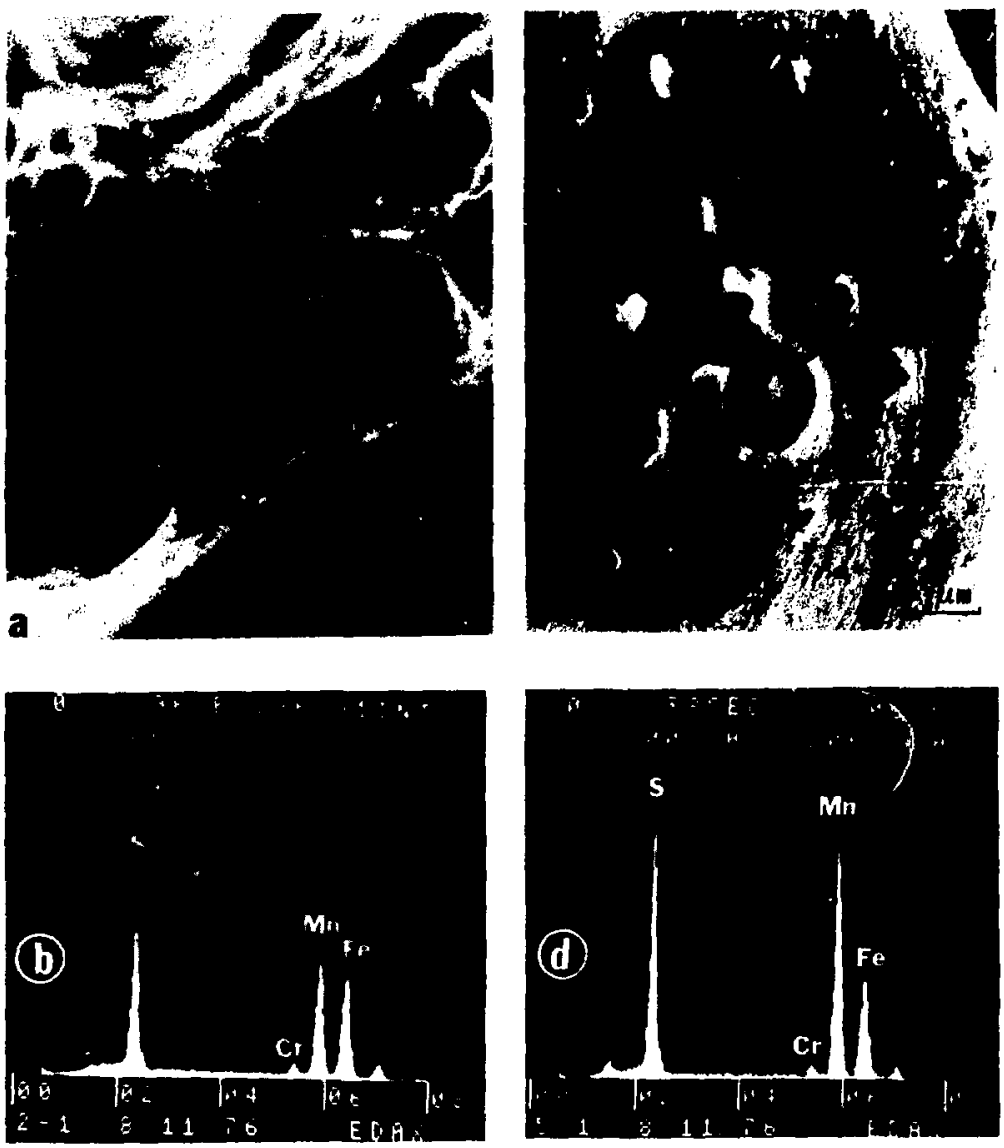

XBВ 782-1183

Fig. 47 
Evolution of Microstructure and Embrittlement During Tempering of Modified Ultra-high Strength Fe $4 \mathrm{Cr}-0.3 \mathrm{C}$ Steels
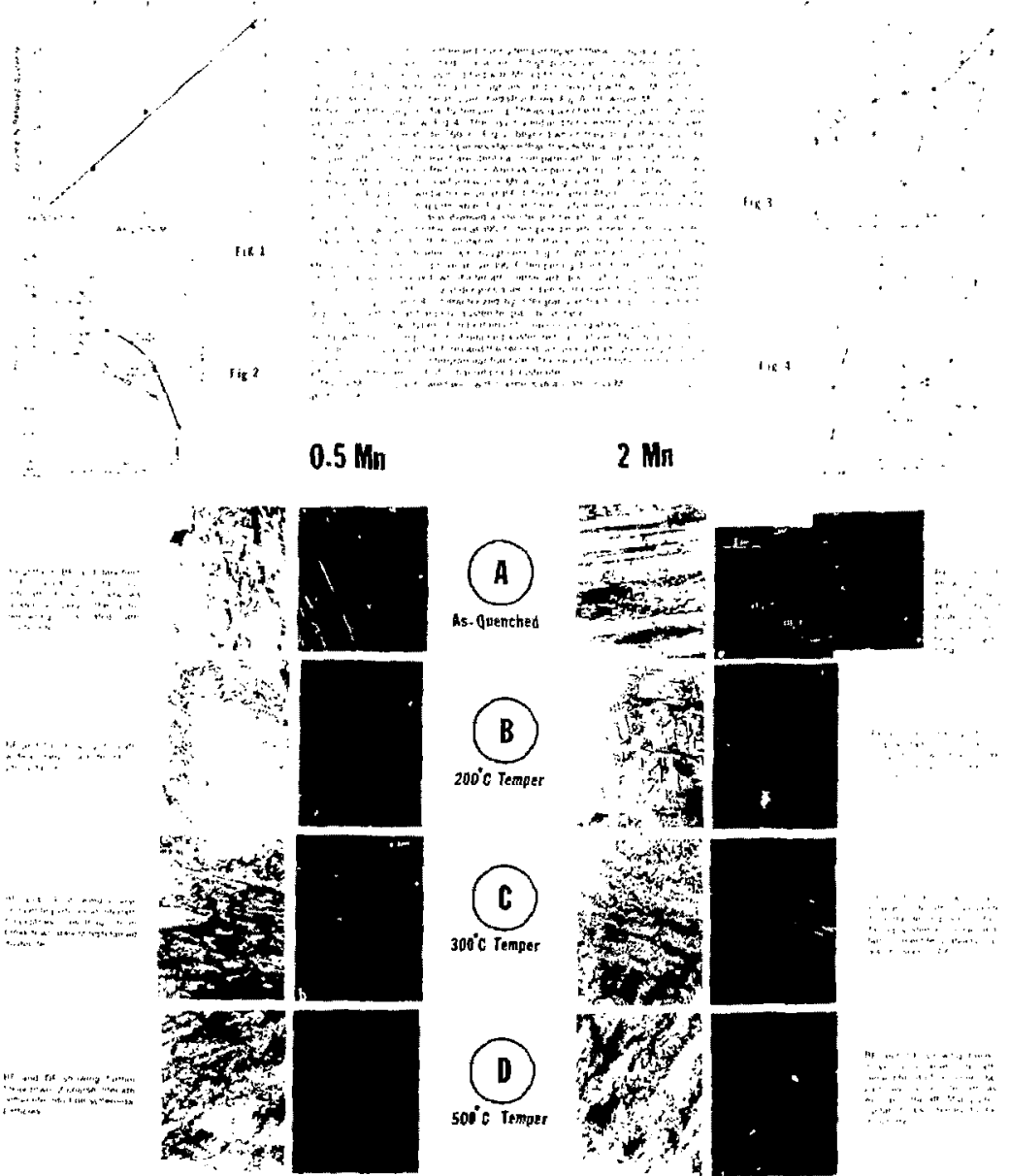

$200^{\circ} \mathrm{C}$ Temper
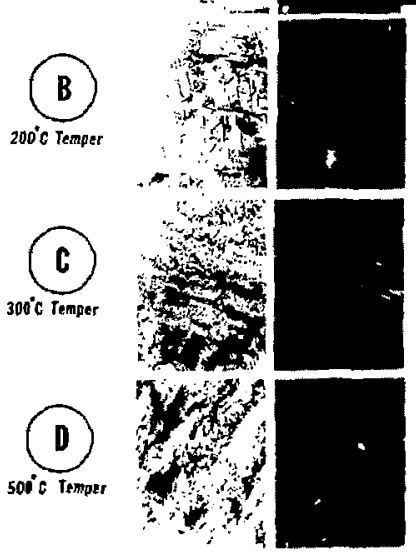

XBB $776-6136$

Fig. 48 
"Fractography of the Evolution of Embrittlement During Tempering of Modified Fe $-4 \mathrm{Cr}-0.3 \mathrm{C}$ Steels"
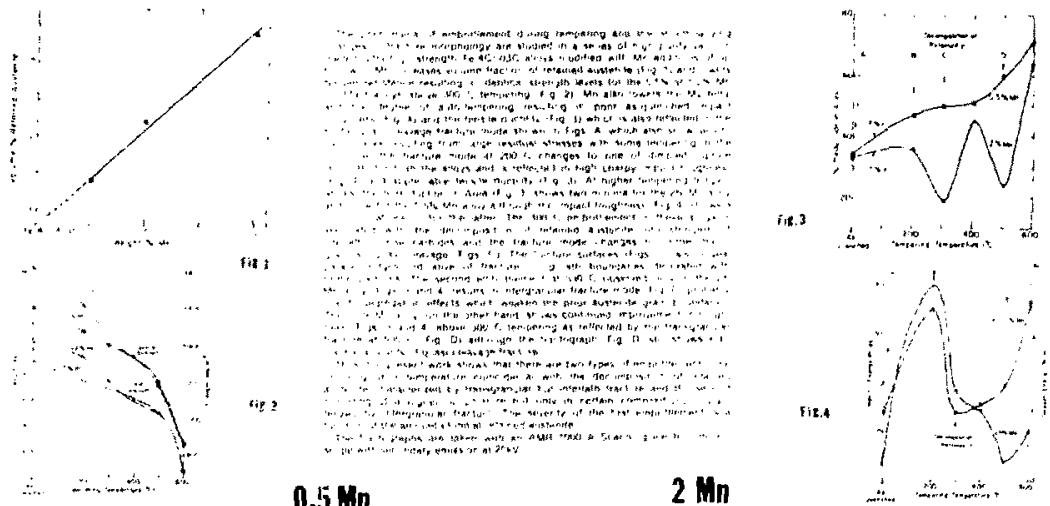

fin:
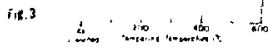

iit 2
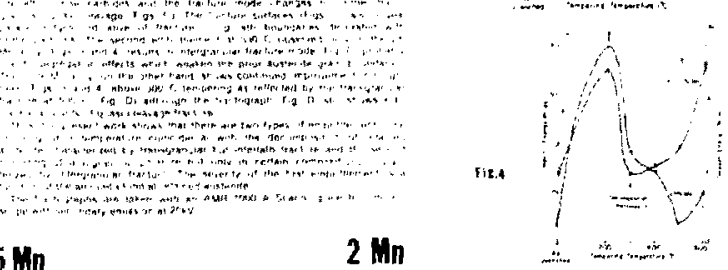

$0.5 \mathrm{mn}$

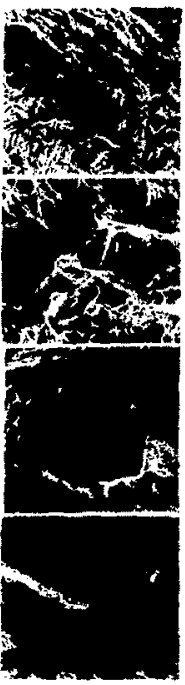

2 in

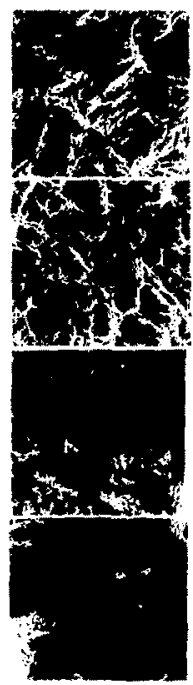

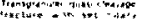

$5 i 5.4$

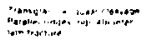

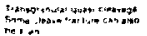

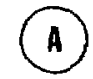

16. Guenelos

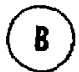

2Ho'C Temper

jot'c Temper

soe c Tonper
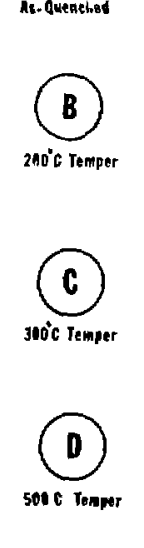

XBB $776-6137$

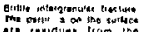
on ing

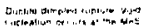
Bix?

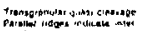

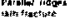

toweinen prereinlicen 


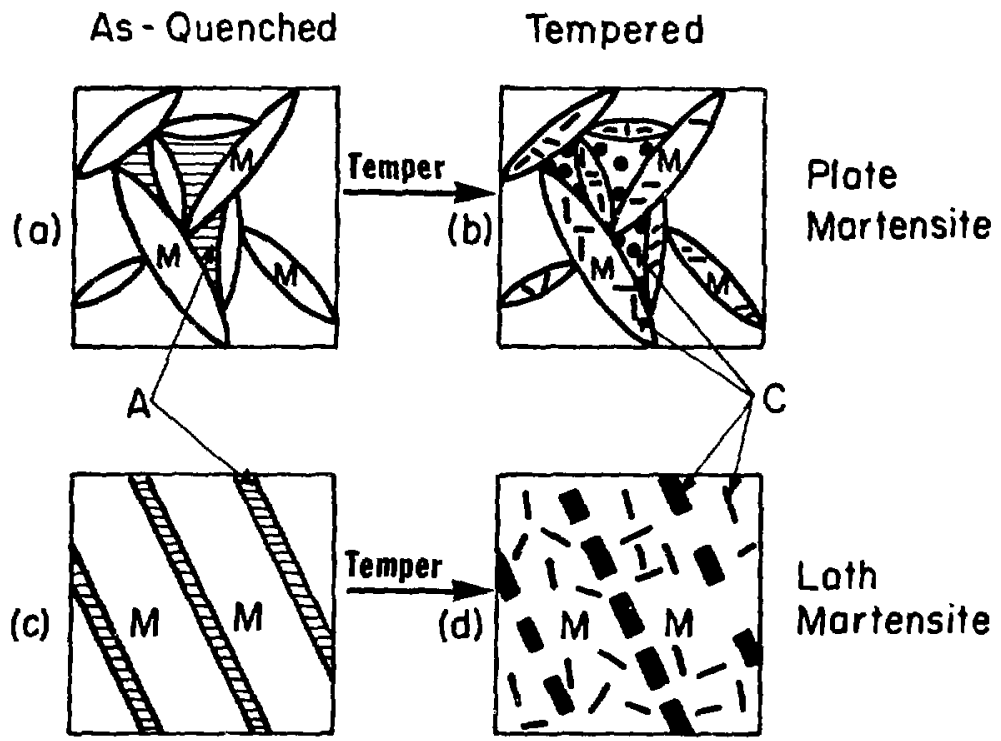

A: Austenite

M: Martensite

C: Carbide

XBL 776-5606

Fig. 50 


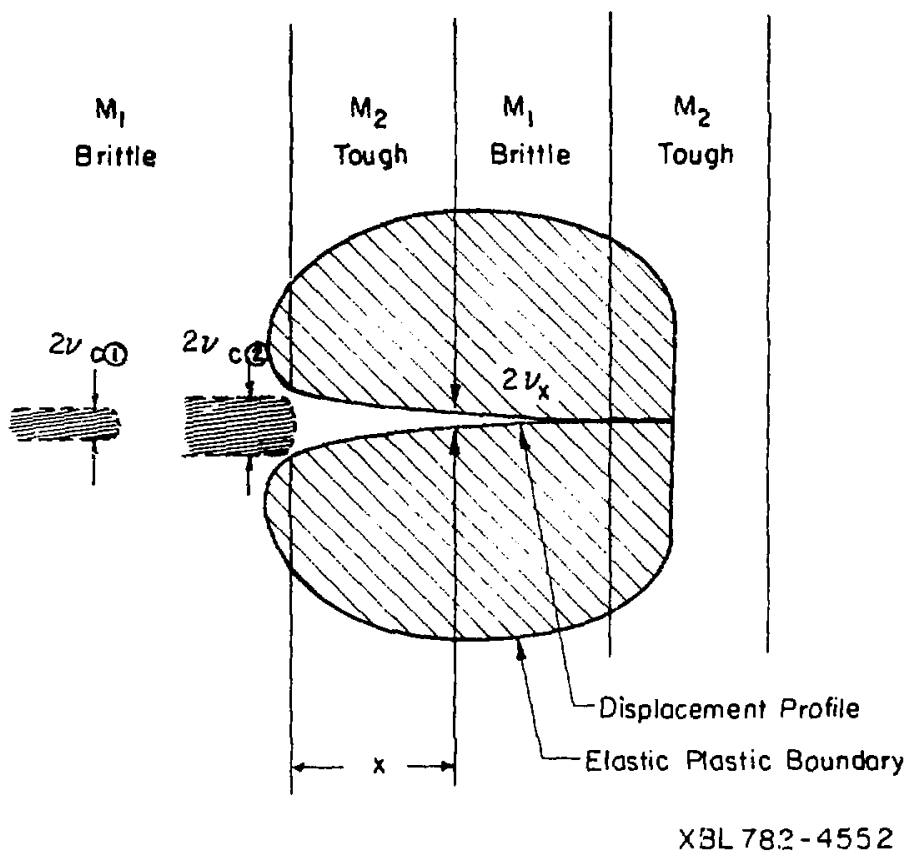

F1g. 51 


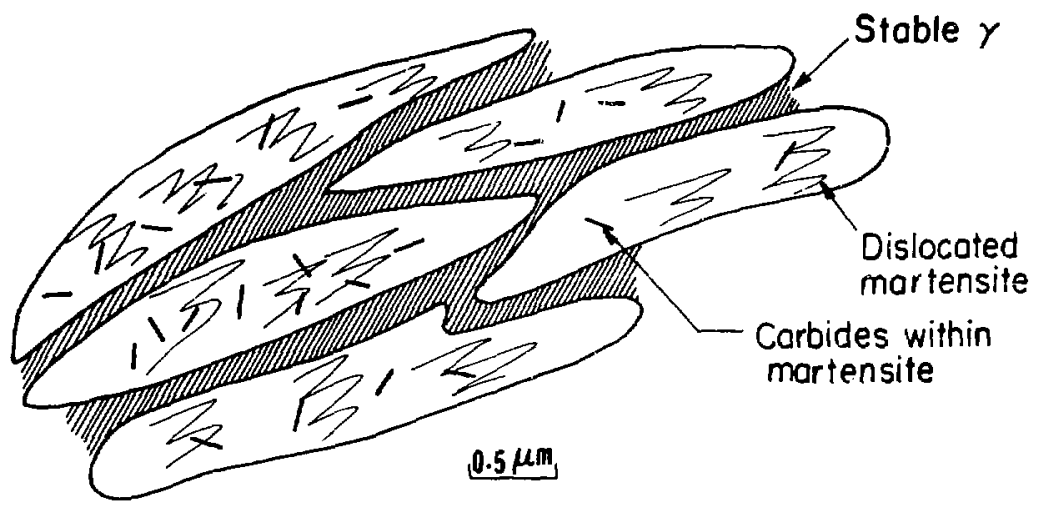

XBL 7711-10457

F1g. 52 


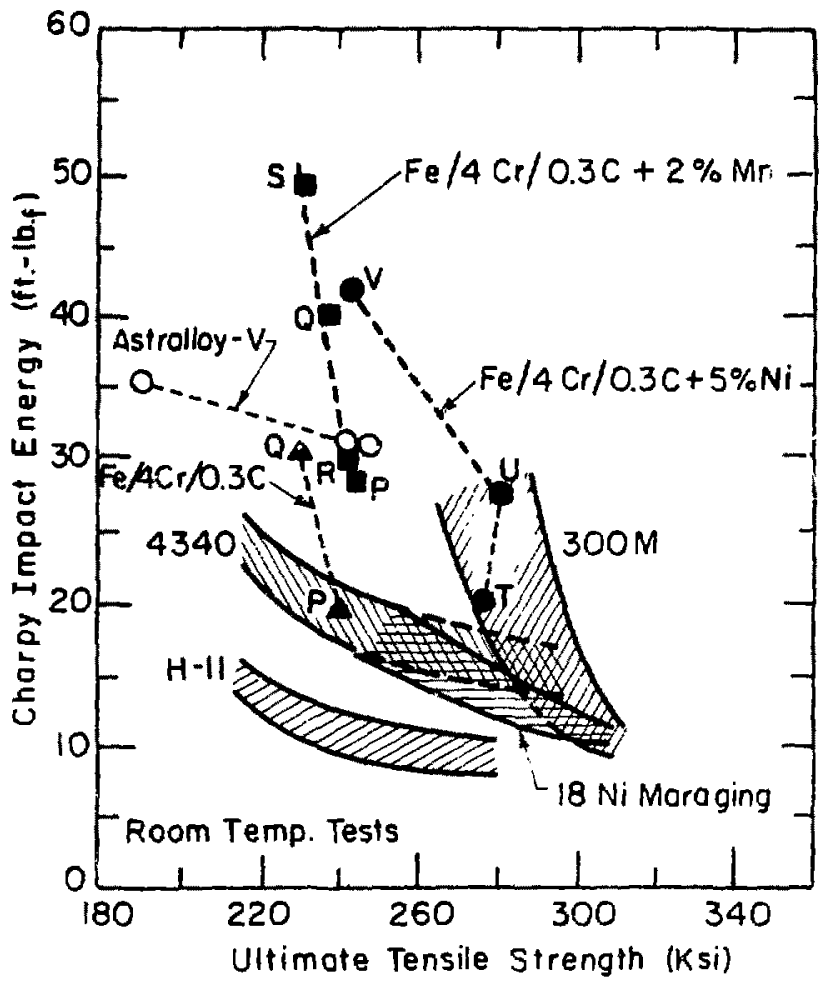

XBL 768-7314A

Fig. 53 (a) 
Ultimate Tensile Strength, ksi

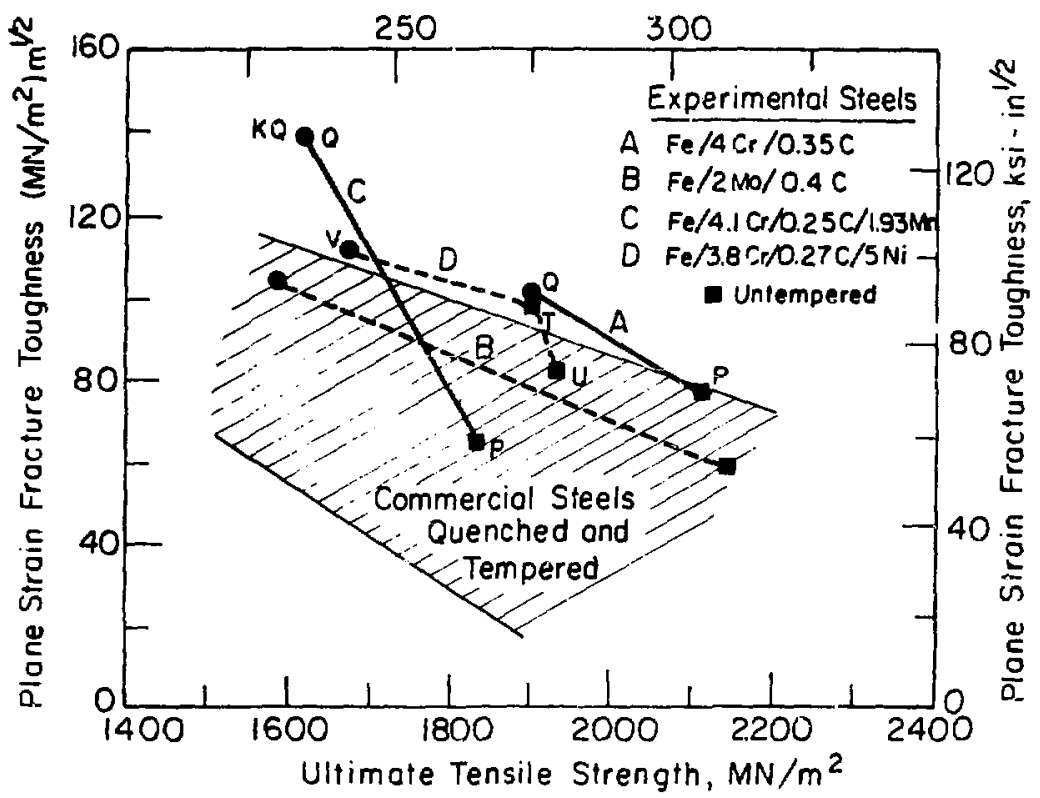

XBL $7710-6803$

Fig. 53 (b) 


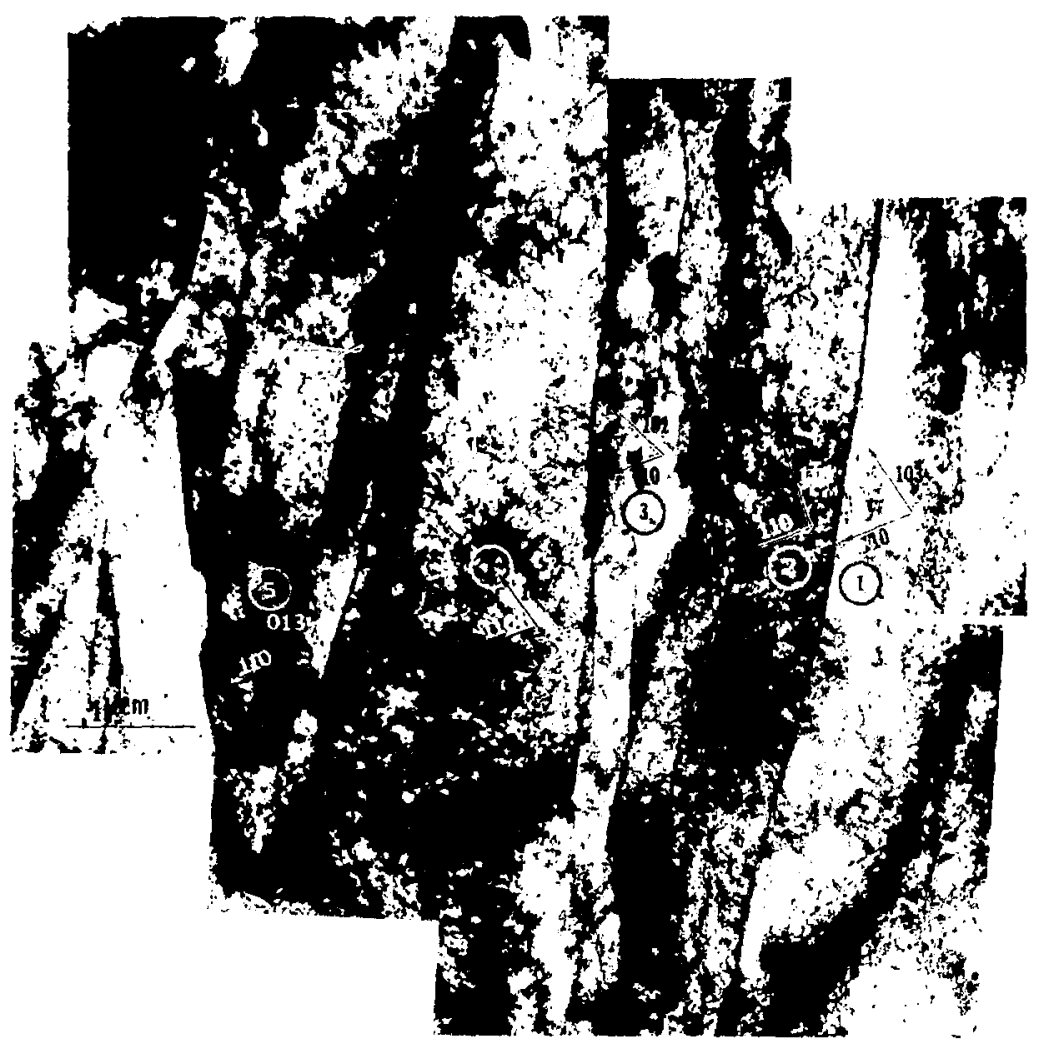

XB日 $775-4292$

Fig. 54 (a) 


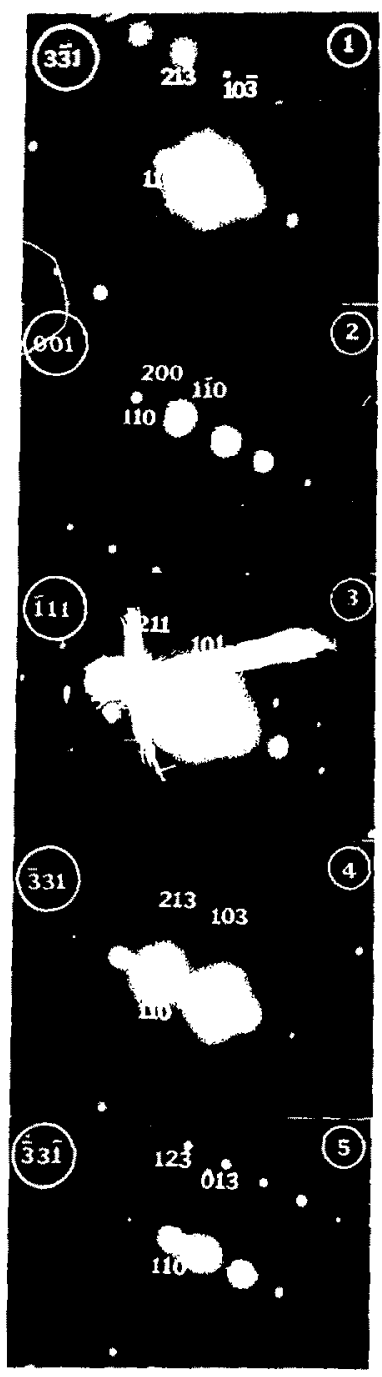

XBB 775-4293 

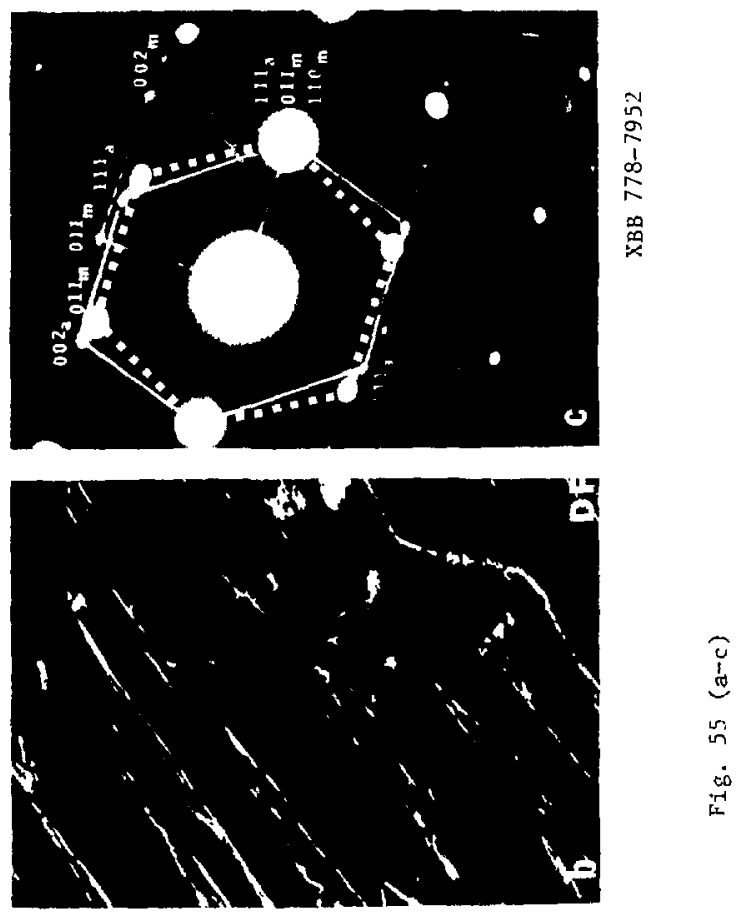

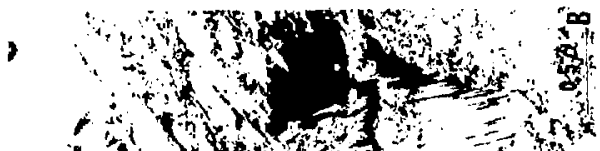

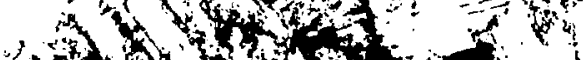

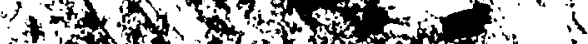

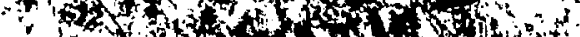

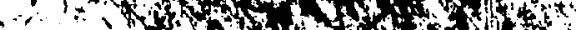

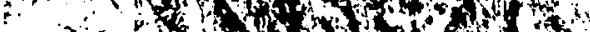

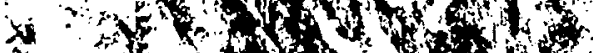

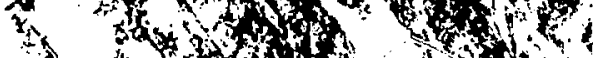

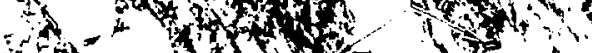
- 14 

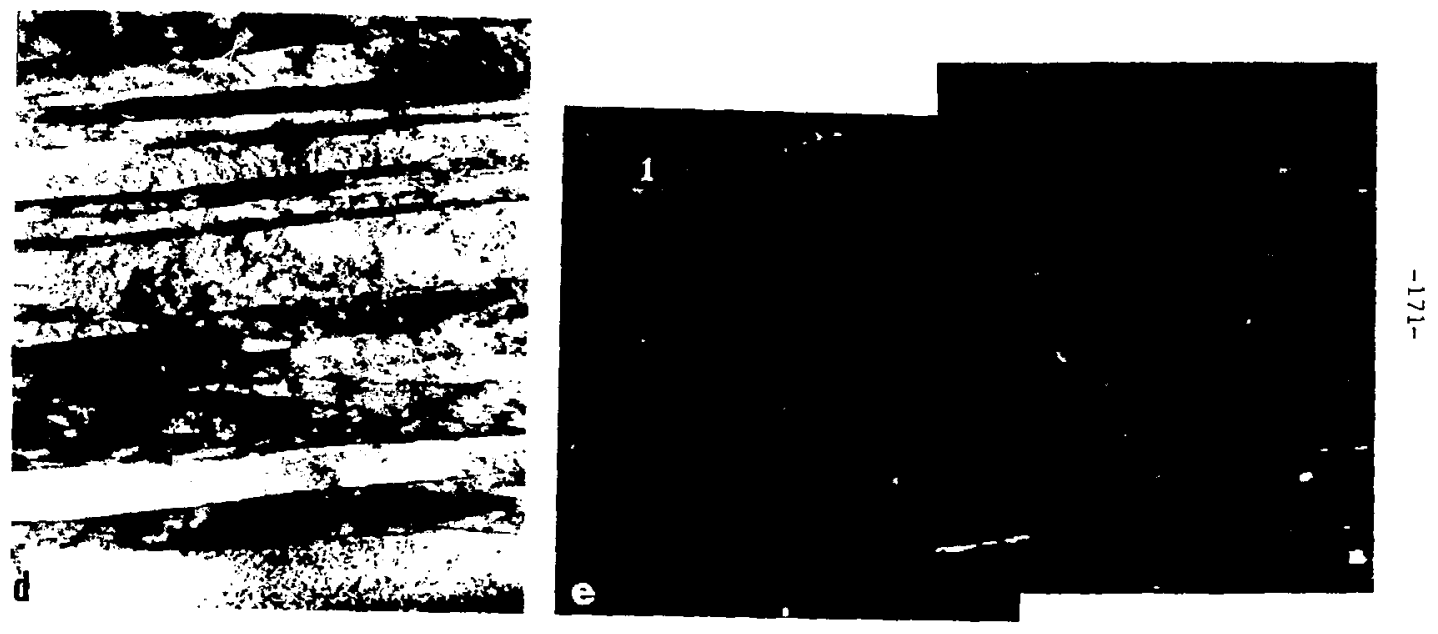

XBB 775-4291

Fig. 55 (d-e) 


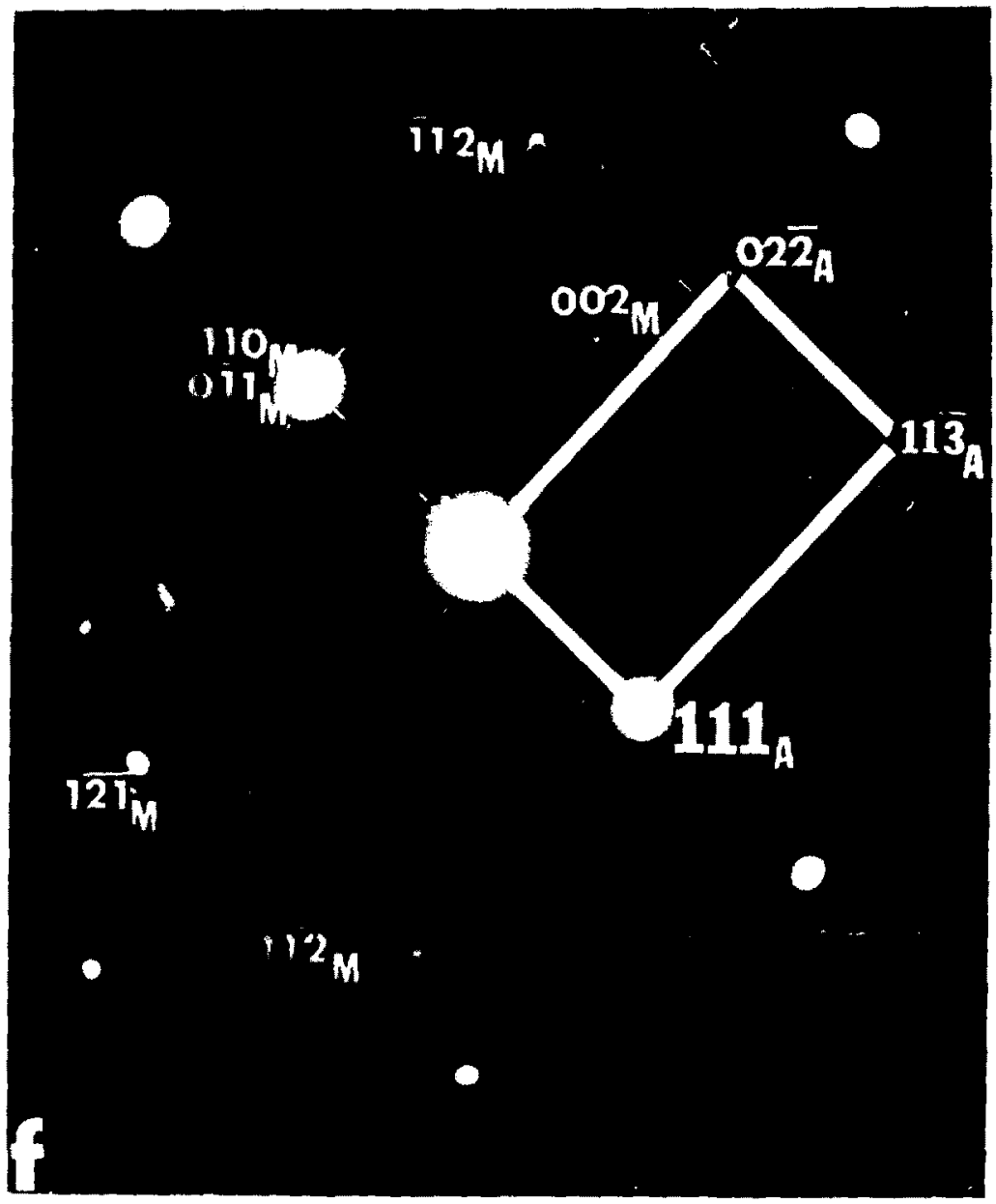

ХВВ $775-4290$

Fig. 55 (f) 


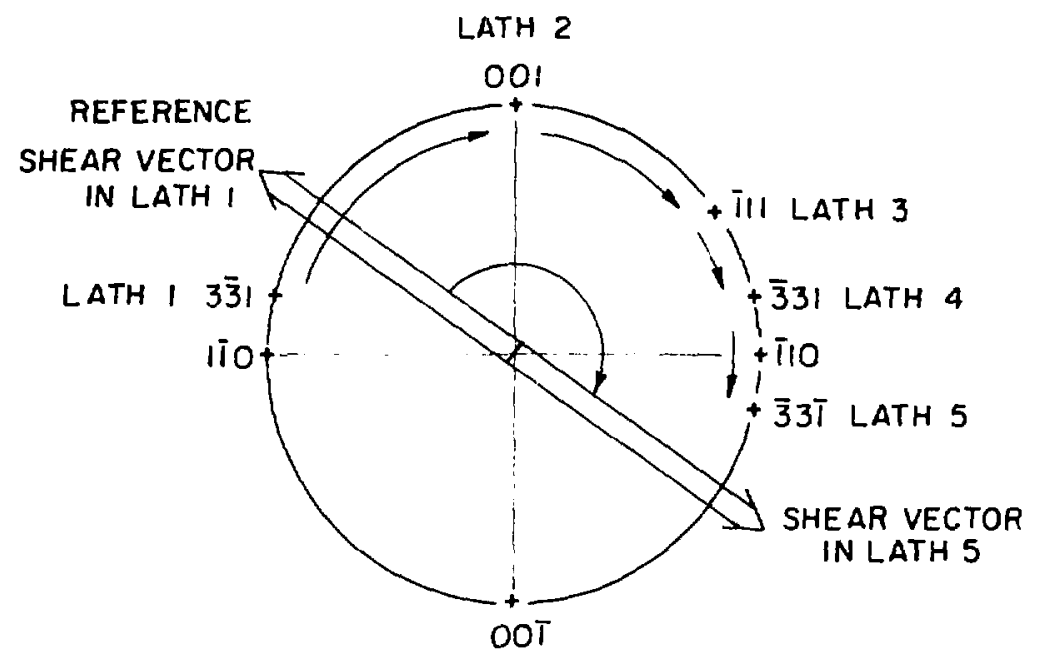

\begin{tabular}{|c|c|c|}
\hline \multicolumn{2}{|c|}{ LATH REGION } & \multirow{2}{*}{$\begin{array}{c}\text { ROTATION } \\
\text { (DEGREES) }\end{array}$} \\
\hline 1 & 2 & 76.75 \\
2 & 3 & 54.71 \\
3 & 4 & 22.01 \\
4 & 5 & 26.53 \\
\hline
\end{tabular}




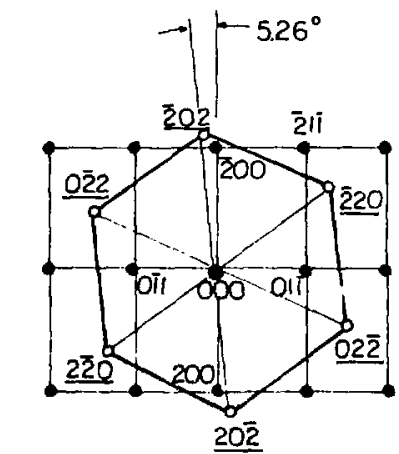

K-S ORIENTATION RELATION:

$(011)_{\text {bec }} / /(I 11)_{\text {fce }}$

$[i 1 i]_{b c c} / /[i 10]_{f c c}$

- nkl bcc

o hkl fCC

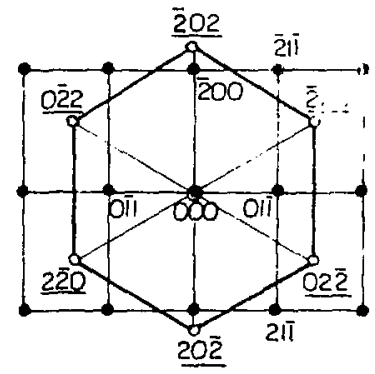

N-W ORIENTATION RELATION

$$
\text { (OII) } \text { oce } / /(111)_{\text {fcc }}
$$

$[100]_{\mathrm{bcc}} /[10 i]_{\mathrm{fcc}}$ 


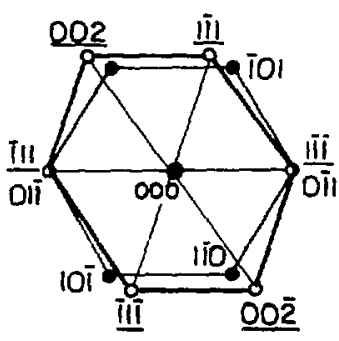

$$
k-S
$$

(OII) ${ }_{\mathrm{bcc}} / /(1 \mathrm{IT})_{\mathrm{fcc}}$

$[111]_{b c c} / /\left[110 j_{f c c}\right.$

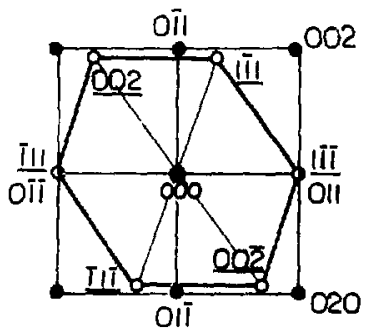

$N-W$

(OII) $_{\mathrm{bcc}} / /(\mathrm{Iii})_{\mathrm{fcc}}$ $[100]_{b c c} / /[110]_{f c c}$

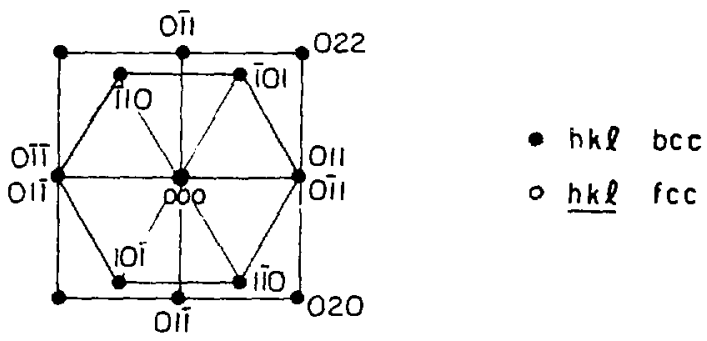

$$
\begin{aligned}
& \text { K-S AND N-W } \\
& (011)_{b c c} / /(011)_{b c c} \\
& {[100]_{b c c} / /[111]_{b c c}}
\end{aligned}
$$

XB:-7710-6263 


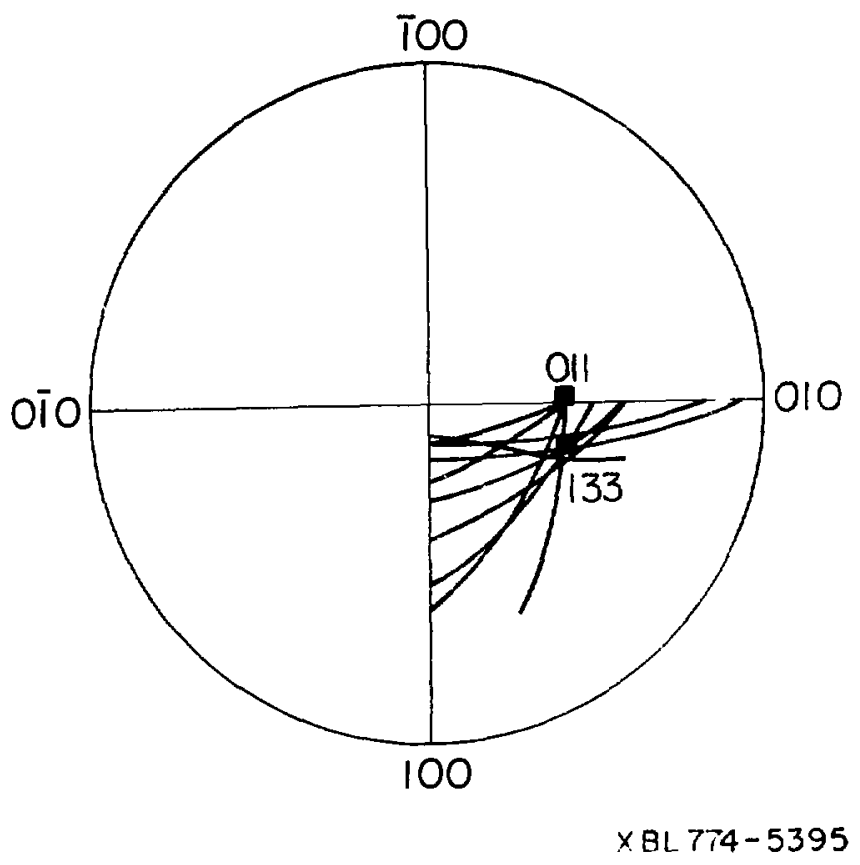

Ffg. 59 (a) 
$-177-$

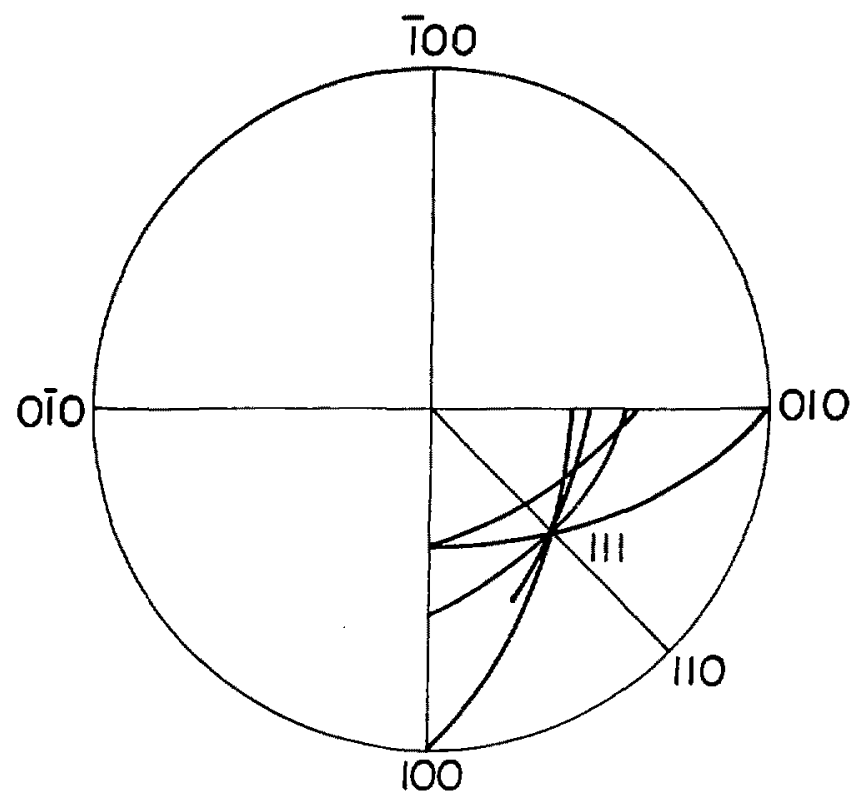

XBL 774-5396

F1g. 59 (b) 
$-178$

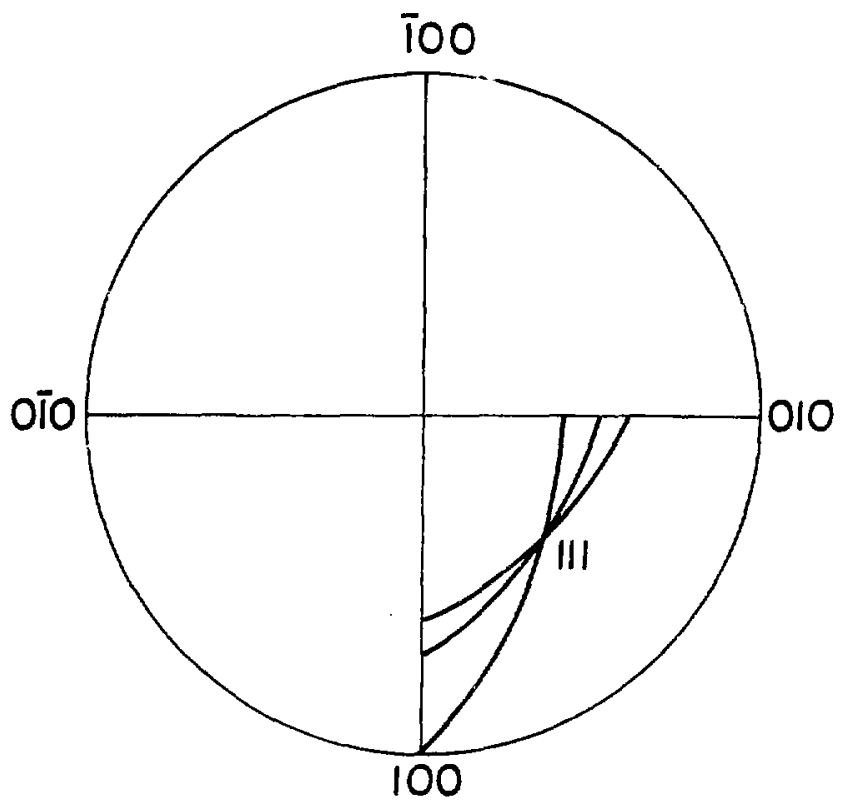

XBL 7T4-5397

FIg. 59 (c) 

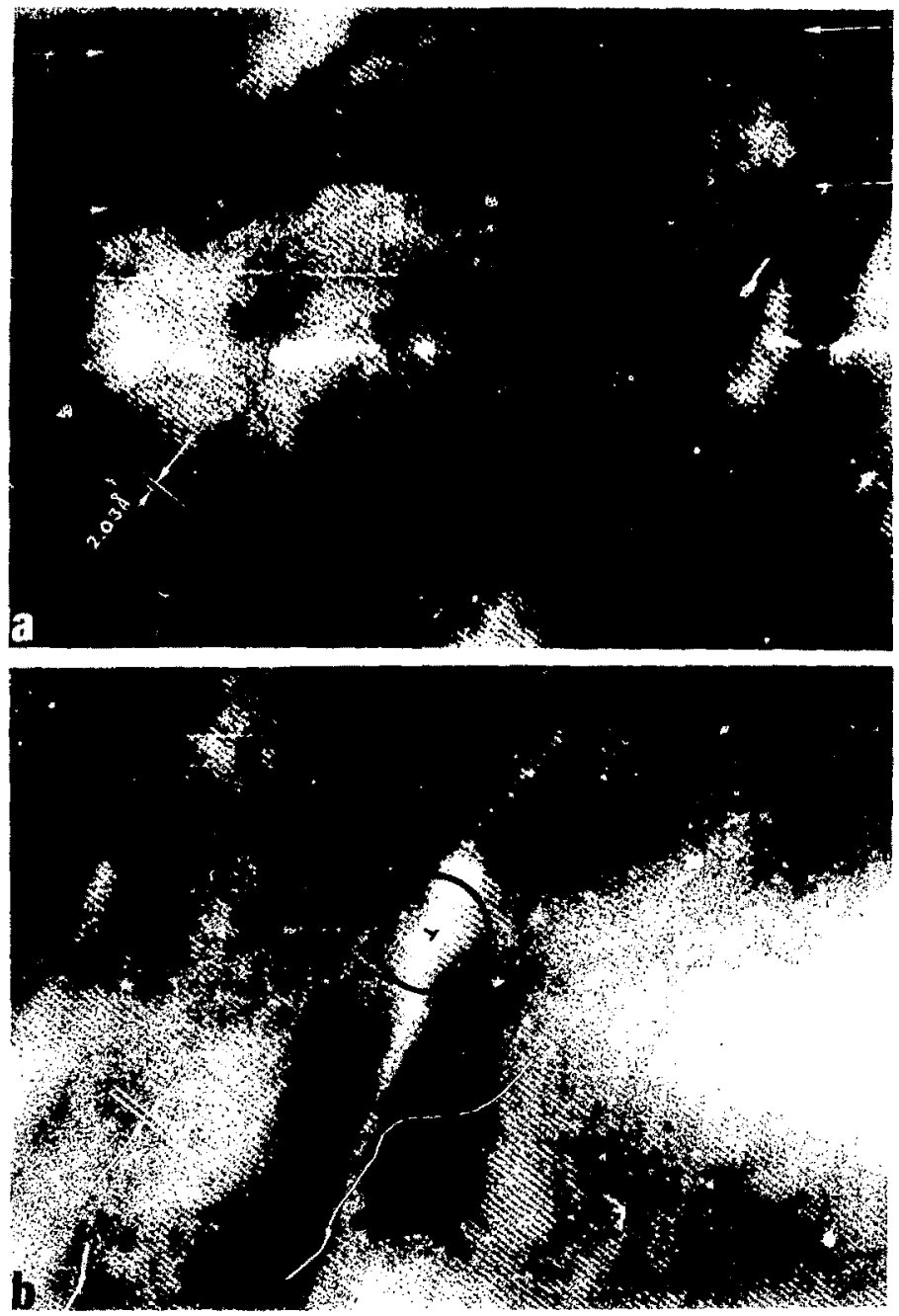

XBB $778-7992$

$F i_{B}, 60$ 


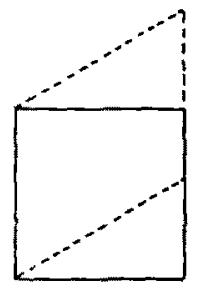

CASE I

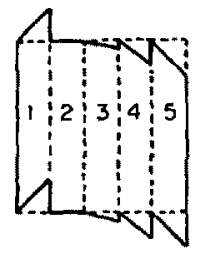

CASE II

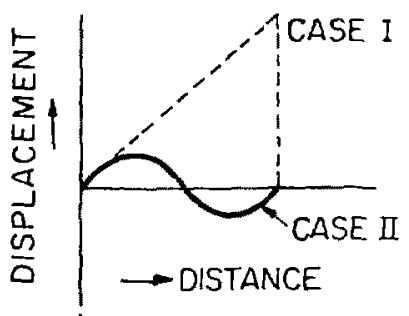

REFERENCE

PATH

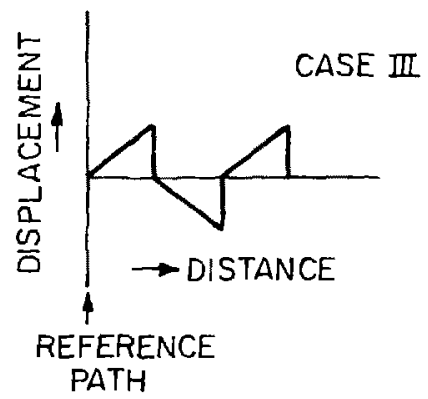

XBL 7710-6264

Fig. 61 


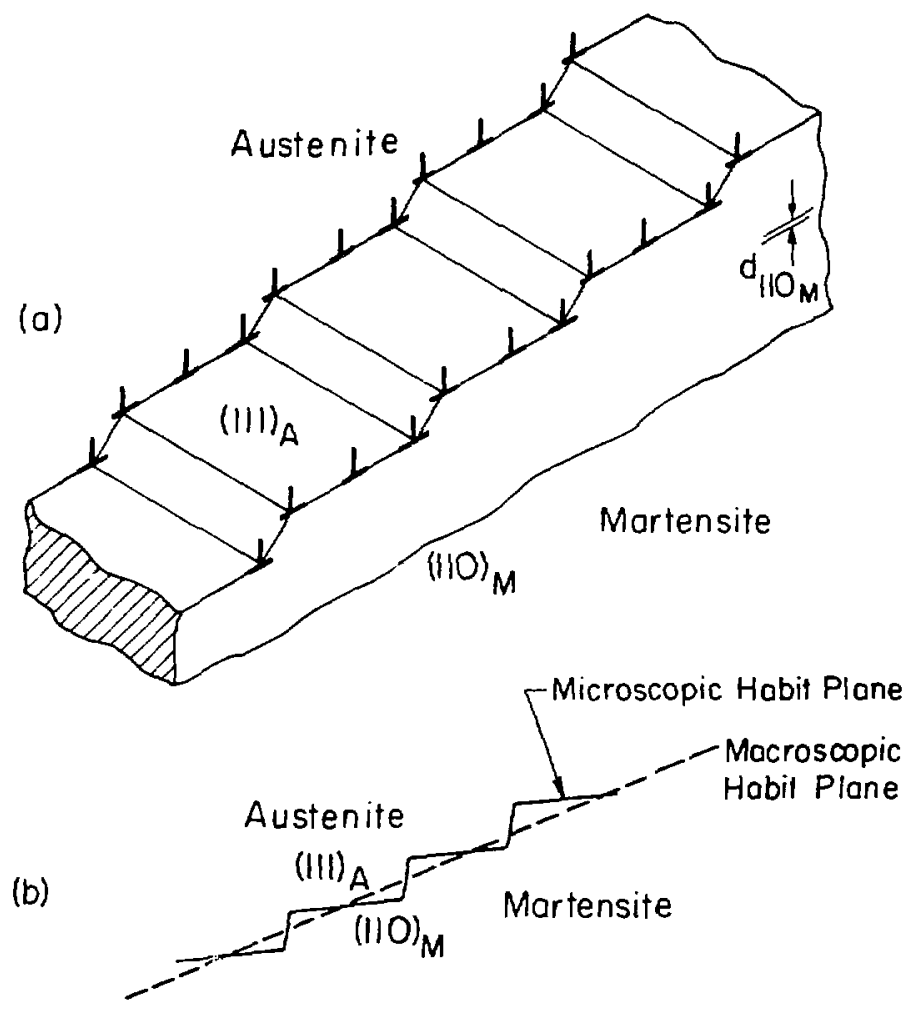

(c)

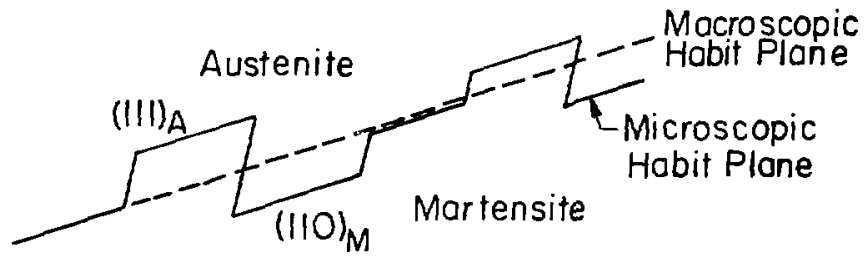

XBL 7 74-5394 


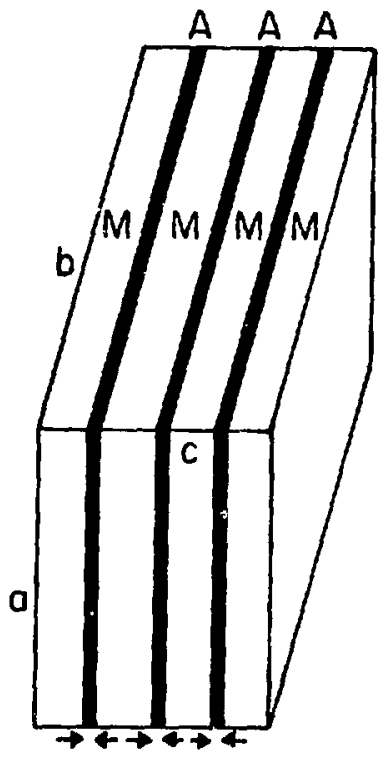

XBL 7 74-5393

Fig. 63 